Universidad Politécnica de Madrid

Escuela Técnica Superior de Ingeniería Aeronáutica y del Espacio

\title{
WRINKLE CHARACTERIZATION IN COMPOSITE MATERIALS USING ULTRASONIC TECHNIQUES
}

Tesis Doctoral

\author{
Beatriz Larrañaga Valsero \\ Ingeniero Aeronáutico \\ Máster en Materiales Compuestos
}

Marzo 2020 
Department of Aerospace Materials and Production

School of Aeronautical and Space Engineering

Polytechnic University of Madrid
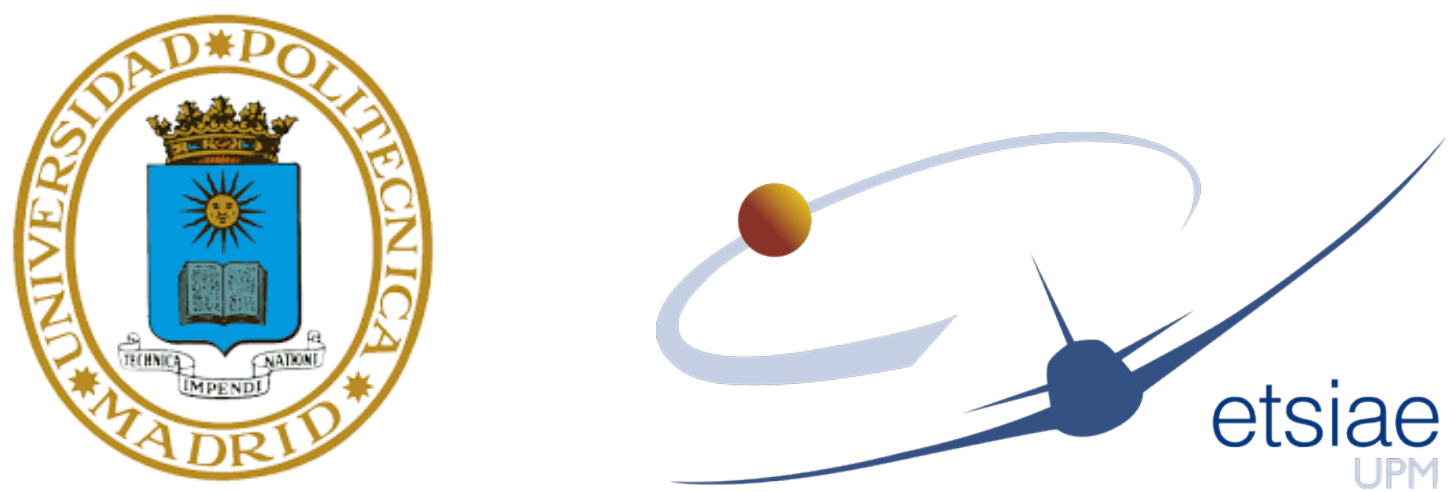

WRINKLE CHARACTERIZATION IN COMPOSITE MATERIALS USING ULTRASONIC TECHNIQUES

Doctoral Thesis

Author:

Beatriz Larrañaga Valsero

Aeronautical Engineer

Master in Composite Materials

Supervised by:

Professor Dr. Jesús Alfredo Güemes Gordo

Marzo 2020 


\section{ABSTRACT}

Ensuring that wind-turbine blades don't unexpectedly fail in service is a priority for the wind power industry. A common manufacturing defect that has caused some wind-turbine blades to unexpectedly fail in service are the wrinkles that may appear in the composite laminates. Therefore, the risk of catastrophic failure will be reduced if wrinkles (also known as out-of-plane waviness) were detected and characterized in the manufacturing line of the factory.

The mayor aim of this work is to compare the effectiveness of three different non destructive techniques for detecting and characterizing out-of-plane wrinkles in the typical glass-carbon hybrid laminates that are used nowadays for wind turbine blades.

Five test sample were manufactured with laminated representative of those used in the wind-turbine industry. Two of them serve as pristine while the other three had internal out-of-plane waviness that are similar of those detected in actual wind turbine blades.

The drop in the mechanical properties that is provoked by wrinkles was check with basic tensile and compression mechanical tests.

The three different ultrasound techniques used are: full-matrix capture (FMC) with the total focusing method (TFM), a commercial phased-array instrument and an immersion test with a raster-scanned single-element focused probe. A one dimensional analytical ultrasonic-propagation model was used in order to determine the resonance frequency of the plies. That frequency is considered the ideal probe frequency for the ultrasonic tests. The ultrasonic images obtained from the inspection were used, when possible, to measure severity parameters of the wrinkle.

Finally, this thesis concludes that not all of the techniques allowed full characterisation of out-of-plane waviness on the specimens. The FMC/TFM method gave better results whilst phased-array technology and single-element immersion testing presented more challenges. 


\section{RESUMEN}

Asegurar que las palas de los aerogeneradores no fallan de forma inesperada en servicio es una prioridad para la industria de la energía eólica. Un defecto de fabricación bastante común y que ha causado que algunas palas de aerogenerador fallen inesperadamente en servicio son las arrugas que pueden aparecer en los laminados compuestos. Por lo tanto, el riesgo de fallo catastrófico se reduce si las arrugas (también conocidas como ondulaciones fuera del plano) se detectan y caracterizan en las líneas de fabricación de las fábricas.

El objetivo principal de este trabajo es comparar la efectividad de tres técnicas de ensayos no destructivas diferentes a la hora de detectar y caracterizar las arrugas en los laminados híbridos de fibra de vidrio y carbono que se usan hoy en día para las palas de aerogenerador.

Se han fabricado cinco muestras de prueba con laminados representativos de los utilizados en la industria. Dos de ellos sirven como referencia, mientras que los otros tres tienen ondulaciones internas que son similares a las detectadas en las palas reales de los aerogeneradores.

La caída en las propiedades mecánicas causada por las arrugas se ha verificado gracias a la realización de ensayos mecánicos de tracción y compresión.

Las tres técnicas de ultrasonidos utilizadas son: "full-matrix capture" (captura de matriz completa) con el "total focusing method" (método de enfoque total), un equipo comercial de "phased-array" y un ensayo por inmersión con un palpador de un solo elemento. Se ha usado un modelo analítico unidimensional de propagación ultrasónica para determinar la frecuencia de resonancia de las capas. Esa frecuencia se considera la frecuencia del palpador ideal con la que realizar los ensayos de ultrasonidos. Las imágenes ultrasónicas obtenidas tras las inspecciones se han utilizado, siempre que ha sido posible, para medir parámetros de severidad de la arruga.

Por último, esta tesis concluye que no todas las técnicas de ultrasonidos permiten caracterizar de forma completa las arrugas en los laminados de material compuesto. El método FMC / TFM dio mejores resultados, mientras que la tecnología "phased-array" y las pruebas de inmersión presentan más complejidades. 


\section{PUBLICATIONS}

Some ideas and figures have appeared previously in the following publications:

\section{Conferences and Proceedings}

6th International Symposium on NDT in Aerospace, 2014, Madrid, Spain. Wrinkle detection with Ultrasonic Phased Array technology. Fernández-López, A., Larrañaga-Valsero, B., \& Guemes, A.

XI Congreso Nacional de Materiales Compuestos MATCOMP'15, 2015, Móstoles-Madrid, Spain. Detección de Arrugas en laminados de fibra de vidrio y de carbono. Larrañaga-Valsero, B., Fernández-López, A., \& Güemes, A.

55th Annual Conference of the British Institute of Non-Destructive Testing, 2016 Nottingham, United Kingdom. Wrinkle characterisation from Ultrasonic Scans of Composites. Larrañaga-Valsero, B., Smith, R. A., Tayong, R. B., Fernández-López, A., \& Güemes, A.

XII Congreso Nacional de Materiales Compuestos MATCOMP'17, 2017, San Sebastian, Spain. Detección de Arrugas en laminados de fibra de vidrio y de carbono usando técnicas de inspección por ultrasonidos. Larrañaga-Valsero, B., FernándezLópez, A., \& Güemes, A. ISSN 2531-0739

\section{Journal Papers}

Larrañaga-Valsero, B., Smith, R. A., Tayong, R. B., Fernández-López, A., \& Güemes, A. (2018). Wrinkle measurement in glass-carbon hybrid laminates comparing ultrasonic techniques: A case study. Composites Part A: Applied Science and Manufacturing, 114, 225-240. https://doi.org/10.1016/j.compositesa.2018.08.014 


\section{RESEARCH STAYS ABROAD}

During my $\mathrm{PhD}$, I was able to expand my research with two international research stays abroad at the same prestigious international centre. I worked with the Ultrasonics and Non-Destructive Testing (UNDT) group of the University of Bristol (UK) under the supervision of Professor Robert Smith.

- During the summer of 2015 (from July 15 to September 13). My stay was founded by the Center of Composite Materials and Smart Structures; "Departamento de Materiales y Producción Aeroespacial", "Universidad Politécnica de Madrid".

O From July to December 2016 (5 months). My stay was founded by "XIV Convocatoria de Ayudas del Consejo Social para el Fomento de la Formación y la Internacionalización de Doctorandos para el Curso 20152016" by the "Universidad Politécnica de Madrid". 


\section{AGRADECIMIENTOS}

En primer lugar, me gustaría mostrar mi agradecimiento al personal del departamento de Materiales y Producción Aeroespacial de la ETSIA donde he desarrollado mi tesis, y muy en especial a mi tutor, Alfredo Güemes, por su paciencia, esfuerzo, dedicación, guía y ayuda.

Agradecer a todos mis compañeros en la universidad; Antonio, Ángel, Patricia, Renato, Rebeca, Jeromy, Andrés, Martín, Anxo, Juanjo e Isabel; su amistad y apoyo en los momentos buenos y sobre todo en los menos buenos. Gracias por ayudarme y hacerme ver que el final estaba más cerca de lo que yo pensaba, que valía la pena seguir intentándolo y que todos podíamos conseguirlo. Gracias también a Mari Carmen, Lucía y Amor por haberme ayudado siempre que lo he necesitado. A todos, os deseo lo mejor.

I am also very grateful to the members of the Ultrasonics and Non-Destructive Testing (UNDT) group of the University of Bristol (UK), specially to Dr Robert Smith and Dr Rostand Tayong for sharing their knowledge and for their guidance and assistance for the success of this thesis. In addition a thank you to Dr Christina Fraij, my fellow labmate, for the moments shared and for making me feel welcome and part of the team.

I would also like to thank Olympus and specially Mr. Andre Lamarre, for their support in making it possible to use the $2.25 \mathrm{MHz}$ phase-array probe. 


\section{CONTENTS}

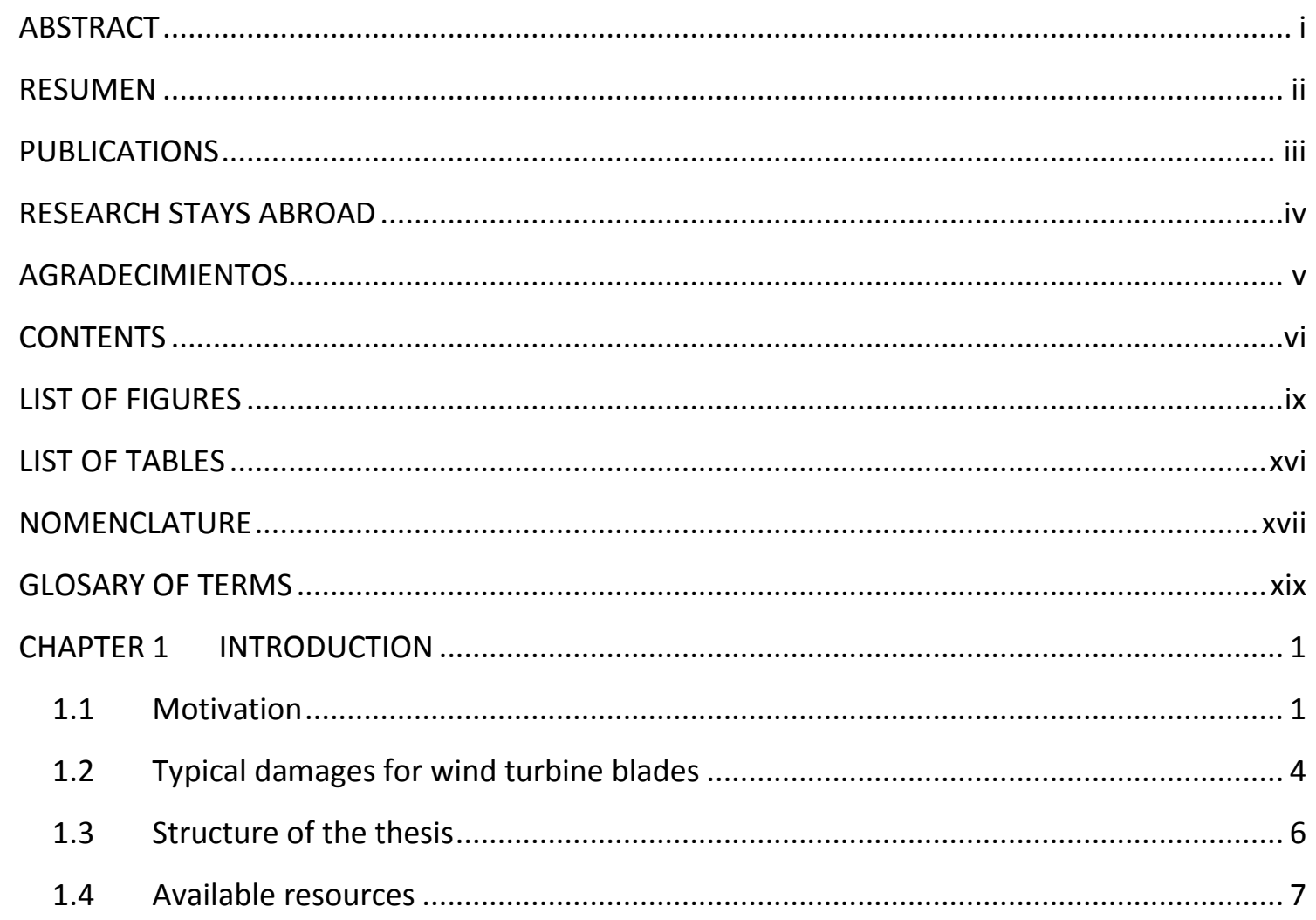

CHAPTER 2 REVIEW OF NON-DESTRUCTIVE EVALUATION (NDE) METHODS FOR COMPOSITE

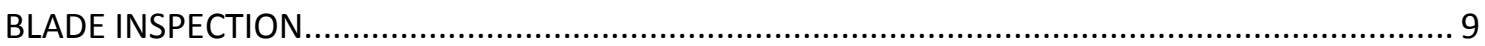

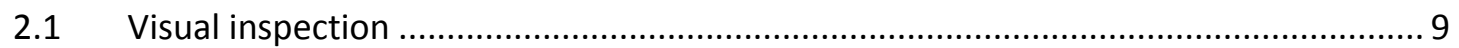

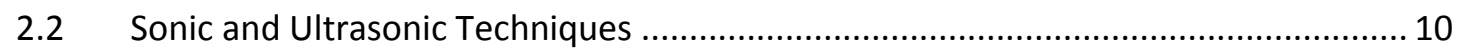

2.2.1 Tap-test and local resonance spectroscopy .................................................... 10

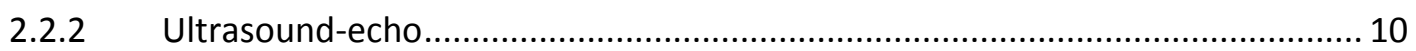

2.2.3 Commercial phased-array ultrasound technology........................................... 14

2.2.4 Full-matrix capture (FMC) with total-focusing method (TFM) ........................... 17

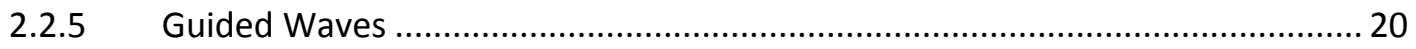

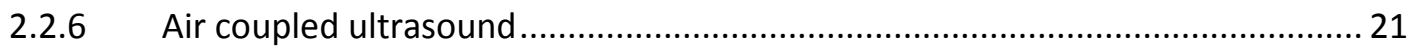

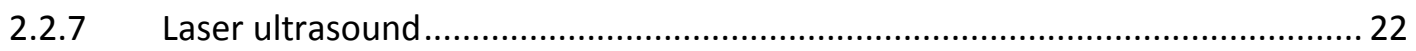

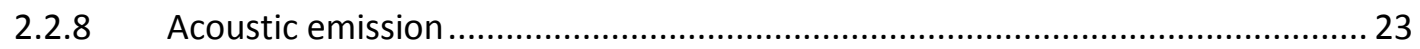

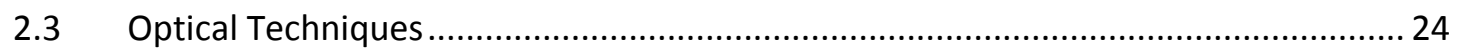

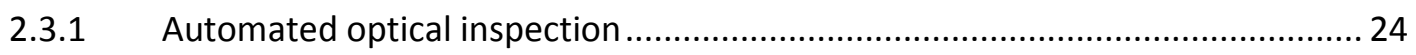

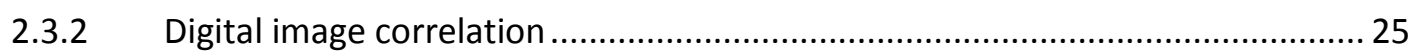




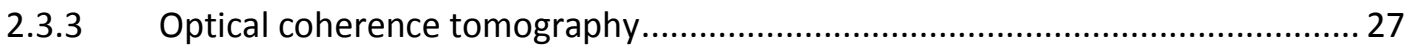

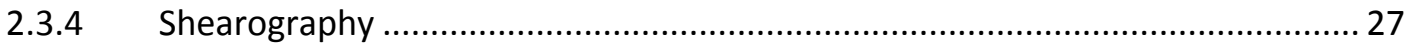

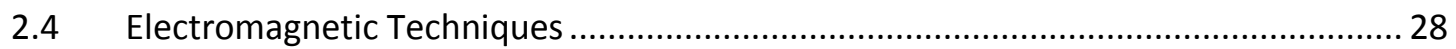

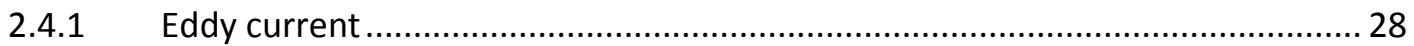

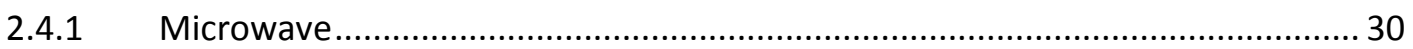

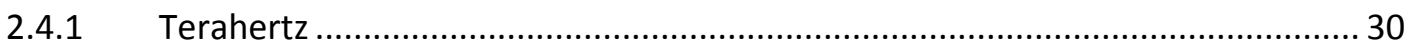

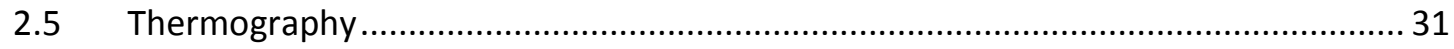

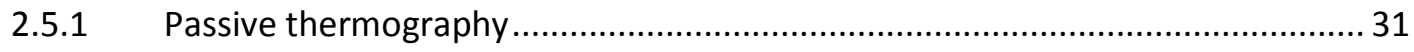

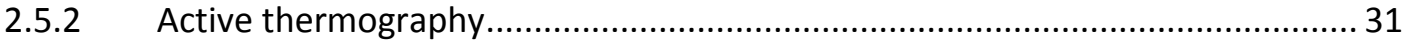

2.5.3 Thermography for wind turbine blade inspection............................................. 36

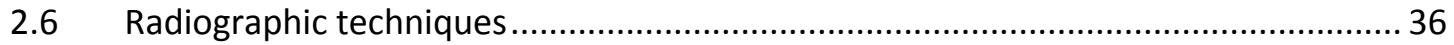

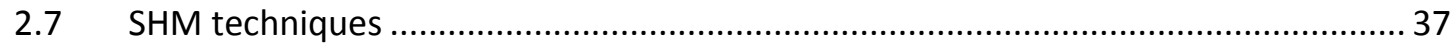

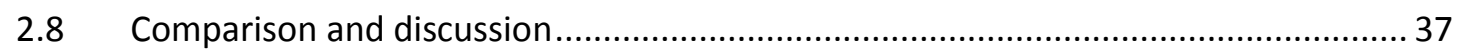

CHAPTER 3 SAMPLE MANUFACTURING AND MECHANICAL TESTING ….................................. 40

3.1 Sample manufacturing procedure …………..................................................... 40

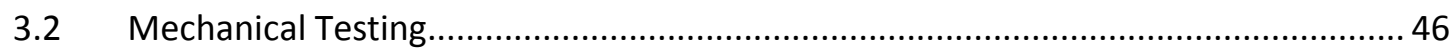

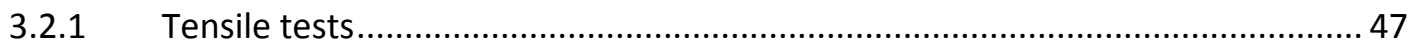

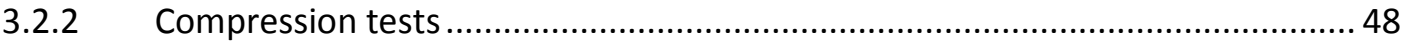

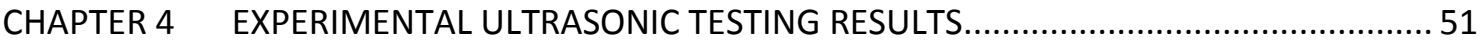

4.1 Single element immersion scanning with a spherically focused probe. ..................... 51

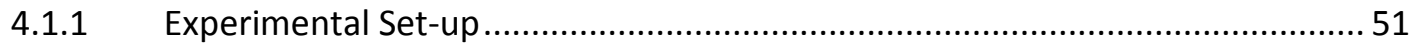

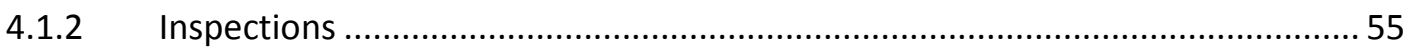

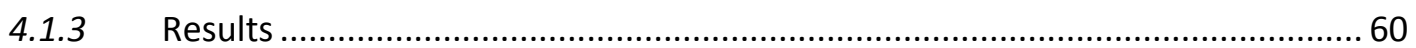

4.2 Commercial phased-array ultrasonic technology (PAUT) ......................................... 61

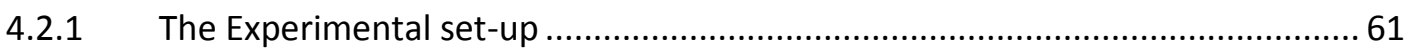

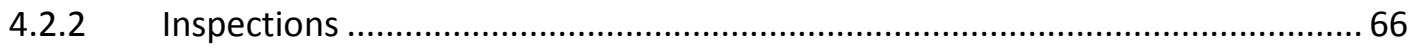

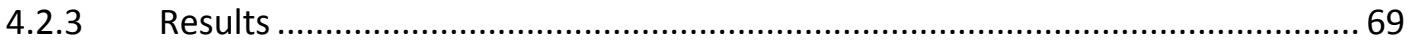

4.3 Full-matrix capture (FMC) with total-focusing method (TFM) ................................... 70

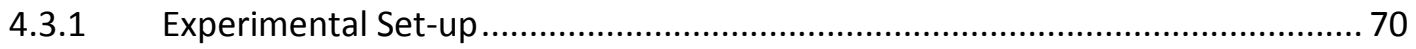

4.3.2 Inspections using an isotropic post processing algorithm ................................ 76

4.3.1 Inspections using the adapted-TFM algorithm to account for anisotropic

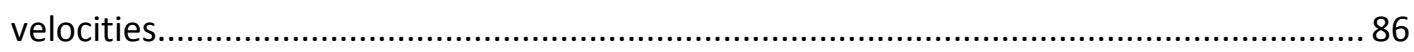

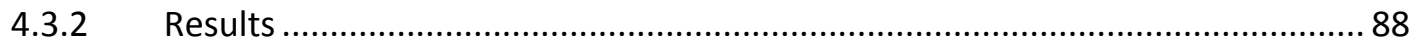

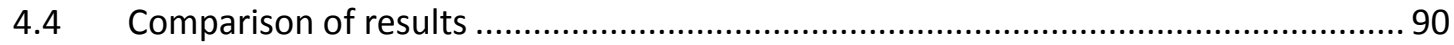




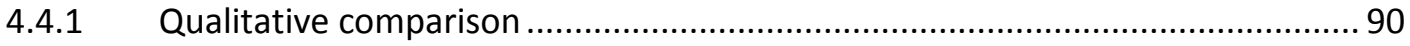

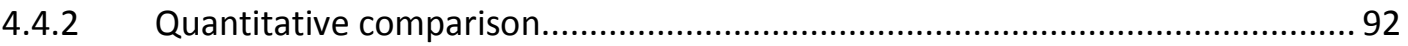

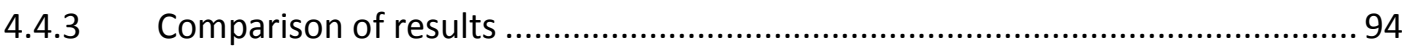

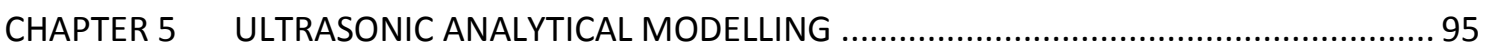

5.1 The one-dimensional recursive analytical multi-layer model ...................................... 95

5.2 Determination of the resonance frequency of the plies............................................. 98

5.3 Model for a carbon laminate with a wrinkle ............................................................. 103

5.4 Models for the mixed carbon/glass laminates............................................................. 104

5.5 A preliminary 2D Model ............................................................................................. 110

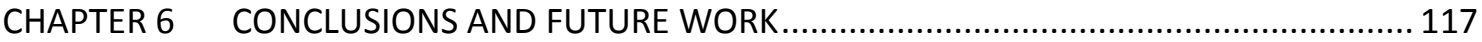

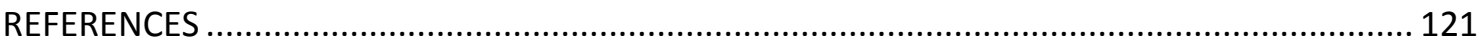

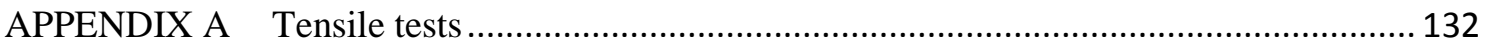

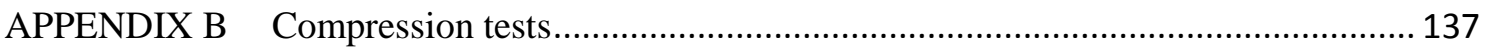




\section{LIST OF FIGURES}

FIGURE 1: WIND TURBINE PLANT IN MARANCHÓN, GUADALAJARA, SPAIN ............................... 1

FIGURE 2: SOME OF THE DAMAGES THAT MAY APPEAR AT A WIND TURBINE BLADE ................ 5

FIGURE 3: SOME OF THE DEFECTS THAT MAY APPEAR DURING THE MANUFACTURING OF A BLADE

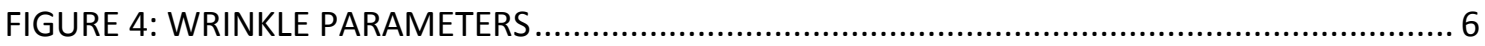

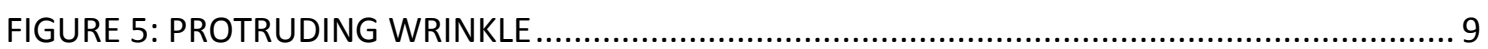

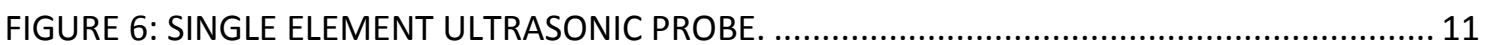

FIGURE 7: SCHEME OF THE PULSE-ECHO (LEFT) AND THROUGH-TRANSMISSION (RIGHT)

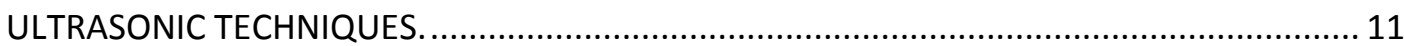

FIGURE 8: CLASSIC ULTRASONIC VIEWS: A-SCAN, B-SCAN AND C-SCAN ................................... 12

FIGURE 9: THREE VIEWS OF A SIMULATED ANALYTIC-SIGNAL PULSE-ECHO RESPONSE FROM FOUR COMPOSITE PLIES SEPARATED BY FIVE THIN PARALLEL LAYERS OF RESIN, ALL EMBEDDED IN AN INFINITE COMPOSITE MEDIUM. THE REAL SIGNAL AND HILBERT ENVELOPE (UP) ARE OFTEN THE ONLY PROJECTIONS VIEWED BUT THE ANALYTIC SIGNAL IS THREE-DIMENSIONAL AS SHOWN ABOVE (DOWN) FROM TWO DIFFERENT VIEWPOINTS (R A SMITH ET AL. 2015)

FIGURE 10: THREE DIFFERENT ULTRASONIC BEAMS GENERATED BY DIFFERENT FOCAL LAWS IN A PHASED-ARRAY PROBE. THE BEAM CAN BE STEERED AND FOCUSED AT DIFFERENT POINTS ELECTRONICALLY.

FIGURE 11: SCANNING IS PERFORMED ALONG THE PHASED-ARRAY PROBE LENGTH . 15

FIGURE 12: B-SCAN (ABOVE) AND C-SCAN (BELOW) OF A COMMERCIAL PHASED-ARRAY ULTRASONIC INSPECTION OF A 5MM THICK CFRP SPECIMEN AFTER AN IMPACT AT ENERGY 38.86J. THE INSPECTION WAS PERFORMED IN THE CCMSS LABORATORY AT THE UPM.

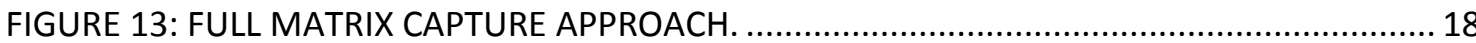

FIGURE 14: AIR COUPLED ULTRASOUND EXPERIMENT PERFORMED AT THE CCMSS LABORATORY.

FIGURE 15: FULL WAVEFORM ULTRASONIC INSPECTION IN WHICH THE ULTRASONIC WAVE WAS GENERATED BY PULSED LASER BEAMS. THE EXPERIMENT WAS PERFORMED AT THE TECNATOM LABORATORY IN MADRID

FIGURE 16: SPECKLE PATTERN IN THE SURFACE OF A SAMPLE PREPARED FOR A DIGITAL IMAGE CORRELATION TEST.

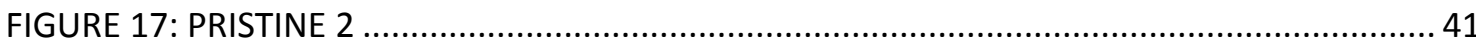

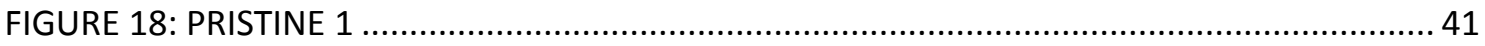

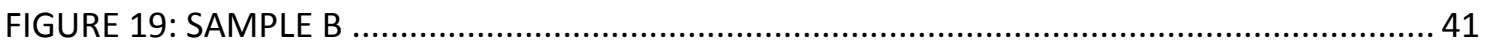

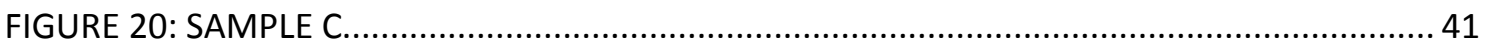

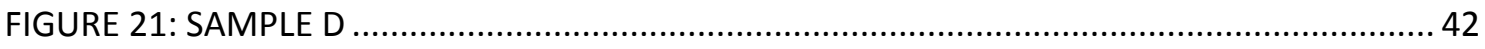

FIGURE 22: ALUMINIUM MALE TOOL WITH A WRINKLE MAXIMUM HEIGHT OF 3 MM AND A WRINKLE "SEVERITY" OF 0.030.

FIGURE 23: ALUMINIUM MALE TOOL WITH A WRINKLE MAXIMUM HEIGHT OF 6 MM AND A WRINKLE "SEVERITY" OF 0.090. 
FIGURE 24: HOT PLATE PRESS IN OPERATION

FIGURE 25: CURING CYCLE USED IN THE MANUFACTURE OF THE SPECIMENS ............................ 44

FIGURE 26: DIAGRAM OF THE TWO STEPS OF THE MANUFACTURING PROCESS (FIRST STEP ON

THE LEFT, SECOND STEP ON THE RIGHT). ALUMINIUM TOOL USED DURING THE

MANUFACTURE OF THE SPECIMENS WITH HALF OF THE PLIES STACKED ON IT BEFORE

CURING (TOP LEFT). THE EFFECT WHERE THE LAYERS DO NOT CONFORM TO THE

GEOMETRY OF THE TOOL CAN BE SEEN CLEARLY (TOP).................................................. 45

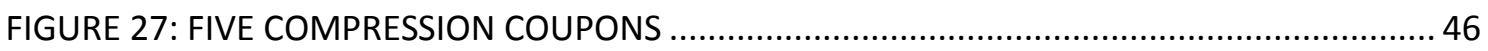

FIGURE 28: SAMPLE C COUPON AFTER TENSILE TEST ........................................................ 47

FIGURE 29: TENSILE STRENGTH (MPA) OF SAMPLES PRISTINE 1, B, C, PRISTINE 2, AND D........ 48

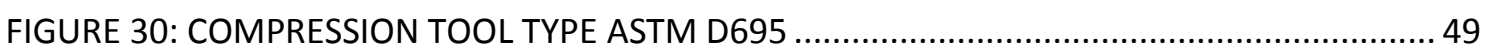

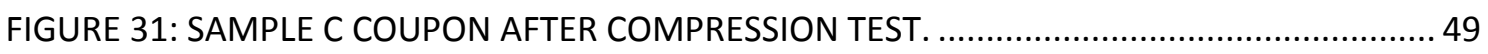

FIGURE 32: STRENGTH (MPA) OF SAMPLES PRISTINE 1, B, C PRISTINE 2 AND D......................... 50

FIGURE 33: DIAGRAM SHOWING SOME OF THE PARAMETERS OF THE ACOUSTIC BEAM ..........51

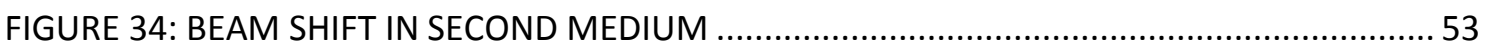

FIGURE 35: RECONSTRUCTED B-SCAN OF THE FULL WAVEFORM AT 2.25MHZ OF THE SPECIMEN

D WITH A WATER-PATH OF 3MM. MULTIPLE ECHOES FROM THE FRONT WALL APPEAR

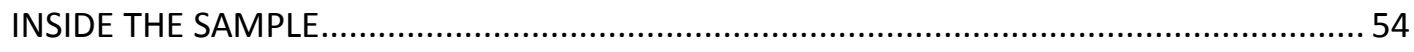

FIGURE 36: FULL WAVEFORM INSPECTION AT 5MHZ OF THE SPECIMEN C. B-SCAN (TOP), D-

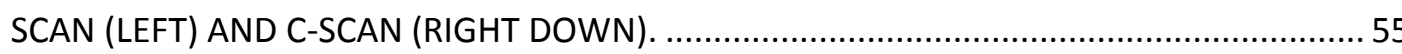

FIGURE 37: B-SCAN OF THE FULL WAVEFORM (TOP) AND INSTANTANEOUS PHASE (BOTTOM)

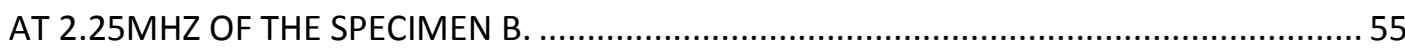

FIGURE 38: BACK ECHO (BLACK CIRCLE) AND MEASURE OF THE WRINKLE IN THE SPECIMEN B

WITH RECONSTRUCTED B-SCAN OF THE INSTANTANEOUS PHASE. ..................................5 56

FIGURE 39: B-SCAN OF THE FULL WAVEFORM (TOP) AND INSTANTANEOUS PHASE (BOTTOM)

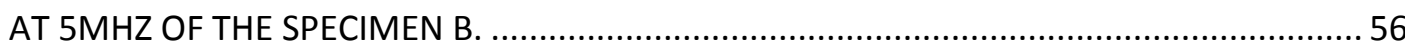

FIGURE 40: B-SCAN OF THE FULL WAVEFORM (TOP) AND INSTANTANEOUS PHASE (BOTTOM)

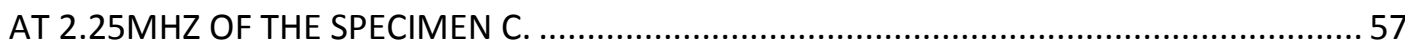

FIGURE 41: MEASURE OF THE WRINKLE IN THE SPECIMEN C WITH THE RECONSTRUCTED B-

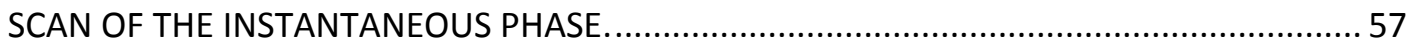

FIGURE 42: B-SCAN OF THE FULL WAVEFORM (TOP) AND INSTANTANEOUS PHASE (BOTTOM)

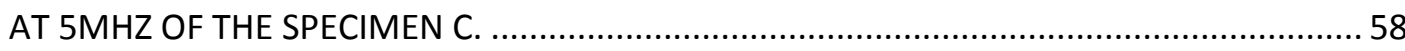

FIGURE 43: : B-SCAN OF THE FULL WAVEFORM (TOP) AND INSTANTANEOUS PHASE (BOTTOM)

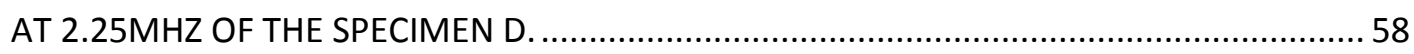

FIGURE 44: BACK ECHO (BLACK CIRCLE) AND MEASURE OF THE WRINKLE IN THE SPECIMEN D

WITH THE RECONSTRUCTED B-SCAN OF THE INSTANTANEOUS PHASE AT 2.25MHZ ........59

FIGURE 45: B-SCAN OF THE FULL WAVEFORM (TOP) AND INSTANTANEOUS PHASE (BOTTOM)

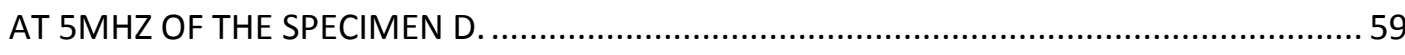

FIGURE 46: BACK ECHO (BLACK CIRCLE) AND MEASURE OF THE WRINKLE IN THE SPECIMEN D

WITH THE RECONSTRUCTED B-SCAN OF THE INSTANTANEOUS PHASE AT 5MHZ.............60

FIGURE 47: PHASED-ARRAY INSPECTION SET-UP WITH THE 5MHZ PROBE................................. 61

FIGURE 48: 1-D LINEAR PHASED ARRAY PROBE WITH RECTANGULAR PIEZOELECTRIC CRYSTALS.

61

FIGURE 49: RECONSTRUCTED B-SCAN OF THE FULL WAVEFORM (LEFT) AND “INSTANTANEOUS PHASE” (RIGHT) AT 5MHZ OF THE SPECIMEN D. THE NEAR-SURFACE DEAD ZONE OF THE 
PROBE IS LARGE (9 MM) AND DOES NOT ALLOW MEASUREMENT OF THE WRINKLE. THE

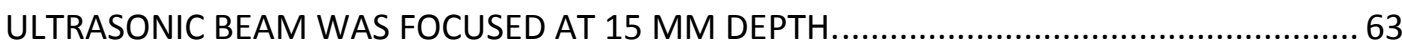

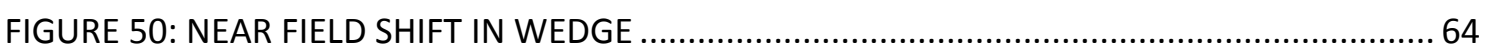

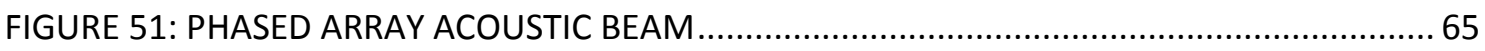

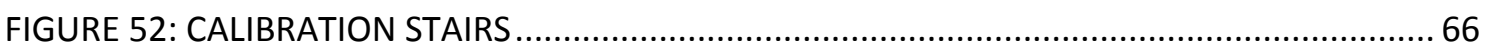

FIGURE 53: RECONSTRUCTED B-SCANS OF THE FULL WAVEFORM (LEFT) AND INSTANTANEOUS PHASE (CENTRE) AT 2.25 MHZ OF THE SPECIMEN B. THE BACK-WALL ECHO IS LABELLED 'B' AND THE FIRST AND SECOND MULTIPLE ECHOES OF THE WEDGE ARE LABELLED ' 1 ' AND ' 2 ' RESPECTIVELY. THE MEASUREMENTS ARE SHOWN IN THE RIGHT FIGURE.

FIGURE 54: RECONSTRUCTED B-SCANS OF THE FULL WAVEFORM (LEFT) AND INSTANTANEOUS PHASE (RIGHT) AT 5MHZ OF THE SPECIMEN B. THE BACK-WALL ECHO IS LABELLED 'B' AND THE SECOND MULTIPLE ECHOES OF THE WEDGE IS LABELLED ' 2 '.

FIGURE 55: RECONSTRUCTED B-SCANS OF THE FULL WAVEFORM (LEFT) AND INSTANTANEOUS PHASE (CENTRE) AT 2.25 MHZ OF THE SPECIMEN C. THE BACK-WALL ECHO IS LABELLED 'B' AND THE FIRST AND SECOND MULTIPLE ECHOES OF THE WEDGE ARE LABELLED ' 1 ' AND ' 2 ' RESPECTIVELY. THE MEASUREMENTS ARE SHOWN AS AN EXAMPLE (RIGHT). 67 FIGURE 56: RECONSTRUCTED B-SCANS OF THE FULL WAVEFORM (LEFT) AND INSTANTANEOUS PHASE (RIGHT) AT 5MHZ OF THE SPECIMEN C. THE BACK-WALL ECHO IS LABELLED 'B' AND THE FIRST AND SECOND MULTIPLE ECHOES OF THE WEDGE ARE LABELLED ' 1 ' AND ' 2 ' RESPECTIVELY 68

FIGURE 57: RECONSTRUCTED B-SCANS OF THE FULL WAVEFORM (LEFT) AND INSTANTANEOUS PHASE (RIGHT) AT 2.25 MHZ OF THE SPECIMEN D. THE BACK-WALL ECHO IS LABELLED 'B' AND THE FIRST AND SECOND MULTIPLE ECHOES OF THE WEDGE ARE LABELLED ' 1 ' AND ' 2 ' RESPECTIVELY. THE MEASUREMENTS ARE SHOWN IN THE RIGHT FIGURE. 68 FIGURE 58: RECONSTRUCTED B-SCANS OF THE FULL WAVEFORM (LEFT) AND INSTANTANEOUS PHASE (RIGHT) AT 5 MHZ OF THE SPECIMEN D. THE BACK-WALL ECHO IS LABELLED 'B' AND THE SECOND MULTIPLE ECHOES OF THE WEDGE IS LABELLED ' 2 '. THE MEASUREMENTS ARE SHOWN IN THE RIGHT FIGURE... 68

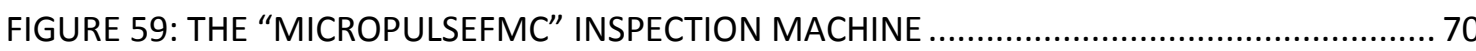
FIGURE 60: B-SCAN OBTAINED WITH 500 TIME POINTS (LEFT) AND WITH 1000 TIME POINTS (RIGHT).

FIGURE 61: EXAMPLE OF THE PLACEMENT OF THE PROBE DURING THE INSPECTION OF THE SPECIMENS: TO THE LEFT OF THE WRINKLE (A), OVER THE WRINKLE (B) AND TO THE RIGHT OF THE WRINKLE(C).

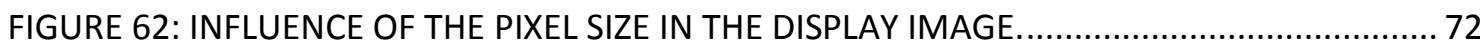

FIGURE 63: CHANGE IN COMPRESSION VELOCITY VALUE WITH THE FIBRE VOLUME FRACTION (SMITH, 2010).

FIGURE 64: MEASURED PHASE VELOCITIES PROFILE OBTAINED USING BACK-WALL REFLECTION METHOD (BRM) SHOWING A THIRD-ORDER POLYNOMIAL FIT TO THE DATA. A) SPECIMEN B AT $2.5 \mathrm{MHZ}$; B) SPECIMEN ( AT 2.5 MHZ; C) SPECIMEN D AT $2.5 \mathrm{MHZ}$; D) SPECIMEN B AT $5 \mathrm{MHZ}$; E) SPECIMEN C AT $5 \mathrm{MHZ;} \mathrm{F)} \mathrm{SPECIMEN} \mathrm{D} \mathrm{AT} 5$ MHZ(LARRAÑAGA-VALSERO ET AL. 2018) .75

FIGURE 65: SIGNAL-TO-NOISE RATIO FOR A WRINKLE LOCATED HALF WAY THROUGH SPECIMEN B AS A FUNCTION OF THE MAXIMUM PROPAGATION ANGLE FOR TFM RESULTS.(LARRAÑAGA-VALSERO ET AL. 2018) 
FIGURE 66: RECONSTRUCTED B-SCANS OF THE INSTANTANEOUS AMPLITUDE (ABOVE) AND INSTANTANEOUS PHASE (BELOW) AT 2.5MHZ OF THE SPECIMEN B FROM THE CONVEX SIDE OF THE WRINKLE.

FIGURE 67: RECONSTRUCTED B-SCANS OF THE INSTANTANEOUS AMPLITUDE (ABOVE) AND INSTANTANEOUS PHASE (BELOW) AT 2.5MHZ OF THE SPECIMEN B FROM THE CONCAVE SIDE OF THE WRINKLE.

FIGURE 68: BACK ECHO (YELLOW) AND MEASURE OF THE WRINKLE IN THE SPECIMEN B WITH THE RECONSTRUCTED B-SCANS OF THE INSTANTANEOUS PHASE

FIGURE 69: RECONSTRUCTED B-SCANS OF THE INSTANTANEOUS AMPLITUDE (ABOVE) AND INSTANTANEOUS PHASE (BELOW) AT 5MHZ OF THE SPECIMEN B FROM THE CONVEX SIDE OF THE WRINKLE.

FIGURE 70: RECONSTRUCTED B-SCANS OF THE INSTANTANEOUS AMPLITUDE (ABOVE) AND INSTANTANEOUS PHASE (BELOW) AT 5MHZ OF THE SPECIMEN B FROM THE CONCAVE SIDE OF THE WRINKLE.

FIGURE 71: RECONSTRUCTED B-SCANS OF THE INSTANTANEOUS AMPLITUDE (ABOVE) AND INSTANTANEOUS PHASE (BELOW) AT 2.5MHZ OF THE SPECIMEN C FROM THE CONVEX SIDE OF THE WRINKLE.

FIGURE 72: DETAIL OF THE RECONSTRUCTED B-SCANS OF THE INSTANTANEOUS AMPLITUDE AT 2.5MHZ OF THE SPECIMEN C FROM THE CONVEX SIDE OF THE WRINKLE. THIS IS THE INSPECTION THAT WAS PERFORM ON THE CENTRAL PART OF THE WRINKLE WITHOUT ANY COMPOSITION WITH THE LEFT AND THE RIGHT INSPECTION................................... 79

FIGURE 73: MEASUREMENT OF THE WRINKLE IN SPECIMEN C WITH A 2.5 MHZ PROBE. ......... 80 FIGURE 74: RECONSTRUCTED B-SCANS OF THE INSTANTANEOUS AMPLITUDE (ABOVE) AND INSTANTANEOUS PHASE (BELOW) AT 2.5MHZ OF THE SPECIMEN C FROM THE CONCAVE SIDE OF THE WRINKLE.

FIGURE 75: RECONSTRUCTED B-SCANS OF THE INSTANTANEOUS AMPLITUDE (ABOVE) AND INSTANTANEOUS PHASE (BELOW) AT 5MHZ OF THE SPECIMEN C FROM THE CONVEX SIDE OF THE WRINKLE.

FIGURE 76: RECONSTRUCTED B-SCANS OF THE INSTANTANEOUS AMPLITUDE (ABOVE) AND INSTANTANEOUS PHASE (BELOW) AT 5MHZ OF THE SPECIMEN C FROM THE CONCAVE SIDE OF THE WRINKLE.

FIGURE 77: RECONSTRUCTED B-SCANS OF THE INSTANTANEOUS AMPLITUDE (ABOVE) AND INSTANTANEOUS PHASE (BELOW) AT 2.5MHZ OF THE SPECIMEN D FROM THE CONVEX SIDE OF THE WRINKLE.

FIGURE 78: MEASUREMENT OF THE WRINKLE PARAMETERS IN SPECIMEN D WITH A $2.5 \mathrm{MHZ}$ PROBE FROM THE CONVEX SIDE OF THE WRINKLE. THE BLACK WALL ECHO IS CIRCLED IN YELLOW.

FIGURE 79: RECONSTRUCTED B-SCANS OF THE INSTANTANEOUS AMPLITUDE (ABOVE) AND INSTANTANEOUS PHASE (BELOW) AT 2.5MHZ OF THE SPECIMEN D FROM THE CONCAVE SIDE OF THE WRINKLE.

FIGURE 80: MEASUREMENT OF THE WRINKLE PARAMETERS IN SPECIMEN D WITH A $2.5 \mathrm{MHZ}$ PROBE FROM THE CONCAVE SIDE OF THE WRINKLE. THE BLACK WALL ECHO IS CIRCLED IN YELLOW. 
FIGURE 81: RECONSTRUCTED B-SCANS OF THE RECONSTRUCTED B-SCANS OF THE INSTANTANEOUS AMPLITUDE (ABOVE) AND INSTANTANEOUS PHASE (BELOW) AT 5MHZ OF THE SPECIMEN D FROM THE CONVEX SIDE OF THE WRINKLE. 84

FIGURE 82: MEASUREMENT OF THE WRINKLE IN SPECIMEN D WITH A 5 MHZ PROBE. THE BLACK WALL ECHO IS CIRCLED IN YELLOW. .85

FIGURE 83: RECONSTRUCTED B-SCANS OF THE INSTANTANEOUS AMPLITUDE (ABOVE) AND INSTANTANEOUS PHASE (BELOW) AT 5MHZ OF THE SPECIMEN D FROM THE CONCAVE SIDE OF THE WRINKLE.

FIGURE 84: RECONSTRUCTED B-SCANS OF THE INSTANTANEOUS PHASE (BELOW) AT 2.5MHZ OF THE SPECIMEN B FROM THE CONVEX SIDE OF THE WRINKLE................................... 86 FIGURE 85: RECONSTRUCTED B-SCANS OF THE INSTANTANEOUS PHASE (BELOW) AT 5MHZ OF THE SPECIMEN B FROM THE CONVEX SIDE OF THE WRINKLE. .86 FIGURE 86: RECONSTRUCTED B-SCANS OF THE INSTANTANEOUS PHASE (BELOW) AT 2.25MHZ OF THE SPECIMEN C FROM THE CONVEX SIDE OF THE WRINKLE..

FIGURE 87: RECONSTRUCTED B-SCANS OF THE INSTANTANEOUS PHASE (BELOW) AT 5MHZ OF THE SPECIMEN C FROM THE CONVEX SIDE OF THE WRINKLE.

FIGURE 88: RECONSTRUCTED B-SCANS OF THE INSTANTANEOUS PHASE (BELOW) AT 2.25MHZ OF THE SPECIMEN D FROM THE CONVEX SIDE OF THE WRINKLE. .88 FIGURE 89: RECONSTRUCTED B-SCANS OF THE INSTANTANEOUS PHASE (BELOW) AT 5MHZ OF THE SPECIMEN D FROM THE CONVEX SIDE OF THE WRINKLE. .88 FIGURE 90: RECONSTRUCTED B-SCANS OF THE INSTANTANEOUS PHASE AT 2.5 MHZ OF SAMPLE C. THE CENTRE OF THE IMAGE PRESENT A DEEPER PENETRATION THAN THE SIDES DUE TO THE BORDER EFFECT.

FIGURE 91: RECONSTRUCTED B-SCAN OF THE FULL WAVEFORM AT 2.25MHZ OF THE SPECIMEN B. THE STRONGER GLASS-FIBRE PLY REFLECTIONS IN THE FLAT REGION ARE POINTED WITH ARROWS.

FIGURE 92: GRAPH SHOWING A COMPARISON OF THE MEASURED AND ACTUAL MAXIMUM WRINKLE ANGLES FOR THE THREE METHODS AND FOR $2.25 \mathrm{MHZ}$ (SOLID SYMBOLS) AND 5 MHZ (OPEN SYMBOLS). THE LINE REPRESENTS WHERE THE MEASURED ANGLE EQUALS THE ACTUAL ANGLE.

FIGURE 93:DIAGRAM ILLUSTRATING THE PROCESS WHERE THE RESIN-RICH INTER-PLY LAYERS ARE CONVERTED INTO SINGLE INTERFACES WITH COMPLEX REFLECTION AND TRANSMISSION COEFFICIENTS. Z IS THE ACOUSTIC IMPEDANCE OF THE MATERIAL, $K$ IS THE WAVE NUMBER (2חF/C), L IS THE THICKNESS OF THE THIN RESIN-RICH INTER-PLY LAYER AND P IS THE ACOUSTIC PRESSURE.

FIGURE 94: DIAGRAM ILLUSTRATING THE PROCESS INVOLVED IN THE RECURSIVE ANALYTICAL MODEL

FIGURE 95: SIMULATED RESPONSE FROM EIGHTEEN CFRP 0.6 MM THICK PLIES USING A 1.5MHZ CENTRE FREQUENCY AND A 3 MHZ BANDWIDTH. FULL WAVEFORM (LEFT) AND INSTANTANEOUS PHASE (RIGHT).

FIGURE 96: REFLECTION COEFFICIENT OF AN 18 LAYERS CARBON FIBRE LAMINATE WITH A 0.6 MM PLY THICKNESS.

FIGURE 97: SIMULATED RESPONSE FROM EIGHTEEN 0.6 MM THICK PLIES WITH A 2MM HIGH PROTRUDING WRINKLE USING A 2.5MHZ CENTRE FREQUENCY AND A $2.5 \mathrm{MHZ}$ BANDWIDTH. FULL WAVEFORM (LEFT) AND INSTANTANEOUS PHASE (RIGHT). 100 
FIGURE 98: REFLECTION COEFFICIENT AT THE THINNEST POINT OF THE WRINKLE OF AN 18 LAYERS CARBON FIBRE LAMINATE WITH A 2 MM PROTRUDING WRINKLE. THE PLY THICKNESS IS AT THAT POINT 0.488 MM.

FIGURE 99: REFLECTION COEFFICIENT OF AN 18 LAYERS E-GLASS FIBRE LAMINATE WITH A 0.44 MM PLY THICKNESS. 101

FIGURE 100: SIMULATED RESPONSE FROM EIGHTEEN 0.44 MM THICK PLIES WITH A 1 MM HIGH PROTRUDING WRINKLE USING A 4 MHZ CENTRE FREQUENCY AND A 4 MHZ BANDWIDTH. FULL WAVEFORM (LEFT) AND INSTANTANEOUS PHASE (RIGHT). 102

FIGURE 101: REFLECTION COEFFICIENT AT THE THINNEST POINT OF THE WRINKLE OF AN 18 LAYERS GLASS FIBRE LAMINATE WITH A 1 MM PROTRUDING WRINKLE. THE PLY THICKNESS IS AT THAT POINT 0.384 MM. 102

FIGURE 102: SIMULATED INSTANTANEOUS AMPLITUDE (TOP) AND PHASE (BOTTOM) FOR 36 CARBON-FIBRE PLIES OF THICKNESS 0.59 MM WITH 0.01 MM RESIN LAYERS AND A 3 MM AMPLITUDE WRINKLE AT THE CENTRE. 2.25 MHZ CENTRE FREQUENCY AND 2.25 MHZ BANDWIDTH (LEFT) AND 5 MHZ CENTRE FREQUENCY AND 2.5 MHZ BANDWIDTH (RIGHT).

FIGURE 103. SIMULATED RESPONSES USING A 2.25 MHZ CENTRE FREQUENCY AND $2.25 \mathrm{MHZ}$ BANDWIDTH FOR CARBON-FIBRE PLIES OF THICKNESS 0.59 MM AND 0.01 MM RESIN LAYERS BUT WITH A 0.44 MM THICK GLASS-FIBRE PLY EVERY 6TH PLY OF A TOTAL 36 PLIES WITH A 3 MM WRINKLE IN THE MIDDLE. LAY-UP DIAGRAM (LEFT), INSTANTANEOUS AMPLITUDE (MIDDLE) AND INSTANTANEOUS PHASE (RIGHT). 105

FIGURE 104. SIMULATED RESPONSE FROM SIX 1.5 MM THICK PLIES SEPARATED BY 0.2 MM RESIN LAYERS. (LEFT) INSTANTANEOUS AMPLITUDE. (MIDDLE) INSTANTANEOUS PHASE. (RIGHT) INSTANTANEOUS PHASE IN COLOUR MODERATED BY AMPLITUDE IN BRIGHTNESS. 106

FIGURE 105: SIMULATION OF INSTANTANEOUS AMPLITUDE (A) AND INSTANTANEOUS PHASE (B) OF THE SPECIMEN B WITH THE RAS LAYER MODEL WITH PULSE LENGTH VARIATION USING A 2.5MHZ CENTRE FREQUENCY AND A $2.5 \mathrm{MHZ}$ BANDWIDTH. 106 FIGURE 106: SIMULATION OF INSTANTANEOUS AMPLITUDE (A) AND INSTANTANEOUS PHASE (B) OF THE SPECIMEN B WITH THE RAS LAYER MODEL WITH PULSE LENGTH VARIATION USING A 5MHZ CENTRE FREQUENCY AND A 5 MHZ BANDWIDTH. 107 FIGURE 107: SIMULATION OF INSTANTANEOUS AMPLITUDE (A) AND INSTANTANEOUS PHASE (B) OF THE SPECIMEN C WITH THE RAS LAYER MODEL WITH PULSE LENGTH VARIATION USING A 2.5MHZ CENTRE FREQUENCY AND A $2.5 \mathrm{MHZ}$ BANDWIDTH. 108 FIGURE 108: SIMULATION OF INSTANTANEOUS AMPLITUDE (A) AND INSTANTANEOUS PHASE (B) OF THE SPECIMEN C WITH THE RAS LAYER MODEL WITH PULSE LENGTH VARIATION USING A 5MHZ CENTRE FREQUENCY AND A 5 MHZ BANDWIDTH. 108 FIGURE 109: SIMULATION OF INSTANTANEOUS AMPLITUDE (A) AND INSTANTANEOUS PHASE (B) OF THE SPECIMEN D WITH THE RAS LAYER MODEL WITH PULSE LENGTH VARIATION USING A 2.5MHZ CENTRE FREQUENCY AND A 2.5 MHZ BANDWIDTH. 109 FIGURE 110: SIMULATION OF INSTANTANEOUS AMPLITUDE (A) AND INSTANTANEOUS PHASE (B) OF THE SPECIMEN J WITH THE RAS LAYER MODEL WITH PULSE LENGTH VARIATION USING A 5MHZ CENTRE FREQUENCY AND A 5 MHZ BANDWIDTH. 109 FIGURE 111: 8 YARN LAMINATE WITH A 3 MM HIGH WRINKLE MODEL GENERATED WITH TEXGEN. 
FIGURE 112: DETAIL OF THE MESH SHOWING THE DIFFERENCE BETWEEN THE PRINCIPAL DIRECTION OF ORTHOTROPY IN THE LAMINATE IN THE WRINKLED AREA AND THE COORDINATE DIRECTIONS OF THE MESH.

FIGURE 113: FINAL MATERIAL ASSIGNMENT FOR AN 8 LAYERS LAMINATE WITH WRINKLE. EACH COLOR REPRESENT A DIFFERENT MATERIAL.

FIGURE 114: PZFLEX MODEL FOR AN 8 LAYERS LAMINATE WITH WRINKLE.

FIGURE 115: A-SCANS AT 2.5MHZ FOR AN 8 LAYERS LAMINATE. A-SCAN AT THE AREA WITHOUT THE WRINKLE (LEFT) AND A-SCAN AT THE AREA OF THE WRINKLE MAXIMUM AMPLITUDE (RIGHT) 115 FIGURE 116: B-SCAN AT 2.5MHZ FOR AN 8 LAYERS LAMINATE WITH WRINKLE....................... 115

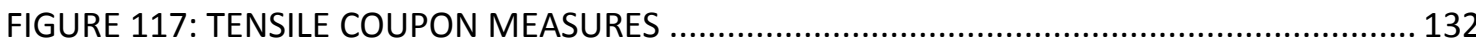

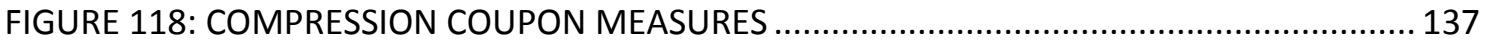




\section{LIST OF TABLES}

TABLE 1: SUMMARY AND COMPARISON FOR MAJOR NDT METHODS FOR WRINKLE DETECTION IN WIND

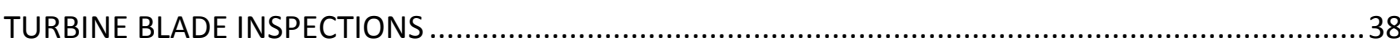

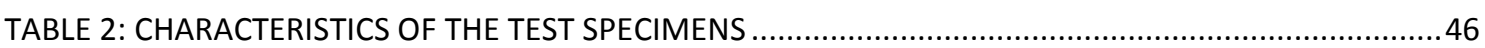

TABLE 3: CHARACTERISTICS OF THE TWO SINGLE ELEMENT IMMERSION ULTRASONIC PROBES ..............52

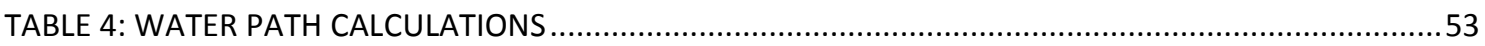

TABLE 5: COMPARISON BETWEEN THE ACTUAL PARAMETERS OF THE PARTS AND THOSE OBTAINED FROM THE CONVEX SIDE OF THE SAMPLES BY THE INSPECTION WITH THE SINGLE-ELEMENT

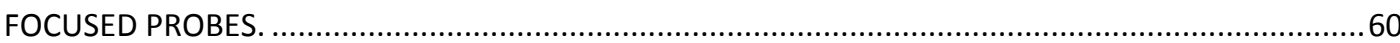

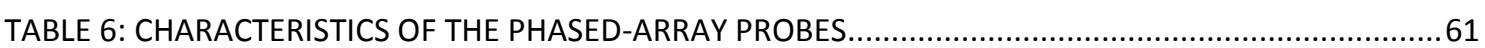

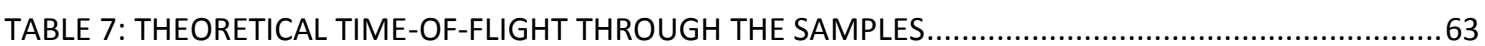

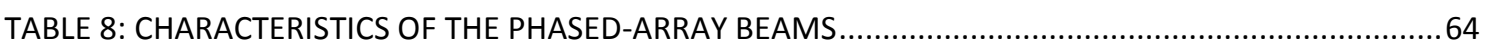

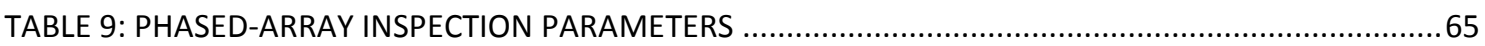

TABLE 10: COMPARISON BETWEEN THE ACTUAL PARAMETERS OF THE PARTS AND THOSE OBTAINED FROM THE CONVEX SIDE OF THE SAMPLES BY THE INSPECTION WITH THE PHASED-ARRAY PROBES.

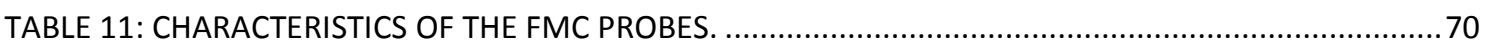

TABLE 12: COMPARISON BETWEEN THE ACTUAL PARAMETERS OF THE PARTS AND THOSE OBTAINED FROM THE CONVEX SIDE OF THE SAMPLES BY THE INSPECTION WITH THE TFM PROBES. ...............89

TABLE 13: COMPARISON BETWEEN THE WRINKLE PARAMETERS MEASURED AND EXPECTED AT $2.5 \mathrm{MHZ}$ FOR SPECIMEN D.

TABLE 14: COMPARISON BETWEEN THE ACTUAL PARAMETERS OF THE WRINKLES AND THOSE OBTAINED FROM THE CONVEX SIDE OF THE SPECIMENS BY EACH OF THE THREE INSPECTIONS TECHNIQUES.93

TABLE 15: MATERIAL PROPERTIES OF COMPONENT MATERIALS USED IN THE ONE-DIMENSIONAL

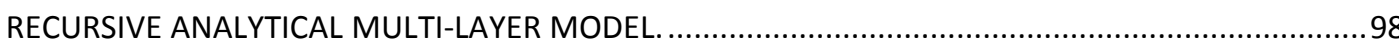

TABLE 16:VARIATION OF THE RESONANCE FREQUENCY WITH THE PLY THICKNESS ON A CARBON WRINKLED LAMINATE 101

TABLE 17: VARIATION OF THE RESONANCE FREQUENCY WITH THE PLY THICKNESS ON A WRINKLED GLASS LAMINATE

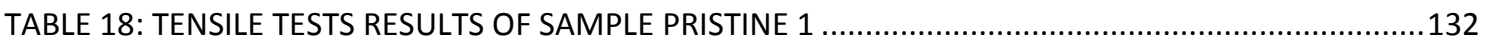

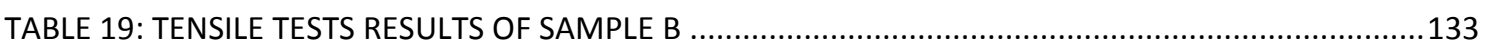

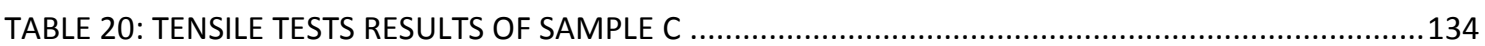

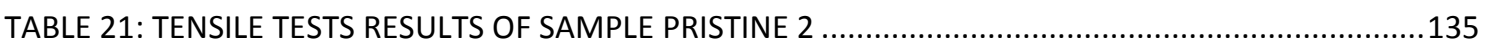

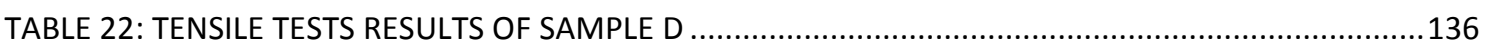

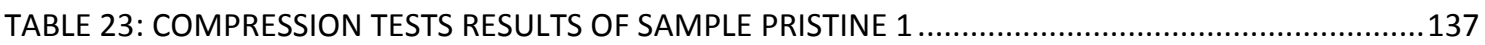

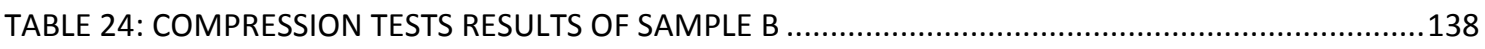

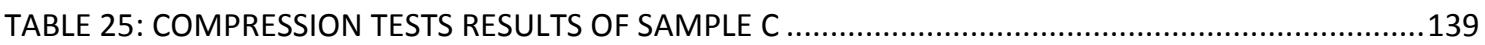

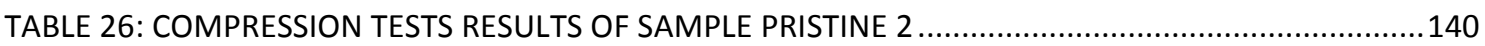

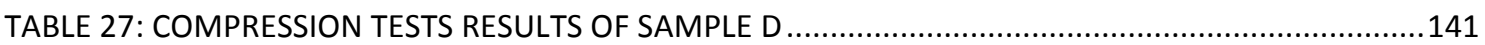




\section{NOMENCLATURE}

Roman symbols
A Wrinkle amplitude $(\mathrm{H} / 2)$
b Coupon high
c Sound velocity
D Diameter
E Young's Modulus
e Pitch
F $\quad$ Focal length
f Frequency
G Shear Modulus
$\mathrm{H} \quad$ Maximum wrinkle Height
h Coupon width
K Bulk Modulus
$\mathrm{k} \quad$ Wave number $(2 \pi \mathrm{f} / \mathrm{c})$
L Wrinkle wavelength
$1 \quad$ Resin-rich inter-ply layer thickness
M Compression Modulus
N Natural focus, beam near-field distance
$\mathrm{p} \quad$ Acoustic pressure
R Reflection coefficient
S Probe Area
$\mathrm{T} \quad$ Transmission coefficient
Z Acoustic impedance 
Greek symbols

$\varepsilon \quad$ Error

$\theta \quad$ Wrinkle angle

$\lambda \quad$ Wavelength

$v \quad$ Longitudinal wave velocity

$\phi \quad$ Instantaneous phase

$\rho \quad$ Density 


\section{GLOSARY OF TERMS}

BRM Back-wall Reflection Method

CCMSS Centre of Composite Materials and Smart Structures

CFRP Carbon-Fibre Reinforced Plastic

DAC Distance-amplitude correction

GFRP Glass-Fibre Reinforced Plastic

FMC Full Matrix Capture

FVF $\quad$ Fibre Volume Fraction

NDE Non-destructive evaluation

NDT Non-destructive testing

PAUT Phased-Array Ultrasonic Technique

SHM Structural Health Monitoring

SNR Signal to Noise Ratio

TFM Total Focusing Method

UD Unidirectional

UPM Universidad Politécnica de Madrid 
(this page has been intentionally left blank) 


\section{CHAPTER 1 INTRODUCTION}

This chapter provides a general overview of the motivation for the research topic of this thesis. The parameters chosen to characterise the wrinkles are presented. The structure of the thesis and the available resources are also presented through this introductory chapter.

\subsection{Motivation}

The issues of global warming and climate change have become increasingly serious over the past years. Almost all the countries in the world have set emission reduction targets in order to achieve sustainable development. One of the main challenges is to increase the generation of electricity in order to meet the increasing worldwide demand while reducing the environmental impact caused by the conventional electricity generation technologies based on fossil fuels or nuclear fission.

In the last years the use of renewable energies has gained more and more importance and the European Union set the goal of increasing the rate of renewal energies up to $20 \%$ in the overall energy consumption by $2020^{1}$. The aim is an scenario powered by wind, water, and solar resources. In order to achieve that goal, an increase number of wind energy plants have been installed across Europe (Figure 1). Other world superpowers have set similar goals.

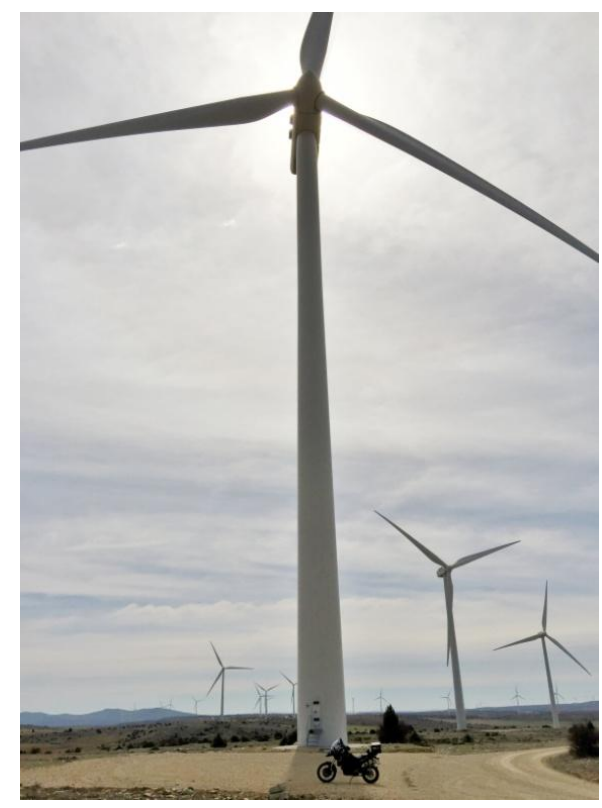

Figure 1: Wind turbine plant in Maranchón, Guadalajara, Spain.

\footnotetext{
${ }^{1}$ Directive 2009/28/EC of the European Parliament and of the Council of 23 April 2009 on the promotion of the use of energy from renewable sources and amending and subsequently repealing Directives 2001/77/EC and 2003/30/EC
} 
A wind turbine is able to convert wind power into mechanical energy and then generate electricity. Wind power was used for energy generation for centuries and the technology development during the $20^{\text {th }}$ century led to modern wind turbine systems. Since the energy crisis in 1970, the development of wind power for energy generation has increased worldwide. As a result, wind power can now be considered a mature green technology with a remarkable share in the energy market. By the end of 2018, 6\% of the global electricity demand can be covered by the electricity produced by all the wind energy plants installed worldwide. Their overall world capacity has reached 597 Gigawatt with the 50,100 Megawatt that were added on $2018^{2}$.

A wind turbine is a complex system consisting on several mechanical and electric components including blades, rotor, gearbox, shaft, generator and tower. The blades are the main aerodynamic elements. Therefore, an important part of the design work is dedicated to them. They must be manufactured in lightweight materials that are mainly resistant to bending loads. Up to $20 \%$ of the manufacturing cost of each wind turbine is dedicated to the manufacturing of the blades (Zhou et al. 2014).

Those blades are one of the most critical components mainly because the efficiency of the wind turbine is depending on them. Longer and wider power blades are being manufactured that have to withstand larger bending moments that appear at their root. The blades are highly stressed parts of the turbine. Nowadays, giant enormous turbine blades are designed using thick carbon fibre reinforced plastic (CFRP) and glass fibre reinforced plastic (GFRP) laminates.

The rotor diameter has increase from the average $54 \mathrm{~m}$ in 1998 to an average of $158 \mathrm{~m}$ in 2017 for on-shore wind turbines and from the average $76 \mathrm{~m}$ in 2005 to an average of $164 \mathrm{~m}$ in 2017 for the new installations of off-shore wind turbines. The increased rotor diameter equals a larger swept area, which enables the wind turbine to harvest more energy from the wind. The rotor diameter starts at $100 \mathrm{~m}$ and goes up to $160 \mathrm{~m}$ for wind turbine with capacities greater than 4 Megawatt. Nowadays fewer wind turbines need to be installed per installed Megawatt thus reducing cost and the visual impact of the wind turbine farms. However, wind turbines more vulnerable to surface obstacles and areas with height restrictions due to the increased rotor diameters have made.(Enevoldsen and Xydis 2019).

After some decades of wind capacity expansion, the majority of installed wind turbines are aging. Wind turbines have an expected service life of 15-20 years. Throughout those years, they will inevitably need maintenance and repairs.

Wind turbine accidents happen from time to time. According to Caithness Windfarm Information Forum ${ }^{3}$, by June 30 2019, a total of 2500 accidents have been reported worldwide. A total of 193 accidents happen in 2018. As expected, more accidents occur as more wind turbines are built.

\footnotetext{
${ }^{2}$ The World Wind Energy Association. www.wwindea.org

${ }^{3}$ http://www. caithnesswindfarms.co.uk
} 
Although damage can appear at any part of the wind turbine, blade failures are the most common type of damage that occurs in a wind turbine. According to the accident statistics provided by Caithness Windfarm Information Forum a total of 423 separate incidences were due to blade failure. Blades are documented as landing as far as $500 \mathrm{~m}$ from the tower. When one wind turbine blade fails, it may affect other blades, the wind turbine itself and even additional wind turbines located in neighbour (Raišutis et al. 2008). It is also important to remember that, even before causing a catastrophic failure; the presence of damage in a blade will affect the structural performance in general terms of the wind turbine thus increasing wind energy costing.

Wind turbine failure is very costly and forces wind-farm operators to repair the blades in-situ if the failure has not destroyed the whole turbine. Wind turbine blade repairs are not only expensive but also inconvenient as technicians have to work suspended from the rotor hub (Marsh 2011). Up to 30\% of the energy generation cost corresponds to the operation and maintenance costs of wind turbine.

In order to prevent wind turbine failure once the turbine has been installed and thus reducing wind energy costing; reliable and effective non-destructive testing (NDT) inspections are routinely performed. With the tower and the mechanical parts like the gear, the turbine blades are an important part of the NDT inspections.

Nowadays different NDT techniques can be performed once the blade has been manufactured or installed. The different available NDT techniques are based on visual, ultrasound, optic, electromagnetic, thermo and radiographic techniques. Some of them have already show their potential to inspect turbine blades while some others still present some challenges. Not all the available techniques can be performed at a wind turbine blade once the blade is in operation.

On one hand, blades are affected by the environment condition when in service. They can be affected by moisture absorption, atmospheric corrosion, rain, fatigue, gusts of wind or lighting strikes. This type of damage may appear at any time in a wind turbine so wind energy plants have to be inspected at regular intervals.

On the other hand, the blade manufacturing process can also produce some flaws. When such defects are not detected during the manufacturing process or during the routine in-service test, the blades may unexpectedly fail in service. In order to reduce that risk, designers over-engineer wind turbine blades by adding even more plies, and weight, that the strictly necessary. If some of the flaws were detectable during the manufacturing process, the blades could be repaired before leaving the factory, which would avoid expensive in-situ repairs and would allow the designers to refine the laminates.

Some common defect that seriously degrades the mechanical properties may appear during manufacturing and are difficult to detect with the NDT techniques that are nowadays suitable for inspection of the wind turbine blades. 
One common flaw that appears during manufacturing and that is difficult to detect nowadays is misalignment in fibre orientation. This defect can appear as in-plane wrinkles or as out-of-plane wrinkles. Both are common defects that seriously degrade the mechanical properties of the blades.

The motivation to carry out this thesis revolves around the need to fully characterise the increasing large wind turbine blades manufactured by the industry. If defects such as out-of-plane wrinkles were detectable during the manufacturing process; the damaged blades could be rejected before leaving the factory thus avoiding expensive in-situ repairs or unexpectedly catastrophic failures in service. It would also allow the designers to refine the laminates used for the blades which translates into cost savings.

The mayor aim of this work is to compare the effectiveness of different non destructive techniques for detecting and characterising out-of-plane wrinkles in the typical glass-carbon hybrid laminates that are used nowadays for wind turbine blades. In order to achieve that goal, several test samples were manufactured using laminates and defects that are representative of those used in the modern wind turbine systems. Three different NDT technique were chosen among the available techniques.

The starting point for this thesis was a contract placed in 2012 among Gamesa, the main Spanish wind turbine manufacturer, and our Department at UPM, for studying the detection and consequences of wrinkles at thick laminates. This research emphasizes the practical interest for this work.

\subsection{Typical damages for wind turbine blades}

As formerly mentioned damages encountered in a wind turbine blade have different sources. Sometimes the source of the damage is random and cannot be predicted. It is the case of lightening damage or bird impacts. Those can be considered accidental damages. Wind turbine blades can also present fatigue damage as they operate under cyclic loads. Fatigue damage is usually presented as cracks. Depending on where the wind farm is located, the turbines will suffer different types of environmental damage. The blades can be severely damaged by moisture, absorption, atmospheric corrosion, rain, or gusts of wind. Off-shore turbine can be facing specially harsh and complex service environments. Finally, the blades can present operational damage. This kind of damage appears when the blades operate under abnormal operations.

Depending on the manufacturer of the blade the cross section may vary slightly. However, the main parts like the laminate shell with the aerodynamic shape and shear web are similar in most blades. A typical cross section of a wind turbine blade is shown in Figure 2 with some of the damages that may be sustained by a wind turbine blade. 


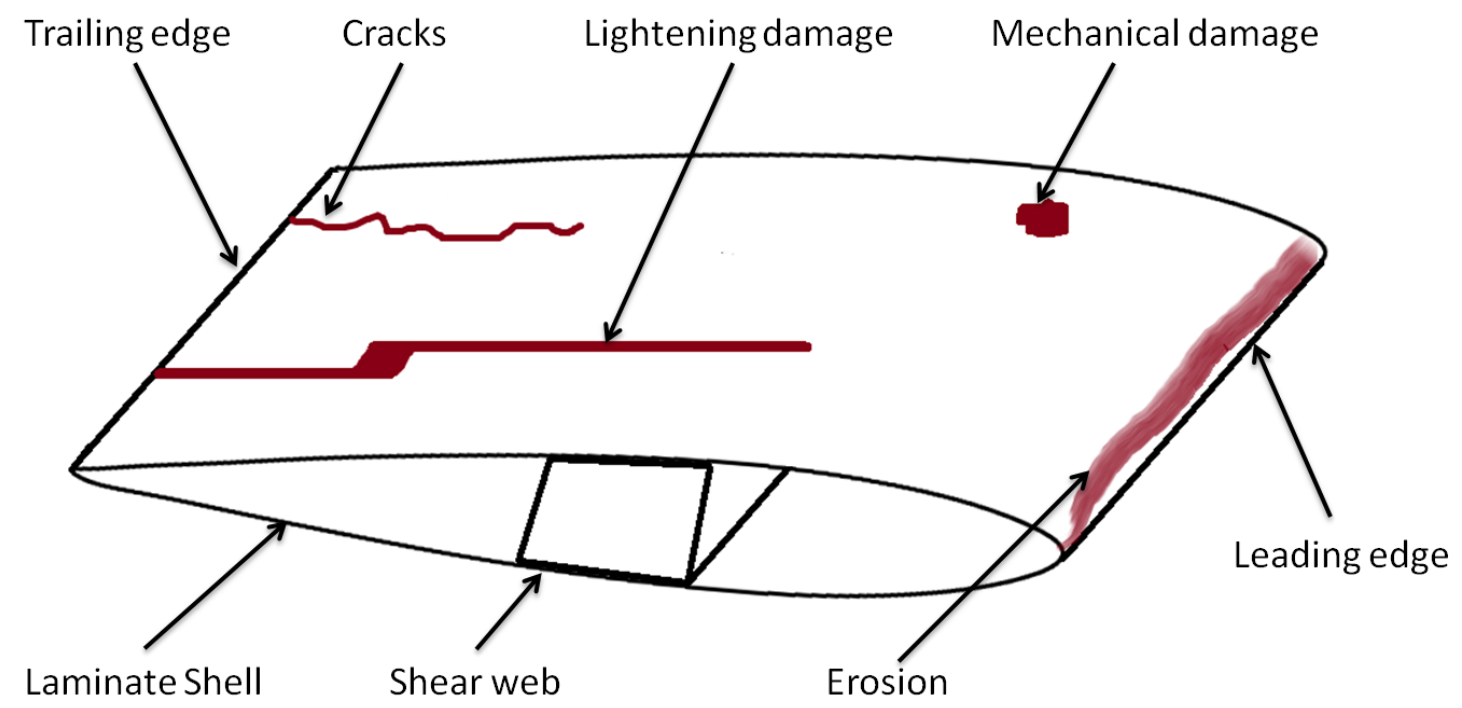

Figure 2: Some of the damages that may appear at a wind turbine blade

Damages can be discriminated from manufacturing defects. Manufacturing flaws can cause problems during normal operation. Typical manufacturing flaws are delaminations, adhesive flaws and resin poor areas. Some of these defects appear at specific locations. Studies have categorised seven types of defects: skin/adhesive debonding, adhesive joint failure, sandwich debonding, delamination, splitting along the fibers, bucking induced skin/ adhesive debonding and cracks in gelcoat (Yang, He, and Zhang 2016). Discarding a blade due to a defect is expensive so blades with severe defect need to be repaired. A typical cross section of a wind turbine blade is shown in Figure 3 with some of the defects that may appear during the manufacturing of a wind turbine blade.

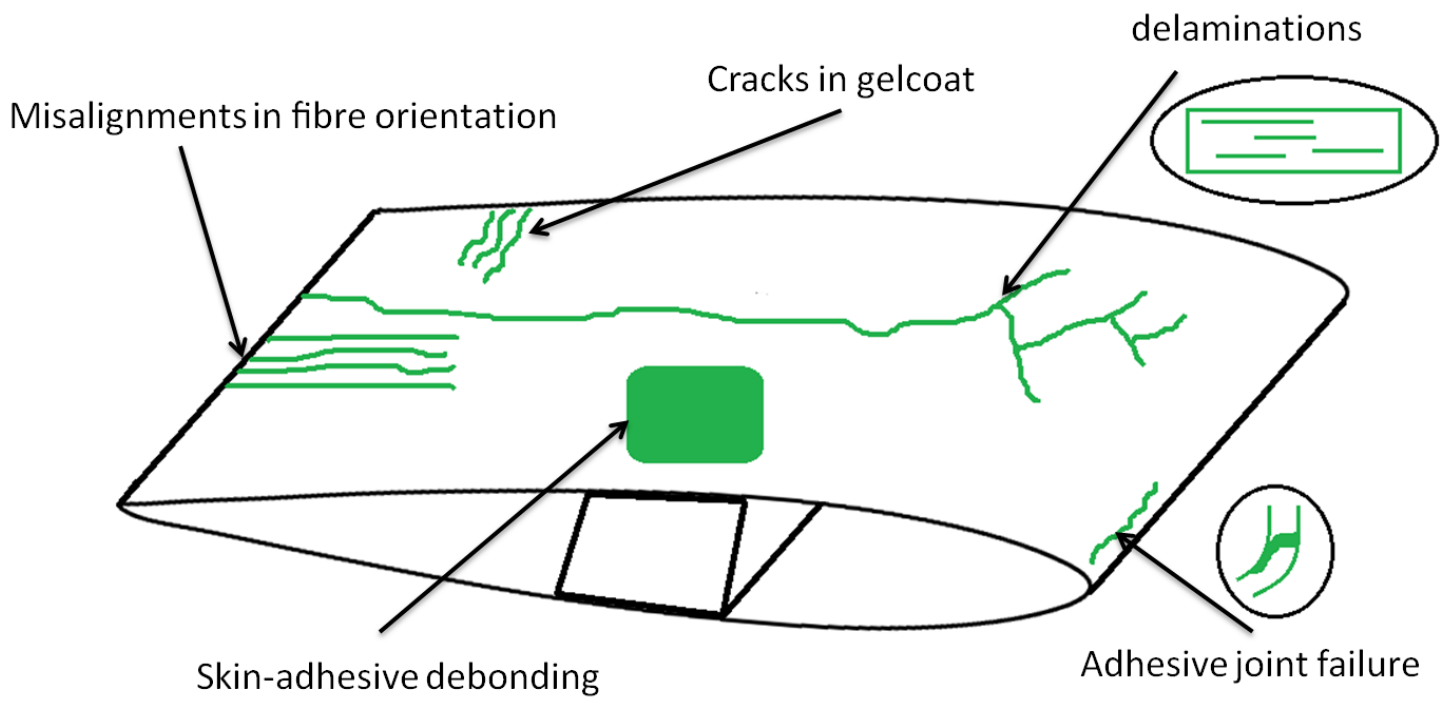

Figure 3: Some of the defects that may appear during the manufacturing of a blade 
Misalignments in fibre orientation (out-of-plane and in-plane waviness) are inherent to the manufacturing process generally considered by the manufacturers for blades. Pre-fabricated reinforcements such as pultruded tapered beams are used in order to reduce production time. This process account for the large thickness and rapid change in thickness in the root while avoiding many ply drops in close proximity to each other. Blades are usually manufactured using the Vacuum Assisted Resin Transfer Moulding process that increases the probability of causing wrinkles when the vacuum is applied in the root due to the significant change in stiffness from the pultruded beam to the dry uncured fibre mats (Bender, Hallett, and Lindgaard 2019).

The formation of wrinkles (out-of-plane waviness) is a complex process that results from local buckling, lamination residual stresses, an incorrect curing procedure, unintended foreign bodies or inserts, etc.(Davidson and Waas 2017).

The wrinkles that appear in the thick laminates used in the shell of the wind turbine blades have a specific geometry. In the literature, several parameters have been used to characterise the misalignment with respect to loading direction: maximum amplitude (H) (K. Potter et al. 2008), severity (Adams and Bell 1995) or maximum angle $\theta$ (Xie et al. 2018). The geometry of wrinkles found in case-study blades and the parameters chosen are shown in Figure 4. L is defined as a wrinkle wavelength so the 'severity' of the wrinkle (A/L) is consistent with the literature (Takeda 2018). Figure 4 should be used as a reference through the different chapters of the thesis.

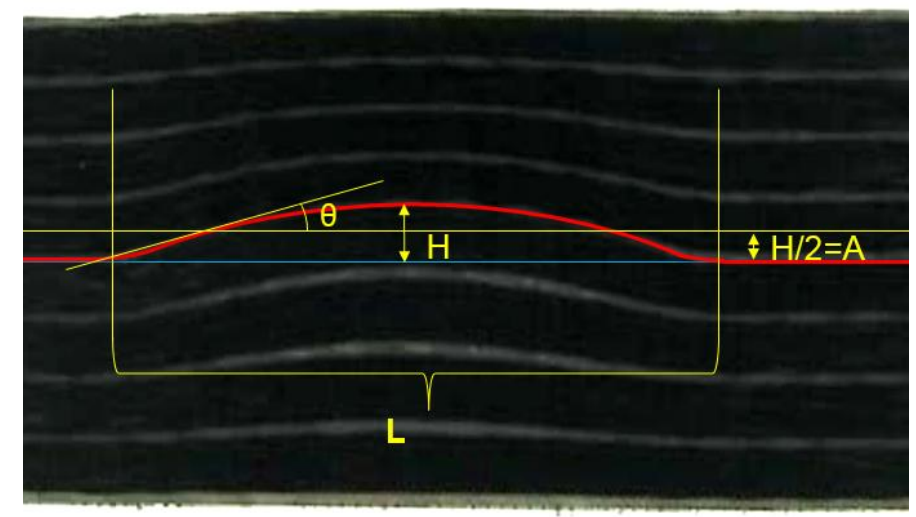

Figure 4: Wrinkle parameters

\subsection{Structure of the thesis}

This thesis is divided into six chapters.

The first part of this thesis is mainly theoretical. A specific chapter is dedicated to describe the current state-of-the-art of the different NDT techniques available for testing and evaluation for wind turbine composite blades. The objective of Chapter 2 is to determine which of the available techniques are the most promising and suitable for detecting internal out-of-plane wrinkles on wind turbine blades. 
Chapter 3 describes the manufacturing of the specimens that are going to be used to carry out the experimental part of the thesis. The lay-ups, defect shapes and sizes were chosen based on lay-ups, defect shapes and sizes observed in the manufacture of real turbine blades. This chapter also includes the results from the mechanical test that were performed to determine the real detriment in mechanical properties that such wrinkles can cause.

Chapter 4 compares the results from three different ultrasonic data-acquisition techniques: full-matrix capture (FMC) with total-focusing method (TFM) reconstruction, phased-array ultrasound and an immersion test with a raster-scanned single-element probe.

Chapter 5 an ultrasonic model is used to simulate the ultrasonic response from the mixed carbon/glass laminates. The objective of this chapter is to determine the ideal inspection frequency at which the experiments were performed.

In Chapter 6 the conclusion and results are presented to evaluate the capabilities of the three NDT techniques to detect and characterise out-of-plane wrinkles in the typical glass-carbon hybrid laminates that are used for wind-turbine blades.

\subsection{Available resources}

This thesis has been mainly carried out at the Centre of Composite Materials and Smart Structures (CCMSS) located at the Polytechnic University of Madrid (UPM) ${ }^{4}$. The systems and equipment that have been used in this thesis and that have been available at the CCMSS department can be summarized as follows:

- $\quad$ CFRP and GFRP prepreg plies to manufacture composite coupons.

- Aluminium plates to manufacture specimens.

- Mechanical Testing machines

○ MTS 810 equipped with a $100 \mathrm{k}-\mathrm{N}$ load cell and a $25 \mathrm{~mm}$ extensometer.

o INSTRON 4202 equipped with a $100 \mathrm{k}-\mathrm{N}$ load cell.

- Two CFRP calibration stairs

- Coupling gel

- OmniScan MX2 with the 16:64 Phased Array Unit

- Two Phased-Array Probes and Wedges:

- 2.25L32-A5 probe with the SA5-OL-25MM wedge

\footnotetext{
${ }^{4}$ https://www.aero.upm.es/departamentos/smart-composites/index.html
} 
○ 5L64-NW1 probe with the SNW1-OL wedge

- The MiniWheel ${ }^{\mathrm{TM}}$ encoder

- Signal processing developed in software environments:

○ The Mathworks, MATLAB.

- The Olympus NDT Data Access Library

Part of this thesis has been carried out at the University of Bristol (UK) with the Ultrasonics and Non-Destructive Testing group ${ }^{5}$. The systems and equipment that have been used in this thesis and that have been available at the University of Bristol can be summarized as follows:

- Ultrasonic full-waveform capture composites scanning tank

- Two single element immersion ultrasonic probes

○ $2.25 \mathrm{MHz}$ frequency probe

○ $5 \mathrm{Mhz}$ frequency probe

- Diagnostic Sonar 'FIToolbox' array controller

- Coupling gel

- Two array probes

○ $2.25 \mathrm{MHz}$ frequency probe

○ $5 \mathrm{Mhz}$ frequency probe

- Signal processing developed in software environments:

○ post-processing Matlab-based software "brain" (BRistol Array INspection)

- Open source software developed for modelling the geometry of textile structures

○ TexGen

- Analytical finite element model software

○ PZFlex

\footnotetext{
${ }^{5}$ http://www.bristol.ac.uk/engineering/research/ndt/
} 


\section{CHAPTER 2 REVIEW OF NON-DESTRUCTIVE EVALUATION (NDE) METHODS FOR COMPOSITE BLADE INSPECTION.}

This chapter reviews the different NDE methods that are used for composite blade inspection nowadays. The ability of each technique to detect internal out-of-plane wrinkles in the typical glass-carbon hybrid laminates that are used nowadays for wind turbine blades is analyzed. Finally, the three most promising techniques will be chosen to compare their effectiveness for detecting and characterising wrinkles.

\subsection{Visual inspection}

Visual inspection is the most obvious technique to detect surface damage in any type of parts. Nowadays, traditional human visual inspection and fully automatic techniques can both be used during the manufacturing process and during routine maintenance inspection (See et al. 2017). Most human visual inspection tasks are complex and the accuracy of the measurements relies on the inspector 'tacit knowledge' as well as in his explicit knowledge (Johnson et al. 2019) so typical error ranges between $20 \%$ and 30\% (Drury, C. G., \& Fox 1975). For wind turbine blades, visual inspections during routine maintenance are a challenge as typical tower height is around 50-150m (Yang, He, and Zhang 2016). During manufacturing visual inspection is used to detect surface damage as visible cracks whereas inner damage such as fibre waviness cannot be identify (only protruding wrinkles, see Figure 5, could be identify with a visual inspection). Inspection techniques that allow the detection of internal defects are still required after a visual inspection.

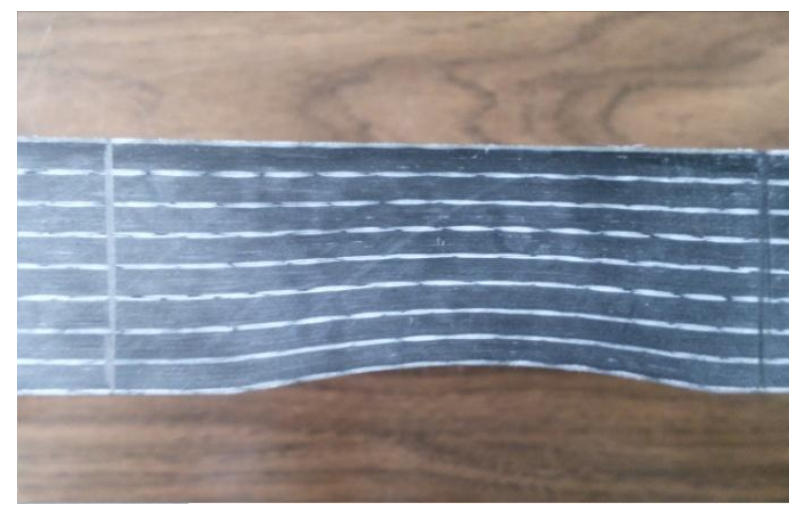

Figure 5: Protruding wrinkle 


\subsection{Sonic and Ultrasonic Techniques}

Sonic and ultrasonic are the techniques the most frequently used in industries. Sonic and ultrasonic techniques involves different techniques, such as tap test, local resonance spectroscopy, ultrasound-echo, phased-array ultrasound, air coupled ultrasound, laser ultrasound, acoustic emission and guided waves.

\subsubsection{Tap-test and local resonance spectroscopy}

During routine maintenance, the difficulties in accessing the blades traditionally limits the non-destructive techniques that operators can use to visual inspection and tapping tests (Jüngert and Grosse 2009). A traditional tap-test consist on knocking on the structure (with, for example, a special hammer) and listening to the sound emitted by the structure. The sound will change when delamination, a disbond or porosity are present near the surface of thin laminates or sandwich structures. These methods are not effective on thicker parts, so they are mainly use to detect a disbond between the skin laminate and the main spar of a turbine blade. (Drewry and Georgiou 2007).

Local resonance spectroscopy is an advanced tap test technique in which an impulse hammer is used to knock on the structure and a microphone is used to record the echo. Local resonance spectroscopy is gradually replacing the manual tapping test perform by experts during regular inspections. A print of the damaged area can be produced to get a picture of the internal delaminations, disbond or porosity of the blade. Additionally, extra information about the internal structure is provided from the exciting force of the hammer (Jüngert 2008). The analysis on the recorded echo can be used to detect defects in the blades. Some studies have shown that the depth of the delamination can be estimated based on the recorded echo (Peng et al. 2014). It is important to bear in mind that neither tap test nor local resonance spectroscopy are absolute techniques. The internal condition of the blade is stated by comparison of adjacent points and the knowledge of the internal construction of the sample. Other internal defects, such as wrinkles, cannot be detected with a tap-test or a local resonance spectroscopy.

\subsubsection{Ultrasound-echo}

Single element ultrasonic planar or focused probes (Figure 6) are widely used to inspect composite parts after manufacture. In an ultrasonic non destructive test, a probe is used to generate a beam of high frequency sound waves that is transmitted into the part. The mechanical waves travel through the material and are reflected and refracted at interfaces. Some loss of energy occurs in the process. 


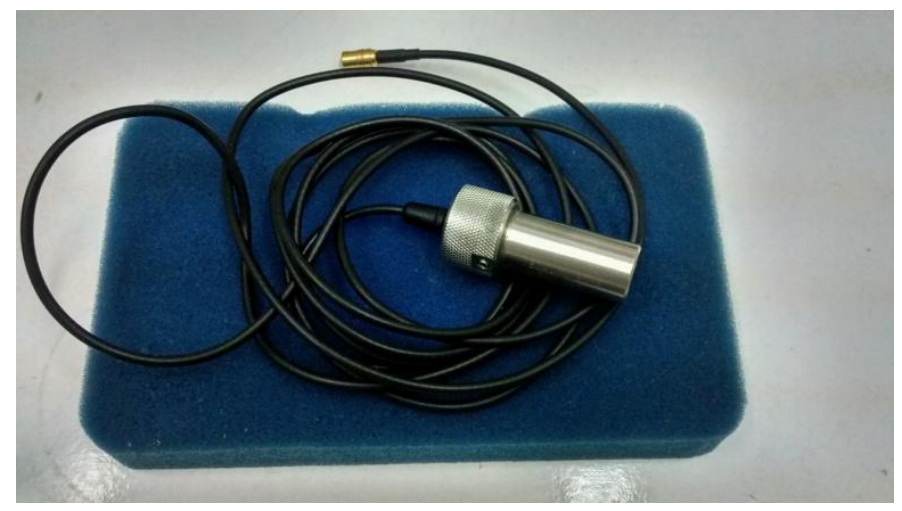

Figure 6: Single element ultrasonic probe.

Either the reflected or the refracted beam is displayed and analyzed to assess the presence and location of discontinuities inside the samples. Depending on the size and shape of the samples under inspection, through-transmission or pulse-echo techniques are applied at the industrial quality control process (Figure 7). If the two sides of the part are accessible, the through-transmission test is generally carried out, as it is necessary to locate a transducer at each side of the material. In this case the refracted wave is displayed and analysed. If only one side of the part is accessible, the pulse-echo technique is necessary because it allows both transducers (or a single transmitterreceiver transducer) to be placed on that side of the material. In this case the reflected wave is displayed and analysed.(Wróbel and Pawlak 2007).

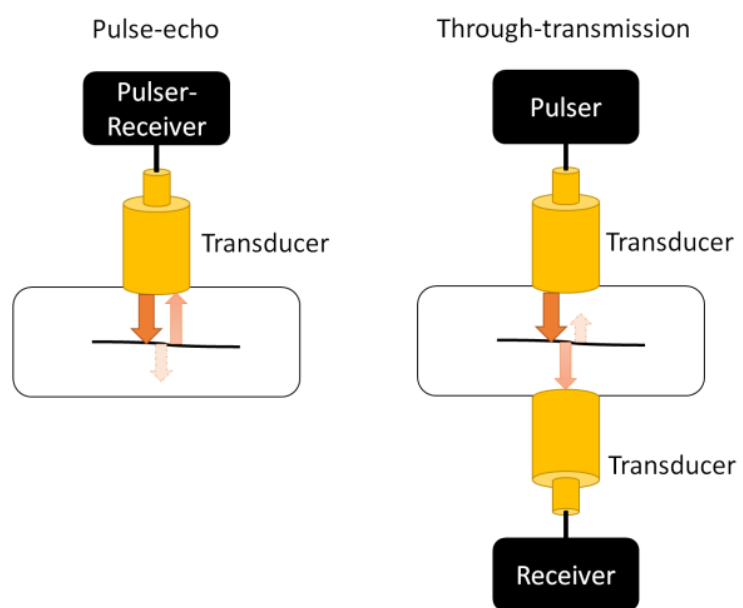

Figure 7: Scheme of the pulse-echo (left) and through-transmission (right) ultrasonic techniques.

Conventional ultrasonic systems for inspecting composite materials collect and display one dimensional ultrasound signal. Ever since the first ultrasonic signal was obtained, the interpretation of that signal is not an straightforward process. To facilitate the interpretation of inspections, standard 1D and 2D view of recorded ultrasound data are defined. An A-Scan is the representation of the received ultrasonic pulse amplitude versus time of flight. A B-Scan is, essentially, a series of stacked A-Scans where the horizontal axis is the scan position and the vertical axis is the ultrasound signal. A CScan is a top or plan view of the test specimen. The value of the amplitude at a chosen depth is displayed. The classic ultrasonic views are presented in Figure 8. 


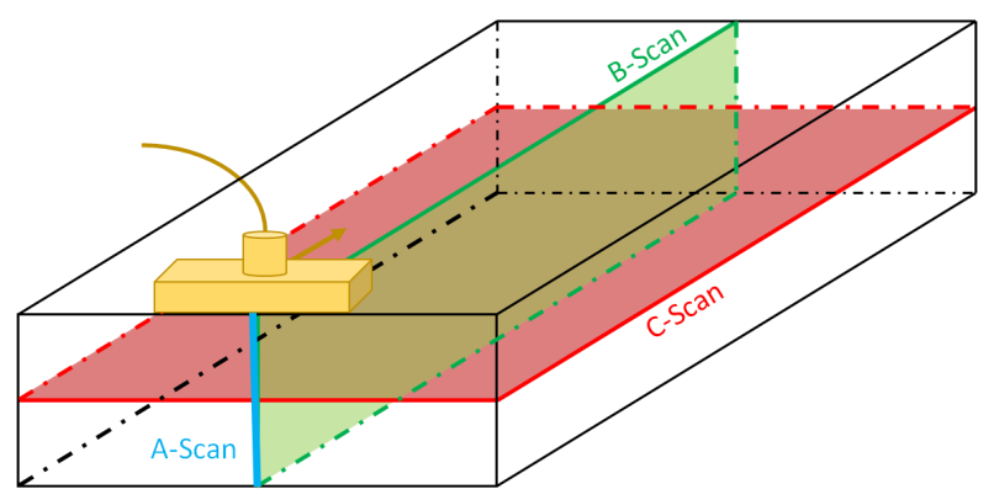

Figure 8: Classic ultrasonic views: A-Scan, B-Scan and C-Scan

The ultrasound-echo technique provides an easy detection of delamination in composite samples because those kinds of defects provoke a high reflection of normalincidence ultrasonic signals. Likewise, interlaminar voids or porosity can be easily detected because they provoke a higher attenuation (Fahr and Kandeil 1992).

The general intention of the systematic inspections in the production line is to measure the thickness of the parts and detect defects such as delaminations, disbands, porosity, voids or inclusions (Marsh 2002). In an ultrasound-echo inspection, the depth of the interfaces can be calculated based on the time of flight of the pulse (the delay between the pulse transmission and the received echo) and the speed of sound in the material of the sample.

Wind turbine blades have a curved surface. Even if the surface curvature shape is known in advance, the implementation of this technique requires a precise set-up that can be complicated because the ultrasonic transducer should be positioned strictly perpendicular to the scanned surface. The ultrasonic contact pulse-echo immersion testing technique with an ultrasonic transducer (focused or planar) mounted into a moving water container allows the recognition of artificial internal (drilled) defects from a wind turbine blade. The moving water container ensure the perpendicularity between the ultrasonic transducer and the surface. The ultrasonic images obtained with this technique also display natural defects, such as delaminations; and allow the measurement of the artificial defects (Jasiuniene et al. 2008).

Ultrasound-echo technique has also the potential to be used for wind turbine blades maintenance. In order to carry out in-situ wind turbine blade inspections, fully automated ultrasonic NDT system controlled by a computer are being developed. Ye, Neal, Boot, Kappatos, Selcuk and Gan (Ye et al. 2014) have presented a light prototype consisting of an ultrasonic pulser-receiver and an automated positioning device that can be carried by an inspector climbing onto the wind turbine blade and should be affixed on the wind turbine. The system was tested on experimental wind turbine blades made of GFRP samples and the results showed that internal defects could be identified on the C-Scan image. 
Unfortunately, internal out-of-plane wrinkles are not easily detected in an ultrasonic inspection because to detect them it is necessary to track the depth of the resin layers between plies and to do so it is crucial to understand the interaction of ultrasound with the composite stack. Current research shows how the resin-rich interfaces between plies can be tracked using the analytical signal (R A Smith et al. 2015).

The analytical signal is a complex function that describes the propagation in time and space of the ultrasonic wave. It can be calculate from equation (1):

$$
x_{a}(t)=A(t) e^{i \phi(t)}
$$

where $A(t)$ is the instantaneous amplitude (magnitude, or envelope, of the signal) and $\phi(t)$ is the instantaneous phase at time $t$. The measured real component is $\operatorname{Re}\left(\mathrm{x}_{\mathrm{a}}\right)$ and the imaginary part can be calculated by applying a Hilbert transform to $\operatorname{Re}\left(\mathrm{x}_{\mathrm{a}}\right)$. (Subhash 1970). The rate of change of phase at time $t$ in the response at the measurement location is known as the instantaneous frequency, $f(t)$, and is given by equation (2) (B. Boashash 1992):

$$
f(t)=\frac{1}{2 \pi} \frac{d \phi}{d t}
$$

The simulated analytic-Signal pulse-echo response from four composite plies separated by five thin parallel layers of resin all embedded in an infinite composite medium is shown as an example in Figure 9.
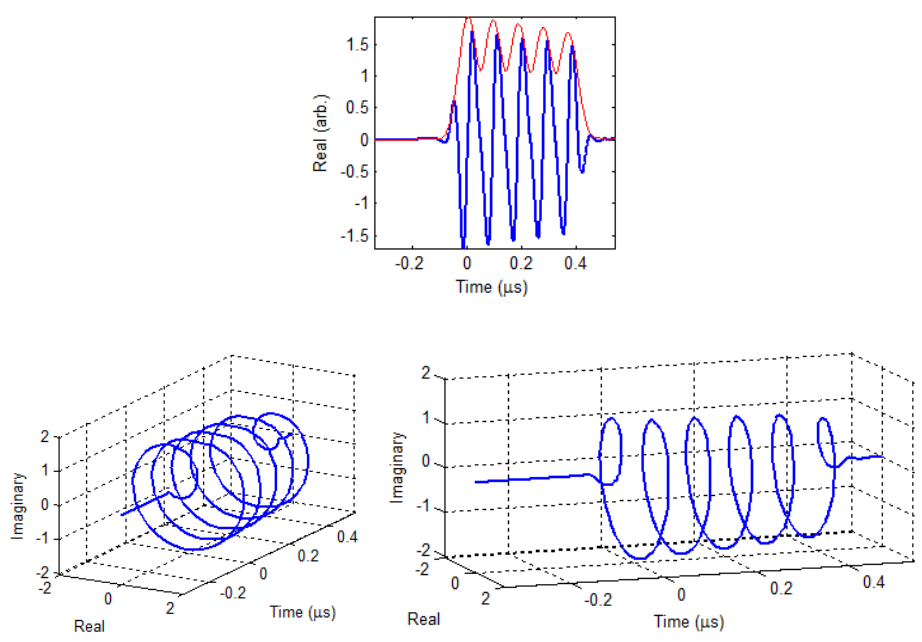

Figure 9: Three views of a simulated Analytic-Signal pulse-echo response from four composite plies separated by five thin parallel layers of resin, all embedded in an infinite composite medium. The real signal and Hilbert envelope (up) are often the only projections viewed but the Analytic Signal is three-dimensional as shown above (down) from two different viewpoints ( $R$ A Smith et al. 2015).

Ultrasonic-echo techniques providing an acceptable detail level for 3D characterisation of fibre orientation can be used on large components and allow the inspection of both glass and carbon fibre. 
Smith, Nelson, Mienczakowski and Wilcox (Robert A. Smith et al. 2018a) use the instantaneous amplitude, phase and frequency of the ultrasonic response in 3D scans to allow 3-D characterization of the microstructure of a composite laminate. They have characterised the effect that different features present in composite sample (such as front and back surface echoes; delamination, resin-filled ply drops and out-of-plane wrinkling) have on the instantaneous amplitude, phase, and frequency. When analyzing the inspections carried out on parts with wrinkles, it is especially important to take into account that the instantaneous amplitude present small peaks at resin layers and large peak at the front and back surface. However it is possible to enhance the reflections from the thin inter-ply resin layers by using a probe with a centre frequency close to the resonant frequency of the plies. Also, the instantaneous phase increases by $2 \pi$ radians for each resin-rich layer traversed when the material is excited by the fundamental ply resonance. To see whether or not a sample has out-of-plane wrinkles special consideration must be given to the instantaneous phase of the analytical signal. Best results are obtained at locations closer to the front surface. (Nelson, Smith, and Mienczakowski 2018).

\subsubsection{Commercial phased-array ultrasound technology}

The growth of microelectronic and computer components in recent decades lead to the development of phased array ultrasonic system. Phased-array ultrasonic technology (PAUT) has been commercially available for nearly twenty years.

Phased-array transducers most commonly have from 16 to 128 piezoelectric elements, much smaller than conventional transducers; that are incorporated into a single transducer assembly. Arrays can be arranged with different patterns: linear, square, annular or circular. The multiple elements in the array can be pulsed as a group or separately in a programmed pattern.

In the PAUT equipments that are available commercially, the elements in the phased-array transducer are pulsed as a group and in such a way as to cause the beam generate by each element to interact with each other according to the principle of constructive and destructive interaction of waves. Only a number of adjacent elements are pulsed simultaneously. By varying the timing of the waves generated by each element, it is possible to create a single combined wave front which can be steered and focused. The delay value of each element depends on the focal distance and angle among others parameters. The focal delay laws (focal laws) are programmed to generate longitudinal waves. This means that important ultrasonic parameters such as focal distance are controlled through software. It also means that it is possible to generate several ultrasonic beam profiles from a single phased-array probe. (See Figure 10). Only one focal depth can be used for each inspection, although it would be possible to repeat the scan with a different focal depth. 


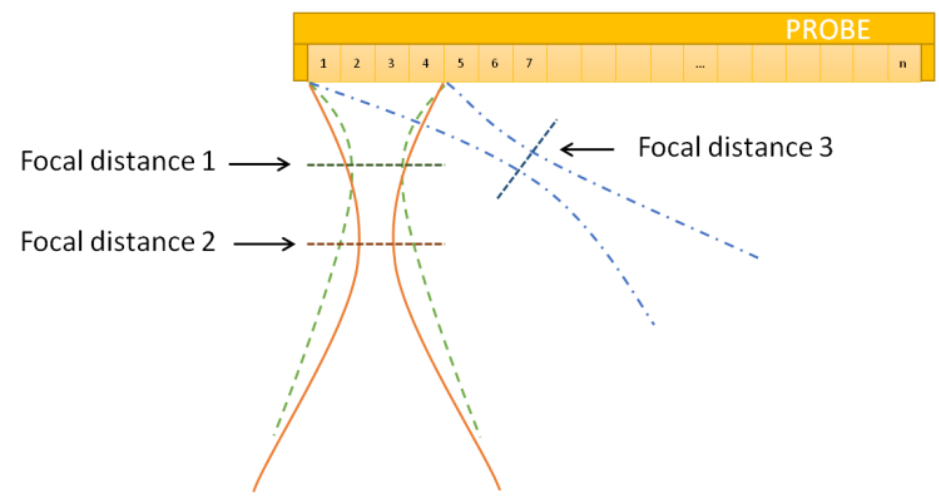

Figure 10: Three different ultrasonic beams generated by different focal laws in a phased-array probe. The beam can be steered and focused at different points electronically.

Similarly, the input for several elements is electronically combined into a single ultrasonic pulse: a 2D representation of the azimuth plane beneath the sample. This allows to visualize the results using angular beam scan images. The $2 \mathrm{D}$ images obtained for conventional linear arrays have usually low resolution in the direction perpendicular to the array elements. Methods to improve the elevation resolution in PAUT inspections are currently being developed. (Brizuela et al. 2019).

The active elements are then electronically shifted along the length of the array (Figure 11), with the time domain signals obtained from each step being combined to form the final B-scan image. The width of the group of active elements is named aperture.

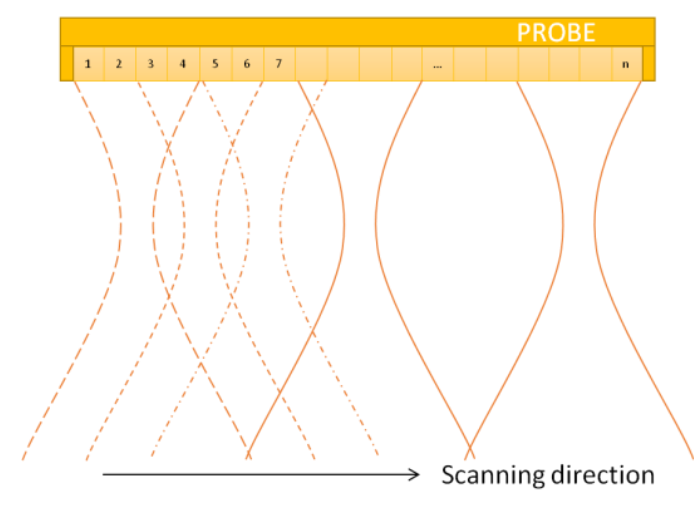

Figure 11: Scanning is performed along the phased-array probe length

This technique relies on the same laws of physics than single-element probe scanning but offers speed and imaging improvements. One advantage of this technique is the reduction of the number of transducers to be used to fully inspect a piece of complex geometry and large dimensions such as a wind turbine blade. This would reduce the inspection time during the manufacturing process.

Phased array probes are larger than conventional probes and it may be necessary to mount them on a holder to account for the curved shape and structure of wind turbine blades. 
Commercial PAUT can be used to detect inner damage in structures such as wind turbines blades. It has proven the ability to recognize and evaluate artificial inclusions inside composite laminates. As in single-element probe scanning, the high reflections of the ultrasonic waves allows to determine the position, size and shape of the inclusions.(Caminero et al. 2019). This technique is also effective in the estimation of the thickness and can be used to detect several delaminations at different depths through the thickness of the sample. Meola, Boccardi, Carlomagno, Boffa, Monaco \& Ricci (Meola et al. 2015) used commercial phased-array technology to detect impact damage in carbon fibre reinforced composites. Low velocity / energy impact can cause important damage inside the part without any perception on the impacted side. From the $\mathrm{C}-\mathrm{Scan}$ view it is possible to detect an average diameter of the impact damage. From the B-Scan view, it is possible to detect the surface indentation and the different delamination that appear near the bottom after an impact in the sample. Figure 12 was obtained in the CCMSS laboratory and illustrates commercial phased-array images of a 5mm thick CFRP sample after an impact at energy 38.86J.
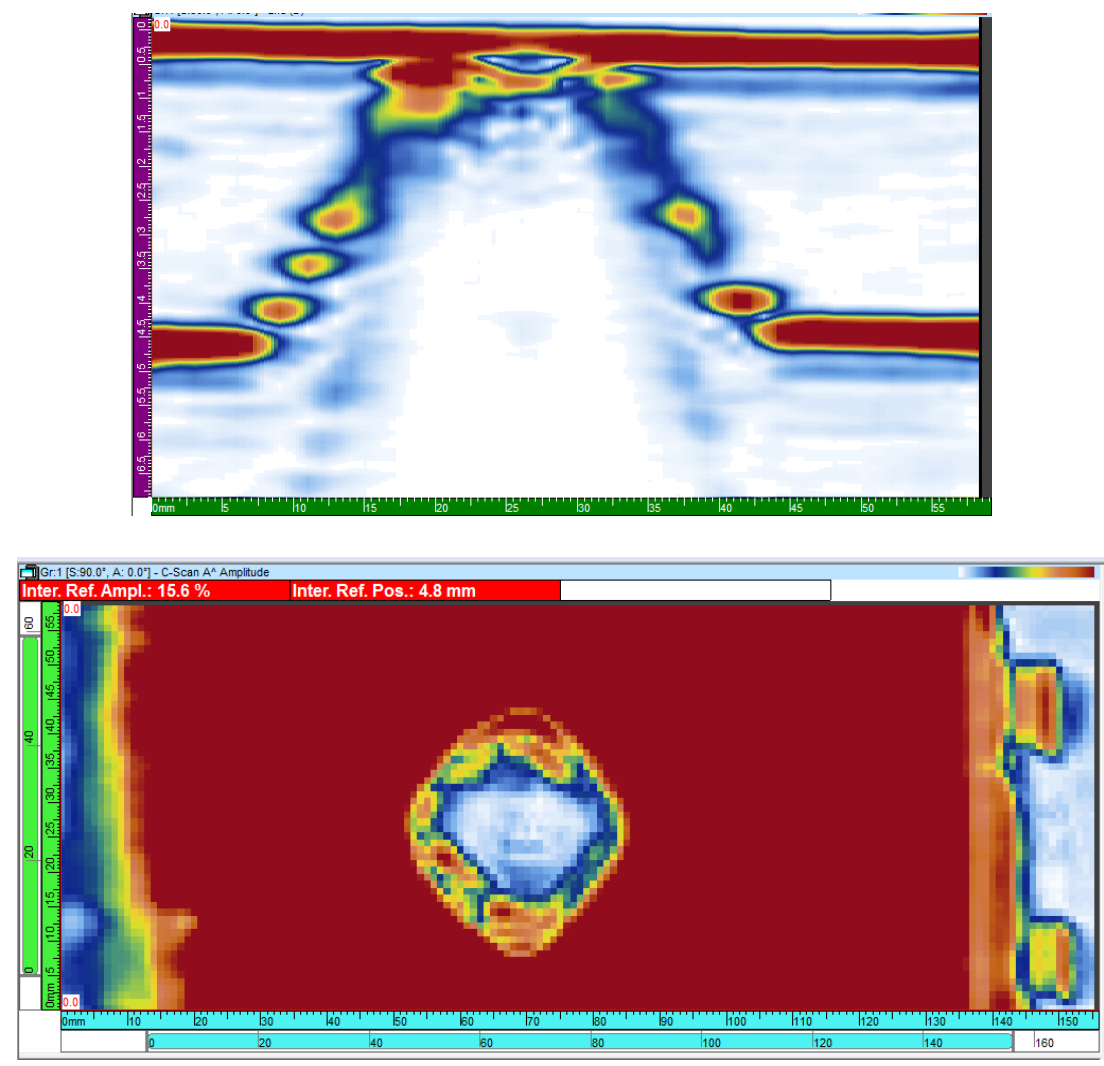

Figure 12: B-Scan (above) and C-Scan (below) of a commercial phased-array ultrasonic inspection of a $5 \mathrm{~mm}$ thick CFRP specimen after an impact at energy 38.86J. The inspection was performed in the CCMSS laboratory at the UPM.

Boychuk, Generalov and Stepanov (Boychuk, Generalov, and Stepanov 2014) also used commercial phased-array technology to detect impact damage and delamination in carbon fibre reinforced composites. They characterize the defect size which can be detected in $90 \%$ cases with $95 \%$ confidence probability for a CFRP laminate of $10 \mathrm{~mm}$ depth. 
Amenabar, Mendikute, Lopez-Arraiza, Lizaranzu and Aurrekoetxea (Amenabar et al. 2011) used commercial phased-array technology to inspect a $10 \mathrm{~mm}$ thick GFRP sample. The thickness was chosen taking into account the thickness of wind turbine blades with typical thicknesses of several millimetres. Two different centre frequencies were used: $5 \mathrm{MHz}$ and $10 \mathrm{MHz}$. The acoustic wave at $10 \mathrm{MHz}$ suffered a high attenuation and no reflection was detected. However the reflected acoustic wave at 5 $\mathrm{MHz}$ was clearly detected. To inspect parts with large thickness, such as a wind turbine blade, it may be necessary to use low acoustic waves frequencies in order to achieve high penetration capability.

Because this approach has the same performance as a plane transducer, commercial ultrasonic phased arrays equipments are now routinely used in the industry for ultrasonic inspection after manufacturing instead of traditional transducer. Existing inspection procedures are directly replicated.

Even though 2-axis encoded scanner, that can be placed along the length wind blade, are available; the characteristics of the equipment currently available do not allow this technique to be considered as a viable alternative for in-situ inspection of wind turbine blades.

Some preliminary experiments were carried out using PAUT to detect wrinkles in composites (Fernández-López, Larrañaga-Valsero, and Guemes 2014). Also, as in single-element probe scanning, the instantaneous amplitude, phase and frequency of the ultrasonic response could be used to detect wrinkles inside a laminate.

\subsubsection{Full-matrix capture (FMC) with total-focusing method (TFM)}

Even though the approach from the previous section uses phased-array transducers, it has the same performance as a plane transducer and the returning signal that arrives at the inactive elements is not analysed.

Alternatively, phased array probes can be used in a way that each element transmits and receives signals individually. The responses for each transmitter-receiver element pair of the array can be acquired sequentially. A single element is fired and the signal that arrives at all the others elements is recorded. The transmit-receive time domain signals from all element combinations is captured and then collated to form the so-called full matrix (Figure 13). This approach is called full matrix capture (FMC) (Holmes, Drinkwater, and Wilcox 2005). 


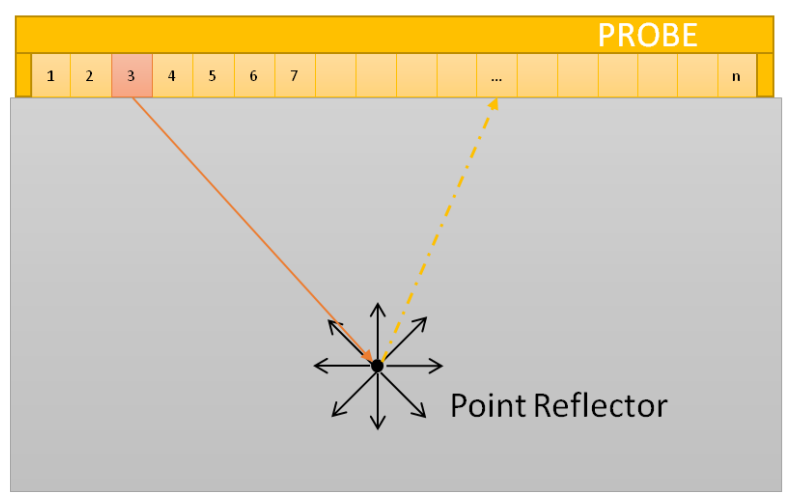

Transmitting element

Receiving elements

Figure 13: Full matrix capture approach.

The full matrix capture process cannot necessarily be performed with the available commercial phased-array ultrasound technology because the electronic algorithms and analysis are different.

Once the full matrix has been captured, post processing algorithms can be implemented. The total focusing method (TFM) is a post processing algorithm for use with the full matrix of array data. The first step of the TFM post-processing algorithm is the discretization of the region under inspection into a grid. Each point in the grid would correspond to a pixel in the final image. Then, the delayed time domain data of all transmit-receiver pairs is summed (coherent summation) to synthesise a focus at every point in the grid. As a result, in the TFM the beam is focused at every image pixel in the target region. It is worth noting that, with this approach, an actual beam is never physically achieved in the sample under inspection. The effects of the given beam are synthesised from the full data set (J. Zhang et al. 2010).

The FMC with reconstruction of B-scan slices using the TFM is the current state of the art in imaging. However, these techniques are not yet being applied for the inspection of wind turbine blades in the industry. It is quite time consuming due to the high number of transmit sequences and the computational power required to perform the post-processing algorithm. Zhang, Drinkwater \& Wilcox (J. Zhang, Drinkwater, and Wilcox 2011) analysed the effects of array transducer inconsistencies on the TFM and concluded that the algorithm was reasonably robust.

When reconstructing the B-scan slices using the TFM algorithm, for any image point (x, y), its image intensity $\mathrm{I}(\mathrm{x}, \mathrm{y})$ is given by equation (3) (Lin, Cao, and Luo 2018). $A_{i j}$ is the full matrix obtained with FMC that contains the signal of transmitter element $i$ and receiver element $j$; $h$ denotes the Hilbert transform and $M$ is the number of elements in the array probe. $\mathrm{t}_{\mathrm{i}}(\mathrm{x}, \mathrm{y})$ and $\mathrm{t}_{\mathrm{j}}(\mathrm{x}, \mathrm{y})$ are the ultrasonic wave travel time from element $\mathrm{i}$ and $\mathrm{j}$ to image point $(\mathrm{x}, \mathrm{y})$, respectively.

$$
I(x, y)=\left|\sum_{i=1}^{M} \sum_{j=1}^{M} h\left(A_{i j}\left(t_{i}(x, y)+t_{j}(x, y)\right)\right)\right|
$$


The usual benefits of averaging (the TFM algorithm combines multiple waveform) entail an additional benefit in terms of signal-to-noise. The incoherent (temporal) noise is reduced inversely proportional to the square-root of the number of waveforms combined

For isotropic materials, $\mathrm{t}_{\mathrm{i}}(\mathrm{x}, \mathrm{y})$ and $\mathrm{t}_{\mathrm{j}}(\mathrm{x}, \mathrm{y})$ can be calculated by dividing the straight-line propagation distance by the constant velocity of material (isotropic TFM). But for layered anisotropic CFRP; the ultrasonic path and travel time are complex.

If the distribution of anisotropy is known, 'Path-finding' algorithms can be used to predict the ultrasonic path through the material thus allowing to correctly image composite components. Nowers, Duxbury, Zhang, Drinkwater (Nowers et al. 2014) investigate different ray-tracing algorithms using a simulated inspection scenario. They conclude that the Dijkstra's algorithm (Dijkstra 1959) and the $A^{*}$ algorithm (Hart, Nilsson, and Raphael 1968) maintain similar accuracy but the $A^{*}$ algorithm exhibit reductions in computation time. Lin, Cao, Luo, (Lin, Cao, and Luo 2019) used a modified TFM method based on the Dijkstra's path-finding algorithm to inspect a $5.79 \mathrm{~mm}$ thick CFRP laminate. Compared with commercial PAUT acquisitions and isotropic TFM; the modified TFM images show an increment in peak image amplitudes and an improvement in the quality of the image. Both the isotropic TFM and the modified TFM were able to clearly image three different side-drilled holes whereas the commercial PAUT only showed an unique weak echo.

Thus the directionally-dependent velocity of CFRP laminates can be accounted for by a modified TFM algorithm. However, the ray tracing methods have the potential to be applied only when an accurate velocity model of the structure is available.

Because the TFM is a post- acquisition process, different TFM could be applied for the same FMC inspection and different algorithms could be used and combine to optimise the detection of different defects or different parts of the samples. Potter, Wilcox \& Croxford (J. N. Potter, Wilcox, and Croxford 2018) propose a modified TFM that optimises near surface imaging. Near surface acoustic information is generally obscured by acquisition artefacts and nonlinear effects. The process was demonstrated experimentally on an CRFP block containing near-surface holes.

The FMC with TFM technique has the potential to be used in thick laminates like those used in wind turbine blades. Li, Pain, Wilcox, Drinkwater (C. Li et al. 2013) used a modified TFM algorithm to inspect a CFRP laminate with a thick-section. The composite sample used was $19 \mathrm{~mm}$ thick carbon fibre composite block, with a total of 82 plies. By accounting for velocity anisotropy and implementing a frequency filter; a side-drilled hole at $16 \mathrm{~mm}$ depth becomes clearly visible. During the inspection using a basic TFM with a constant velocity on the same sample, the positions of the inner holes could not be detected.

Similar experiments have been carried out using these techniques to detect wrinkles in composites with good results. (Larrañaga-Valsero et al. 2016). 


\subsubsection{Guided Waves}

In traditional ultrasound inspection only longitudinal waves are analysed. However when an ultrasonic wave interacts with a structural discontinuity, mode conversion and scattering in all direction may also occur. This happens if the ultrasonic transducer is not positioned strictly perpendicular to the scanned surface. In guided waves testing, shear, Rayleigh and Lamb waves are analysed to obtain information about the damage in the inspected structure. This technique can be an attractive alternative to remotely inspect areas of the sample where it is not possible to position a probe perpendicular to the surface.

A main difference between traditional ultrasonic inspection and guided waves is that in traditional ultrasound inspection, the probe is normally moved along the surface of the sample and the waves propagate perpendicular to the surface whereas in a guided wave inspection, the probe stand still and the direction of propagation is parallel to the surface of the sample.

The shear horizontal wave, from the mode conversion of the fundamental symmetric Lamb wave has been used for quantitative identification of delamination in composite beams with promising results. A set of characteristics able to define several delamination cases was defined and used to calibrate an artificial neural algorithm. (Su et al. 2007). However, in comparison with other non destructive evaluation techniques, Lamb wave-based quantitative damage identification are still in a very early stage ( $\mathrm{Su}$, Ye, and Lu 2006).

Recent studies focus on analyzing and understanding the effect of both anisotropy and geometry on guided waves propagation. Ultrasonic guided wave testing of composites is challenging due to the anisotropy of the material that complicate wave propagation. (Yu et al. 2016). Li, Slesarenko, Galich \& Rudykh (J. Li et al. 2018) analysed the propagation of shear waves through layered composites and through finitely deformed layered composites.

Lamb waves have attracted the most attention among the guided waves techniques. However Lamb waves only travel in thin plates, which means that these techniques could not be applied to the thick laminates that are generally used in wind turbine blades.

Ultrasonic non destructive testing of wind turbine blades using guided waves is generally carried out using air coupled ultrasound because no contact is needed and it has the potential to be used to inspect blades in service. This technique is the subject of the following section. 


\subsubsection{Air coupled ultrasound}

Traditionally, ultrasound inspection uses a coupling medium such as water or a coupling gel, because of impedance mismatch. Even a thin layer of air between the probe and the part under inspection cause a significant attenuation of the ultrasound signal. Nowadays, low impedance focused narrow band transducers and sensitive electronics allow the possibility of air-coupled ultrasound (Stoessel et al. 2002). Figure 14 shows an air coupled ultrasound laboratory experiment. The sample is placed between two ultrasonic probes. One of the probes emits an ultrasonic signal that travels through the air, the part, the air again and is finally detected by the other probe.

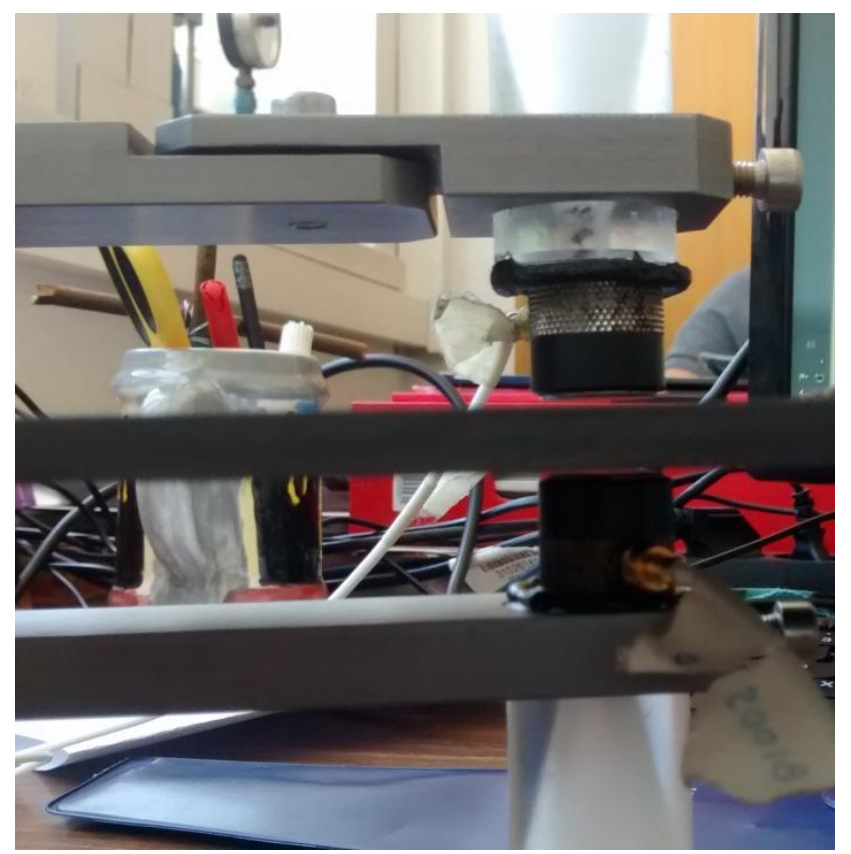

Figure 14: Air coupled ultrasound experiment performed at the CCMSS laboratory.

If the air couple ultrasound inspection configuration forces ultrasonic waves to incise normally to the surface, only longitudinal waves are transmitted to the sample. This non-contact technique has the same principles of "ultrasound-echo" wave propagation but eliminate the need to wet or dirty the specimens under inspection. However, with this configuration, the energy transmission coefficient is extremely small due to the severe impedance mismatch.

In order to increase acoustic transmission, the ultrasonic wave can incise obliquely, but this cause that plate mode waves are generate inside the sample (Solodov et al. 2006).

Raišutis, Jasiūnienè, Žukauskas (Raišutis, Jasiūnienė, and Žukauskas 2008) used ultrasonic guided waves with the air-coupled technique to inspect a GFRP wind turbine blade. A pair of $290 \mathrm{kHz}$ air-coupled transducers were used to generate a Lamb wave inside the sample. The C-scan image of the wind turbine sample allows the detection and approximate characterisation of two artificial circular defects. 
Chakrapani, Dayal, Barnard, Eldal \& Krafka (Chakrapani et al. 2012) used air coupled ultrasonic to detect internal out of plane waviness in trailing edge sections of wind turbine blades. The transducer was inclined at an angle beyond the second critical angle so Rayleigh wave were generated on the surface of the samples. Sensitivity to detection of waviness was high but the effect of depth on Rayleigh wave propagation need to be studied in detail.

Panda, Rajagopal \& Balasubramaniam (Panda, Rajagopal, and Balasubramaniam 2018) used air-coupled ultrasonic guided waves to inspect a full-scale complex composite structural component. The received guided wave signal was difficult to be interpreted due to the presence of stringers and stiffeners, but some defects could be located and identified. Although, air coupled ultrasonic equipment is commercially available; it has yet to be used for in-situ inspection of wind turbine blades.

\subsubsection{Laser ultrasound}

The so-called Laser Ultrasound is a non-contact ultrasound wave excitation technique that uses lasers instead of piezoelectric to generate extremely short ultrasound transient inside the samples. Lasers are able to produce shear, longitudinal and surface waves in both electrically conducting and non-conducting materials. Ultrasonic waves can be generated by pulsed laser beams in three different manners: radiation pressure, ablation and thermo-elasticity (Green Jr 2004). Although the ablation process slightly causes damage on the surface of the specimens, the damage is relatively small, so this technique can still be considered as non-destructive. It should be noted that composite structures are more vulnerable to ablation that metallic structures because of the lower thermal conductivity (Pierce et al. 1997). Laser ultrasound generation techniques are available since 1960s.

Laser ultrasound is a non contact technique that can be used from a long distance which means that this technique has the potential to be used for in situ inspection of wind turbine blades. Lee, Shin, Chia, Dhital, Yoon \& Huh (Lee et al. 2011) proposed a portable long distance ultrasonic propagation imaging system that uses a laser beam targeting and scanning system to excite sensors installed in the blade. If this method was to be used to inspect wind turbine blades systematically, the sensors should be embedded in the inner surface of a turbine blade at various locations during manufacturing. The method was tested on a CFRP wind turbine blade. The tests were performed at $40 \mathrm{~m}$ from a specimen with a disbond.

The visualization of delamination and debonding using laser ultrasound has also been demonstrate in a CFRP aircraft wing and in a GFRP wind turbine blade by Park, An \& Sohn (Park, An, and Sohn 2014). An ultrasonic wave was generated using a pulse laser beam and the ultrasonic response was measured using a laser Doppler vibrometer. The proposed technique is non-contact and unlike the previous proposed technique, it does not need to embed sensors during manufacturing. A real scale $10 \mathrm{~kW}$ GFRP wind turbine blade was used as test specimen and a delamination was successfully visualized using this technique. 
More recent studies use the laser beam to generate guided waves in a CFRP composite. The purpose of the recent studies is not yet to detect damage but to verify the possibility and efficiency of non-contact excitation and focusing of the guided waves. Various methods of wave focusing are actually been analysed.(Jurek et al. 2018).

The ultrasonic signal obtained from laser ultrasound experiments can also be analysed to detect wrinkles in composites as in simple ultrasound-echo experiments. Although the possibility of using a laser ultrasound system to in-situ evaluate damage in wind turbine blade has proven to be feasible; this technique has yet to effectively be used for in-situ inspection of wind turbine blades. The performance of the techniques under various operating conditions need further study.

Figure 15 show the results of a ultrasonic inspection in which the ultrasonic wave was generated by pulsed laser beams. Data was interface triggered which is why there are many locations where there is a lack of waveform data. The image shows that, nowadays, data quality using laser ultrasound is not up to the standard of immersion scanning.

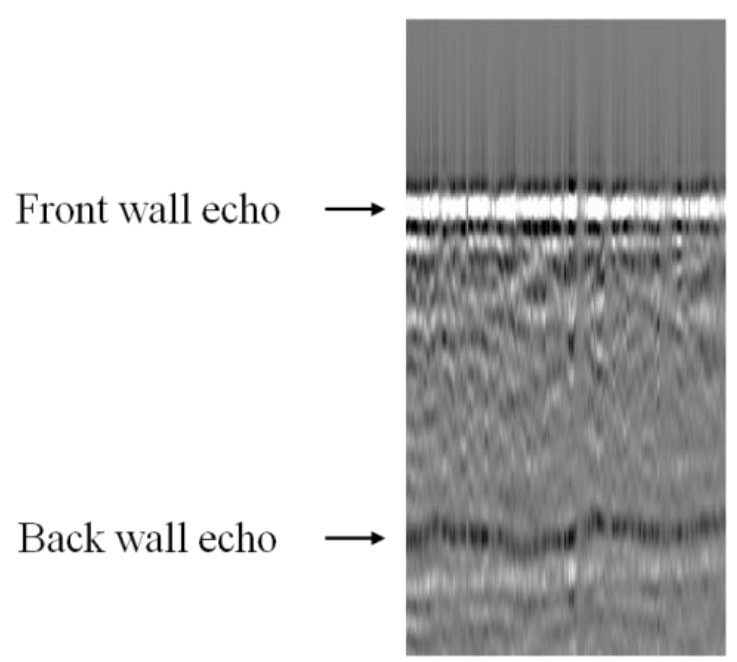

Figure 15: Full waveform ultrasonic inspection in which the ultrasonic wave was generated by pulsed laser beams. The experiment was performed at the Tecnatom laboratory in Madrid.

Although laser ultrasound is a very promising technique to inspect wind turbine blades, additional research is needed before this technique can be routinely applied.

\subsubsection{Acoustic emission}

Acoustic Emission is a technique that is more than 50 years old. In acoustic emission monitoring, surface mounted piezoelectric sensors detect the wave sounds that travel through the sample as a consequence of the activation of a damage mechanism. This technique is known as a powerful tool to detect the growth of any pre-existing cracks or to characterize damage mechanics in homogeneous materials as well as in CFRP (Barile 2019). 
Acoustic emission has been used to monitor full-scale wind turbine blades during static and fatigue laboratory tests (Joosse et al. 2002). Due to the high effectiveness in detecting and identifying crack damage at an early stage, testing procedures developed during a laboratory blade testing programme were applied to an in-service wind turbine blade (Blanch and Dutton 2003). When applying this acoustic emission to an in-service wind turbine blade, the technique is more like a structural health monitoring (SHM) method than an NDT method. One of the mayor problems encountered in the in-service test is that there are many acoustic sources other than the cracks of interest. Although the results of the experiment showed the potential of acoustic emissions for wind blade in service monitoring, further development is still needed.

Since internal wrinkles are a manufacturing defect, they do not introduce a change in the structure that generate a wave sounds; they cannot be detected using the acoustic emission technique.

\subsection{Optical Techniques}

Optical techniques involve different techniques, such as automated optical inspection, digital image correlation, optical coherence tomography and shearography. These methods have been developed over the last few years. The mayor advantage of these techniques is that they are capable to inspect large areas within a relatively short time. Thus they should be suitable to inspect wind turbine blades. All of these techniques are limited to surface/subsurface inspection. Thus internal defects, such as internal out-of-plane wrinkles, cannot be detected with them.

\subsubsection{Automated optical inspection}

In Automated optical inspections, digital image analysis techniques are used to detect defect on the surface of the elements. Nagarajan, Rajadurai \& Kumar (Nagarajan, Selwin Rajadurai, and Annil Kumar 2012) proposed a digital image analysis to evaluate the delaminations caused by holes drilled in the composite laminates during the manufacturing process at the machining centre. The damage was captured qualitatively using a digital camera and a refined neural network was used to calculate a refined delamination factor for each image. The value of that factor could accounts for the severity of damage at each hole.

Zhang \& Jackman (Huiyi Zhang and Jackman 2014) evaluated several image processing techniques for detecting cracks in wind turbine blades. According to their study, the line detection method is ideally suited for quick scans of the entire blade surface as it can quickly identify cracks that are invisible to the naked eye. However uneven lighting and background noise in the images may influence the quality of the results.

Denhof, Staar, Lütjen \& Freitag (Denhof et al. 2019) used image data taken with a digital single-lens reflex camera to create a data set containing images of various rotor blades and then employ convolutional neural networks in order to decide whether an 
image section contains a defect or not. According to this study, powerful image classification methods like pre-trained convolutional neural networks are needed to discriminate difficult cases such as the discrimination of weathered adhesive labels from actual defects. The operating conditions of wind turbine blades make that the number of cases difficult to discriminate is high. The longer the training time and the higher the amount of training, the better were the overall performances for most of the tested models.

High quality images of in-service wind turbine blade are needed so these image processing techniques can consistently be applied. In order to obtain those high resolution images of the wind turbine blades, the blades could be dismantled and moved to an onshore inspection laboratory. However, that option is extremely expensive and includes the risk that wind turbine blades are damaged during the transfer.

Recent studies, explore the possibility of obtaining images from the blades using automated scanning devices (robot devices) or unmanned aerial systems (commonly called drones). The ultimate goal being to automate the whole inspection process.

The Fraunhofer Institute for Factory Operation and Automation IFF $^{6}$ has been developing a robot able to inspect composite wind turbine blades on location. The robotic system automatically manoeuvres along the blades. It consists of a frame structure that fully encloses the rotor blade and move on ropes along the rotor blade. Other type of light-weight multi-axis scanning systems are also being developed.

Reddy, Indragandhi, Ravi \& Subramaniyaswamy (Reddy et al. 2019) used drone technology to collect images in wind turbine blades of heights around $150-200 \mathrm{~m}$. Those images were used to train a Convolutional Neural Network that detects and classify typical wind turbine blade damage (lightening damage, tip open, erosion, mechanical damage or cracks ). Accuracies above $90 \%$ were achieved. Drone inspection may be an alternative to manual inspection which is quite time consuming and involves risks for workers. A flight strategy is needed to perform a complete blade inspection using a single battery. To keep a safe operation area for the drone, a minimum distance from the wind turbine blade and a maximum displacement speed must be defined. This limits the size of the images that can be obtained with the aerial survey. A drone inspection may become a very useful tool for rapid decision taking as a flight inspection may take as little as 20 minutes and the image processing takes only a few second.

\subsubsection{Digital image correlation}

Digital image correlation is a non-contact optical measurement method. This technique is based on the comparison of digital images of the surface of an object to measure the full-field displacement and strain distributions as it deforms. The displacement and strain distribution can be used to identify surface cracks. To measure deformation in three dimensions, the general setup requires the use of two or more

\footnotetext{
${ }^{6}$ https://www.iff.fraunhofer.de/en/business-units/robotic-systems/riwea.html
} 
cameras. This technique combines methods from photogrammetry, computer vision, and image registration.

Prior to the experiment, the surface under inspection should be sprayed with randomly distributed speckles to enhance the contrast. Figure 16 shows a typical speckle pattern for the samples that are prepared for a digital image correlation test. Digital image correlation is an image matching method that compares two images obtained from different views. The first image is the reference one, that correspond to "before" deformation. The second image correspond to "after" deformation. The changes in the speckle pattern allow the determination of the full-field deformation.

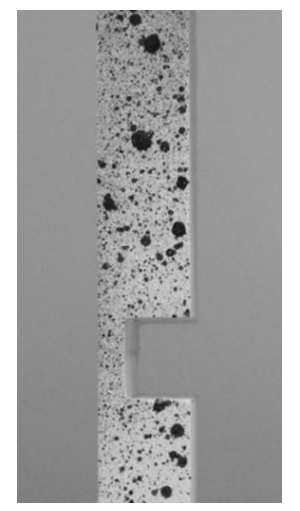

Figure 16: Speckle pattern in the surface of a sample prepared for a digital image correlation test.

Nowadays, there are rare reports detailing full-field measurement of wind turbine blades in operation using the digital image correlation technique.

Ozbek, Rixen , Erne \& Sanow (Ozbek et al. 2010) conducted several photogrammetric test on a wind turbine that has a rotor diameter and tower height of 80 $\mathrm{m}$. A total of 55 reflective markers were placed on the turbine and four different cameras at a distance of $220 \mathrm{~m}$ were used to track them. The deformation on the wind turbine blades were measured with an average accuracy of $25 \mathrm{~mm}$. An advantage of this technique is that all the measurement systems are located on the ground and the same system could be used to inspect all the turbines in the same wind farm. Another advantage is that the pictures of the blades can be taken while the turbine is rotating. However, the tower measurements are interrupted each time a blade passed in front of it, so the turbine should stop for the tower inspection.

Wu, Zhang, Yu, Jiang \& Arola (Wu et al. 2019) conducted a three-dimensional digital image correlation test on a small wind turbine with $4 \mathrm{~m}$ diameter composite blades and $6 \mathrm{~m}$ tower height. The blades were prepared with a random black-and-white speckle pattern. The test was conducted outdoors and two digital cameras were used. The full-field relative deformation of the blades was measured and analyzed to identify the existence of opening cracks in the blades. High-speed cameras would be needed to monitor wind turbine blades in service. This technique can also be applied to larger wind turbine blades. 


\subsubsection{Optical coherence tomography}

Optical coherence tomography is a contactless and high resolution imaging method that was originally developed for the imaging of the human retina. This technique is based on low coherence interferometry of backreflected light from interfaces within the sample. It allows the reconstruction of cross-sectional and volumetric images to characterize the microstructure within a specimen.

Liu, Groves \& Benedictus (Liu, Groves, and Benedictus 2014) examined the growth of a delamination in a glass fibre composite sample using optical coherence tomography. The lay-up configuration of the composite specimen was based on the configuration that is generally used for the spar webs in wind turbine blades. Volumetric images of the sample at different stages of crack growth were obtained. The results show that an optical coherence tomography system could be used for the monitoring of the delamination propagation within a glass fibre composite. However, the glass fibre composite sample used for the experiment was thinner than the laminated used for wind turbine blades. The layer thickness of the specimen was only about 0.3 $\mathrm{mm}$.

Although this technique allows the reconstruction of 3D depth images, it has only proven effective in the detection of sub-surface damages. An increase in penetration depth is necessary before this technique is applicable to thick walled composites. However, optical coherence tomography research is nowadays, mainly focused on biomedical applications.

\subsubsection{Shearography}

Shearography is an interferometric technique that measures derivatives of surface displacements. Shearography is normally compared to holography which measures surface displacements. The advantages of shearography compared to holography are a simpler set up and that surface strains can be directly provided thus eliminating the need to numerically differentiate displacement data.(Hung 1999).

This technique uses a laser light to generate a speckle pattern on the testing surface. The pattern on the surface is recorded by a camera. The pattern changes if the specimen is under test by mechanical, thermal, pressure or vibratory means. This technique can be used to detect damage-induced surface strain anomalies. It can also be used to detect regions with subsurface damage, which will exhibit strain anomalies.

Digital shearography is able to perform non-contact full-field measurements and could be used to detect delamination, disbonding or impact damage in composite wind blades (Gryzagoridis and Findeis 2010).

Sutherland, Beattie, Hansche, Musial, Allread, Johnson \& Summers (Sutherland et al. 1994) used shearography to monitor the behaviour of a wind turbine blade during a quasi-static test-to-failure. 
Niezrecki, Avitabile, Chen, Sherwood, Lundstrom, LeBlanc, et al. (Niezrecki et al. 2014) used thermal shearography to test a wind turbine blade containing six known embedded wave defects in the laminate. The wave defects were inserted during the blade manufacturing resulting in six protruding wrinkles with an amplitude of $3 \mathrm{~mm}$. Thermal shearography heat the defect locations at the blade for a few seconds. The tests were able to detect crack formation on the fibre waves and the protruding out-of-plane fibre wave defects.

Although encouraging test results were reported, nowadays this technique is currently limited to quality control procedures rather than to field inspections.

\subsection{Electromagnetic Techniques}

Electromagnetic techniques involve different techniques, such as eddy current, microwave and terahertz inspections. $X$ rays is an special kind of electromagnetic waves, with major importance for NDT inspection, that will be considered in an independent paragraph.

\subsubsection{Eddy current}

Basic eddy current technique uses a cylindrical coil to simultaneously generate and sense the electrical current in the part under inspection. This technique is widely used in metallic components. These techniques enables detection of some kinds of surface and subsurface damage and can be applied to non-magnetic metallic items. Eddy current imaging of CFRP is based on the anisotropic electrical properties of the composite where significant differences in conductivity between the fibres and the matrix can be found (Mook, Lange, and Koeser 2001).

Some experiments have been done with cross-ply laminates trying to detect surface waviness and subsurface in-plane and out-of-plane waviness using eddy currents.

Mizukami, Mizutani, Kimura, Sato, Todoroki \& Suzuki (Mizukami, Mizutani, Kimura, et al. 2016) used a rectangular race-track coil to detect and characterise the size and shape of surface waviness with adequate accuracy whereas it significantly underestimated the size of the subsurface waviness. The probe could detect waviness at 18 layers depth. However, this eddy-current imaging method cannot detect in-plane waviness when the direction of the carbon fibre plies with waviness is perpendicular to the long sides of the rectangular driver coil.

Mizukami, Mizutani, Todoroki \& Suzuki (Mizukami, Mizutani, Todoroki, et al. 2016) used the same rectangular probe to detect out-of-plane waviness in unidirectional CFRP. The location of the highest amplitude of the wrinkle could be estimated accurately by plotting the scanning results in a complex plane. Scanning results of CFRP with out-of-plane waviness shows ring-shaped plots around the origin of the complex plane. The maximum amplitude of the wrinkle in the specimen used for the experiment was located at a depth of $12 \mathrm{~mm}$. For eddy current imaging, higher 
sensitivity is obtained at higher frequencies. However, the penetration depth of the eddy currents decreases at higher frequencies.

An important advance in Eddy current method was the development of pulse eddy current. Scanning pulse eddy current can be used for inspecting a larger area and CScan imaging can be perform(He, Luo, and Pan 2010). As in phased-array ultrasonic technique, defect characterisation can be carried out based on the C-scan image.

He, Tian, Pan \& Chen (He et al. 2014b) used pulse eddy current scanning to characterise impact defects and inner delamination defects in CFRP laminates and honeycomb sandwich panels. The proposed method was able to effectively detect the defects caused by a low energy impact. This method has a high reliability and is able to detect deep defects.

Bouloudenine, Feliachi \& Latreche (Bouloudenine, Feliachi, and Latreche 2017) developed a circular arrayed eddy current probe for detecting fibres orientation and inplane fibre waviness. This sensor allows to overcome the limitation of the rectangular sensor because it allows the detection of in-plane waviness in every direction. Compared to a traditional rectangular rotating sensor, the proposed device minimizes the measurement noise and is able to perform fast inspections. The circular arrayed eddy current probe was successfully used to detect the in-plane fibre waviness and characterizing their direction with one static measurement in very thin CFRP plates.

Eddy current technology with frequency range up to $100 \mathrm{MHz}$ is known as radio frequency eddy current (Heuer et al. 2015). Radio frequency eddy current devices measure the complex impedance that is influenced by both permittivity and conductivity of the material. The electrical conductivity contains information about fibre texture like orientations, gaps or undulations in a multilayered material. Radio frequency eddy current based methods are interesting due to the possibility of integrating the sensors in the process chain without affecting the material properties and quality. The initial trials have shown the potential of this technique to detect manufacturing defects such as waviness or inserted Copper foils. However more research is still necessary before this technique can be used on a production line.

The most recent experiments performed to detect fibre waviness in CFRP laminates using eddy currents were perform by Zeng, Wang, Liu, Lin \& Dai (Zhiwei Zeng et al. 2019). They use a probe that consists of two rectangular coils (one for excitation and one for reception) that are perpendicular to each other. The excitation coil is along the designed fibre direction. The results show that the resolution of testing fibre direction using the proposed method is as small as $0.5^{\circ}$ and fibre waviness can be detected according to the variation of scanning signal.

Eddy current techniques are still insufficient for practical use in waviness detection of CFRP laminates. At the moment, all the experiments have been carried out in laboratory samples. Also, eddy-current imaging technique does not work on GFRP 
laminates. Thus, eddy-current imaging is not a suitable technique for the inspection of the glass-carbon hybrid laminates commonly used on turbine blades.

\subsubsection{Microwave}

Microwaves are a type of electromagnetic radiation with frequencies ranging from $300 \mathrm{MHz}$ to $300 \mathrm{GHz}$. Microwave signals penetrate inside dielectric materials and interact with their inner structures without suffering from high attenuation.

Microwave has already been used for wind turbine tower NDT inspection (Pieraccini et al. 2008). Experiments were carried out to analyze the dynamic behaviour of the towers holding the wind turbines. The microwave sensor operates remotely and has been proven to be able to test structures in-service.

Roach, Neidigk, Rice, Duvall \& Paquette (Roach et al. 2015) performed a microwave inspection on a GFRP wind turbine blade coupon to detect some defects and internal structure. Defects are detected by detecting changes in electromagnetic properties or the location of changes in such properties. Flat bottom holes, inserts and surface defects were imaged with the microwave technique.

Li, Zhou, Lei \& Pei (Z. Li et al. 2019) build a microwave near-field and far-field imaging platform to inspect a GFRP composite plate with hat stiffeners. Combining near-field and far-field imaging methods they were able to detect fibre wrinkling defects in $39 \mathrm{~mm}$ thick hat stiffener.

However, microwave techniques are still insufficient for practical use in wind turbine blade inspections. At the moment, all the experiments have been carried out in laboratory samples. More experiments are needed to check if this technique is also able to characterize wrinkles.

\subsubsection{Terahertz}

Terahertz waves are a type of electromagnetic radiation with frequencies ranging from 0.1 to $10 \mathrm{THz}$. This technique enables non-invasive, non-ionizing and non-contact examinations. Hsu, Im, Chiou \& Barnard (Hsu et al. 2011) explored the utilities of terahertz waves for the non destructive evaluation of composite materials and structures. Terahertz radiation can penetrate considerable thickness of dielectric materials such as conducting polymer composites reinforced with glass, quartz, or Kevlar fibres. CFRP composites are generally too conducting for terahertz waves to penetrate.

Martin, Sabato, Schoenberg, Giles \& Niezrecki (Martin et al. 2018) used a terahertz inverse synthetic aperture radar to inspect several fibreglass panels with a set of specific embedded defects emulating those that are typically found in wind turbine blades as a result of the manufacturing process. The terahertz technique has been shown to make some significant near-surface defects visible (including protruding wrinkles), although it struggles to reveal the existence of more profound defects. The lack of penetration may be explained by the frequency chosen for the experiments. 
The primary limitation of terahertz techniques for wind turbine blade inspections would be the presence of the CFRP composite and other conducting materials. Also, more experiments are needed to improve imaging performance with this technique.

\subsection{Thermography}

Infrared thermography NDE can be divided into two approaches: passive thermography and active thermography. Active thermography requires an external thermal source for heating of the material under tests whereas passive thermography does not.

\subsubsection{Passive thermography}

Passive thermography measures thermal variations of a material using an infrared vision device without external thermal sources. The feature of interest should be at a higher or lower temperature than the background (Yang and He 2016).

Hahn, Kensche, Paunter, Dutton, Kildegaard \& Kosgaard (Hahn et al. 2002) used passive thermography to observe a GFRP wind turbine blade during a fatigue test. When an elastic material is stressed under adiabatic conditions, the temperature changes. The thermoelastic stress analysis was able to detect stress concentrations that were not predicted by the finite element analysis.

Melnyk, Tuluzov \& Melnyk (Melnyk, Tuluzov, and Melnyk 2014) used passive thermography to monitor rotor blades from ground level without stopping the blade rotation. The periodic loads that occur in the process of blade rotation, cause the heating of the blade. That heating is sufficient for registration using a thermal imager. Although some factors limit the capabilities of remote passive thermograph testing of rotor blades; defects like superficial cracks, lamination or water accumulation could be characterized by specific dynamics of heat flows.

\subsubsection{Active thermography}

In active thermography, the materials under test are stimulated by an external heat source. Krstulović-Opara, Klarin, Garafulić \& Domazet (Krstulović-Opara et al. 2011) compared thermograms of various GFRP wind turbine blades with and without pulse heating. Anomalies such as trapped air pockets, cracks or hidden blade structure that did not appear for the passive thermograms where no pulse heating was applied; become visible for the active thermograms with the pulse heating. The active thermography approach enables clearer distinction of material defects.

There are different techniques of active thermography that can be classified in several ways. The main classification is by heating function. Infrared conventional optical thermography techniques include flash thermography and halogen lamp thermography. Non-optical heating sources such as laser, eddy current, microwave, and ultrasound are drawing increasingly attentions for composites NDT inspections. 
Another important classification of the available techniques is the classification by heating style. Those techniques that base the defect depth quantification on the heat conduction from the surface to the inner parts of the specimen, are named as surface heating thermography. The most common types of surface heating thermography are pulsed thermography, stepped thermography, modulated thermography, lock-in thermography and pulsed phase thermography.

Under certain heat excitation source such as high frequency induction current or microwaves; composites materials are volumetric heated (when induction current is used as excitation, CFRP is volumetric heated and, when microwave is used as excitation, GFRP is volumetric heated). Those techniques are named volume heating thermography. With those techniques inside defects or interesting objects are heated in a different manner than the host material. Defects will not generate heat, generate more heat than the host material or be heated when the host material is not heated (Yang and He 2016).

\subsubsection{Pulsed thermography}

In pulsed thermography, also known as flash thermography, the temporal evolution of the specimen surface temperature is measured with an infrared camera after the application of a thermal pulse. The thermal front propagates by diffusion under the surface. The diffusion rate is reduced by the presence of an internal defect. Consequently, an area of different temperatures with respect to their surrounding indicates the presence of a defect. The deeper the defect is; the later the defect will be observed.

Flash thermography is an example of surface heating technique. In optical flash thermography, the sample surface is heated by a brief pulse of light. The time at which heat deposited at the surface encounters a subsurface interface can be measured and analysed. Thus, this technique offers reliable measurement of sample thickness, defect depth and thermal diffusivity (Shepard 2007).

Szwedo \& Hellstein (Szwedo and Hellstein 2014) present a pulsed thermography system that is ready to be implemented in an end line wind turbine blade manufacturing quality control. The system was tested on a portion of a wind turbine blade with improper resin impregnation. The surface of the blade was heated with two lamps for 10 seconds, with 40 seconds of cooling phase afterwards. The dry laminate areas were easily identified as brighter fields.

Zeng, Tao , Feng , Li , Ma \& Zhang (Zhi Zeng et al. 2014) used pulsed thermography to monitor the breakpoints of a heating wire embedded in the GFRP wind blade moulds. The heating wire is embedded in fibre glass as a sandwich structure in order to heat the mould to a certain temperature for curing. The wire may break after a long time usage at high temperatures and the precise location of the breakpoint reduce cost and time of the repair. 


\subsubsection{Lock-in thermography}

In lock-in thermography, a sinusoidal heat source at a specific frequency is applied to the surface of the object under inspection. The heat wave propagates by diffusion under the surface and is reflected when it encounters a defect. The reflection causes a phase shift of the resulting heat wave with respect to the input heat wave. The depth resolution of a test is fixed as a function of the frequency of excitation. With this technique, several test need to be performed on the sample test sample in order to locate defects at various depths which is quite time consuming.

Amenabar, Mendikute, Lopez-Arraiza, Lizaranzu \& Aurrekoetxea (Amenabar et al. 2011) compared the detection capabilities and performance of pulsed and lock-in thermography techniques for the inspection of GFRP wind turbine blades with delamination defects. Both pulsed and lock-in modulations detected clearly all the delaminations. Due to their lower conductivity, composite materials require long acquisition times (up to 150s) especially in thick parts. Although qualitative information of the delamination dimension was obtained, the thermal images showed a clear blurring effect that depends on the thickness of the part.

Montanini \& Freni (Montanini and Freni 2012) explored the use of optically excited lock-in thermography for the detection of sub-surface defects in thick GFRP laminated plates. Although lock-in thermography has proven to be an effective, practical and contactless full-field NDE tool, when applied for the inspection of relatively thick GFRP structures some limitations were highlighted. The study found a correlation between flaw depth assessment and flaw geometry. Results showed that, square or circular shaped flaws are more easily detectable than rectangular or lengthened discontinuities. Lock-in thermography can also be used to detect impact damage with excellent defect size estimations.

Ekanayake, Gurram \& Schmitt (Ekanayake, Gurram, and Schmitt 2018) proposed a method to determine the defects depth in CFRP structures using lock-in thermography. The accuracy of depth measurement with thermography on delamination caused by impact damage is significantly influenced by lateral heat flow and the contact resistance. The developed method enables an accurate depth determination on thin samples (thickness up to $4 \mathrm{~mm}$ ). However, further investigation is needed in order to be able to quantitative determine the defect area and position.

\subsubsection{Pulsed phase thermography}

Pulsed phase thermography was originally developed in 1996 by Maldague \& Marinetti (Maldague and Marinetti 1996). This technique combines advantages of pulsed thermography and lock-in thermography. Pulsed phase thermography is phase analysis in the frequency domain of pulsed thermography built on thermal wave propagation. Although the thermal pulse in composites is different from that of an ideal temporal pulse, it can be identified as a sum of thermal waves. 
Some experiments have been carried out using pulsed phase thermography for the evaluation of GFRP wind turbine blades. The different materials present in the blade (plastic, composite and foam material) can be identified through different phase values in the phasegrams. However, this technique is limited in some cases of defect detection (Yang and $\mathrm{He}$ 2016).

\subsubsection{Line scanning thermography}

Line scan thermography is a dynamic thermography technique. The particularity of this technique is that the heat source is moved across the sample's surface at a constant speed. An infrared detector that moves in tandem with the heat source is used to record the temperature changes on the surface. The cooling behaviour after heat deposition is then analysed in order to detect the presence of defects or material property changes.

Moran \& Rajic (Moran and Rajic 2019) developed a remote line scan thermography technique that can be used to detect flat-bottom-hole defects and barely visible impact damage on carbon epoxy laminates. It has been shown that low-cost equipment can be used to perform rapid inspection of carbon-epoxy laminates using this technique with a $500 \mathrm{~mm}$ stand-off. Work on implementing this capability on a unmanned aerial systems is currently underway. When achieved, this technique could be used to monitor wind turbine blades in service.

\subsubsection{Eddy current thermography}

Eddy current thermography is an emerging NDT technique that is based on non conventional heating sources. The material under test is heated directly by electromagnetic (eddy current) means. It is a type of volume heating thermography for CFRP. Eddy current thermography is a combination of eddy current and thermography techniques. Some of the benefits of this technique are non-contact, fast, full-field and high resolution. (Gao et al. 2014).

Pan, He, Tian, Chen \& Luo (Pan et al. 2012) performed eddy current thermography tests on a CFRP sample. The inductor and the infrared camera were placed on opposite sides of the component (transmission mode). The results of the experiments show that the detection mechanisms for impact and delamination in CFRP with this technique are different. Superficial impact damage leading to decrease conductivity can be detected in the heating phase. However, internal delamination can be characterized using later stage of the cooling phase.

He, Tian, Pan \& Chen (He et al. 2014a) performed eddy current thermography tests on CFRP Laminates impacted with different energies. The $2 \mathrm{~J}$ and $4 \mathrm{~J}$ impacts were not detected. The hot spot shapes at the thermograms vary depending on the impact energy. However, it is difficult to accurately quantify the impact energy from the obtained thermograms. 
Yang \& $\mathrm{He}$ (Yang and $\mathrm{He}$ 2015) performed eddy current pulsed phase thermography through frequency domain phase analysis. Tests were perform on a CFRP laminates with an inner delamination of $100 \mathrm{~mm}^{2}$ in $3.5 \mathrm{~mm}$ thickness. Using eddy current pulsed phase thermography, the detection of delamination is improved over eddy current pulsed thermography because the influence of non-uniform heating disappears. In both thermal and phase images, the fibre woven structure of the laminate can be guessed because carbon fibre is highlighted differently than resin.

Liang, Ren, Tian, Elradi \& Gao (Liang et al. 2016) also conducted an study to detect low energy impact damages using eddy current pulsed thermography. The damage size of the CFRP after a 4J energy impact is small and cannot be observed directly from the original thermal images. Eddy current pulsed phase thermography can detect smaller defects in CFRP than eddy current thermography but it needs image processing using appropriate level of wavelet and frames of thermal images.

\subsubsection{Microwave thermography}

Microwave heating is a new heating technique due to dielectric loss. Microwave sources can be used to heat the water inside composite materials. Advantages of using microwaves for NDT are rapid heat transfer, relatively uniform heating pattern, volumetric and selective heating, compactness of equipment, speed of switching on and off, and pollution-free environment as there are no products of combustion. This technique combines the advantages of microwave technology and infrared thermography. Some of the limitations of microwave thermography are the complex and expensive microwave excitation system and the electromagnetic radiation. Microwave leakage should be kept well below government recommended levels (Hong Zhang et al. 2017).

Galietti, Palumbo, Calia \& Pellegrini (Galietti et al. 2012) developed a microwave pulse and lock-in thermography technique for composite inspection. Tests were carried out on previous damaged CFRP plate using a modified microwaves oven. In the results obtained with microwaves thermography, the impact damaged zone is clearly evident.

\subsubsection{Vibrothermography and ultrasound thermography}

In contrast to classical optical thermography, in vibrothermography the sample is mechanically excited by sonic or ultrasonic oscillations through coupling an ultrasonic transducer to the sample surface. The propagation of the damped acoustic waves along the material converts mechanical energy into thermal energy. This mechanical excitation acts as a selective inner heat source, located just at the defect, which diffuses inside the material and can be detected as a temperature variation at its surface by means of an infrared camera (Yang and He 2016). Trudnowski (Trudnowski 2012) modelled the heat generation that occurs during a vibrothermography test in order to assist in the development of a NDT technique for composite blade inspection. 
Segers, Hedayatrasa, Verboven, Poelman, Van Paepegem \& Kersemans (Segers et al. 2019) inspected two CFRP coupons with barely visible impact damage using vibrothermography. Both samples were excited using a low power piezoelectric glued to the impact side. The thermal and vibrational spectra of the surface are studied for defect quantification and depth profiling.

\subsubsection{Thermography for wind turbine blade inspection.}

The current state of infrared thermography has demonstrated that both passive and active infrared thermographies can be used for the detection of different defects including: stress concentrations, cracks, delaminations, trapped air pockets or dry laminate areas. However, the different thermography techniques are mainly studied in the laboratory. These techniques are still insufficient developed for practical use in wind turbine blades and none of them has been widely used in industry. At the moment, it has not been possible to use thermography to characterize laminates internally (determination of ply stacking sequences). Thus internal wrinkles, cannot be detected using thermography techniques.

\subsection{Radiographic techniques}

Radiographic techniques involve different techniques, such as x-ray and gammaray. The basic principle of radiography is to transmit ionizing radiation through a material and measure its attenuation. These technique can be used to take radiographs (2D) or with a tomography setup (3D). Radiography allows the detection of internal flaws and defects such as cracks, corrosion, inclusions, and thickness variations. Improvements in spatial resolution of detectors and computer hardware used for reconstruction of 3D volumes made X-ray computed micro-tomography a practical technique for the reconstruction of the fibres in composite materials (Pyrz 1999).

Jasiūnienè, Raišutis, Šliteris, Voleišis, Vladišauskas, Mitchard \& Amos (Jasiüniené et al. 2009) inspected a 1005 x 870 mm GFRP wind turbine blade sample using a specially developed microfocus radiography system. The blade sample was mounted on a manipulator capable of $360^{\circ}$ of rotation. Volumetric defects such as lack of glue and internal structural irregularities were detected with the X-ray technique.

Holub \& Haßler (Holub and Haßler 2012) performed computed tomography tests on samples of unidirectional GFRP cut out of a real rotor blade. The samples have internal out-of-plane wrinkles of different kinds and severities. The reconstructions of the sample objects were made with resolutions of $130 \mu \mathrm{m}$. This resolution ensures the ability to track the resin layers between plies that separate the different glass fibres roving layers from each other. High-resolution 3-D computed tomography images were obtained in which the difference in attenuation of the glass fibres versus epoxy gives high enough contrast to visually follow the roving layers and to see the out-of-plane wrinkles in the material. These good results were obtained on samples that have sizes of about $25 \cdot \mathrm{x} 4 \mathrm{x} \cdot 3 \mathrm{~cm}^{3}$. However, it does not seem reasonable to get computed 
tomography images reconstructions of a whole wind turbine blade with such high resolutions.

Nikishkov, Nikishkov \& Makeev (Nikishkov, Nikishkov, and Makeev 2013) used images recorded with X-ray computed micro-tomography as input for finite element mesh generation for unidirectional composites with waviness defects.

Smith, Nelson, Xie, Fraij \& Hallett (R. A. Smith et al. 2015) shows typical X-ray Computed Tomography images of an out-of-plane wrinkled composite test specimen of dimensions $30 \times 250 \times 6 \mathrm{~mm}$. In order to achieve sufficient resolution of fibre orientations, test specimens must be considerably smaller than any wind turbine blade.

Even though Micro-focus X-Ray Computed Tomography is the technique that provides the most detailed information for 3D characterisation of fibre orientation on small components; it is expensive and it is not a practical technique for large components due to the trade-off between resolution and component size. In components as large as turbine blades computed micro-tomography does not achieve sufficient resolution of ply boundaries.

\subsection{SHM techniques}

Structural Health Monitoring can be referred as a process of implementing a damage strategy infrastructure. In a SHM system, sensors integrated on the structure are able to extract damage-sensitive features in order to perform an analysis from which the state of the structure over a period of time can be determined (Balageas, Fritzen, and Güemes 2006). Since wrinkles are a defect that occurs during the manufacturing of wind turbine blades, any SHM system installed on the blades would be useful to evaluate the performance of the damaged wrinkles but cannot be considered an effective system for detecting wrinkles.

Chakrapani, Dayal \& Barnard (Chakrapani, Dayal, and Barnard 2013) detected and characterized waviness in a composite wind turbine blades with the help of air coupled ultrasound. They then developed an SHM system based on PVDF patches to monitor crack and delamination initiation near the wrinkled area in a wind turbine blade. The technique is robust and easily implementable in the field. It could extract extra life out of the wind turbine blade without the need to repair the wrinkled laminate and in a long term help in cost savings of replacing a blade.

\subsection{Comparison and discussion}

Following Table 1 establishes a comparison among the main different non destructive testing techniques here above mentioned and their effectiveness for detecting and characterising internal out-of-plane wrinkles in the typical glass-carbon hybrid laminates that are used nowadays for wind turbine blades. 
Table 1: Summary and comparison for major NDT methods for wrinkle detection in wind turbine blade inspections

\begin{tabular}{|c|c|c|}
\hline NDT techniques & Strength & $\begin{array}{l}\text { Effectiveness for detecting } \\
\text { and characterising wrinkles }\end{array}$ \\
\hline Visual inspection & Low-cost, simple & $\begin{array}{l}\text { Only for protruding } \\
\text { wrinkles }\end{array}$ \\
\hline $\begin{array}{l}\text { Tap-test and local } \\
\text { resonance spectroscopy }\end{array}$ & Low-cost, simple & $\begin{array}{c}\text { wrinkles cannot be } \\
\text { detected }\end{array}$ \\
\hline Ultrasound-echo & \multirow{3}{*}{$\begin{array}{l}\text { Great depth, high } \\
\text { resolution, many } \\
\text { deployment } \\
\text { options }\end{array}$} & \multirow{3}{*}{$\begin{array}{l}\text { Wrinkles can be tracked } \\
\text { using the analytical signal }\end{array}$} \\
\hline Commercial PAUT & & \\
\hline FMC with TFM & & \\
\hline Guided waves & In-service, large areas & $\begin{array}{l}\text { wrinkles cannot be } \\
\text { detected }\end{array}$ \\
\hline Air coupled ultrasound & $\begin{array}{c}\text { No coupling, suitable for } \\
\text { curved or complex } \\
\text { surface }\end{array}$ & $\begin{array}{l}\text { Wrinkles can be tracked } \\
\text { using the analytical signal }\end{array}$ \\
\hline Laser ultrasound & $\begin{array}{l}\text { No coupling, long distance, } \\
\text { broadband generation }\end{array}$ & $\begin{array}{l}\text { Wrinkles can be tracked } \\
\text { using the analytical signal }\end{array}$ \\
\hline Acoustic emission & $\begin{array}{c}\text { In-service, passive, large } \\
\text { areas }\end{array}$ & $\begin{array}{c}\text { wrinkles cannot be } \\
\text { detected }\end{array}$ \\
\hline Optical Techniques & $\begin{array}{c}\text { Non-contact, large areas, } \\
\text { short time }\end{array}$ & $\begin{array}{l}\text { wrinkles cannot be } \\
\text { detected }\end{array}$ \\
\hline Eddy current & $\begin{array}{c}\text { Non-contact, no surface } \\
\text { treatment }\end{array}$ & $\begin{array}{l}\text { Can be detected } \\
\text { not a suitable for GFRP }\end{array}$ \\
\hline Microwave & Non-contact & $\begin{array}{c}\text { More experiments are } \\
\text { needed }\end{array}$ \\
\hline Terahertz & $\begin{array}{l}\text { Non-contact, high } \\
\text { resolution }\end{array}$ & $\begin{array}{l}\text { More experiments are } \\
\text { needed }\end{array}$ \\
\hline Thermography & $\begin{array}{l}\text { Non-contact, full-field, } \\
\text { fast, high resolution, high } \\
\text { sensitivity }\end{array}$ & $\begin{array}{l}\text { wrinkles cannot be } \\
\text { detected }\end{array}$ \\
\hline X-ray & $\begin{array}{l}\text { High resolution, non- } \\
\text { contact }\end{array}$ & $\begin{array}{l}\text { 3-D computed tomography } \\
\text { images gives high enough } \\
\text { contrast to visualise } \\
\text { wrinkles }\end{array}$ \\
\hline
\end{tabular}

According to the literature review, internal out-of-plane wrinkles can be detected with ultrasound, eddy current and $\mathrm{x}$-ray techniques.

Eddy current techniques have shown some potential to detect wrinkle in CFRP laminates. However, eddy current is not a suitable technique to detect wrinkle in wind turbine blade laminates as it only works on CFRP laminates. 
Micro-focus X-Ray Computed Tomography is the technique that provides the most detailed information for wrinkle characterisation, but is expensive and is only practical on small components. In components as large as turbine blades computed micro-tomography does not achieve sufficient resolution to image and visualise wrinkles.

Therefore, ultrasonic techniques are the most promising techniques to detect and characterise internal out-of-plane wrinkles in wind turbine blades. Among the different ultrasonic techniques; ultrasound echo, commercial phased-array ultrasound technology and full-matrix capture with total-focusing method are the most promising. Data quality using laser ultrasound is not up to the standard of immersion scanning. However, once the data quality obtained with this technique is up to the standard, the total-focusing method could be applied to it. 


\section{CHAPTER 3 SAMPLE MANUFACTURING AND MECHANICAL TESTING}

This chapter is divided in two sections. First, the manufacturing process of the samples that are going to be used for the experimental part of the thesis is described. The second part present the results from the mechanical test that are perform to determine the real detriment in mechanical properties that out-of-plane wrinkles induce in the manufactured samples.

\subsection{Sample manufacturing procedure}

After presenting the different NDT methods that are used for composite blade inspection nowadays and selecting the techniques that are the most suitable for detecting wrinkles on wind turbine blades, the next step is to manufacture the parts on which the non-destructive tests will be carried out.

The manufacture of a full wind turbine blade would be too expensive and would exceed the objective of this thesis. Although the characterization of the full-scale structural response is the final output of interest, it would be impractical and unrealistic. Instead a total of five thick composite coupon samples were made. However, the layups, defect shapes and sizes of the samples were based on lay-ups, defect shapes and sizes observed at the root of actual turbine blades.

Two prepreg materials were used for the manufacture of the parts:

- epoxy resin reinforced with unidirectional (UD) carbon fibre with a nominal ply thickness of $0.6 \mathrm{~mm}$ and fibres in the $0^{\circ}$ or load direction

- epoxy resin reinforced with woven +/- 45 glass fibre with a nominal woven-ply thickness of $0.44 \mathrm{~mm}$.

Two different lay-ups are used for the experiments:

1. one woven glass ply every six plies (one glass ply followed by five carbon plies). This lay-up is used in Specimens B and C and Pristine 1.

2. all carbon fibre except the first and last plies, which were of woven glass fibre This lay-up is used in Specimen D and Pristine 2.

All the carbon plies were placed in such a way that all the carbon fibres were placed in the same direction (the load direction).

Two test samples named Pristine 2 (Figure 17) and Pristine 1 (Figure 18), one for each lay-up, were manufactured without defects (with flat plies). They are considered the 'pristine' references for the mechanical tests. 
Figure 17: Pristine 2

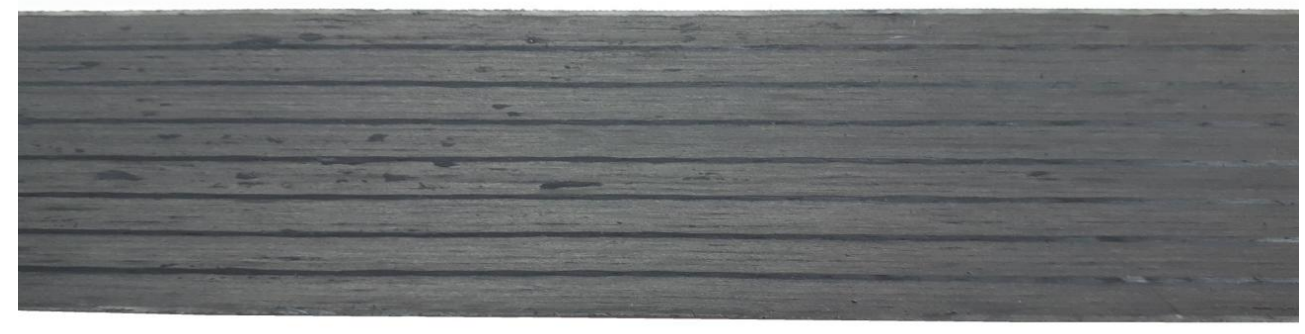

Figure 18: Pristine 1

Three test samples named B, C and D : Samples B (Figure 19), C (Figure 20) and $\mathrm{D}$ (Figure 21) were designed to have a wrinkle of cosine geometry in the middle.

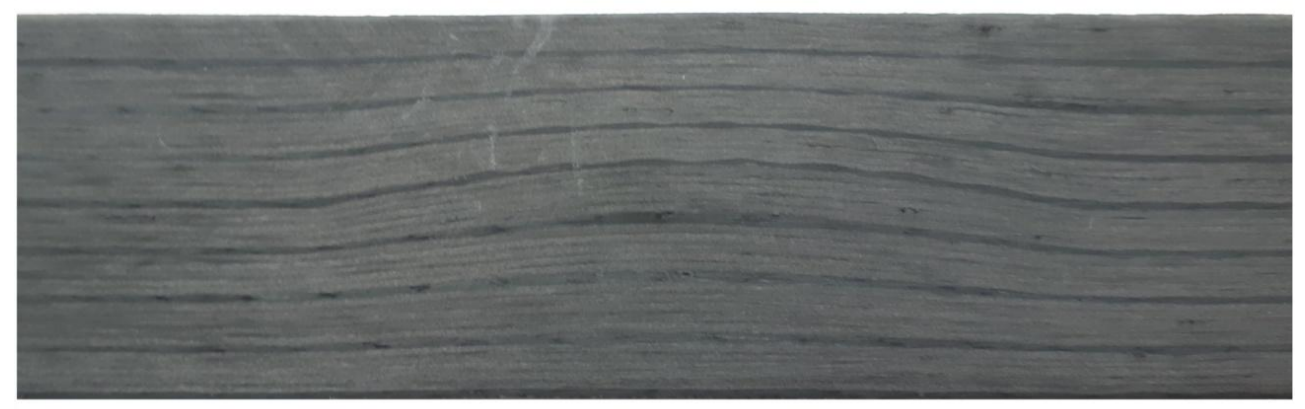

Figure 19: Sample B

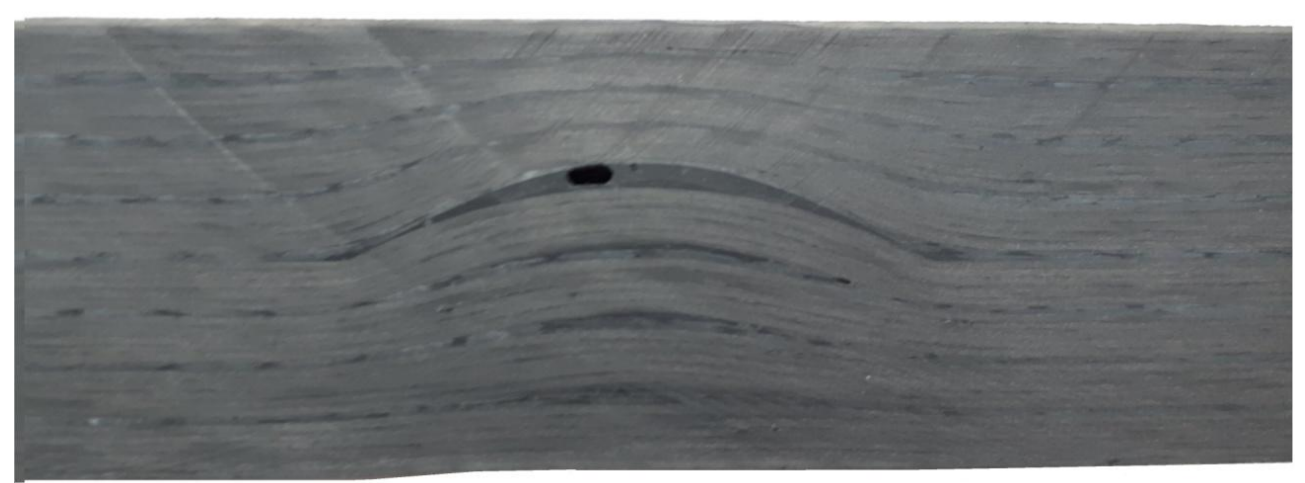

Figure 20: Sample C 


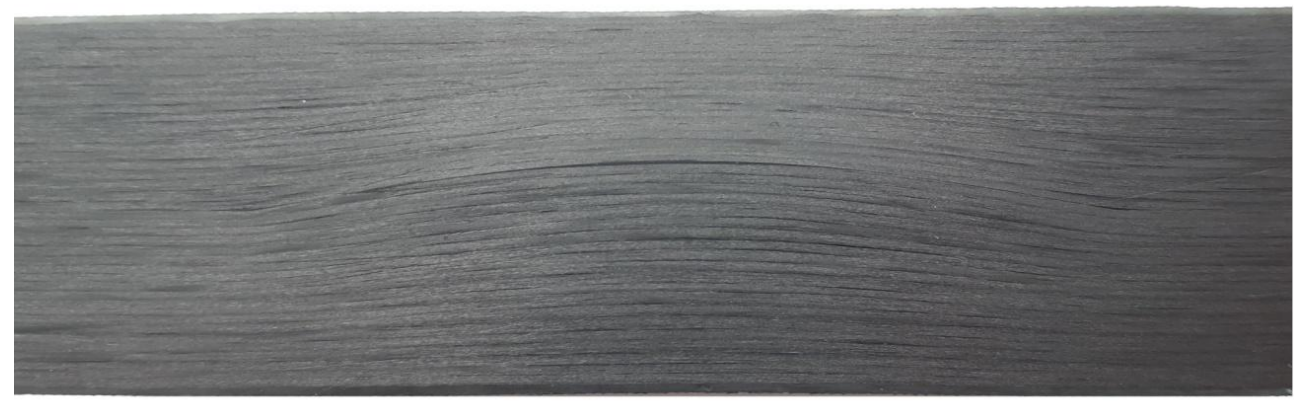

Figure 21: Sample D

In order to built a plate with out-of-plane wrinkles, two methods are considered. One is creating the wrinkle through a process of introducing tape overlaps and gaps at specific locations (Wang et al. 2012). The other is the use of a mould and a two steps curing process. Both options have pros and cons. Creating the wrinkle using tape overlaps and gaps at specific locations allows parts to be manufactured in a single step, but involves adding layers at some points thus changing the original laminate of the wind turbine blade. The use of a mould and the co-bonded process carries the risk that cavities may be formed but ensures that the wrinkle will have the same laminate and geometry as wrinkles observed on wind turbine blades. In this project priority is given to obtaining defects as faithful as possible to those that appear in the manufacturing processes of the actual wind turbine blades. For that reason, the part will be manufactured using a mould and a two step curing process.

Firstly two aluminium male tools were manufactured. Each one of them has the chosen protruding cosine wrinkle geometry. When manufacturing the parts using these moulds, it is ensured that the samples would have a middle ply with a known maximum wrinkle amplitude. The geometry of the tool is given by equation (4). $x_{\text {centre }}$ is the centre of the wrinkle, the centre of the tool and the point of the wrinkle with the highest amplitude.

$$
f(x)=\left\{\begin{array}{l}
0 \quad x<x_{\text {centre }}-\frac{L}{2} \text { and } x>x_{\text {centre }}+\frac{L}{2} \\
A *\left(1+\cos \frac{2 \pi x}{L}\right) \quad x_{\text {centre }}-\frac{L}{2}<x<x_{\text {centre }}+\frac{L}{2}
\end{array}\right.
$$

The first mould, see Figure 22, has a wrinkle maximum height of $3 \mathrm{~mm}$ and a wrinkle "severity" (A/L) of 0.030 . The second mould, see Figure 23, has a wrinkle maximum height of $6 \mathrm{~mm}$ and a wrinkle "severity" (A/L) of 0.090 . 


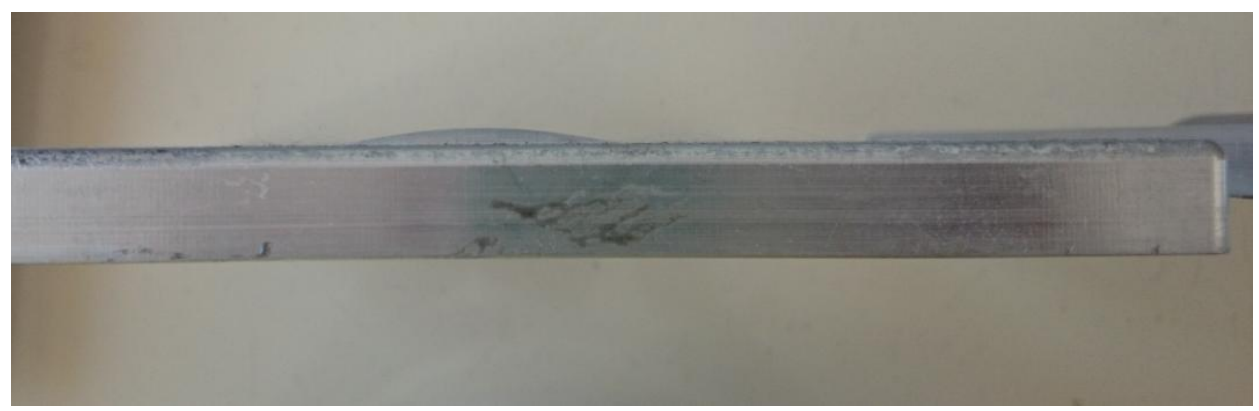

Figure 22: Aluminium male tool with a wrinkle maximum height of $3 \mathrm{~mm}$ and a wrinkle "severity" of 0.030 .

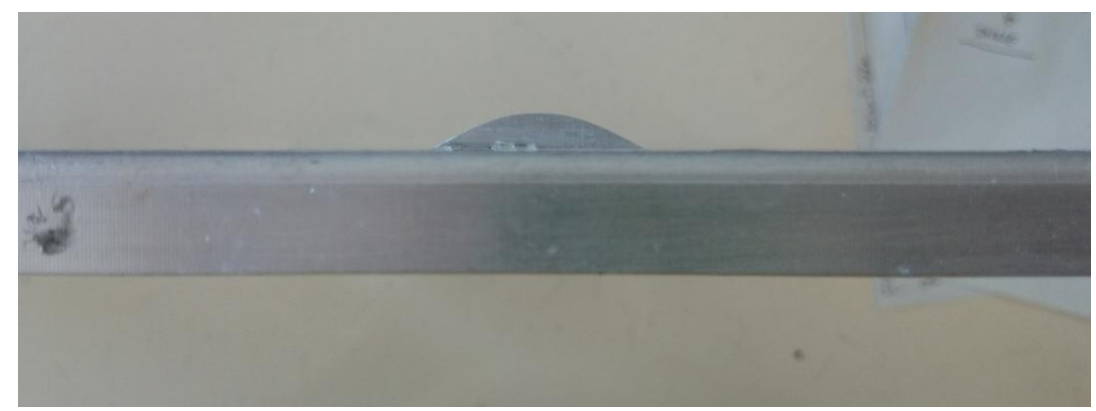

Figure 23: Aluminium male tool with a wrinkle maximum height of $6 \mathrm{~mm}$ and a wrinkle "severity" of 0.090 .

For each sample the plies were manually stacked and cured in a hot plate press (see Figure 24). For the pristine samples, the freshly cut patterns are stacked over an aluminium plate lined with non-stick film. Once the stacking is finished, the uncured piece is surrounded with cork to prevent the resin from flowing. Another aluminium plate lined with non-stick film is used to cover the laminate before putting it in the hot plate press.

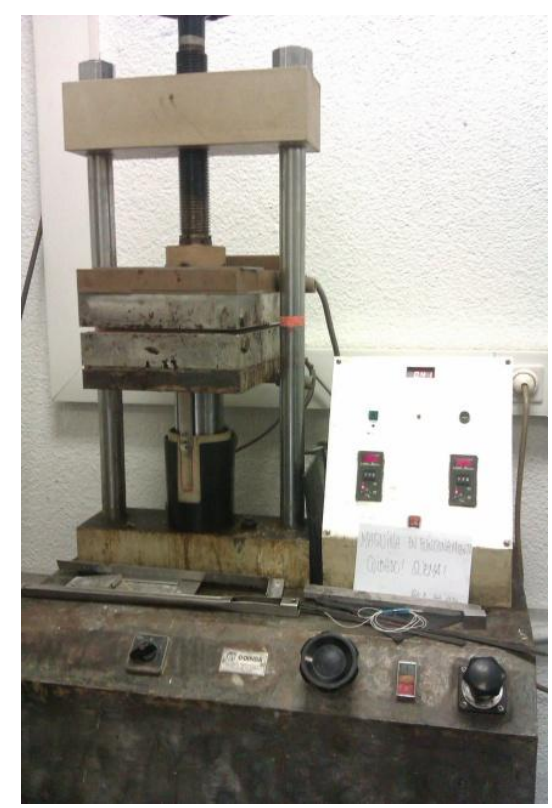

Figure 24: Hot plate press in operation 
The curing of the pieces is carried out in the hot plate press. The curing cycle is a function of the resin. Both prepreg materials that were used for the manufacture of the parts have epoxy resin. The cycle is usually imposed by the manufacturer of the prepreg tape. Two variables are controlled during the cycle: pressure and temperature.

The curing cycle (see Figure 25) used in the manufacture of all the specimens is: 30 minutes of heating to $120^{\circ} \mathrm{C}$ to homogenize the heating of the material, 60 minutes at $120{ }^{\circ} \mathrm{C}$ to allow for the extraction of volatiles, 30 minutes of heating to $180^{\circ} \mathrm{C}$ to homogenize the heating of the material and 120 minutes at $180{ }^{\circ} \mathrm{C}$ to complete the curing of the resin. The heating ramps are imposed by the hot plate press itself.

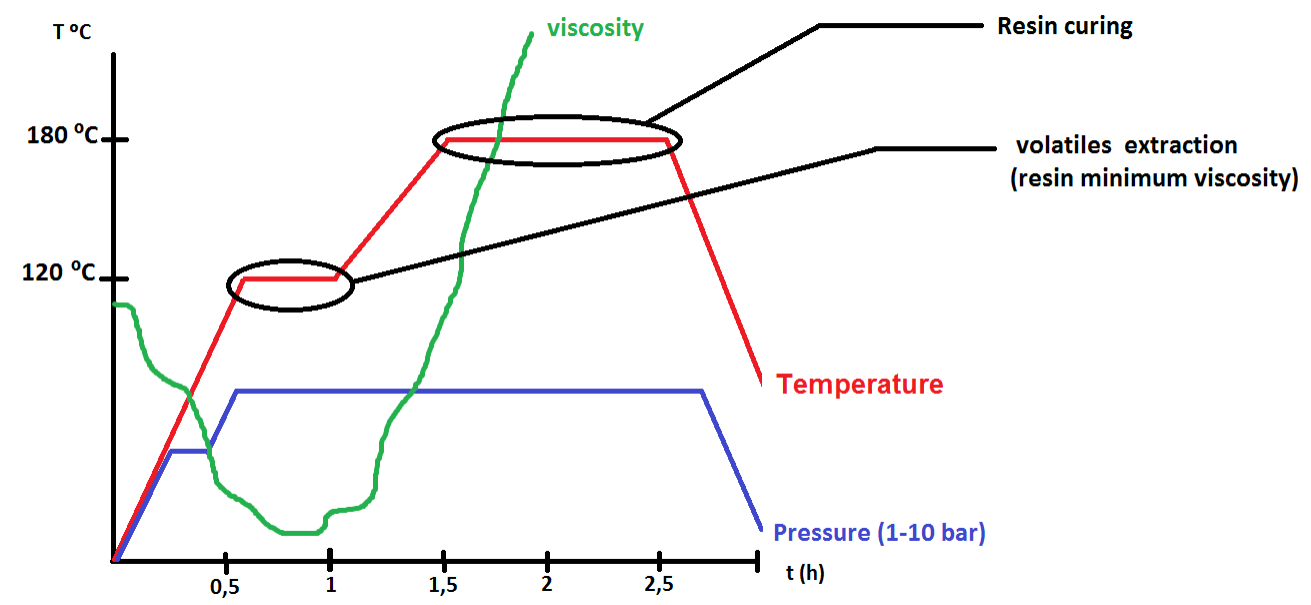

Figure 25: Curing cycle used in the manufacture of the specimens

It is important to keep in mind that the hot plate press introduces the pressure in metric tons (MT). Therefore, the pressure in bars is transformed into pressure in tons using the following expression (equation (5)):

$$
\operatorname{Mass}(M T)=\frac{\text { Pressure }(\text { bar }) * 10^{5} * \text { Sample Area }\left(m^{2}\right)}{9.8 * 10^{3} \mathrm{~N} / \mathrm{MT}}
$$

Once the curing cycle is finished, the piece cool to room temperature inside the press before proceeding to unmold. The demoulding is easily done thanks to the nonstick film. As a final step, it is necessary to cut the edges of the pieces, due to the growths that may occur during the manufacturing.

For samples B, C and D; half of the plies were manually stacked such that fibres follow the defect profile and cured in the hot plate press using the cycle described here above. During this process, the consolidation of the plies over the defect was not perfect and the severity of the wrinkle obtained in the cured part was not as great as the severity of the cosine geometry of the tool, causing a deviation from the intended shape (see Figure 26). This was caused by the stiffness of the carbon and glass fibres that made it difficult to get the pre-preg to adapt to the tool shape. 
After the first cure cycle, the aluminium tool was removed and the remaining layers were manually stacked using the cured half laminate as a tool. The intended top flat geometry is assured by the aluminium plate lined with non-stick film and the hot plate press. Figure 26 shows a diagram of the two steps of the manufacturing process. Again, it was difficult to force the pre-preg into the concave geometry and specimen $\mathrm{C}$ (the specimen with the most severe wrinkle) has a thick resin-rich layer with voids caused by the resistance of the fibres to bend - sometimes called a 'bridging' defect. The number of plies of each sample assures that the wrinkle affects the full width of the parts.
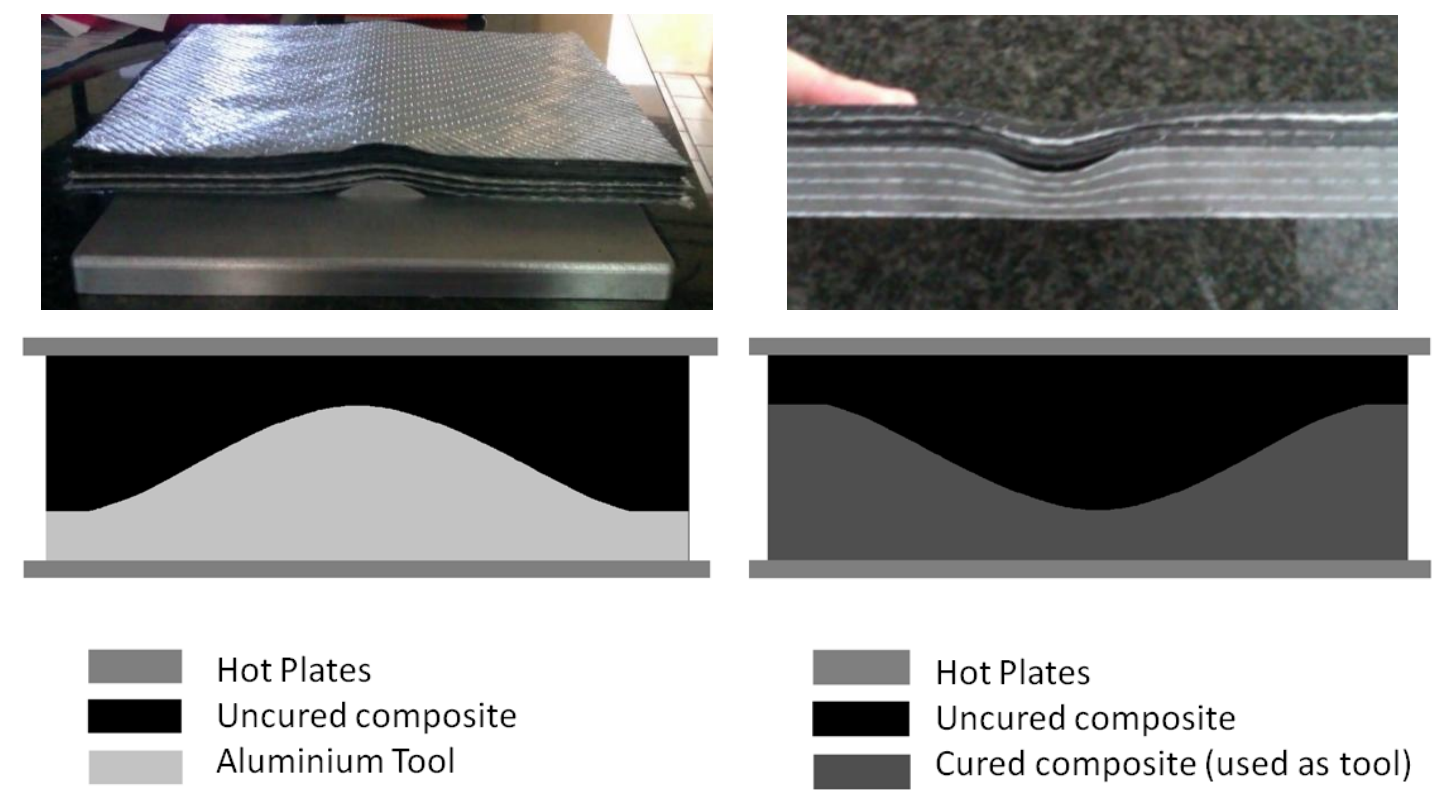

Figure 26: Diagram of the two steps of the manufacturing process (first step on the left, second step on the right). Aluminium tool used during the manufacture of the specimens with half of the plies stacked on it before curing (Top left). The effect where the layers do not conform to the geometry of the tool can be seen clearly (Top).

All the manufactured samples were measured for total thickness, wrinkle maximum height, $\mathrm{H}$, "severity", $\mathrm{A} / \mathrm{L}$ and wrinkle angle, $\theta$. The geometry of the internal out-of-plane wrinkles can be seen with the naked eye in the manufactured parts. The wrinkle angle was measured from the slope of the tangent to the curve at the point where it intersects with the imaginary in-plane line at a distance A from the flat part of the wrinkle - see Figure 4. A summary of the values measured for the panels are given in Table 2 and should be interpreted with reference to Figure 4 from chapter 1 . The nominal fibre volume fraction was not measured but $60 \%$ is considered for the nonwrinkles areas because images indicate good ply consolidation. Nominal inter-ply resinlayer thickness is considered to be $0.01 \mathrm{~mm}$. 
Table 2: Characteristics of the Test Specimens

\begin{tabular}{|c|c|c|c|c|c|}
\hline Specimen & Pristine 1 & B & C & Pristine 2 & D \\
\hline Lay-up & $\begin{array}{c}\text { 1 x glass woven, 5 x carbon UD } \\
\text { This block of 6 plies is repeated } \\
8 \text { times }\end{array}$ & \multicolumn{2}{c|}{$\begin{array}{c}\text { Carbon UD except front and } \\
\text { back in woven glass }\end{array}$} \\
\hline Thickness (mm) & 25 & 27 & 26 & 22 & 23 \\
\hline Number of Plies & 49 & 49 & 49 & 42 & 42 \\
\hline $\begin{array}{c}\text { Wrinkle Maximum } \\
\text { height H (mm) }\end{array}$ & 0 & 3 & 6 & 0 & 3 \\
\hline $\begin{array}{c}\text { Wrinkle "Severity" } \\
\text { A/L }\end{array}$ & 0 & 0.030 & 0.090 & 0 & 0.030 \\
\hline Wrinkle Angle $\theta\left(^{\circ}\right)$ & 0 & 8.5 & 24 & 0 & 8.5 \\
\hline
\end{tabular}

The lateral dimensions of the manufactured panels were $300 \mathrm{~mm} \times 300 \mathrm{~mm}$. Mechanical testing samples were cut from half of the panel, orthogonal to the wrinkles and parallel to the $0^{\circ}$ direction, such that carbon fibres ran along the loading axis. The remaining part of the panel was used for the ultrasonic experiments.

\subsection{Mechanical Testing}

Comprehensive tensile and compression tests were carried out with the purpose to determine the degradation that these particular wrinkles can cause in the mechanical properties of the material. The mechanical properties of parts $\mathrm{B}, \mathrm{C}$ and $\mathrm{D}$ will be compared with the mechanical properties of the pristine parts.

A minimum of ten coupons (five compression coupons (Figure 27) and five tensile coupons) were tested for each sample. 5 coupons of the same sample must be tested to obtain statistically representative results. Tests were conducted at room temperature $24{ }^{\circ} \mathrm{C}$ and average humidity of $55 \%$ under atmospheric pressure.

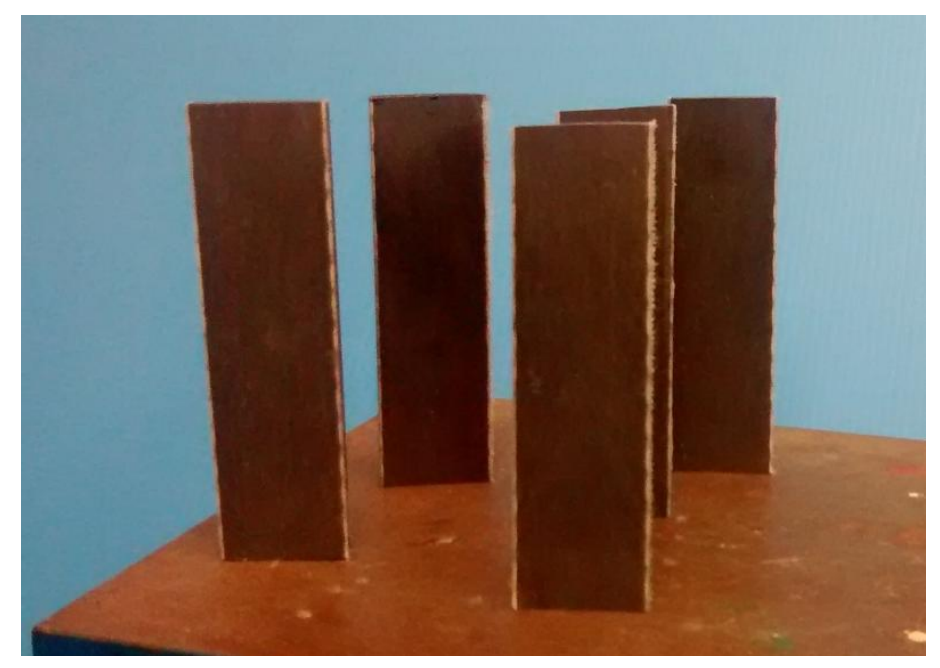

Figure 27: Five compression coupons 


\subsubsection{Tensile tests}

For the tensile properties the UNE-EN ISO $527^{7}$ standard test conditions for unidirectional composite reinforced plastics have been followed. The tests of the pristine samples were conducted according to respective standards using a testing machine MTS 810 equipped with a $100 \mathrm{k}-\mathrm{N}$ load cell and a $25 \mathrm{~mm}$ extensometer.

The coupons of samples B, C, and D were cut with the same dimensions as the coupons of the pristine samples so that the results are comparable. The dimensions of the coupons were $250 \mathrm{~mm}$ long and $4 \mathrm{~mm}$ width, except for the pristine specimens without induced wrinkling, whose nominal width was reduced by half $(2 \mathrm{~mm})$ following the recommendations given by UNE-EN ISO 527, due to the high required loads. The other dimension of the cross section was given by the thickness of the laminate, given at Table 2. The width was adjusted with a machining process. Tests were conducted at a crosshead displacement speed of $2 \pm 0.5 \mathrm{~mm} / \mathrm{min}$.

Figure 28 shows an example of a coupon of sample $\mathrm{C}$ after a tensile test. Whole results of the mechanical tensile test conducted are presented in Appendix A.

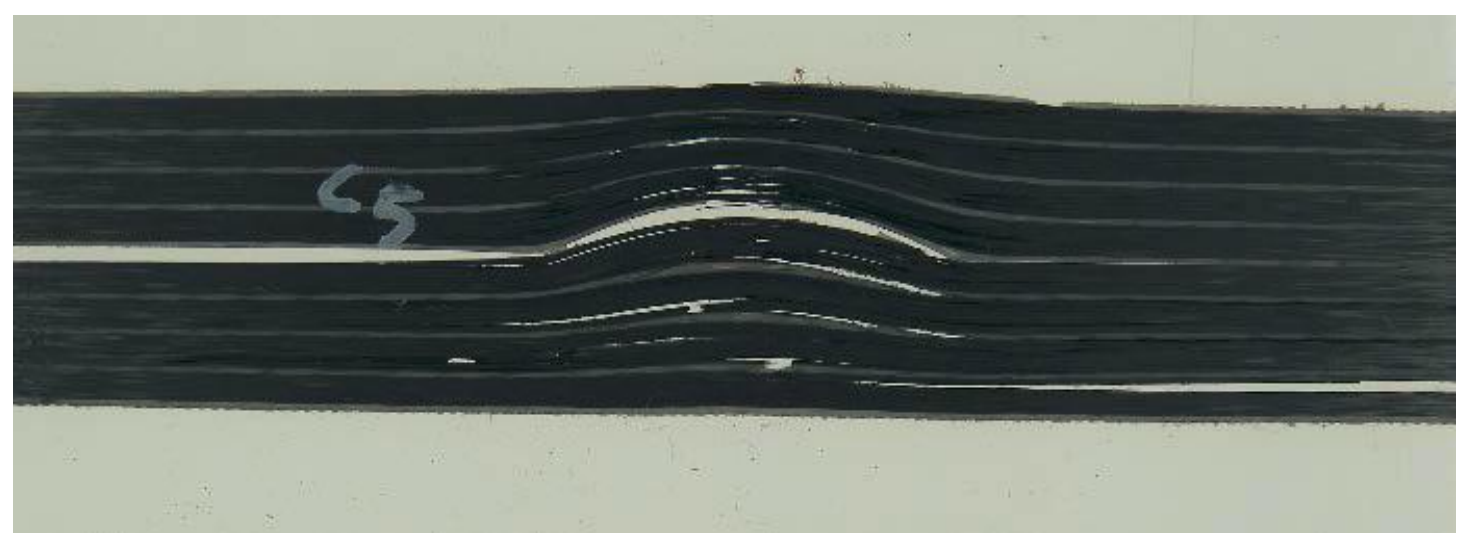

Figure 28: Sample C coupon after tensile test.

Figure 29 shows a comparative study between the five samples. As can be observed the presence of the wrinkle in the laminates degrades severely the tensile properties. The presence of the internal woven glass-layers in Pristine 1, which is the only difference between Pristine 1 and Pristine 2, degraded the tensile strength by up to $30 \%$. The woven glass layers are added in order to reduce the manufacturing costs but the blades thus manufactured meet all the mechanical requirements of the structure. The tensile strengths of specimens $\mathrm{B}$ and $\mathrm{C}$ were respectively $37 \%$ and $58 \%$ of the tensile strength of Pristine 1 . The tensile strength was approximately $63 \%$ lower in specimen D than in Pristine 2.

\footnotetext{
${ }^{7}$ AENOR: Norma UNE-EN ISO 527-5:2010. [Internet]. 2010. Available online: http://www.aenor.es/aenor/normas/normas/fichanorma.asp?tipo=N\&codigo=N0045182\#.WgCNH4ZrzaI
} 


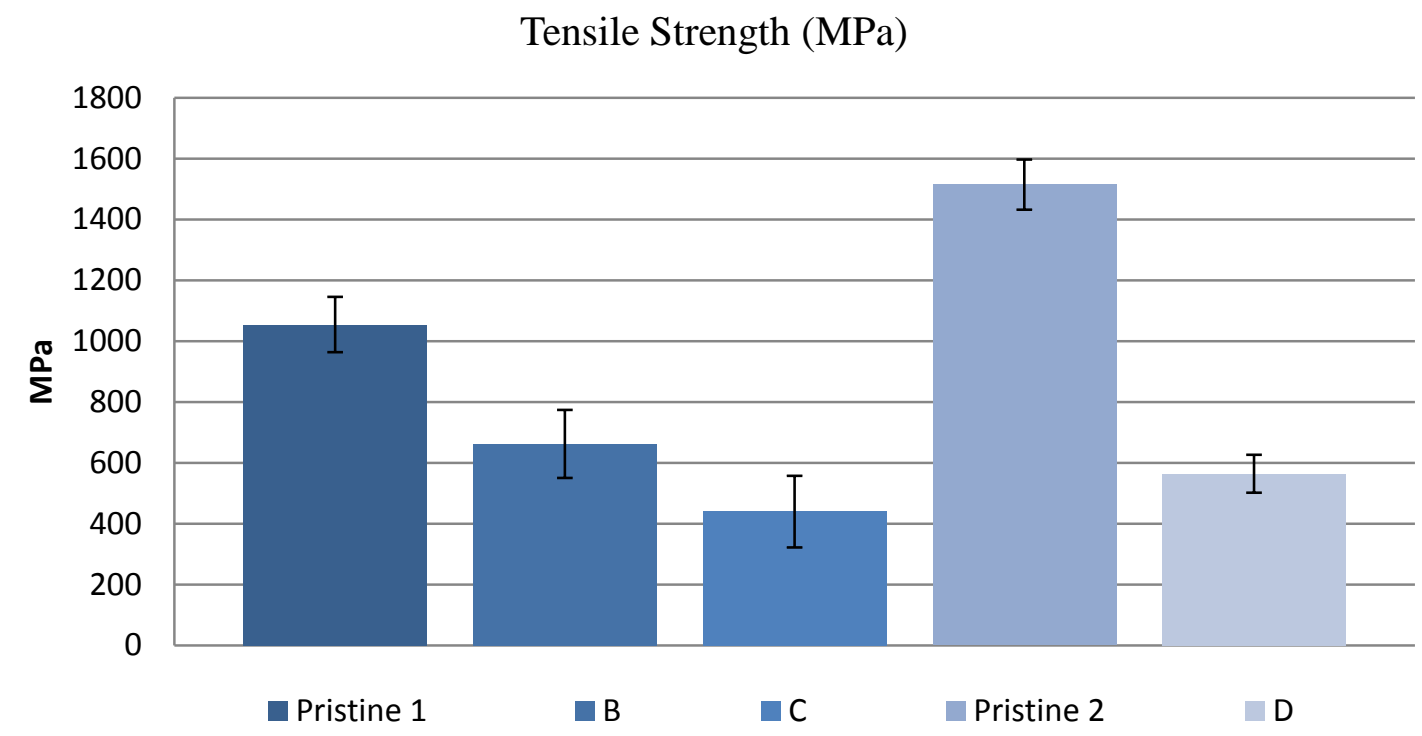

Figure 29: Tensile Strength (MPa) of samples Pristine 1, B, C, Pristine 2, and D.

\subsubsection{Compression tests}

For the compression properties, the ASTM D $695^{8}$ modified version of ISO 14126 : $1999^{9}$, was followed. This method was chosen from among the many different methods for composite material because of the configuration of the specimens. Also, the modification of the tool was done in such a way that the compression load is transmitted to the material by direct load on one of the ends, thus fulfilling the condition that the final break of the specimen takes place with a flexural deformation below $10 \%$. The tool that was used for the experiments is shown in Figure 30. The tests of the pristine samples were conducted according to respective standards using a testing machine (INSTRON 4202) equipped with a $100 \mathrm{k}-\mathrm{N}$ load cell.

The coupons of samples B, C, and D were cut with the same dimensions as the coupons of the pristine samples so that the results are comparable. The required dimensions of the specimens were $80 \mathrm{~mm}$ in length and $4 \mathrm{~mm}$ in width. The thickness of the specimen is conditioned by the thickness of the laminate. Tests were conducted at a crosshead displacement speed of $1+/-0.5 \mathrm{~mm} / \mathrm{min}$.

\footnotetext{
${ }^{8}$ ASTM D695-15 Standard Test Method for Compressive Properties of Rigid Plastics [Internet]. Available online: https://www.astm.org/Standards/D695.htm ${ }^{9}$ AENOR: Norma UNE-EN ISO 14126:1999. Available online: http://www.aenor.es/aenor/normas/normas/fichanorma.asp?tipo=N\&codigo=N0024654\#.WluUL67iY7Y
} 


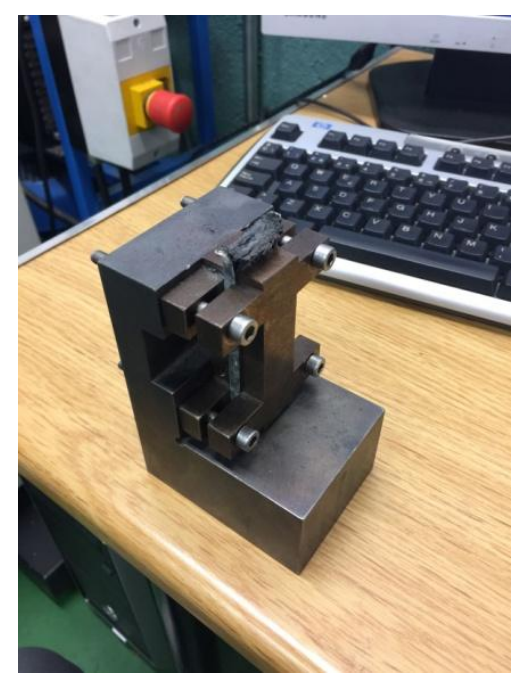

Figure 30: Compression tool type ASTM D695

Figure 31 shows an example of a coupon of sample $\mathrm{C}$ after a compression test. Whole results of the mechanical compression test conducted are presented in Appendix B.

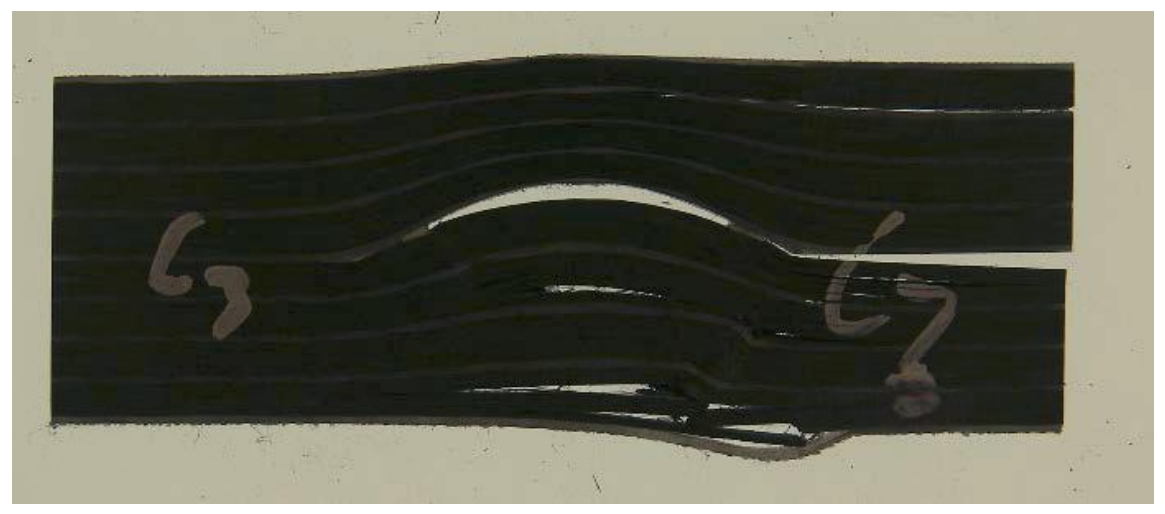

Figure 31: Sample C coupon after compression test.

Figure 32 shows a comparative study between the five samples. It should be noted that the presence of the internal woven-glass layers again adversely affect the mechanical properties (causing a 38\% decrease in compression strength). The compression strengths of specimens $\mathrm{B}$ and $\mathrm{C}$ were respectively $37 \%$ and $60 \%$ of the compression strength of Pristine 1 . The compression strength was approximately $63 \%$ lower in specimen D than in Pristine 2. Thus the wrinkle has approximately the same influence on the compression properties as the tensile properties. 


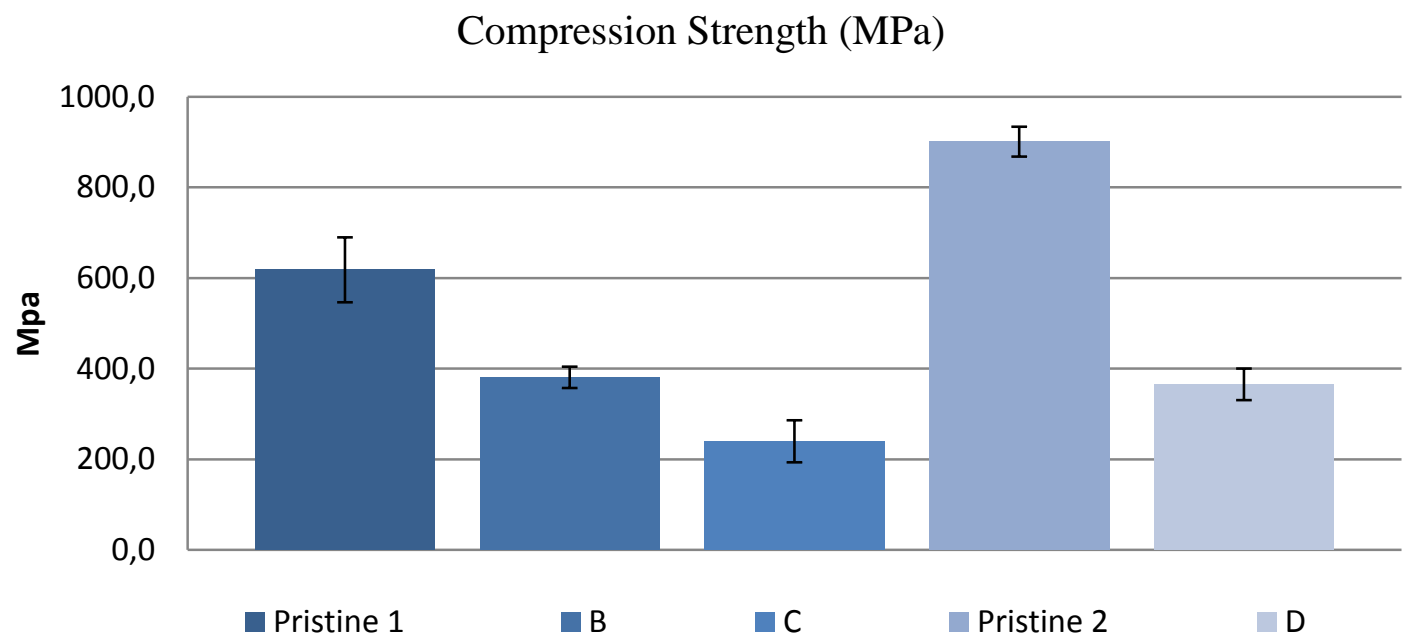

Figure 32: Strength (MPa) of samples Pristine 1, B, C Pristine 2 and D. 


\section{CHAPTER 4 EXPERIMENTAL ULTRASONIC TESTING RESULTS}

In this chapter, the results from the different experimental tests are presented. Three inspection methods were considered: an immersion test with a raster-scanned singleelement probe, commercial phase-array ultrasound technology and full-matrix capture (FMC) with reconstruction of B-scan slices using the total focusing method (TFM). Finally, the experimental results obtained from each technique are compared.

\subsection{Single element immersion scanning with a spherically focused probe.}

\subsubsection{Experimental Set-up}

The wrinkled specimens have been inspected using the ultrasonic full-waveform capture composites scanning tank of the University of Bristol. The pulse-echo technique is used in the experiments due to the type of equipment available.

A focused probe with a focal depth set at the mid-plane of the sample has been shown to be optimal for characterizing wrinkles (Nelson, Smith, and Mienczakowski 2018). A focused probe produce narrower beam that is more concentrated and therefore achieves higher sensitivity and resolution. Each single element immersion probe creates a single wavefront. The first step prior to the experiments, is to calculate the distance between the probe and front surface of the sample, so the ultrasonic beam can be focused at the mid-plane of the samples.

Every transducer produces a "natural focus" $(\mathrm{N})$ at the last axial maximum of the acoustic pressure after which the pressure drops constantly along the beam axis. (Figure 33). The natural focus is also known as near-field distance.

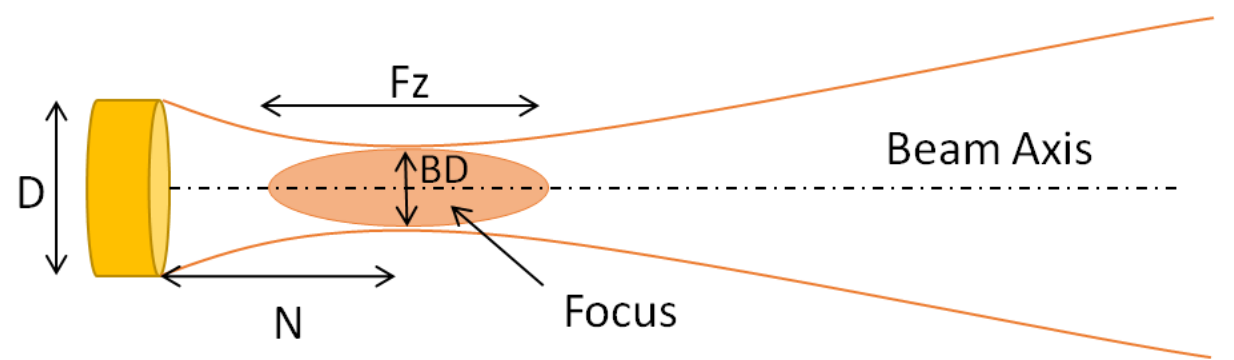

Figure 33: Diagram showing some of the parameters of the acoustic beam

For a circular plane-piston transducer $\mathrm{N}$ is calculated with equation ((6) (Krautkrämer and Krautkrämer 1969). In that equation, $\mathrm{f}$ is the frequency of the probe, $\mathrm{D}$ is the diameter of the probe and $v$ is the longitudinal wave velocity in the material. 


$$
\mathbf{N}=\frac{\mathbf{D}^{2} * \mathbf{f}}{\mathbf{4} * \mathbf{v}}
$$

The two single element immersion ultrasonic probes that are used to inspect the three manufactured samples, had spherically shaped focusing elements instead of planar elements. The spherical shape elements are purchased with a specified focal distance in water $(F)$. It is important to bear in mind that, although the radius of curvature for the probe will have a geometric focus that is the centre of the radius for the spherically shape element, this is not the same as the focal distance. The focal length of the probe will be a function of the acoustic velocity in the test medium (water for immersion probes). The ratio between the focal length $(\mathrm{F})$ and the near-field distance $(\mathrm{N})$ is known as the normalized focal length (Sf) (Equation ((7)). Since it is only possible to focus on the near field, the focal distance can never be greater than the natural focus of the material it is radiating into.

$$
S_{f}=\frac{F}{N} \quad 0 \leq S_{f} \leq 1
$$

For an ultrasound beam, the local pressure is increased at a defined region where the beam is focused. At that region, the beam spot size is reduced and thereby the effects of any interfering item that is just off-axis from the beam is reduced. Focusing of ultrasound also increases the signal to nose ratio. The focal zone (equation $((\mathbf{8})$ ) is the beamwidth at the focus of the transducer.

$$
F_{z}=N * S_{f}^{2} * \frac{2}{1+\frac{S_{f}}{2}}
$$

The Beam diamenter (BD) at the $6 \mathrm{~dB}$ drop boundary is the diameter in the acoustic field at the focus of the transducer. It can be calculate with equation $((\mathbf{9})$.

$$
B D=0.2568 * S_{f} * D
$$

The parameters of the two different probes that have been used for the experiments are resumed in Table 3 . The two frequencies $(2.25 \mathrm{MHz}$ and $5 \mathrm{MHz})$ were chosen among the available probes in accord with the simulation results that will be presented in chapter 5. The diameter of the transducers (D) and the focal length in water (F) were chosen among the available probes so the beam could be focused inside the sample.

Table 3: Characteristics of the two single element immersion ultrasonic probes

\begin{tabular}{lll}
\hline Frequency (f) & $2.25 \mathrm{MHz}$ & $5 \mathrm{MHz}$ \\
\hline Element size (D) & $9.525 \mathrm{~mm}$ & $12.7 \mathrm{~mm}$ \\
\hline Focal Length in water (F) & $25.4 \mathrm{~mm}$ & $38.1 \mathrm{~mm}$ \\
\hline Near Field Distance in water $(\mathbf{N})$ & $34.48 \mathrm{~mm}$ & $136.22 \mathrm{~mm}$ \\
\hline Normalized Focal Length (Sf) & 0.74 & 0.28 \\
\hline Focal zone (Fz) & $27.35 \mathrm{~mm}$ & $18.70 \mathrm{~mm}$ \\
\hline Beam Diameter (BD) & $1.80 \mathrm{~mm}$ & $0.91 \mathrm{~mm}$ \\
\hline
\end{tabular}


In an immersion test the ultrasonic beam is radiated in two different mediums: water and the material (in this case carbon and glass fibre). When the beam is generated in one medium and then coupled into another, the focal point and the near zone change This is illustrated in Figure 34.

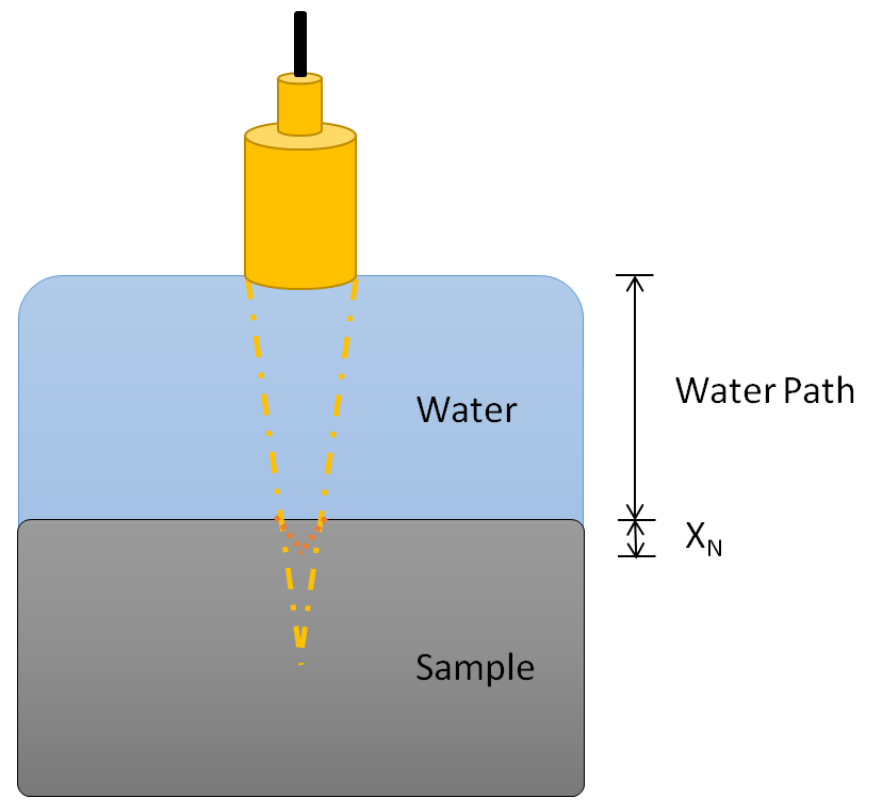

Figure 34: Beam shift in second medium

The distance of the new focal point is calculated by the ratio of the acoustic velocities of the two media. The inspection in the tank requires that the distance between the probe and the sample is the adequate for the ultrasonic beam to be focus at the chosen point inside the sample (in this case the middle of the sample). The distance between the probe and the front surface of the sample is known as the water path. It will be calculated with equation (10) (Ginzel 2009).

$$
\operatorname{Water} \operatorname{Path}(\boldsymbol{m m})=F-X_{N} * \frac{c_{\text {material }}}{c_{\text {water }}}
$$

In equation (10) $c_{\text {water }}$ and $c_{\text {material }}$ are the sound velocities in water and the material respectively, $\mathrm{F}$ is the focal length of the probe in water and $\mathrm{X}_{\mathrm{N}}$ is the distance between the front wall of the sample and the focal plane of the beam - ideally at the mid-plane of the sample. In order to calculate the water path; the sound velocity considered in the material is $3000 \mathrm{~m} / \mathrm{s}$ and the sound velocity considered in water is $1480 \mathrm{~m} / \mathrm{s}$. Table 4 shows the water-path that should be used in the experiments in order to focus the acoustic beam at the centre of the sample.

Table 4: Water path calculations

\begin{tabular}{|l|c|c|c|c|l|c|}
\hline Sample & \multicolumn{2}{|c|}{ B } & \multicolumn{2}{c|}{ C } & \multicolumn{2}{c|}{ D } \\
$\mathbf{X}_{\mathbf{N}}$ at mid-plane of sample (mm) & \multicolumn{2}{|c|}{13.5} & \multicolumn{2}{c|}{13} & \multicolumn{2}{c|}{11.5} \\
\hline Frequency (f) MHZ & 2.25 & 5 & 2.25 & 5 & 2.25 & 5 \\
\hline Water path (mm) & -2.0 & 10.7 & -1.0 & 11.7 & 2.1 & 14.8 \\
\hline
\end{tabular}


The results reveal that it is not possible to focus the $2.25 \mathrm{MHz}$ probe at the midplane of samples B and C because they are too thick and the calculated water path is negative. For sample D, the resulting water-path for the $2.25 \mathrm{MHz}$ probe is positive but too small. If sample D was inspected with a water-path of a few millimetres, the probe could collide with the part if it had small deviations in thickness. Also, such a small water-path will create multiple echoes of the front wall of the sample. The water-path should be big enough so that the multiple echo of the front wall arrives after the back wall of the sample. To illustrate this effect, sample D was inspected with the $2.25 \mathrm{MHz}$ probe with a water-path of $3 \mathrm{~mm}$. The results of that inspection are shown in Figure 35.

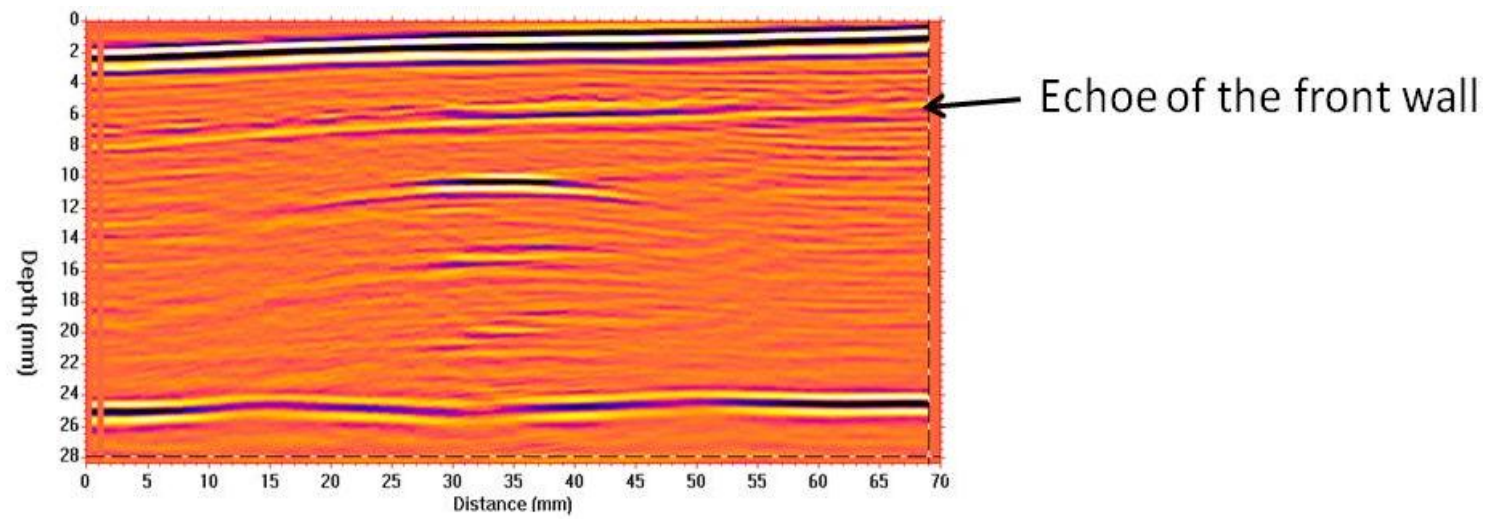

Figure 35: Reconstructed B-Scan of the full waveform at $2.25 \mathrm{MHz}$ of the specimen D with a water-path of $3 \mathrm{~mm}$. Multiple echoes from the front wall appear inside the sample.

Therefore, none of the samples can be inspected using the $2.25 \mathrm{MHz}$ probe with the focal depth set at the mid-plane of the sample. Thus, the three samples have been inspected using the $2.25 \mathrm{MHz}$ probe with the beam focused at $5 \mathrm{~mm}$ depth. The waterpath for samples B, C and D for the $2.25 \mathrm{MHz}$ probe is $15.3 \mathrm{~mm}$.

Finally, in order to calibrate the equipment, a distance-amplitude correction (DAC) curve was established for each different situation. The DAC curve allow for loss in amplitude over material depth. The DAC curve was established using two reference points from the sample itself. Also the surface of the samples has some roughness that prevent the automatic interface trigger to work, so the entire trace was recorded. This implies that the inspection files are larger and it takes longer to process them. The probe moved at a speed of $4 \mathrm{~mm} / \mathrm{s}$ during the inspections and the spatial resolution of the inspections was $0.50 \mathrm{~mm}$.

The results of the inspection with the ultrasonic full-waveform capture composites scanning tank of the University of Bristol allow the reconstruction of any B-Scan, any $\mathrm{C}$-Scan and any D-scan of the sample. The wrinkle is visible only on the B-Scans. As an example, the results from the inspection of sample $\mathrm{C}$ with the $5 \mathrm{MHz}$ probe are shown in Figure 36. 


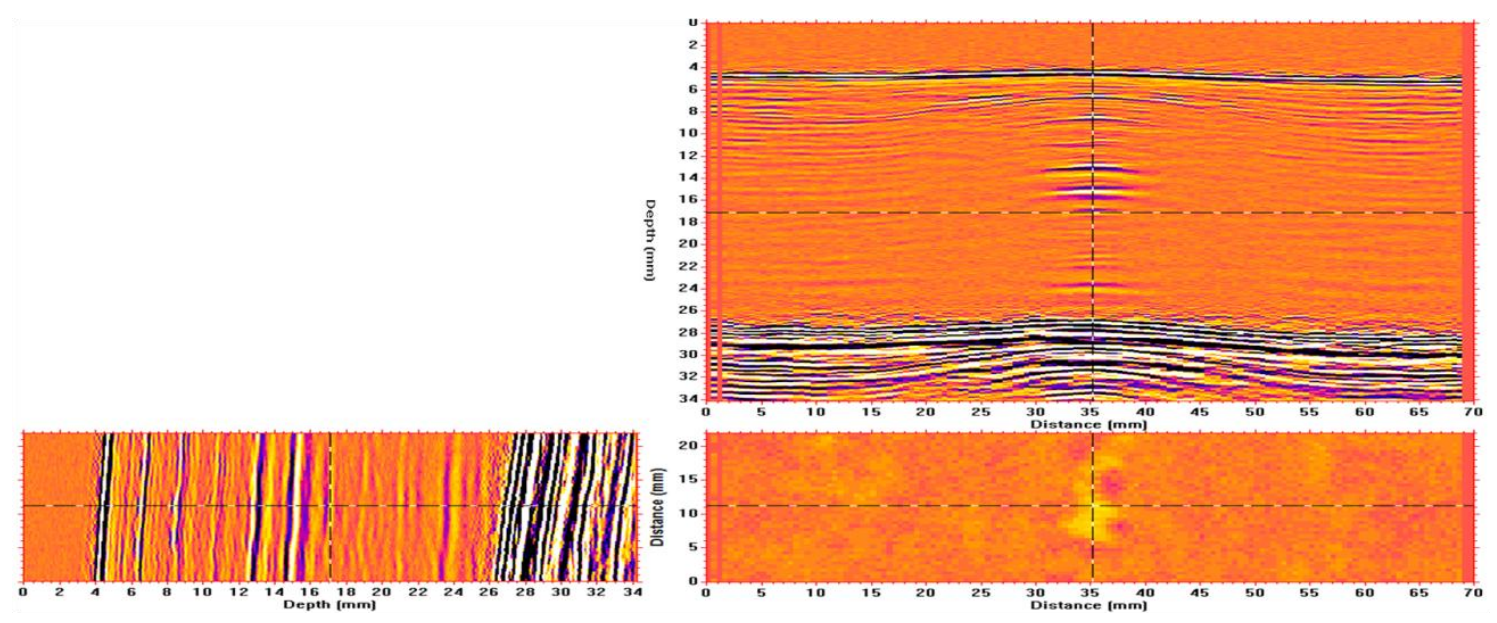

Figure 36: Full waveform inspection at 5MHz of the specimen C. B-Scan (top), D-Scan (left) and C-Scan (right down).

\subsubsection{Inspections}

The specimen B was first inspected with the $2.25 \mathrm{MHz}$ spherical probe from its convex side with the ultrasonic beam focused at $5 \mathrm{~mm}$ depth from the sample surface. (Figure 37).
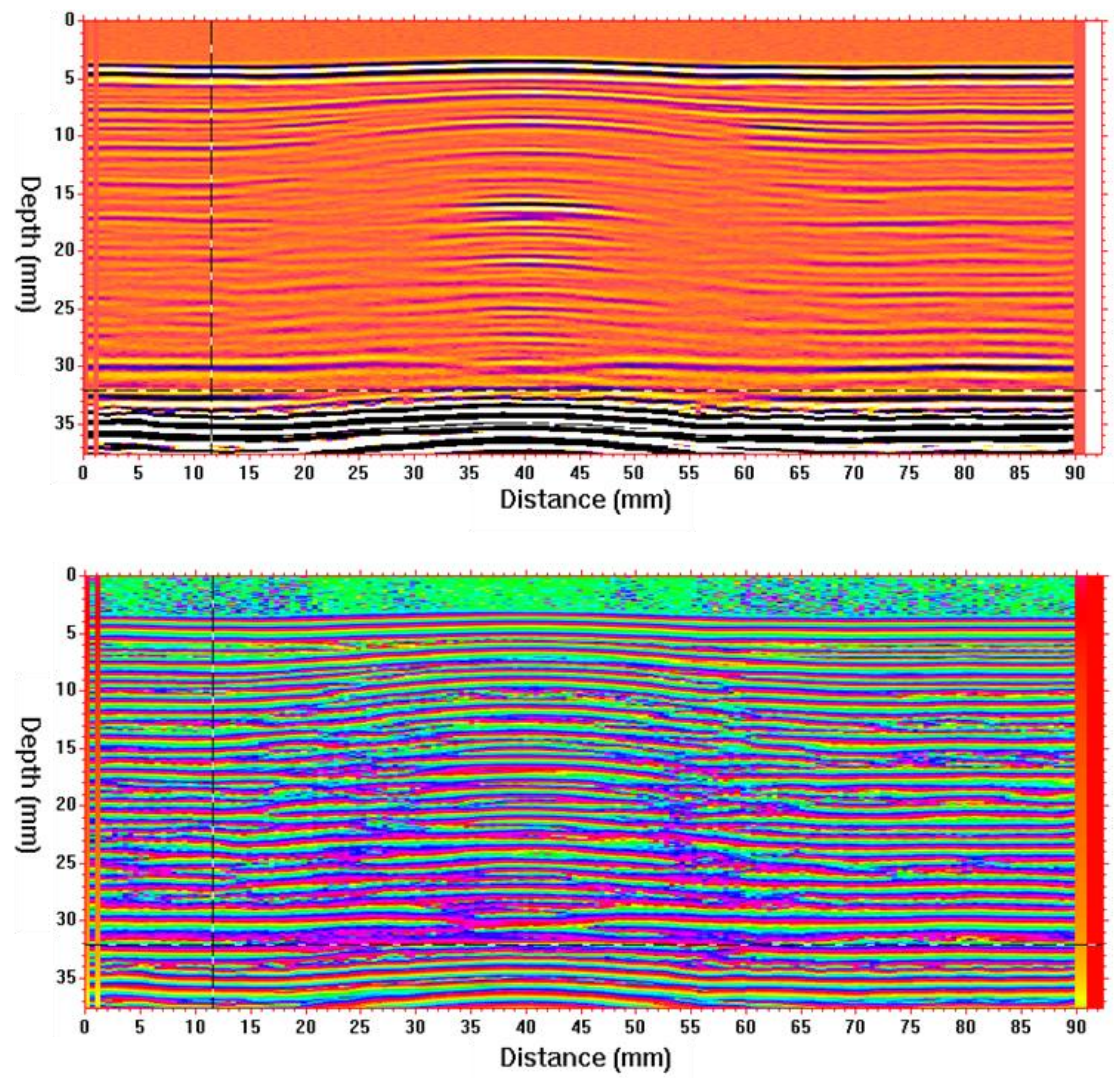

Figure 37: B-Scan of the full waveform (top) and instantaneous phase (bottom) at $2.25 \mathrm{MHz}$ of the specimen B. 
The full waveform shows some waviness and an echo appears that can be clearly identified as the back echo. However, it is in the instantaneous phase where the wrinkle can be detected and characterized. In Figure 38 the colours of Figure 37 were modify to enhance the wrinkle lines.

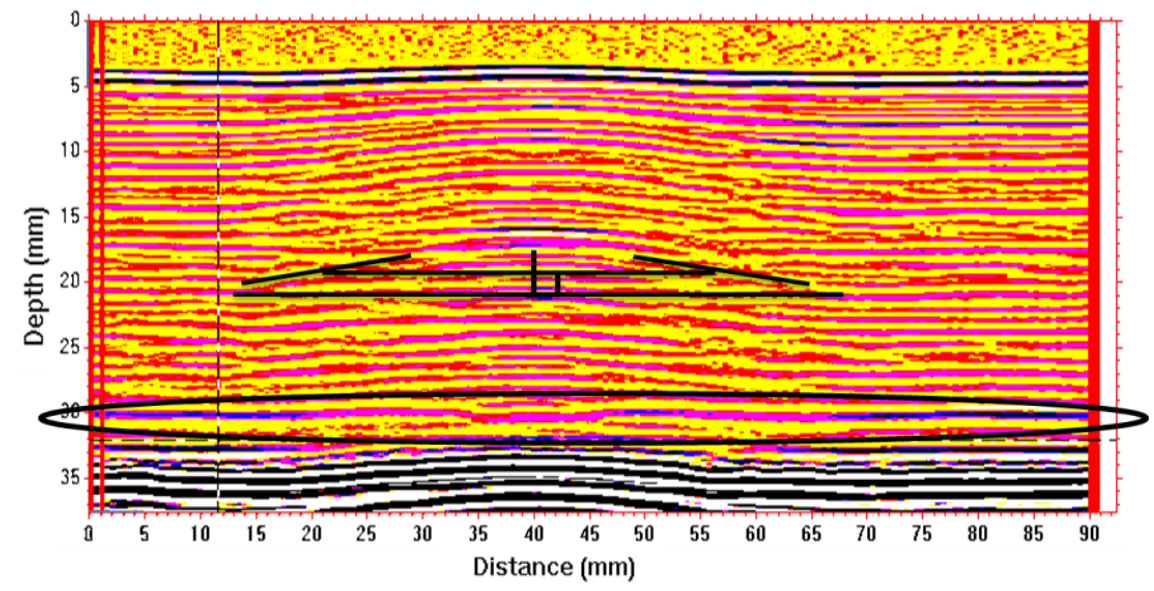

Figure 38: Back echo (black circle) and measure of the wrinkle in the specimen B with reconstructed B-Scan of the instantaneous phase.

The specimen B was then inspected with the $5 \mathrm{MHz}$ spherical probe from its convex side with the ultrasonic beam focused at the centre of the sample (Figure 39). As expected, the instantaneous phase seems to be doubling herself because the frequency has been doubled. The back echo still appears on the full waveform but the wrinkle is not measurable because even if a wrinkle is perceived, there is no a clear line to follow.
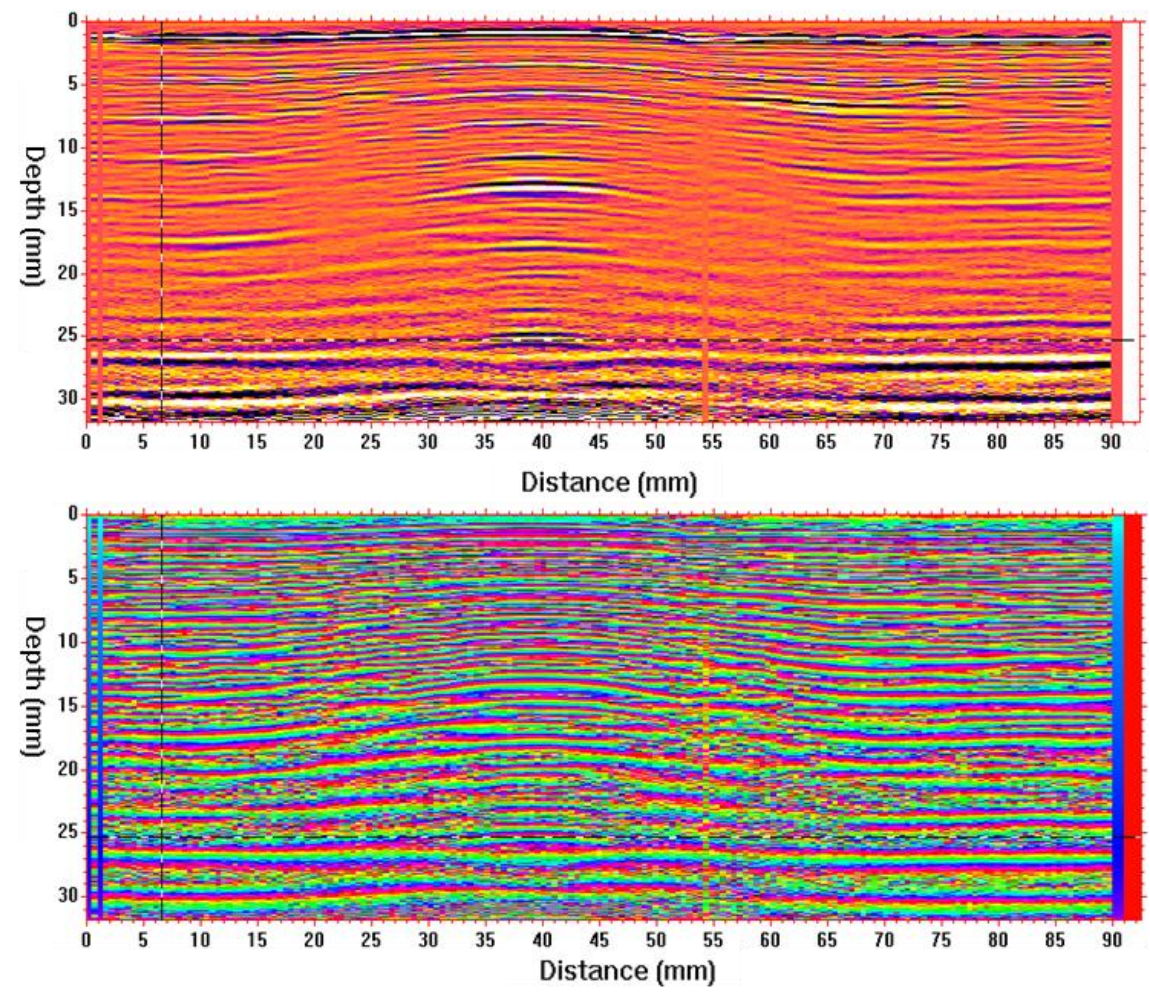

Figure 39: B-Scan of the full waveform (top) and instantaneous phase (bottom) at 5MHz of the specimen B. 
The specimen $\mathrm{C}$ was also inspected with the $2.25 \mathrm{MHz}$ spherical probe from its convex side with the ultrasonic beam focused at $5 \mathrm{~mm}$ depth from the sample surface (Figure 40).
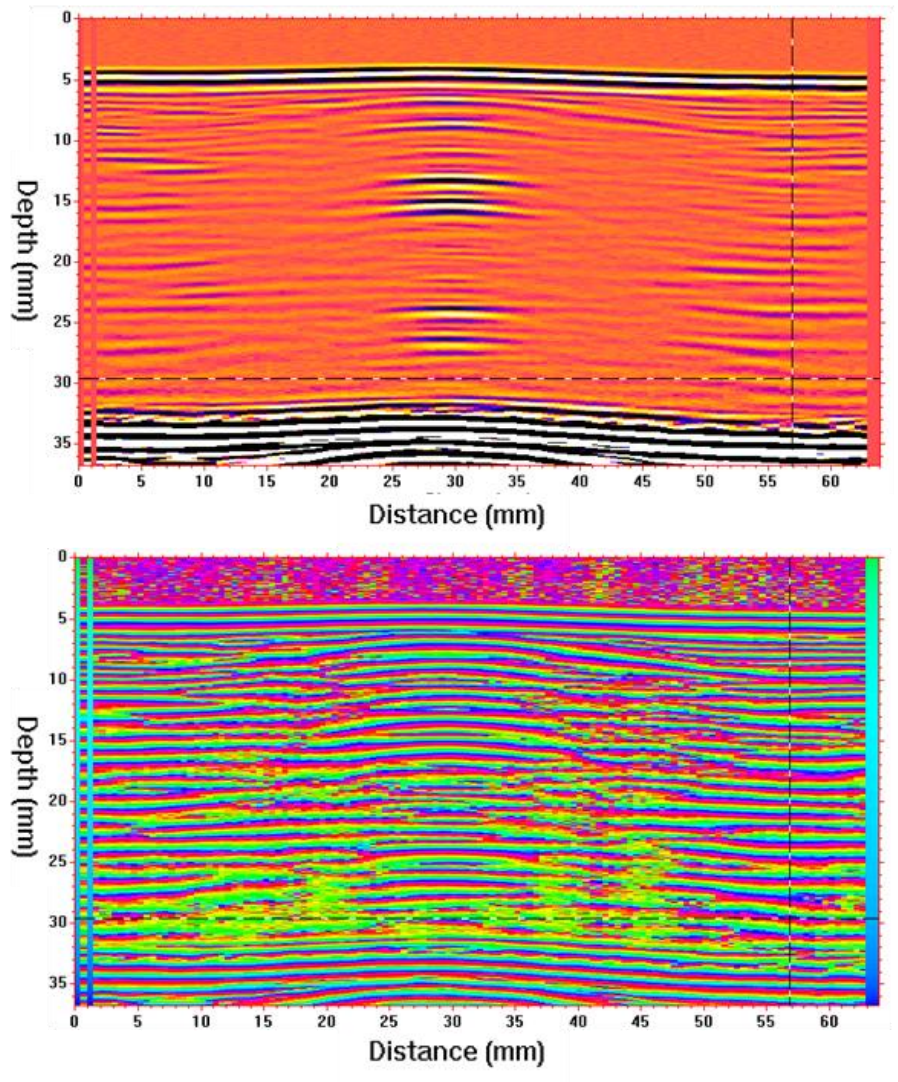

Figure 40: B-Scan of the full waveform (top) and instantaneous phase (bottom) at $2.25 \mathrm{MHz}$ of the specimen $\mathrm{C}$.

The full waveform shows some waviness but no echo appears that can be identified as the back echo. In the instantaneous phase the wrinkle can be detected and characterized. In Figure 41 the colours of Figure 40 were modified to enhance the wrinkle lines.

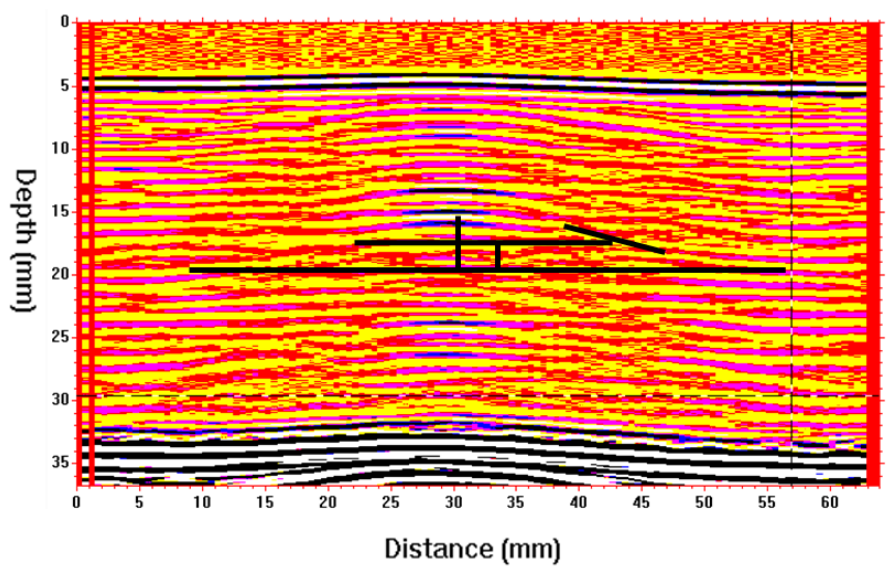

Figure 41: Measure of the wrinkle in the specimen C with the reconstructed B-Scan of the instantaneous phase. 
The specimen $\mathrm{C}$ was then inspected with the $5 \mathrm{MHz}$ spherical probe from its convex side with the ultrasonic beam focused at the centre of the sample. Again, the instantaneous phase seems to be doubling herself but the back echo is not visible and the wrinkle is not measurable because the wrinkle is barely perceived (Figure 42).
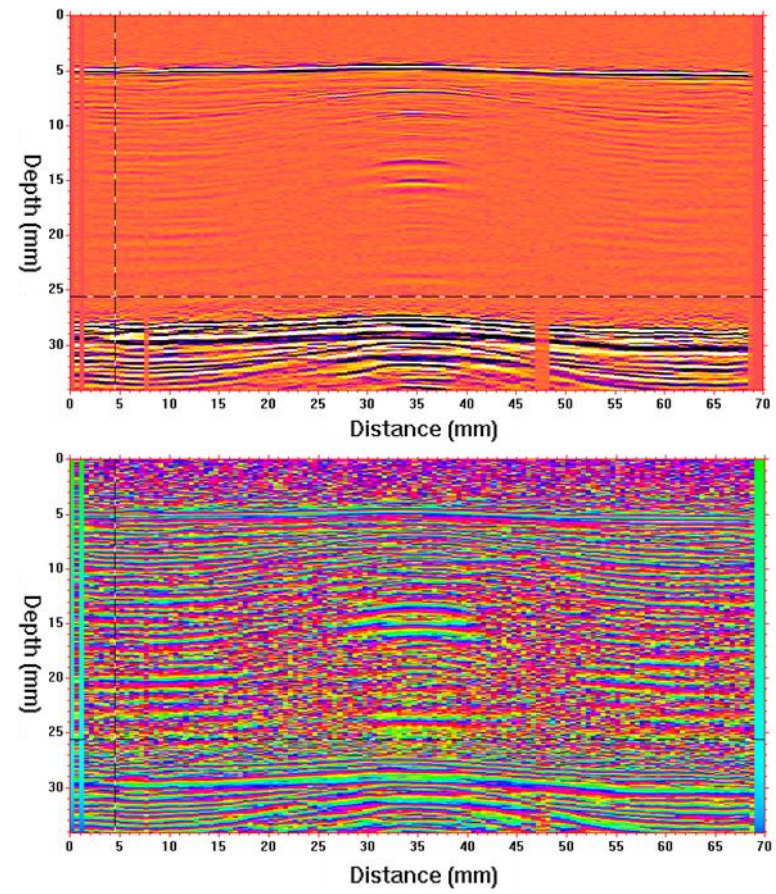

Figure 42: B-Scan of the full waveform (top) and instantaneous phase (bottom) at $5 \mathrm{MHz}$ of the specimen C.

The specimen D was inspected with the $2.25 \mathrm{MHz}$ spherical probe from its convex side with the ultrasonic beam focused at $5 \mathrm{~mm}$ depth from the sample surface (Figure 43).

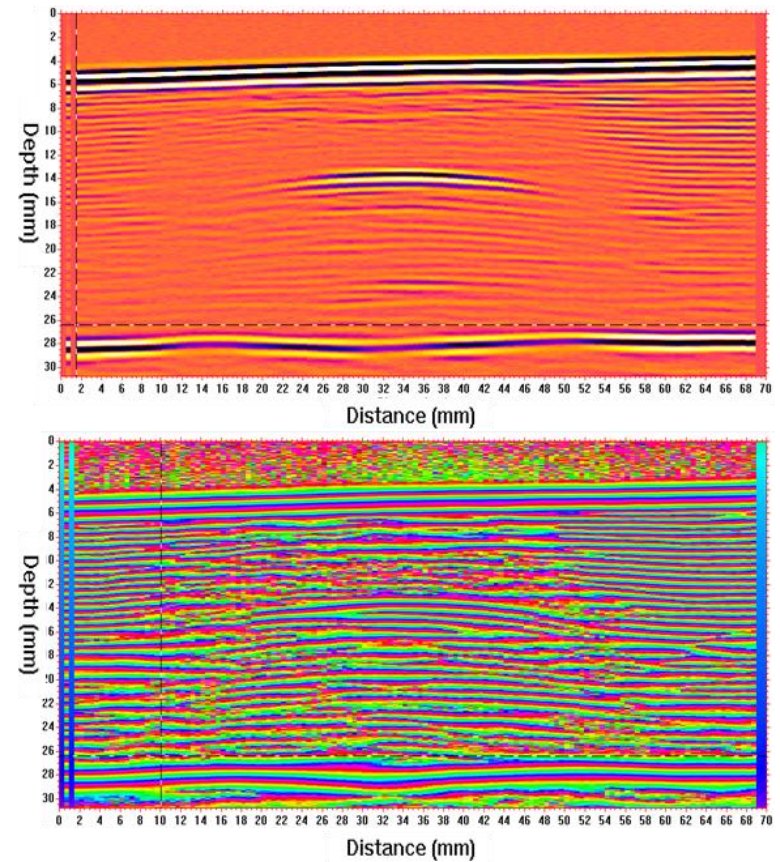

Figure 43: : B-Scan of the full waveform (top) and instantaneous phase (bottom) at $2.25 \mathrm{MHz}$ of the specimen D. 
The full waveform shows some waviness and an echo appears that can be clearly identified as the back echo. However, it is in the instantaneous phase where the wrinkle can be detected and characterized (Figure 44).

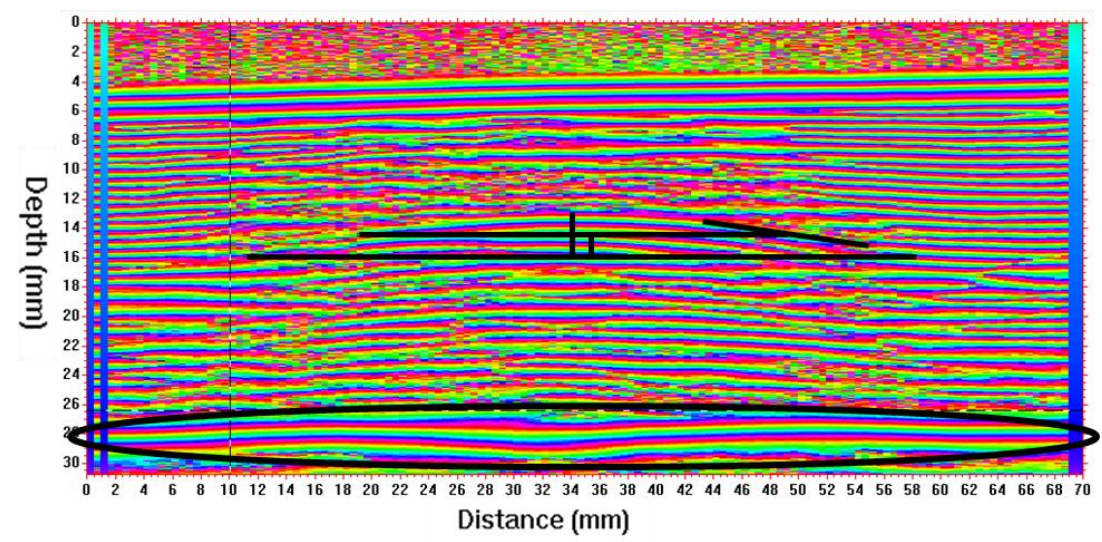

Figure 44: Back echo (black circle) and measure of the wrinkle in the specimen D with the reconstructed B-Scan of the instantaneous phase at $2.25 \mathrm{Mhz}$.

Finally, the specimen $\mathrm{D}$ was inspected with the $5 \mathrm{MHz}$ spherical probe from its convex side. with the ultrasonic beam focused at the centre of the sample (Figure 45).
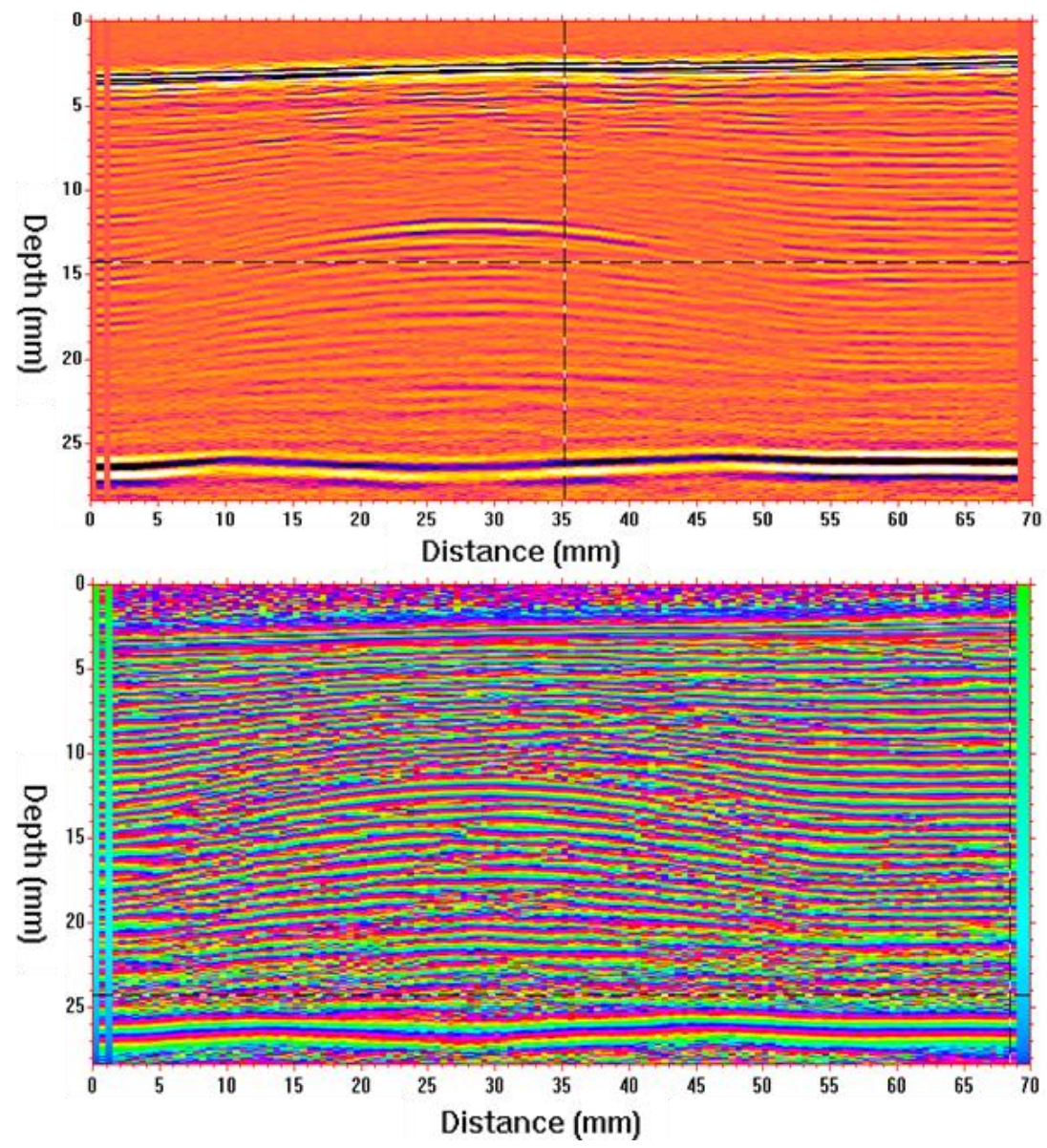

Figure 45: B-Scan of the full waveform (top) and instantaneous phase (bottom) at $5 \mathrm{MHz}$ of the specimen D. 
The full waveform shows some waviness and an echo appears that can be clearly identified as the back echo. However, it is in the instantaneous phase where the wrinkle can be detected and characterized. In Figure 46 the instantaneous phase seems to be doubling herself as expected.

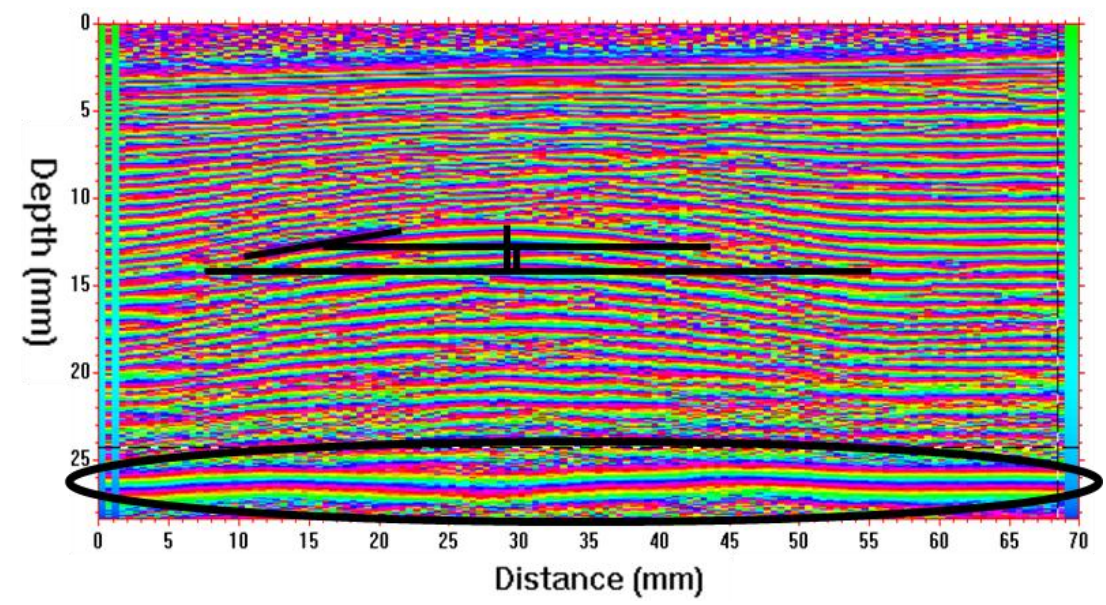

Figure 46: Back echo (black circle) and measure of the wrinkle in the specimen $\mathrm{D}$ with the reconstructed B-Scan of the instantaneous phase at $5 \mathrm{Mhz}$.

\subsubsection{Results}

The measurements of the parameters were achieved with an electronic rule or protractor on the B-Scan slices of instantaneous phase. The results are summarized in Table 5. It is necessary to use the instantaneous phase of the receive signal. When using the resonance frequency as the inspection frequency more accurate results are obtained (in this case $2.25 \mathrm{MHz}$ ).

Table 5: Comparison between the actual parameters of the parts and those obtained from the convex side of the samples by the inspection with the single-element focused probes.

\begin{tabular}{|c|c|c|c|c|c|c|}
\hline \multirow{2}{*}{\multicolumn{2}{|c|}{$\begin{array}{c}\text { Specimen } \\
\text { and wrinkle } \\
\text { parameters. }\end{array}$}} & \multirow[b]{2}{*}{ Actual } & \multicolumn{2}{|c|}{$2.25 \mathrm{MHz}$} & \multicolumn{2}{|c|}{$5 \mathrm{MHz}$} \\
\hline & & & Measured & erel & Measured & erel \\
\hline \multirow[t]{4}{*}{$\mathbf{B}$} & $\mathrm{H}(\mathrm{mm})$ & 3 & 3.1 & $3.33 \%$ & & \\
\hline & $\mathrm{L}(\mathrm{mm})$ & 53 & 55 & $3.77 \%$ & & \\
\hline & $\mathrm{A} / \mathrm{L}$ & 0.030 & 0.028 & $6.67 \%$ & & \\
\hline & $\theta$ & $8.5^{\circ}$ & $7.5^{\circ}$ & $11.76 \%$ & & \\
\hline \multirow[t]{4}{*}{$\mathrm{C}$} & $\mathrm{H}(\mathrm{mm})$ & 6 & 4.0 & $33.33 \%$ & & \\
\hline & $\mathrm{L}(\mathrm{mm})$ & 37 & 50 & $35.14 \%$ & & \\
\hline & $\mathrm{A} / \mathrm{L}$ & 0.090 & 0.040 & $55.56 \%$ & & \\
\hline & $\theta$ & $24^{\circ}$ & $14^{\circ}$ & $41.67 \%$ & & \\
\hline \multirow[t]{4}{*}{ D } & $\mathrm{H}(\mathrm{mm})$ & 3 & 2.9 & $3.33 \%$ & 2.9 & $3.33 \%$ \\
\hline & $\mathrm{L}(\mathrm{mm})$ & 53 & 48 & $9.43 \%$ & 50 & $5.66 \%$ \\
\hline & $\mathrm{A} / \mathrm{L}$ & 0.030 & 0.030 & $0.00 \%$ & 0.029 & $3.33 \%$ \\
\hline & $\theta$ & $8.5^{\circ}$ & $7.6^{\circ}$ & $10.59 \%$ & $7.6^{\circ}$ & $10.59 \%$ \\
\hline
\end{tabular}




\subsection{Commercial phased-array ultrasonic technology (PAUT)}

\subsubsection{The Experimental set-up}

The equipment used for the phased-array inspections of the wrinkle specimens was manufactured by Olympus and is comprised of:

- OmniScan MX2 with the 16:64 Phased Array Unit

- Two Phased-Array Probes and Wedges:

2.25L32-A5 probe with the SA5-OL-25MM wedge

5L64-NW1 probe with the SNW1-OL wedge (Figure 47)

- $\quad$ The MiniWheel ${ }^{\mathrm{TM}}$ encoder

- The NDT Data Access Library

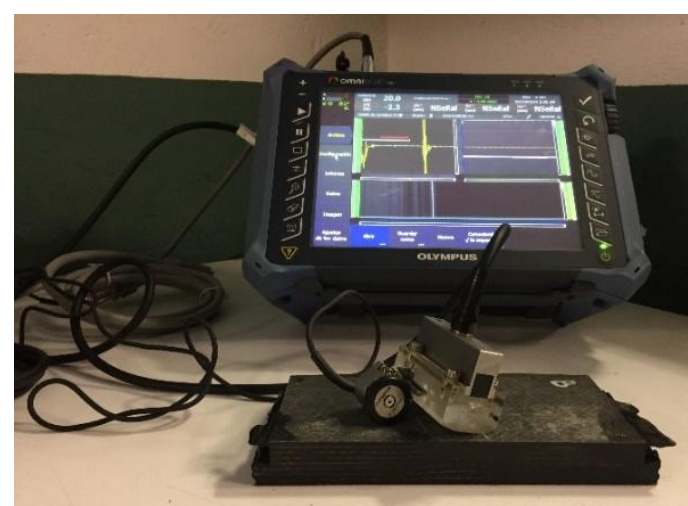

Figure 47: Phased-array inspection set-up with the 5MHz probe.

The pulse-echo technique is used in the experiments due to the type of equipment available. The wrinkled specimens have been inspected using two different phasedarray probes with rectangular elements. The two frequencies $(2.25 \mathrm{MHz}$ and $5 \mathrm{MHz})$ were chosen among the available probes in accord with the simulation results that will be presented in chapter 5 . The most relevant parameters of the probes are resumed in Table 6 and should be interpreted with reference to Figure 48.

Table 6: Characteristics of the Phased-array probes.

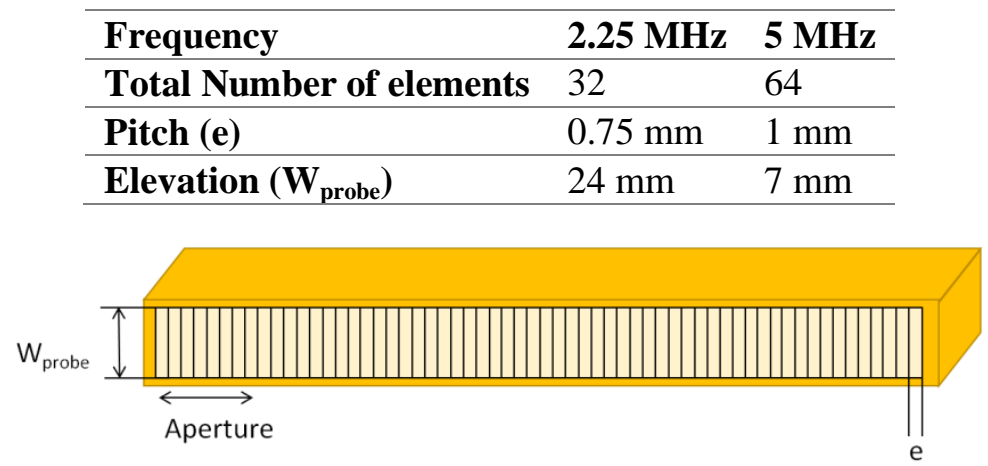

Figure 48: 1-D linear phased array probe with rectangular piezoelectric crystals. 
Phased array probes allow to focus the beam at the desired depth by changing the aperture; this is the number of elements that are pulse as a group to create a single wavefront. The first step prior to the experiments, is to calculate the aperture, so the ultrasonic beam can be focused at the mid-plane of the samples.

The phased array probes that are used on the experiments are composed by rectangular piezoelectric crystals. In those kind of probes, the near field distance for the beam can be calculated using the equation (11) for the more general condition (Krautkrämer and Krautkrämer 1969). In that equation, $f$ is the frequency of the probe, $\mathrm{S}$ is the probe Area (to a maximum of a 2:1 ratio of probe sides for a rectangular probe), $\mathrm{N}$ is the Near Field Distance and $v$ is the longitudinal wave velocity in the material.

$$
\mathbf{N}=\frac{\mathbf{S} * \mathbf{f}}{\boldsymbol{\pi} * \mathbf{v}}
$$

The element length or probe width is the elevation and is a characteristic of the probe. The aperture can be calculated using equation (12).

$$
\text { Aperture }=\frac{\mathrm{s}}{\text { Elevation }}=\text { Pitch } * \text { Number of elements }
$$

Specimen D was first inspected with the $5 \mathrm{MHz}$ probe mounted directly on the surface of the sample. During the experiments, a gel layer is placed in between the samples and the probe. This gel layer has two objectives. First, to protect the probe from direct contact with the piece that may cause scratches and damage the piezoelectric crystals: And secondly, to ensure the transmission of the ultrasonic signal to the sample. In this first approach the effect of the gel layer on the near field is dropped as the gel layer thickness is a small number compared to the probe height.

Initially, the probe was focused at $15 \mathrm{~mm}$ depth $(\mathrm{N})$, slightly below the centre of the sample. The speed of sound considered in the material in order to obtain the probe area is $3000 \mathrm{~m} / \mathrm{s}$ because sample D is mainly carbon fibre. With the $5 \mathrm{Mhz}$ probe, the required probe area is, according to equation (13), $28 \mathrm{~mm}^{2}$. Equation (13) is easily obtained from equation (11). And according to equation (12), that probe area is obtained with a $4 \mathrm{~mm}$ aperture.

$$
S=\frac{\pi * c_{\text {material }} * N}{f}
$$

The results from this inspection are shown in Figure 49. The OmniScan does not provide the instantaneous phase of the wave, so the ultrasonic signal was processed in Matlab to obtain a coarse 'instantaneous phase' which just shows whether the fullwaveform is positive (black) or negative (white) - ie black for a phase $\phi$ of $-\pi / 2<\phi<$ $\pi / 2$ and white for a phase $\pi / 2<\phi<3 \pi / 2$. The Matlab function angle was used.

Although the back-wall echo does appear on both phase and full-waveform images, the top surface of the sample is hidden in the dead zone of the probe, preventing proper characterization of the wrinkle. 

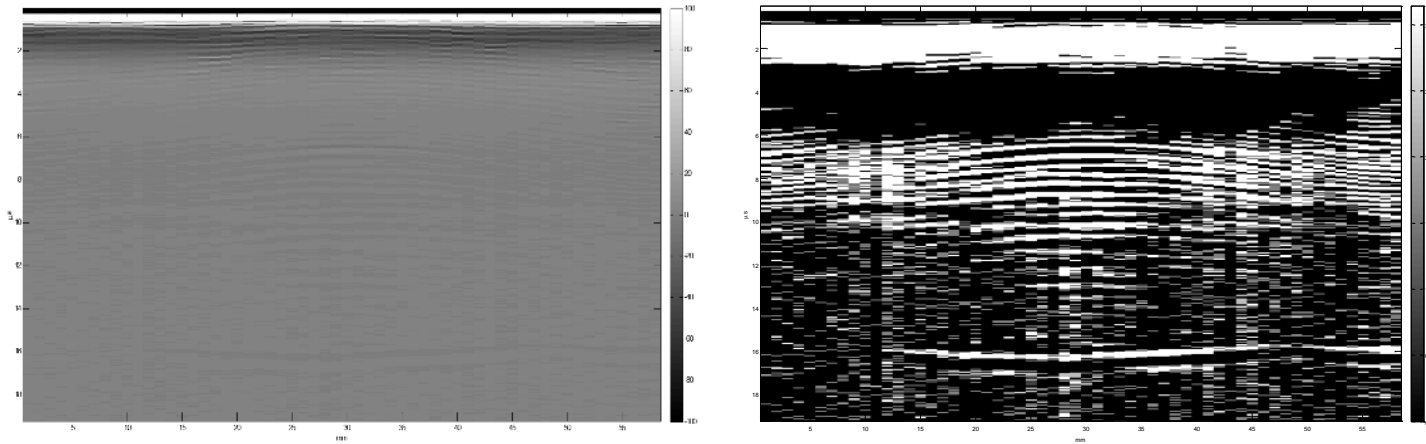

Figure 49: Reconstructed B-Scan of the Full waveform (left) and "Instantaneous Phase" (right) at $5 \mathrm{MHz}$ of the specimen $\mathrm{D}$. The near-surface dead zone of the probe is large $(9 \mathrm{~mm})$ and does not allow measurement of the wrinkle. The ultrasonic beam was focused at $15 \mathrm{~mm}$ depth.

In order to avoid the effect of the dead zone, a wedge can be placed between the probe and the sample. Using a wedge or stand-off is a common practice with ultrasonic probes in order to force the dead zone to occur before the front-surface reflection, so that it does not interfere with the echoes of the sample.

The thickness of the stand-off is a very important parameter and is governed by two criteria. The first criterion is that the time-of-flight through the stand-off must be greater than through the sample because otherwise the interface between the stand-off and the sample creates a strong multiple-reflection echo, which would be superimposed on the actual defect echoes. The second criterion is that the focal depth should be inside the sample.

The theoretical time-of-flight through the samples was calculated to check the first criterion using equation (14) and is summarize in Table 7. The speed of sound considered in the material is $3000 \mathrm{~m} / \mathrm{s}$.

$$
\text { time }- \text { of }- \text { flight }=\frac{\text { sample thickness }}{c_{\text {material }}}
$$

Table 7: Theoretical time-of-flight through the samples

\begin{tabular}{ccc}
\hline Sample & Thickness & Time-of-flight \\
\hline B & $27 \mathrm{~mm}$ & $9 \mu \mathrm{s}$ \\
\hline C & $26 \mathrm{~mm}$ & $8.7 \mu \mathrm{s}$ \\
\hline D & $23 \mathrm{~mm}$ & $7.7 \mu \mathrm{s}$ \\
\hline
\end{tabular}

To meet the criterion, the wedge high can be calculated so that the time-of-flight through the stand-off is greater than through the sample. The minimum wedge high can be calculated using equation (15). The speed of sound in the rexolite wedge is $2330 \mathrm{~m} / \mathrm{s}$.

$$
\text { wedge high }>c_{\text {wedge }} * \text { time }- \text { of }- \text { flight }_{\text {sample }}
$$

The minimum wedge high should be $21 \mathrm{~mm}, 20 \mathrm{~mm}$ and $18 \mathrm{~mm}$ for samples $\mathrm{B}, \mathrm{C}$ and $\mathrm{D}$ respectively to meet the first criterion. 
The second criterion marks the maximum height of the wedge. To meet that criterion, the wedge high can be calculated so that the beam is focused at the bottom of the sample. Focusing can only occur for points along the soundpath that are less than the near zone distance. However, when the probes are used upon a wedge a change in the soundpath occurs and the ultrasonic beam can only be focused in the 'equivalent' near-field of the ultrasonic beam. The maximum focus distance will shift closer to the probe (Figure 50) and can be estimated using equation (16) (Ginzel 2009). In that equation, $h$ wedge is the wedge high, $X_{N}$ is the path length inside the sample to focus, $c_{\text {wedge }}$ and $c_{\text {material }}$ are the sound velocities in the wedge and the material respectively, $\mathrm{f}$ is the frequency of the probe and $\mathrm{S}$ is the probe Area.

$$
X_{N}=\frac{S * f}{\pi * c_{\text {sample }}}-h_{\text {wedge }} * \frac{c_{\text {wedge }}}{c_{\text {sample }}}
$$

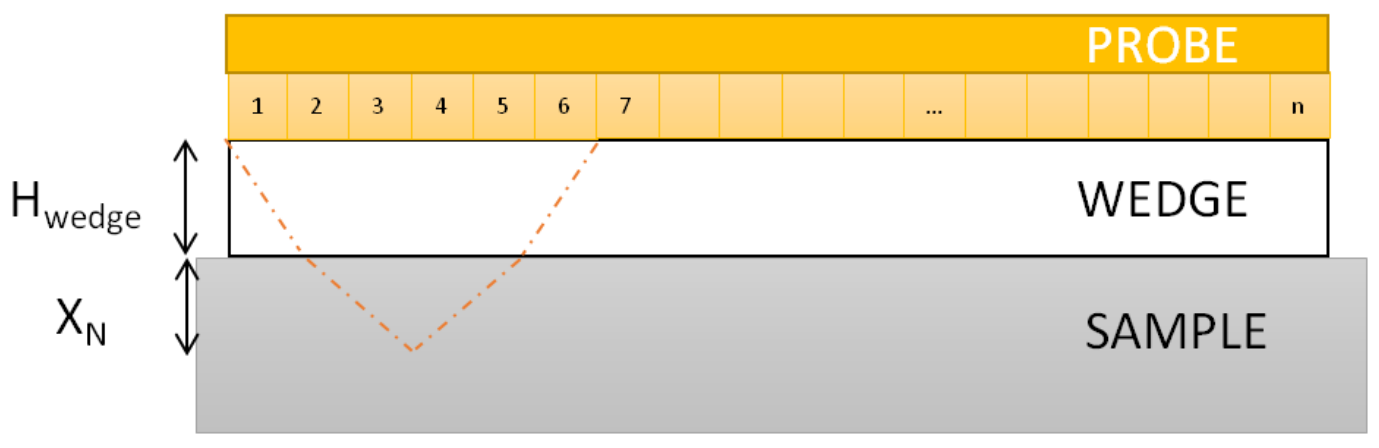

Figure 50: Near Field Shift in Wedge

The maximum near field distance is obtained without the wedge and with the maximum probe area. For the $2.25 \mathrm{MHz}$ probe, the maximum aperture could be $24 \mathrm{~mm}$ because it has 32 elements with a pitch of $0.75 \mathrm{~mm}$. However, the maximum number of elements that can be grouped together is 16 with the available equipment. The maximum probe area is therefore $288 \mathrm{~mm}^{2}$ which is obtained with a $12 \mathrm{~mm}$ aperture. For the $5 \mathrm{MHz}$ probe, the maximum elevation is $14 \mathrm{~mm}$ according to the $2: 1$ ratio of probe sides criterion. The maximum probe area is therefore $98 \mathrm{~mm}^{2}$. The maximum probe area is calculated according to equation (12). The maximum near field distance (without a stand-off) for the $2.25 \mathrm{MHz}$ probe is $69 \mathrm{~mm}$ and for the $5 \mathrm{MHz}$ is $52 \mathrm{~mm}$ according to equation (11). These calculations are summarized in Table 8 for clarity.

Table 8: Characteristics of the Phased-array beams

\begin{tabular}{ccccc}
\hline Frequency Probe & Elevation $\left(\mathbf{W}_{\text {probe }}\right)$ & Maximum Aperture & $\mathbf{S}_{\max }$ & $\mathbf{X}_{\mathbf{N m a x}}$ \\
\hline $\mathbf{2 . 2 5} \mathbf{M H z}$ & $24 \mathrm{~mm}$ & $12 \mathrm{~mm}$ & $288 \mathrm{~mm}^{2}$ & $69 \mathrm{~mm}$ \\
\hline $\mathbf{5 ~ M H z}$ & $7 \mathrm{~mm}$ & $14 \mathrm{~mm}$ & $98 \mathrm{~mm}^{2}$ & $52 \mathrm{~mm}$ \\
\hline
\end{tabular}

The maximum height of the wedge is obtained from equation (16) with the maximum probe area, and the beam focused at the bottom of the sample $\left(X_{N}=30 \mathrm{~mm}\right.$ was considered for the maximum height calculation to cover all the samples). The maximum wedge high should be $50 \mathrm{~mm}$ for the $2.25 \mathrm{MHz}$ probe and $28 \mathrm{~mm}$ for the 5 MHz probe. 
A $20 \mathrm{~mm}$ thick Rexolite wedge was used with the $5 \mathrm{MHz}$ probe which does not meet the first criterion for specimen $\mathrm{B}$ and $\mathrm{C}$, but does meet the second. Therefore, in the inspection of samples $\mathrm{B}$ and $\mathrm{C}$, the second multiple echo from the stand-off will appears at the same depth that the back-wall echo. A $25 \mathrm{~mm}$ thick Rexolite wedge was used with the $2.25 \mathrm{MHz}$ probe which meet both criteria.

In the experiments, the phased-array beam will be focus near the bottom of the sample $\left(\mathrm{X}_{\mathrm{N}}=30 \mathrm{~mm}\right.$ depth$)$. The probe area $(\mathrm{S})$ can be calculated using equation (16) and as a result the aperture can be calculated for each experiment using equation (12). The acoustic beam that is created by a phased-array probe is show in Figure 51.

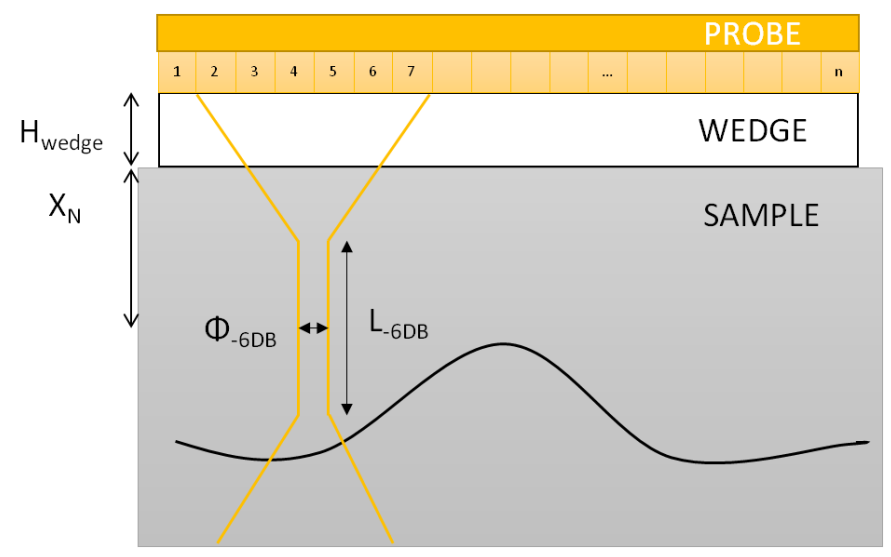

Figure 51: Phased array acoustic beam

The Beam diameter at the $6 \mathrm{~dB}$ drop boundary $\left(\Phi_{-6 \mathrm{BD}}\right)$ in this case can be calculate with equation (17). $\lambda_{\text {wedge }}$ is the wavelength in the wedge. $\lambda_{\text {wedge }}$ is $1.036 \mathrm{~mm}$ for the $2.25 \mathrm{MHz}$ probe and $0.466 \mathrm{~mm}$ for the $5 \mathrm{MHz}$ probe.

$$
\Phi_{-6 D B}=\frac{\left(H_{\text {wedge }}+X_{N} * \frac{c_{\text {sample }}}{c_{\text {wedge }}}\right) * \lambda_{\text {wedge }}}{\text { Aperture }}
$$

The focal zone $\left(\mathrm{L}_{-6 \mathrm{BD}}\right)$ in this case can be calculate with equation $(\mathbf{1 8})$.

$$
L_{-6 D B}=7 * \frac{c_{\text {wedge }}}{c_{\text {sample }}} * \lambda_{\text {wedge }} *\left(\frac{H_{\text {wedge }}+X_{N} * \frac{c_{\text {sample }}}{c_{\text {wedge }}}}{\text { Aperture }}\right)^{2}
$$

The inspection parameters that are used for the inspection are summarized in Table 9.

Table 9: Phased-array inspection Parameters

\begin{tabular}{cccccc}
\hline Frequency Probe & Elevation $\left(\mathbf{W}_{\text {probe }}\right)$ & Aperture & h wedge & $\mathbf{\Phi}_{-\mathbf{6} \boldsymbol{D} \boldsymbol{B}}$ & $\mathbf{L}_{-6 \mathrm{BD}}$ \\
\hline $\mathbf{2 . 2 5} \mathbf{M H z}$ & $24 \mathrm{~mm}$ & $9 \mathrm{~mm}$ & $25 \mathrm{~mm}$ & $7.3 \mathrm{~mm}$ & $281 \mathrm{~mm}$ \\
\hline $\mathbf{5} \mathbf{M H z}$ & $7 \mathrm{~mm}$ & $13 \mathrm{~mm}$ & $20 \mathrm{~mm}$ & $3.0 \mathrm{~mm}$ & $51 \mathrm{~mm}$ \\
\hline
\end{tabular}


Finally, in order to calibrate the equipment, a distance-amplitude correction DAC curve was established. The DAC curve allow for loss in amplitude over material depth. A single DAC curve was established for all the experiments using two calibration stairs (Figure 52). One of the stairs has known internal defects and the other does not. The stairs were manufactured using the same carbon fibre pre-preg as the samples. Although the speed of sound in the samples is not be same as in the stairs, due to the internal glass layers; it is still considered a good enough approximation. The probe was moved manually during the inspections and the position was captured by the encoder. The spatial resolution of the inspections was $0.20 \mathrm{~mm}$.

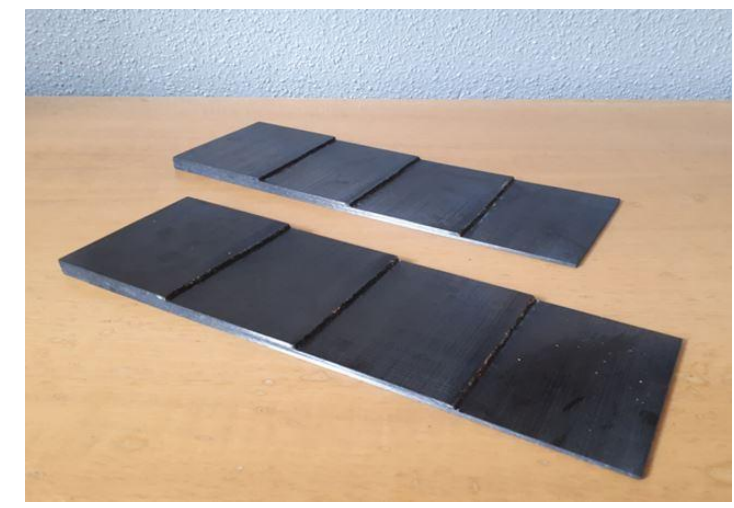

Figure 52: Calibration stairs

\subsubsection{Inspections}

The three specimens were inspected with the $2.25 \mathrm{MHz}$ probe (Figure 53, Figure 55 and Figure 57) and with the $5 \mathrm{MHz}$ probe (Figure 54, Figure 56 and Figure 58) from its convex side mounted on the wedge.

The full-waveform can be visualized in the OmniScan Screen. The acquired data was then retrieve with the NDT Data Access Library and the instantaneous phase of the signal was calculate using Matlab. (ie black for a phase $\phi$ of $-\pi / 2<\phi<\pi / 2$ and white for a phase $\pi / 2<\phi<3 \pi / 2$ ). The instantaneous phase provides a clearer image of the layers inside the composite and therefore the wrinkle.

For specimen $\mathrm{B}$ the back wall echo is expected at $18 \mu \mathrm{s}$, for specimen $\mathrm{C}$ the back wall echo is expected at $17.4 \mu \mathrm{s}$ and for specimen $\mathrm{D}$ the back wall echo is expected at $15.4 \mu \mathrm{s}$. The wedge echo is expected for the $25 \mathrm{~mm}$ high wedge at $21.5 \mu \mathrm{s}$ and for the $20 \mathrm{~mm}$ high wedge at $17.2 \mu \mathrm{s}$. At this point, it is important to remember that the time at which a return echo is expected; is the time it takes the beam to travel through the piece to the discontinuity plus the time it takes the beam to return to the probe. In the following images, the back-wall echo (marked 'B') should not be mistaken for the echo from the wedge (marked ' 2 '), which appears just after the back-wall echo and dominates in the full waveform image. In the images, it also appears a weak echo (marked ' 1 '). 

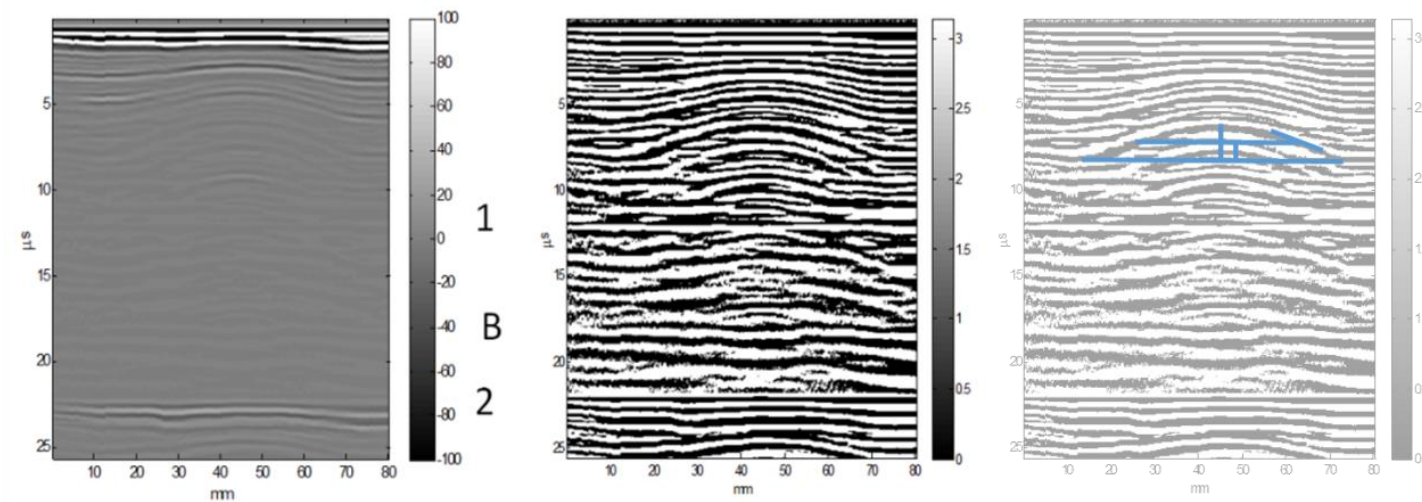

Figure 53: Reconstructed B-Scans of the Full waveform (left) and Instantaneous Phase (centre) at $2.25 \mathrm{MHz}$ of the specimen $\mathrm{B}$. The back-wall echo is labelled ' $\mathrm{B}$ ' and the first and second multiple echoes of the wedge are labelled ' 1 ' and ' 2 ' respectively. The measurements are shown in the right figure.
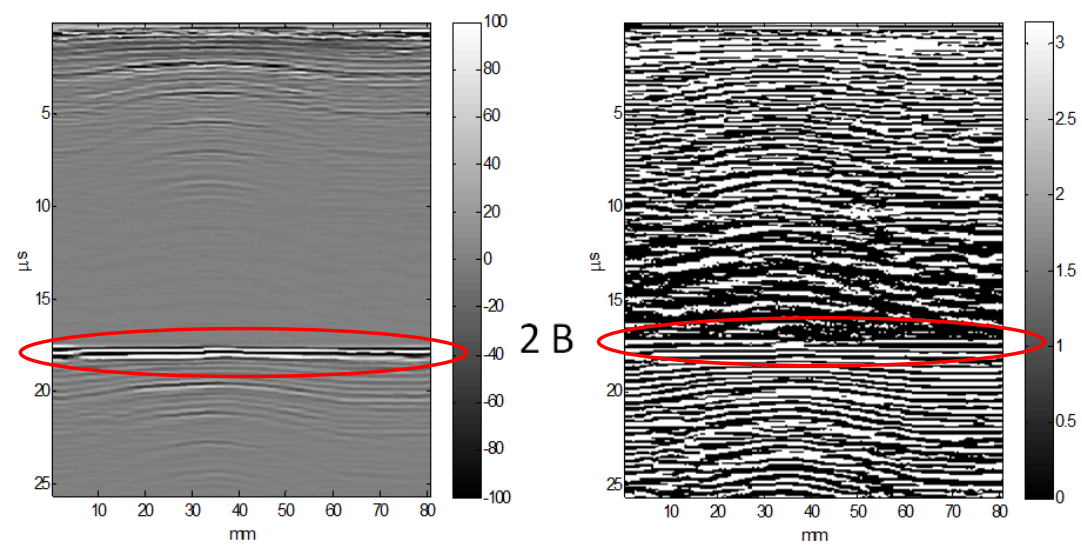

Figure 54: Reconstructed B-Scans of the Full waveform (left) and Instantaneous Phase (right) at $5 \mathrm{MHz}$ of the specimen $\mathrm{B}$. The back-wall echo is labelled ' $\mathrm{B}$ ' and the second multiple echoes of the wedge is labelled ' 2 '.
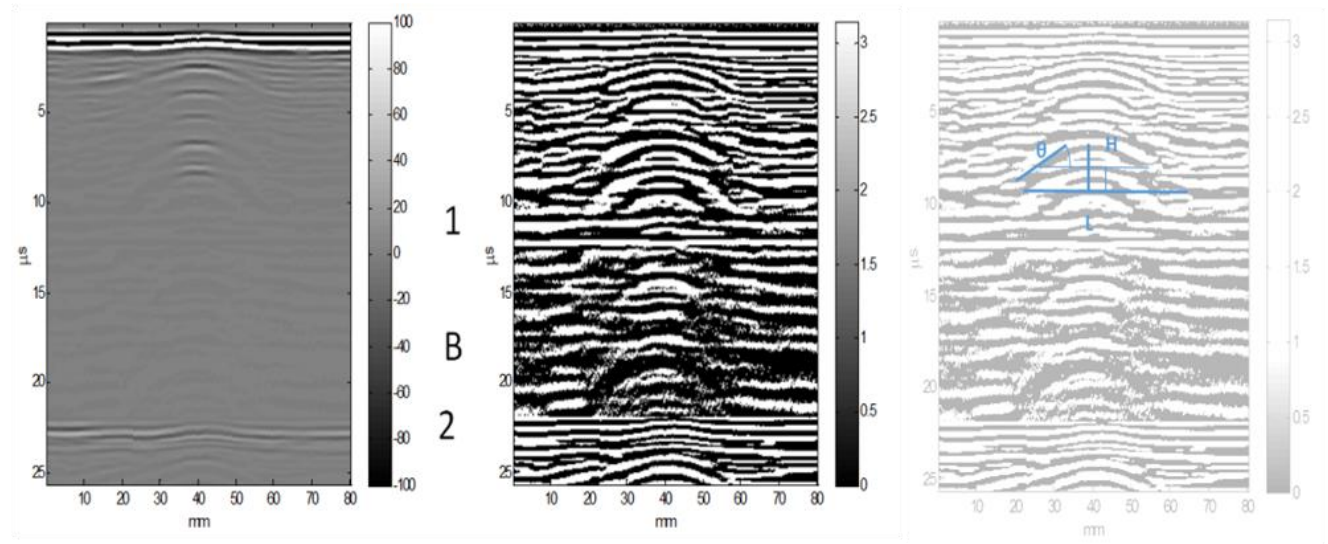

Figure 55: Reconstructed B-Scans of the Full waveform (left) and Instantaneous Phase (centre) at $2.25 \mathrm{MHz}$ of the specimen $\mathrm{C}$. The back-wall echo is labelled 'B' and the first and second multiple echoes of the wedge are labelled ' 1 ' and ' 2 ' respectively. The measurements are shown as an example (right). 

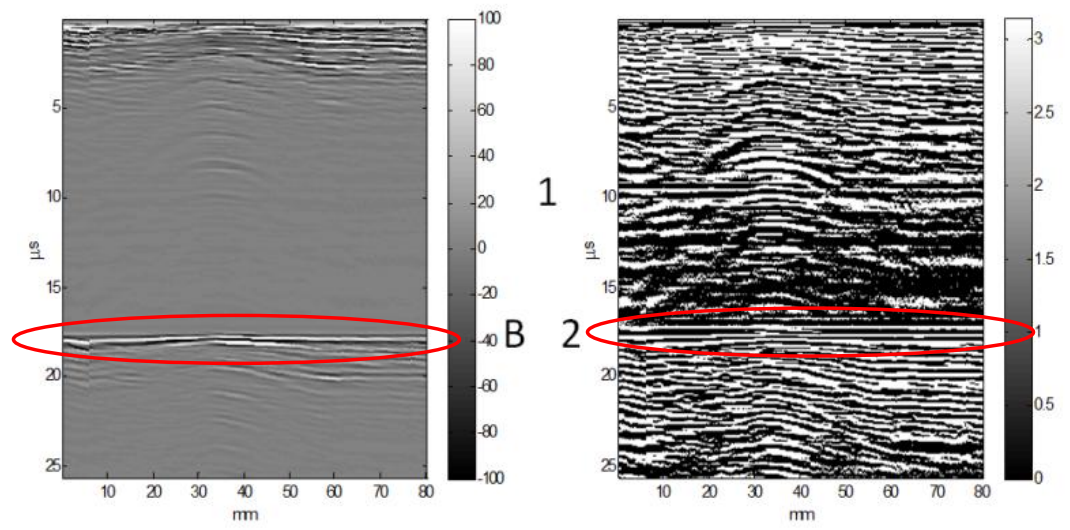

Figure 56: Reconstructed B-Scans of the Full waveform (left) and Instantaneous Phase (right) at $5 \mathrm{MHz}$ of the specimen $\mathrm{C}$. The back-wall echo is labelled ' $\mathrm{B}$ ' and the first and second multiple echoes of the wedge are labelled ' 1 ' and ' 2 ' respectively.
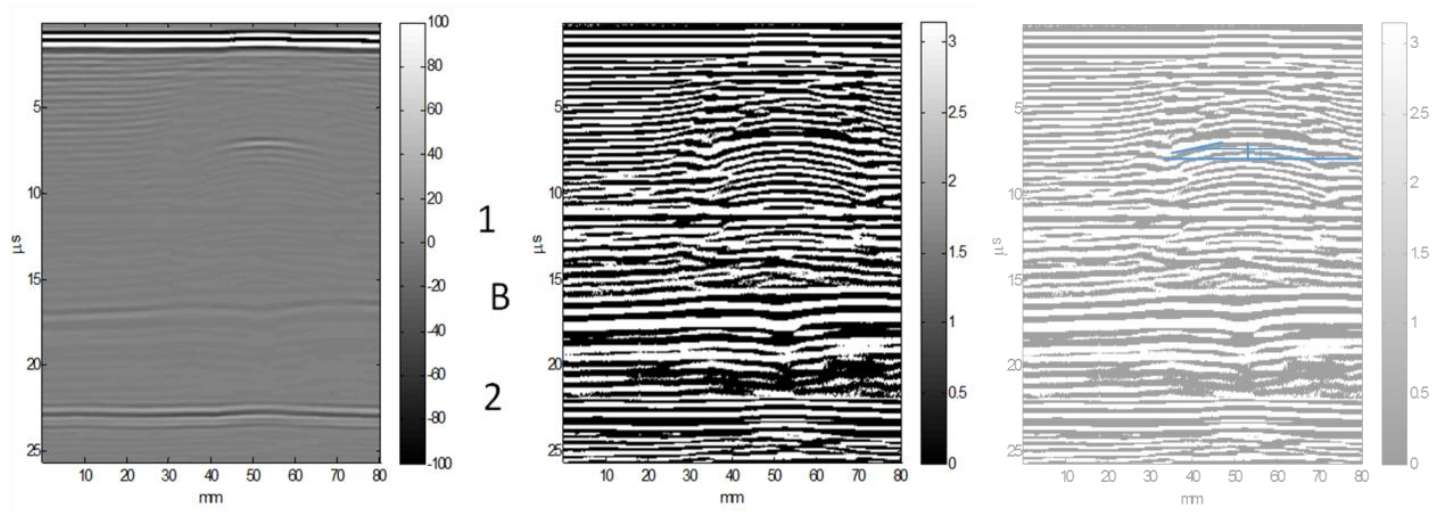

Figure 57: Reconstructed B-Scans of the Full waveform (left) and Instantaneous Phase (right) at 2.25 MHz of the specimen D. The back-wall echo is labelled ' $\mathrm{B}$ ' and the first and second multiple echoes of the wedge are labelled ' 1 ' and ' 2 ' respectively. The measurements are shown in the right figure.
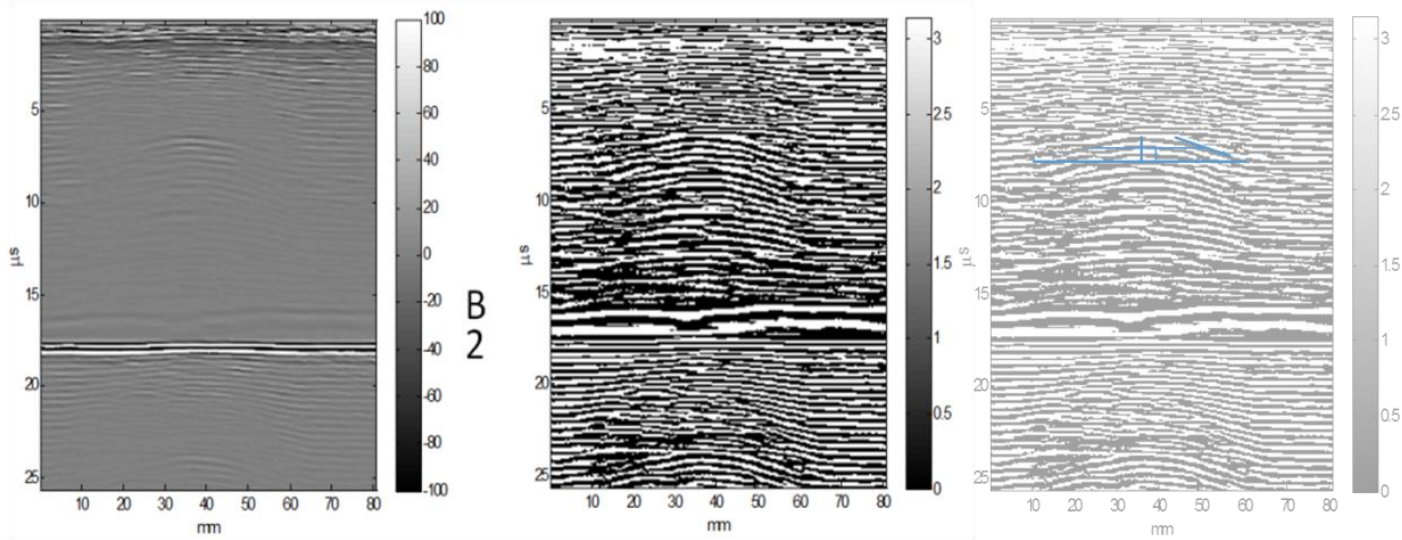

Figure 58: Reconstructed B-Scans of the Full waveform (left) and Instantaneous Phase (right) at $5 \mathrm{MHz}$ of the specimen $\mathrm{D}$. The back-wall echo is labelled ' $\mathrm{B}$ ' and the second multiple echoes of the wedge is labelled ' 2 '. The measurements are shown in the right figure. 


\subsubsection{Results}

The phased-array images are affected by two sources of artefacts. As explained before, the solid stand-off wedge for the $5 \mathrm{MHz}$ probe was not quite thick enough for specimens B and C, so the multiple of the stand-off appears at around the same time-offlight as the back surface echo in those images. These are shown encircled by a red ellipse in the figures.

In addition, the wedges used for the experiment are solid and support shear-wave propagation, so mode-conversion between compression wave and shear wave can occur at the boundaries. This can cause a 'ghost' image of the front surface at approximately half of the wedge time of flight after the front-surface signal, due to either the outward or return signal being a shear wave. The hybrid compression-shear mode reflection from the front surface can be seen superimposed on both the amplitude and phase $2.25-\mathrm{MHz}$ images - just beyond mid-way between the front and back surfaces. These are marked ' 1 ' on the side in the figures.

The B-Scan results that the Omniscan and Matlab give are in time of flight of the ultrasonic signal in ordinate and distance in abscissa. In order to measure the parameters of wrinkles it is necessary to calculate the distance that the signal has travelled in that time. The speed of sound considered in the material in order to obtain the B-Scan data is $3000 \mathrm{~m} / \mathrm{s}$. Again, it is important to mention that the time indicated in ordinates is the time it takes the wave to go and return to a point so the distance travelled is calculated using half the time indicated in the image.

The measurements of the parameters were achieved with an electronic rule or protractor on the instantaneous phase B-Scan slices reconstructed with Matlab. The results are summarized in Table 10.

Table 10: Comparison between the actual parameters of the parts and those obtained from the convex side of the samples by the inspection with the Phased-array probes.

\begin{tabular}{|c|c|c|c|c|c|c|}
\hline \multirow{2}{*}{\multicolumn{2}{|c|}{$\begin{array}{c}\text { Specimen } \\
\text { and wrinkle } \\
\text { parameters. }\end{array}$}} & \multirow[b]{2}{*}{ Actual } & \multicolumn{2}{|c|}{$2.25 \mathrm{MHz}$} & \multicolumn{2}{|c|}{$5 \mathrm{MHz}$} \\
\hline & & & Measured & crel & Measured & crel \\
\hline \multirow[t]{4}{*}{ B } & $\mathrm{H}(\mathrm{mm})$ & 3 & 3.15 & $5 \%$ & & \\
\hline & $\mathrm{L}(\mathrm{mm})$ & 53 & & $18.87 \%$ & & \\
\hline & $\mathrm{A} / \mathrm{L}$ & 0.030 & 0.025 & $16.67 \%$ & & \\
\hline & $\theta$ & $8.5^{\circ}$ & $8.2^{\circ}$ & $3.53 \%$ & & \\
\hline \multirow[t]{4}{*}{ C } & $\mathrm{H}(\mathrm{mm})$ & 6 & 4.1 & $31.67 \%$ & & \\
\hline & $\mathrm{L}(\mathrm{mm})$ & 37 & 41 & $10.81 \%$ & & \\
\hline & $\mathrm{A} / \mathrm{L}$ & 0.090 & 0.05 & $44.44 \%$ & & \\
\hline & $\theta$ & $24^{\circ}$ & $13^{\circ}$ & $45.83 \%$ & & \\
\hline \multirow[t]{4}{*}{ D } & $\mathrm{H}(\mathrm{mm})$ & 3 & 2.6 & $13.33 \%$ & 2.1 & $30.00 \%$ \\
\hline & $\mathrm{L}(\mathrm{mm})$ & 53 & 52 & $1.89 \%$ & 53 & $0.00 \%$ \\
\hline & $\mathrm{A} / \mathrm{L}$ & 0.030 & 0.025 & $16.67 \%$ & 0.02 & $33.33 \%$ \\
\hline & $\theta$ & $8.5^{\circ}$ & $7.6^{\circ}$ & $10.59 \%$ & $6.7^{\circ}$ & $21.18 \%$ \\
\hline
\end{tabular}




\subsection{Full-matrix capture (FMC) with total-focusing method (TFM)}

\subsubsection{Experimental Set-up}

The wrinkled specimens have been inspected using the full-matrix capture (FMC) method with reconstruction of B-scan slices using the total focusing method (TFM).

The FMC/TFM data acquisition was accomplished with two array probes connected to a Diagnostic Sonar 'FIToolbox' array controller (Figure 59) and the postprocessing Matlab-based software "brain" (BRistol Array INspection) developed the University of Bristol ${ }^{10}$ was used to reconstruct the B-Scan slices of instantaneous amplitude and phase from the FMC signal.

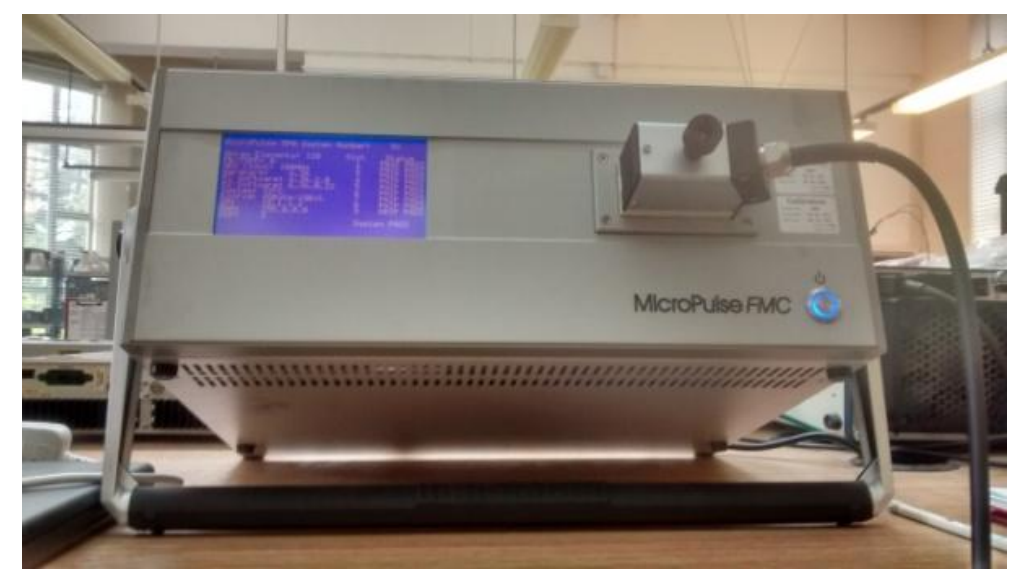

Figure 59: The "MicroPulseFMC" inspection machine

Two different arrays (Table 11) have been used. The two frequencies were chosen in accord with the simulation results that will be presented in chapter 5 .

Table 11: Characteristics of the FMC probes.

\begin{tabular}{lll}
\hline Frequency & $\mathbf{2 . 5} \mathbf{M H z}$ & $\mathbf{5} \mathbf{M H z}$ \\
\hline Elements & 64 & 64 \\
\hline Pitch (e) & $0.50 \mathrm{~mm}$ & $0.63 \mathrm{~mm}$ \\
\hline Width & $31.5 \mathrm{~mm}$ & $39.69 \mathrm{~mm}$ \\
\hline
\end{tabular}

One of the parameters worth noting that the program allows to set are the time points. The time points are related to the maximum depth in the B-Scan. The more time points, the deeper the B-Scan will be. Since the thickness of the specimens is about $25 \mathrm{~mm}$, a $30 \mathrm{~mm}$ depth B-Scan will suffice. Although at 500 time point the $30 \mathrm{~mm}$ depth is reached, the border effects are affecting the area within the specimen should be (Figure 60). 1000 time points allows to stay away of these effects, and to not have an excessive amount of data. The time points are set at 1000 .

\footnotetext{
${ }^{10} \mathrm{http}: / / \mathrm{www}$. bris.ac.uk/engineering/research/ndt/research/array-imaging/ https://sourceforge.net/projects/bristol-brain/
} 

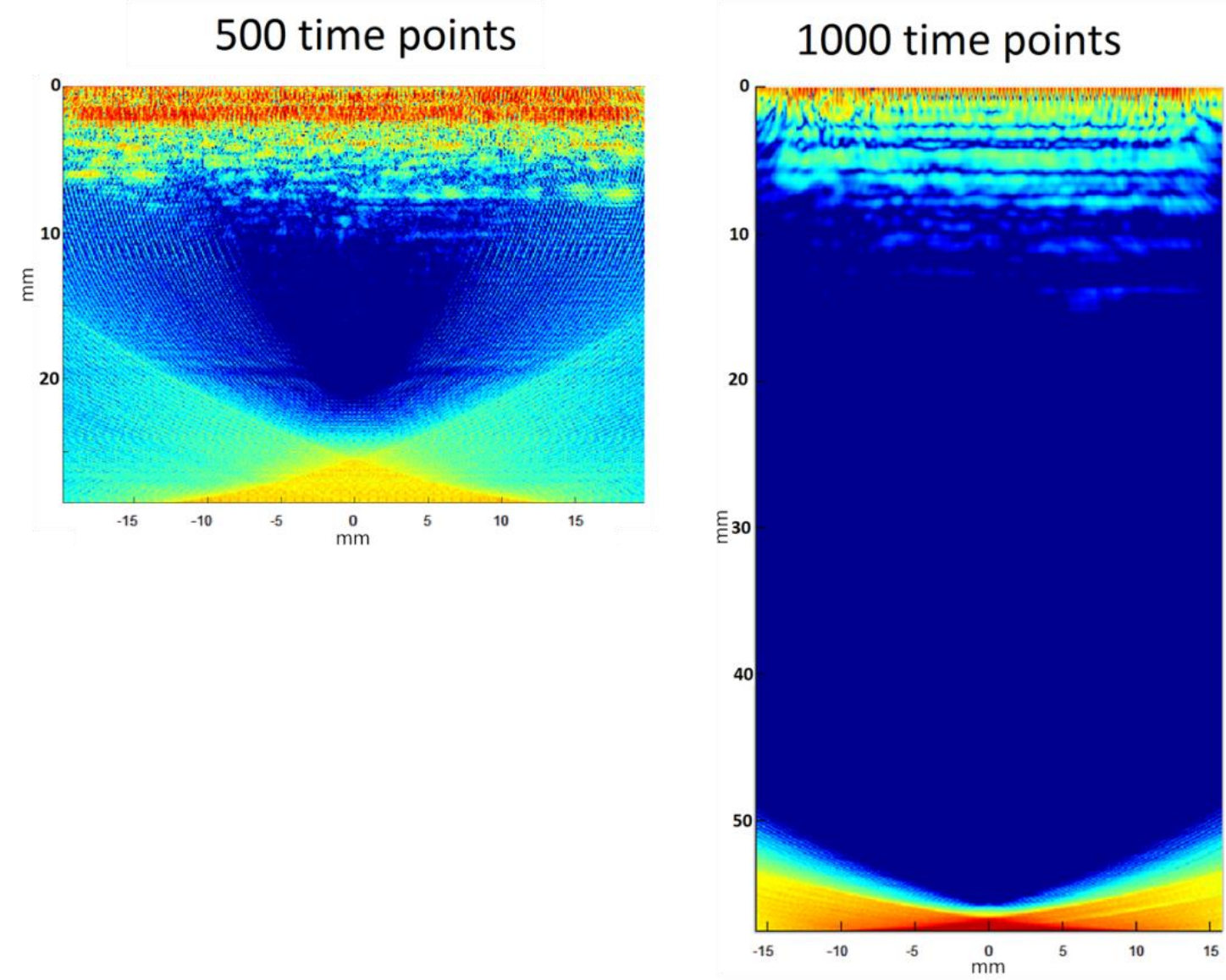

Figure 60: B-Scan obtained with 500 time points (left) and with 1000 time points (right).

The width of a single B-Scan is $31.5 \mathrm{~mm}$ for the $2.5 \mathrm{MHz}$ inspections and 39.69 $\mathrm{mm}$ for the $5 \mathrm{MHz}$ inspections. This correspond to the probe width.

The rest of the parameters that the program allows to change are set as shown in the following. The acquisition mode is Full Matrix Capture (FMC). The sample frequency is $25 \mathrm{MHz}$. The pulse Voltage is $80 \mathrm{~V}$. The pulse width is $80 \mathrm{~ns}$. The sample bits are 8and the Gain is $40 \mathrm{~dB}$.

All inspections were performed with the probe mounted directly on the surface of the sample, without a stand-off or wedge .In order to assure the coupling between sample and array a coupling gel is used.

Each specimen has been inspected from both faces (top and bottom), which means that the wrinkle has been inspected from her concave side (bottom) and also from her convex side (top). Neither of the array used covered the whole wrinkle. From each face, the part has been inspected in 4 points:
a) to the left of the wrinkle
b) over the wrinkle
c) To the right of the wrinkle
d) The non-wrinkled area 
The four inspections carried out allow a reconstruction of the complete wrinkle, from beginning to end. (Figure 61) The inspection of the non-wrinkled area is used as a reference. Only four points have been inspected because of the absence of an encoder.

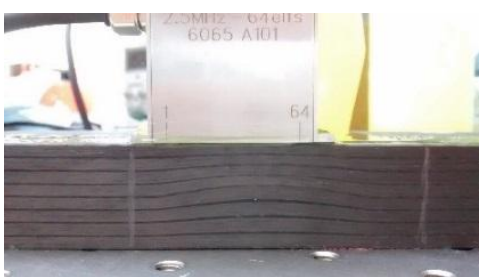

a

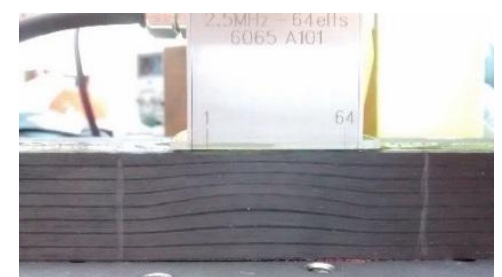

$\mathrm{b}$

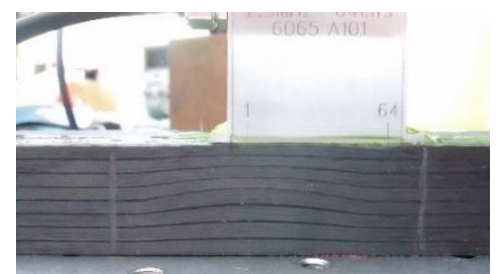

c

Figure 61: Example of the placement of the probe during the inspection of the specimens: to the left of the wrinkle (a), over the wrinkle (b) and to the right of the wrinkle(c).

Once the data of the inspection has been captured, "brain" displays the results at each point. Some parameters need to be changed in order to visualize a correct image. The depth of the images is set at $30 \mathrm{~mm}$, because the back wall of all the samples is expected around $25 \mathrm{~mm}$. The interpolation is set in "linear" instead of "nearest".

The most important set up that needs to be selected is the pixel size. A large pixel size, would not present enough resolution to identify the defects or the part in the final image (Figure 62). The pixel size that is used in all the images below is $0.1 \mathrm{~mm}$.

Pizel size:1.25mm
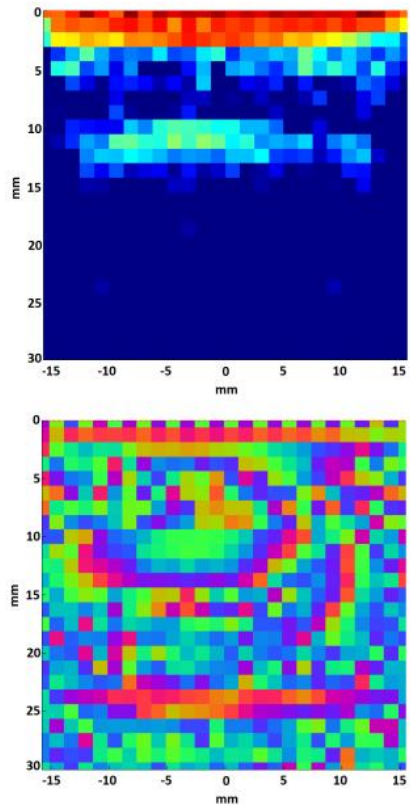

\section{Pizel size:0.1mm}
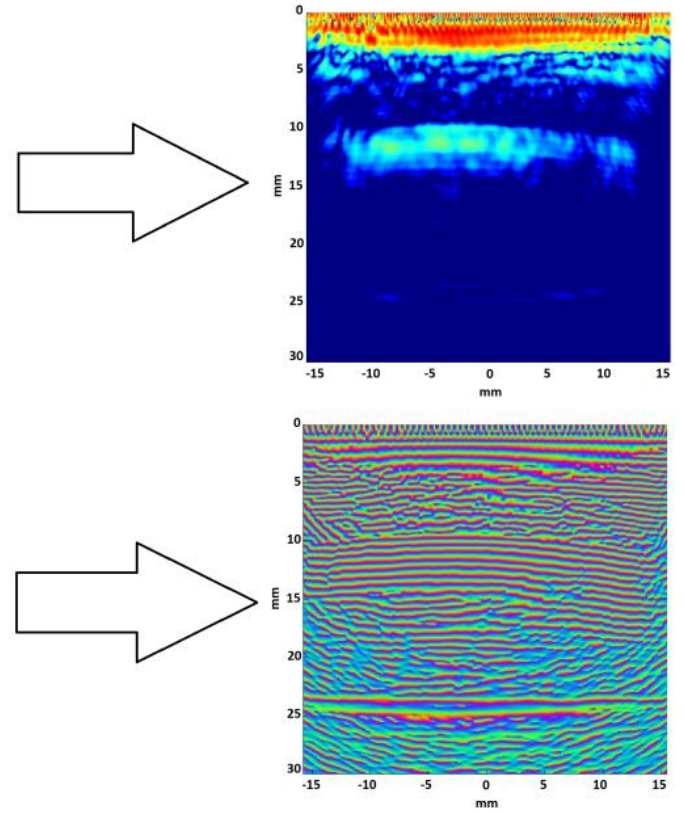

Figure 62: Influence of the pixel size in the display image.

Two TFM algorithm were used to reconstruct the B-Scan slices: isotropic TFM and an adapted-TFM with angle-dependent velocity to account for anisotropic velocities. 
Not all waveforms in the FMC array were used in the reconstructions algorithm because benefit has been shown (C. Li et al. 2013) from limiting the angle of incidence to avoid side-lobes in the directional response. This limitation also improves the Signalto-Noise Ratio (SNR) of a defect; due to a combination of the limited directional response of the array elements and the increase in mode conversion to transverse modes with increased angle.

\subsubsection{Isotropic TFM}

With the isotropic TFM, the angle limit was set at $30^{\circ}$ from normal incidence.

The velocity of sound in the material is considered constant in the isotropic TFM algorithm implemented in "brain". Because the B-Scan results that the program "brain" gives are in distance instead of time, the program forces the choice of the material that is being inspected. The speed used in order to calculate the distance is the speed of sound in the material introduced by the user. In this case the chosen material is "composite (2900)", which means that the speed of sound considered in the material in order to obtain the B-Scan data is $2900 \mathrm{~m} / \mathrm{s}$. That material was chosen among the available materials because it had the speed of sound in the material closest to $3000 \mathrm{~m} / \mathrm{s}$. The scale in all the B-Scans obtained is therefore $\mathrm{mm}$ in both abscissa and ordinate.

The speed of sound in a laminate is a function of the Fibre Volume Fraction (FVF) among many other things. $2900 \mathrm{~m} / \mathrm{s}$ is the speed of sound in the epoxy resin used to pre-impregnate the glass and carbon fibres (the speed of sound with FVF $=0 \%$ would be $2900 \mathrm{~m} / \mathrm{s}$.). The speed of propagation in the layers increases as the percentage of glass or carbon fibre increases. In a CFRP laminate, the speed of sound with FVF = $60 \%$ is $3000 \mathrm{~m} / \mathrm{s}$. Typically, CFRP laminates present a FVF of $60 \%$. This is why, 3000 $\mathrm{m} / \mathrm{s}$ is the speed of sound that has been considered for the calculations in the previous experiments. The theoretical time-of-flight through sample B considering a speed of sound of $3000 \mathrm{~m} / \mathrm{s}$ is $9 \mu \mathrm{s}$ whereas the theoretical time-of-flight through the same sample considering a speed of sound of $2900 \mathrm{~m} / \mathrm{s}$ is $9.3 \mu \mathrm{s}$. The theoretical time-offlight through sample C considering a speed of sound of $3000 \mathrm{~m} / \mathrm{s}$ is $8.7 \mu$ s whereas the theoretical time-of-flight through the same sample considering a speed of sound of 2900 $\mathrm{m} / \mathrm{s}$ is $8.9 \mu \mathrm{s}$. The theoretical time-of-flight through sample D considering a speed of sound of $3000 \mathrm{~m} / \mathrm{s}$ is $7.7 \mu$ s whereas the theoretical time-of-flight through the same sample considering a speed of sound of $2900 \mathrm{~m} / \mathrm{s}$ is $7.9 \mu \mathrm{s}$. Carbon fibre has a speed of sound that is near to that of the resin matrix, which makes that the difference in the resultant time-of-flight are relatively trivial (of the order of $3 \%$ ).

Samples B, C and D are mainly CFRP, so the speed of sound considered for the whole pieces is the speed of sound in CFRP. However, the actual speed of sound in the sample would differ because of the GFRP plies. 
It is worth noting that the glass fibre compression velocity value changes considerably with fibre volume fraction, a change that is very apparent in a wrinkle. Hence the measurements of a wrinkle in glass fibre are likely to need a correction that is not taken into account by the algorithms in "brain". Also, the Fibre Volume Fraction varies considerably inside a wrinkle and this effect can distort the measurement of the amplitude of the wrinkles particularly in the glass specimens. Figure 63 shows this effect of Fibre Volume Fraction on velocity in glass fibre reinforced with epoxy and carbon fibre reinforce with epoxy. This effect could distort the measurement of the amplitude, angle and "severity" with the three ultrasonic techniques.

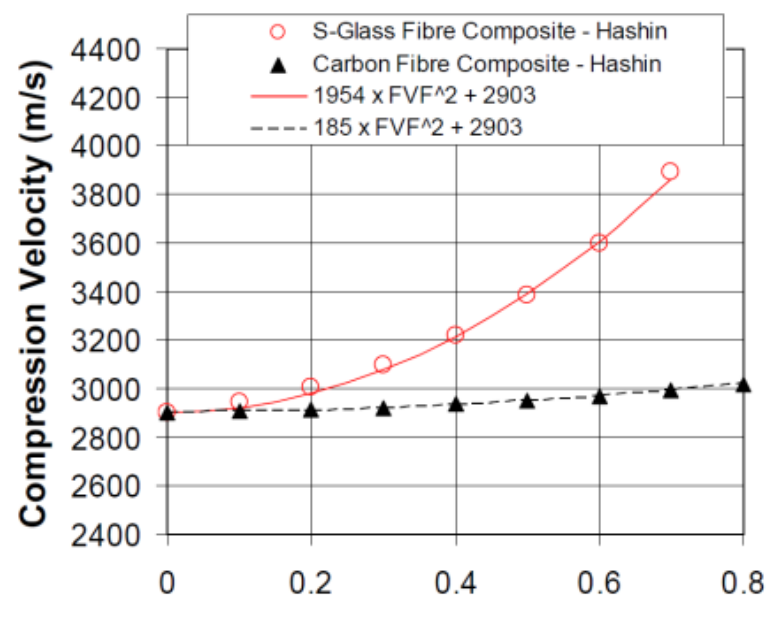

Fibre Volume Fraction

Figure 63: Change in compression velocity value with the fibre volume fraction (Smith, 2010)

\subsubsection{Adapted-TFM algorithm with angle-dependent velocity}

For the adapted-TFM algorithm with angle-dependent velocity, the angle dependence was first determined using the Back-wall Reflection Method (BRM) as described by Yan, Sutcliffe, Wright \& Cooper (Yan et al. 2013). This quick method is applied to a non-wrinkled region of the specimen. As a result, a set of measured group velocities are obtained for a range of propagation angles. Figure 64 shows the results obtained for each specimen using $2.5 \mathrm{MHz}$ and $5 \mathrm{MHz}$ probes. The group velocities range between $3000 \mathrm{~m} / \mathrm{s}$ to $7750 \mathrm{~m} / \mathrm{s}$. This wide range suggest a high anisotropy of the specimens. As can be seen, the cubic fitting matches the velocity measurements well. Thus, the adapted-TFM algorithm implemented in "brain" will incorporate a third-order polynomial fit between velocity and angle. 

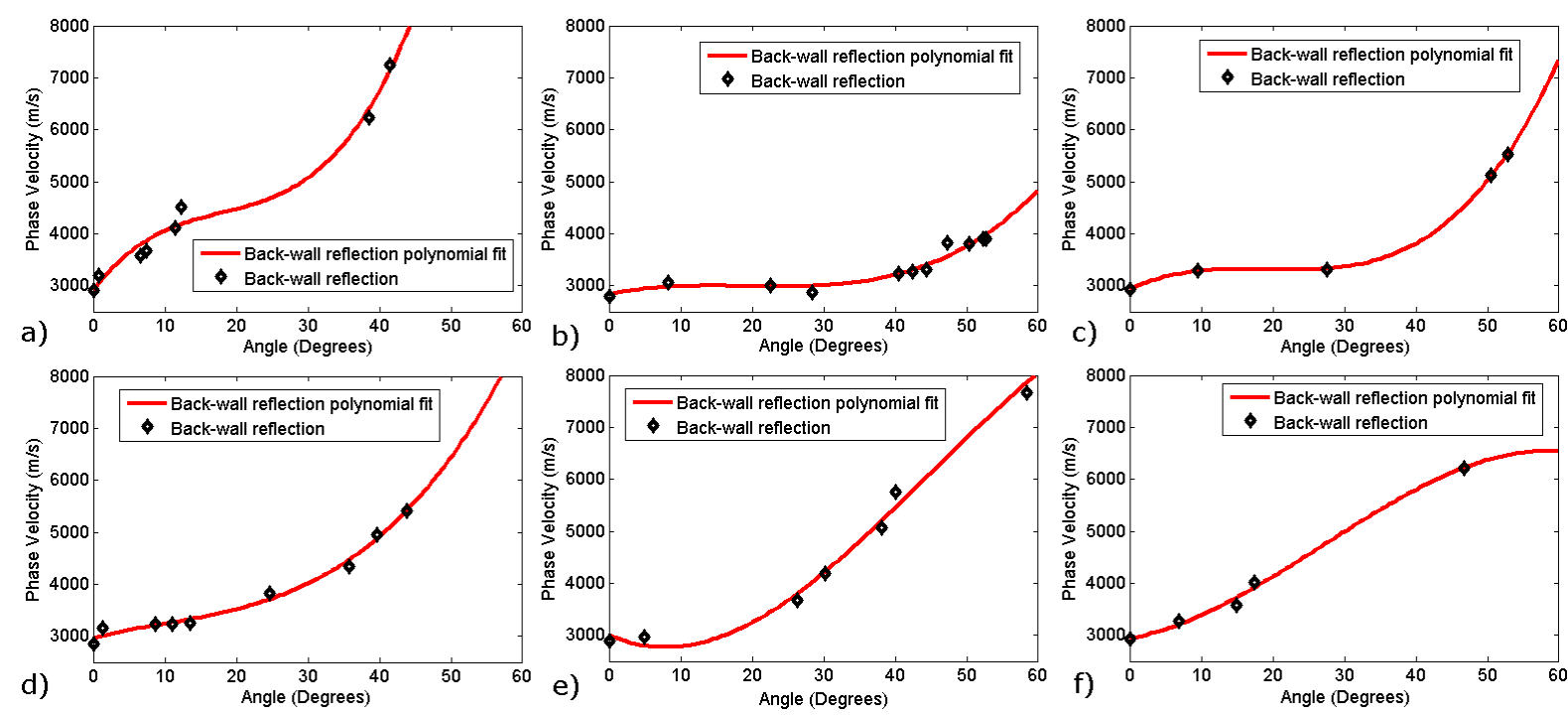

Figure 64: Measured phase velocities profile obtained using Back-wall Reflection Method

(BRM) showing a third-order polynomial fit to the data. a) Specimen B at $2.5 \mathrm{MHz}$; b) Specimen C at 2.5 MHz; c) Specimen D at $2.5 \mathrm{MHz}$; d) Specimen B at $5 \mathrm{MHz}$; e) Specimen C at $5 \mathrm{MHz}$; f) Specimen D at $5 \mathrm{MHz}($ Larrañaga-Valsero et al. 2018)

For the adapted-TFM algorithm with angle-dependent velocity, the angle limit was set at $35^{\circ}$ from normal incidence. The maximum propagation angle $\theta_{\max }$ was determine to maximize signal-to-noise ratio (SNR). For this study, Specimen B with 2.5 $\mathrm{MHz}$ was used. The SNR of the plies in the wrinkled region was calculated for the TFM results using equation (19)

$$
S N R(d B)=20 \log _{10} \frac{I_{\max }}{\sigma}
$$

where $\mathrm{I}_{\max }$ is the maximum instantaneous amplitude in the reconstructed B-scan image for a specific wrinkle and $\sigma$ is the standard deviation of the noise from a rectangular region near to the selected wrinkle but in a region of roughly constant amplitude. Figure 65 shows the SNR of specimen B for $2.5 \mathrm{MHz}$ as a function of the maximum propagation angle $\theta_{\max }$. The maximum of SNR is obtained for a maximum propagation angle of $35^{\circ}$.

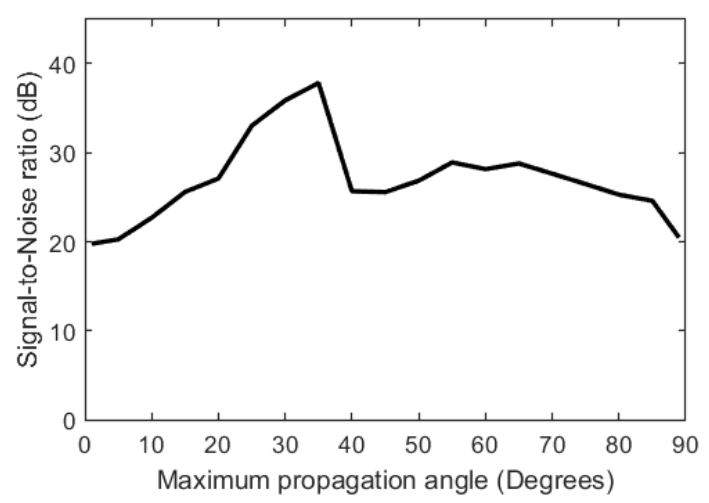

Figure 65: Signal-to-Noise ratio for a wrinkle located half way through specimen B as a function of the maximum propagation angle for TFM results.(Larrañaga-Valsero et al. 2018) 


\subsubsection{Inspections using an isotropic post processing algorithm}

The specimen B was first inspected with the $2.5 \mathrm{MHz}$ probe, from both sides. This allows to visualize the wrinkle from her convex side (Figure 66) but not really from her concave side (Figure 67).

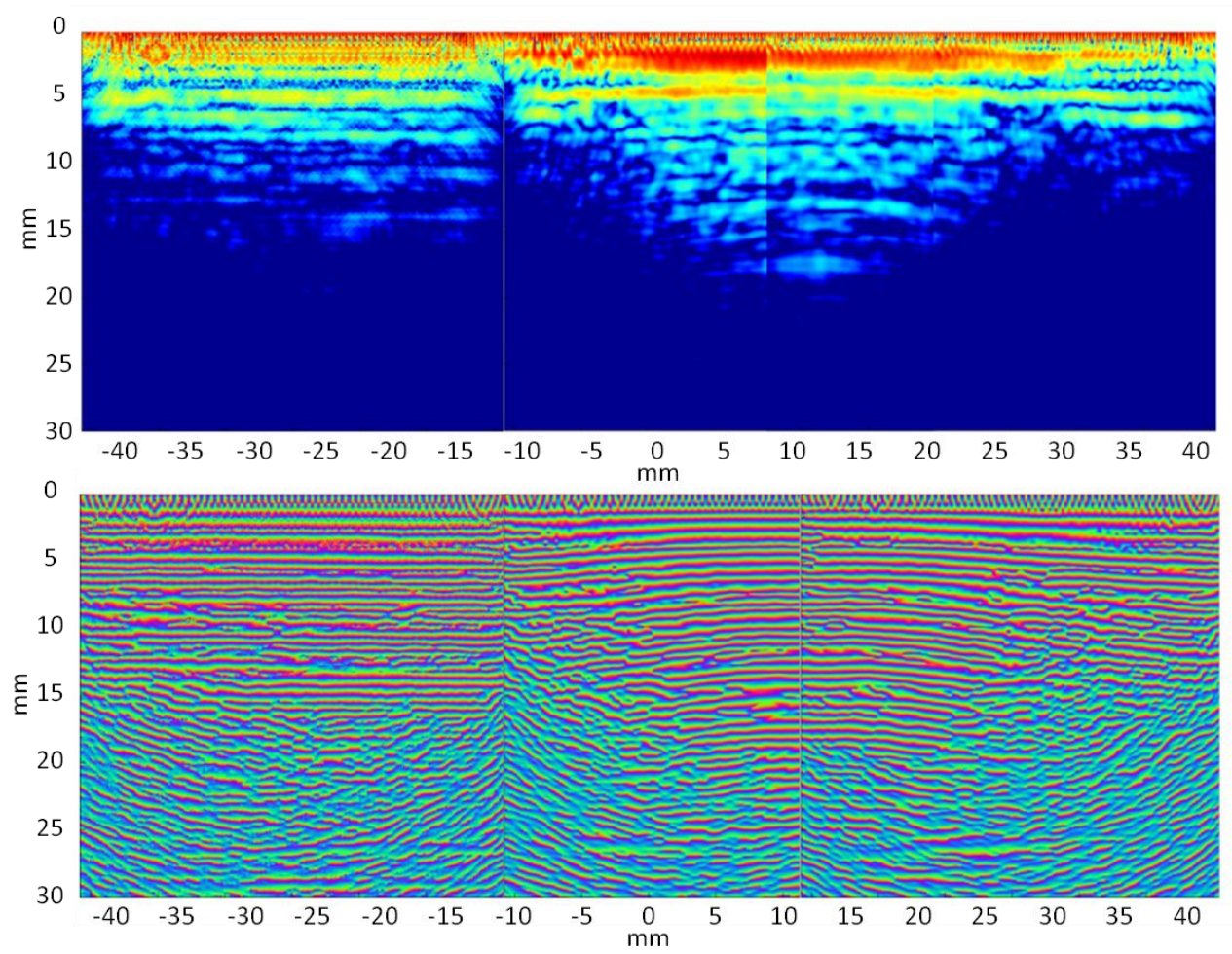

Figure 66: Reconstructed B-Scans of the Instantaneous Amplitude (above) and Instantaneous Phase (below) at $2.5 \mathrm{MHz}$ of the specimen B from the convex side of the wrinkle.
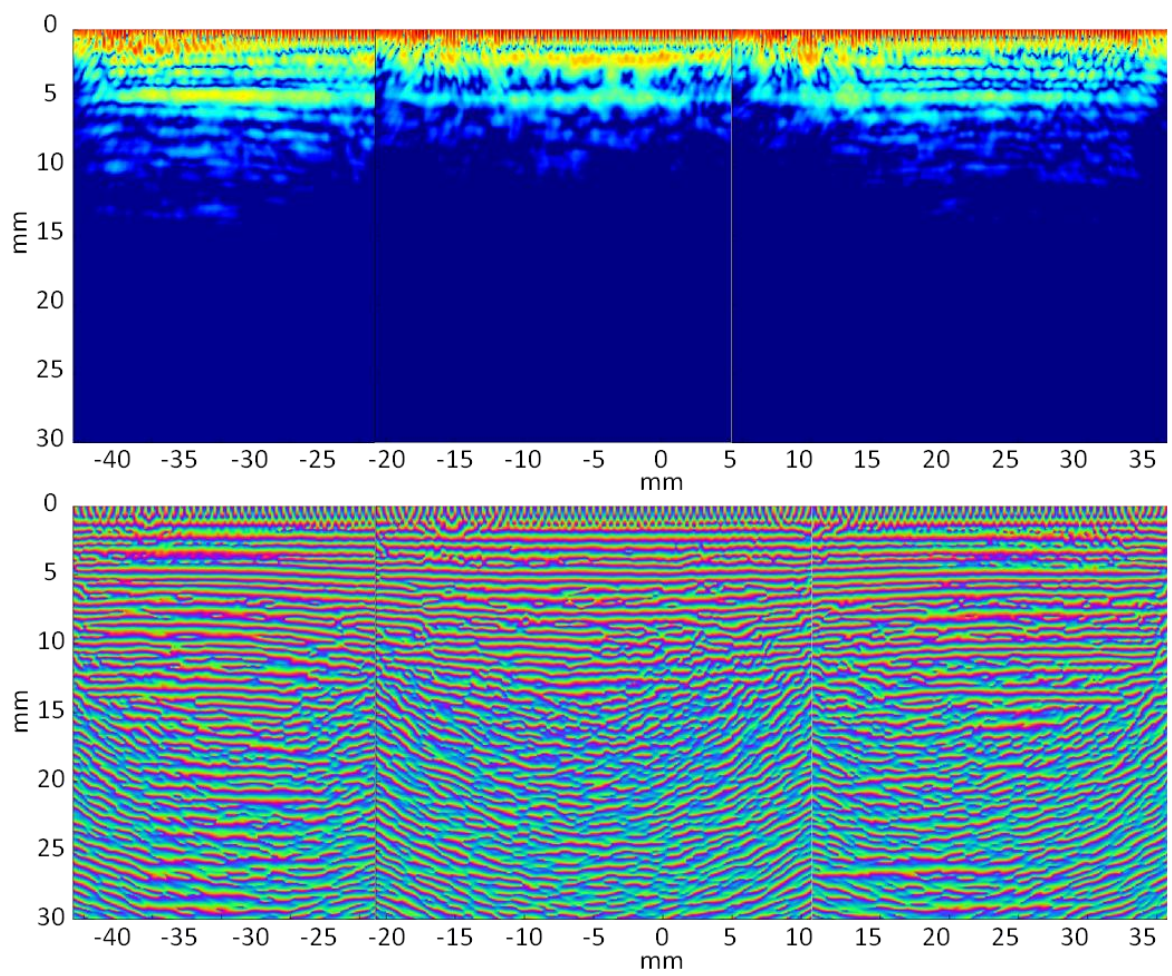

Figure 67: Reconstructed B-Scans of the Instantaneous Amplitude (above) and Instantaneous

Phase (below) at $2.5 \mathrm{MHz}$ of the specimen $\mathrm{B}$ from the concave side of the wrinkle. 
The inspection from the concave side doesn't really allow the detection of the wrinkle, because a wrinkle is barely perceive and there is no a clear line to follow.

However, the inspection from the convex side does. The instantaneous amplitude shows some waviness, but it is in the instantaneous phase where the wrinkle can be detected and characterize. An echo appears that can be identified as the back echo at some areas of the wrinkled and non-wrinkled zone. In the middle of the specimen a different echo allows the measurement of the wrinkle (Figure 68).

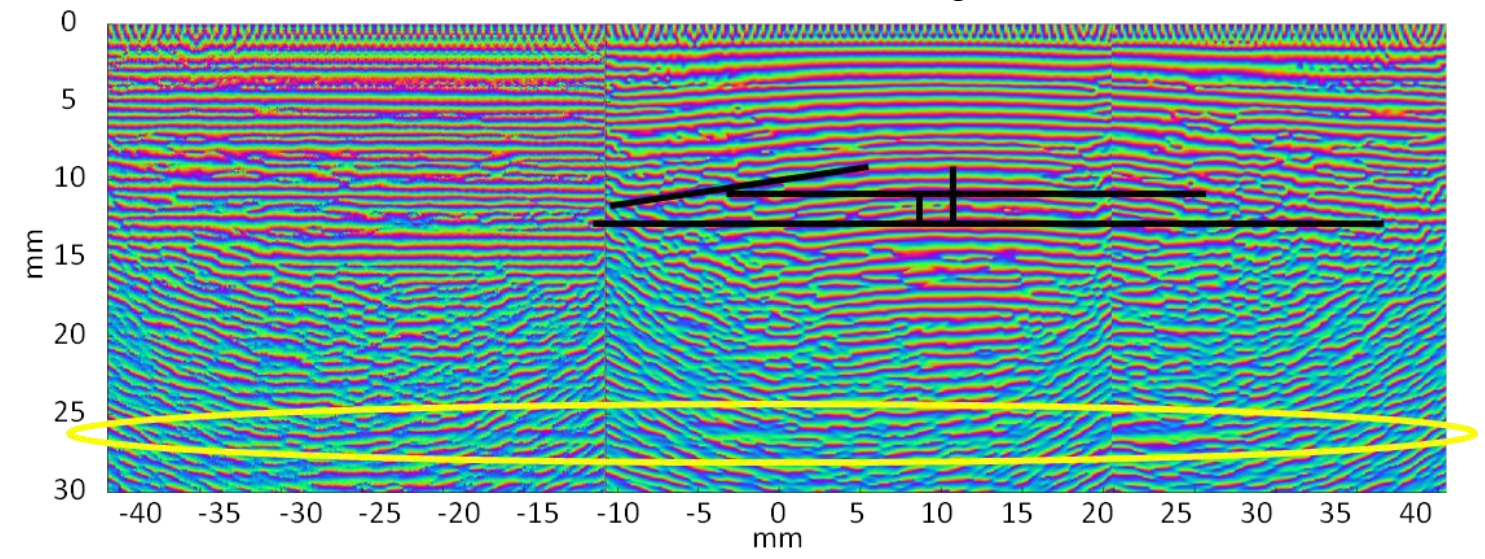

Figure 68: Back echo (yellow) and measure of the wrinkle in the specimen B with the Reconstructed B-Scans of the instantaneous phase

The specimen $\mathrm{B}$ was then inspected with the $5 \mathrm{MHz}$ probe, from both sides. This allows to visualize the wrinkle from her convex side (Figure 69) but not from her concave side (Figure 70).

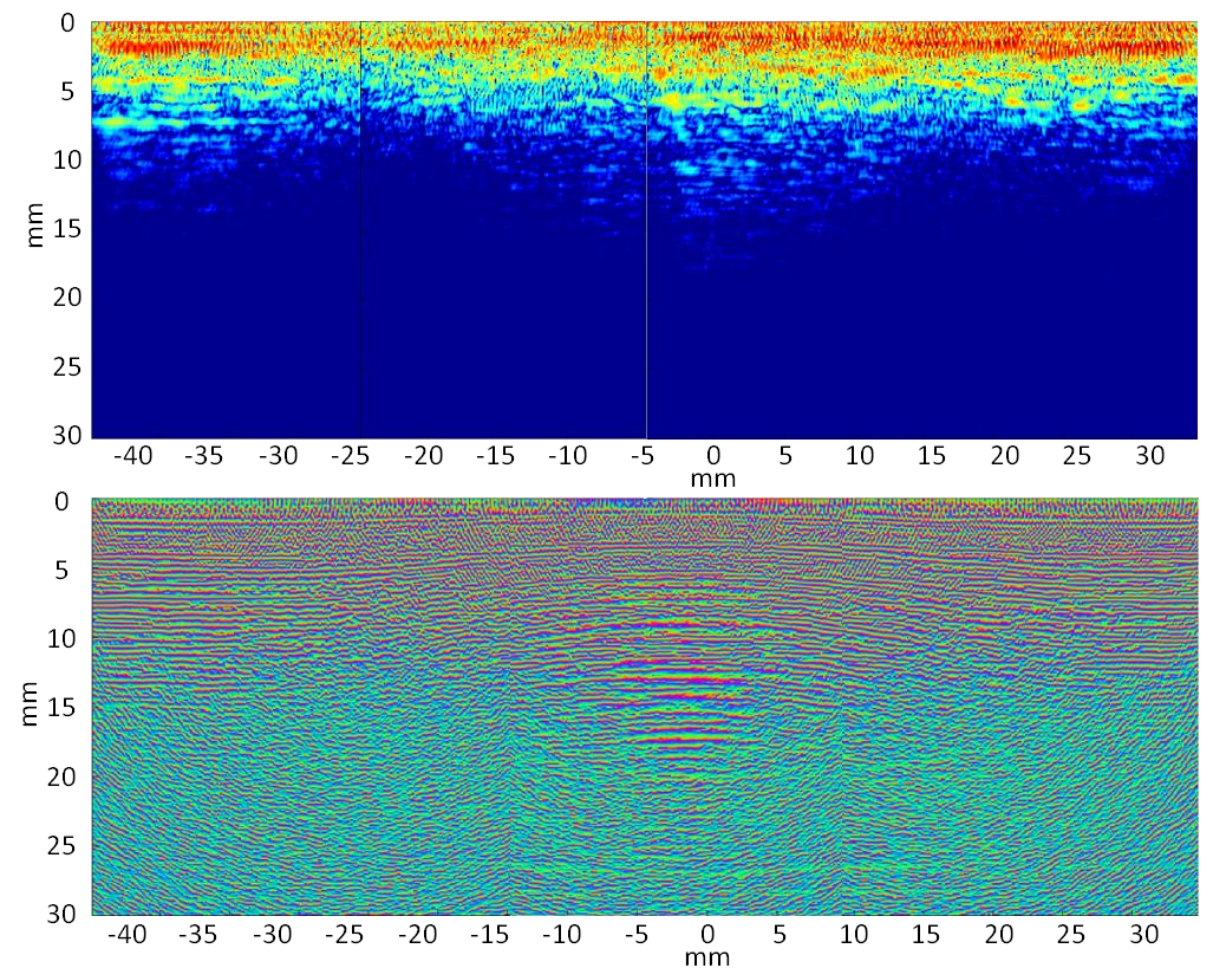

Figure 69: Reconstructed B-Scans of the Instantaneous Amplitude (above) and Instantaneous Phase (below) at $5 \mathrm{MHz}$ of the specimen B from the convex side of the wrinkle. 
As expected in the inspection of this specimen with $5 \mathrm{MHz}$, the instantaneous phase seems to be doubling herself because the frequency has been doubled. The back echo still appears on the phase but the wrinkle is not measurable because even if a wrinkle is perceived, there is no a clear line to follow. To reduce the pixel size while increasing the frequency could also help to produce clearer images, but the pixel size is already at his minimum. Expanding the vertical axis may also help to improve the image but then the back echo will be lost.

Only half of the specimen seems to be clearly represented with both frequencies. Beyond, they are too many interferences to visualize any pattern. However, the inspection from both sides shows that the non-wrinkled area doesn't seems to have any defect. The dampening effect of the glass prevents proper inspection of the entire piece and only weak back echoes are obtained.

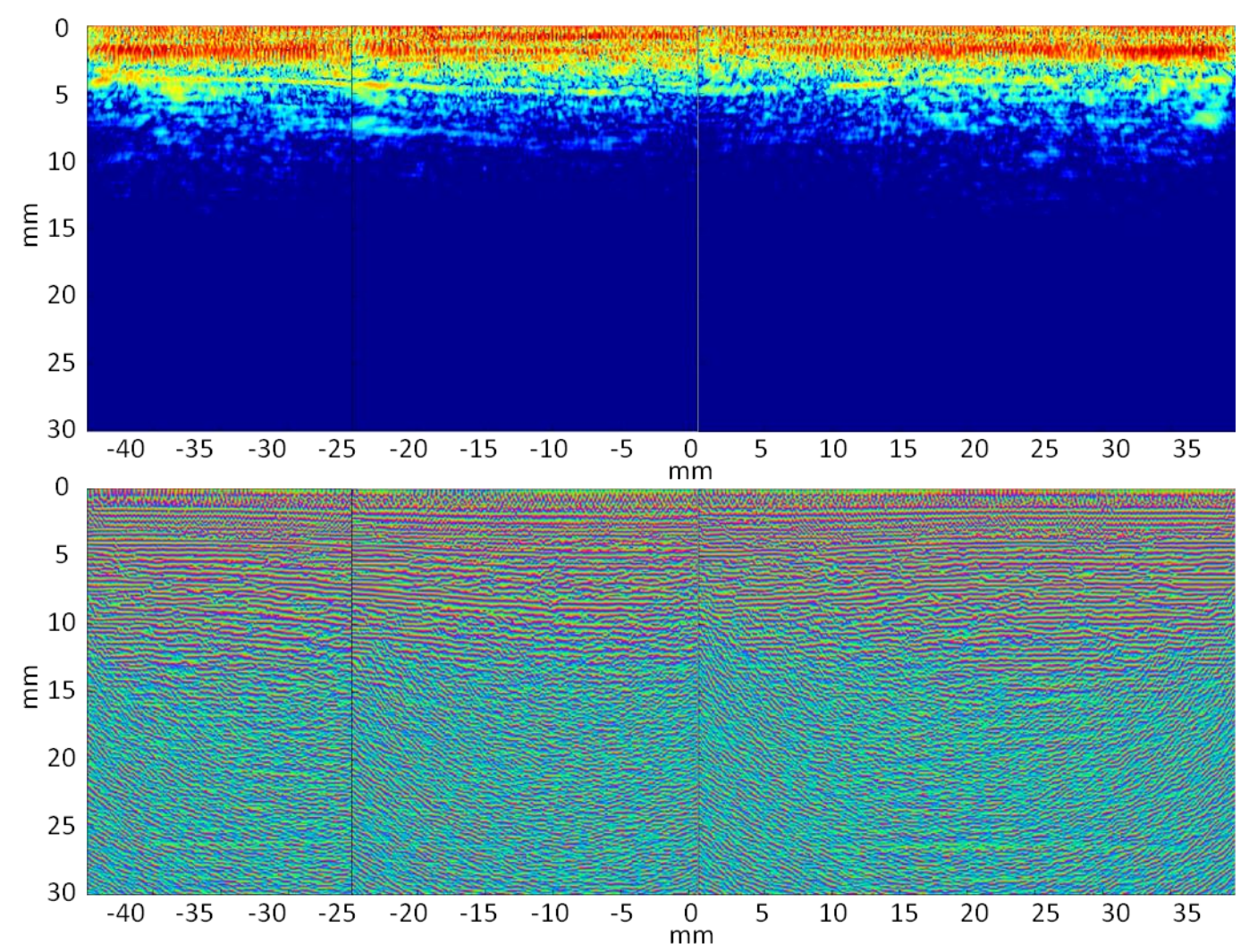

Figure 70: Reconstructed B-Scans of the Instantaneous Amplitude (above) and Instantaneous Phase (below) at $5 \mathrm{MHz}$ of the specimen $\mathrm{B}$ from the concave side of the wrinkle.

The specimen $\mathrm{C}$ was first inspected with the $2.5 \mathrm{MHz}$ probe, from both sides. This allows to visualize the wrinkle from her convex side (Figure 71 and Figure 72). 

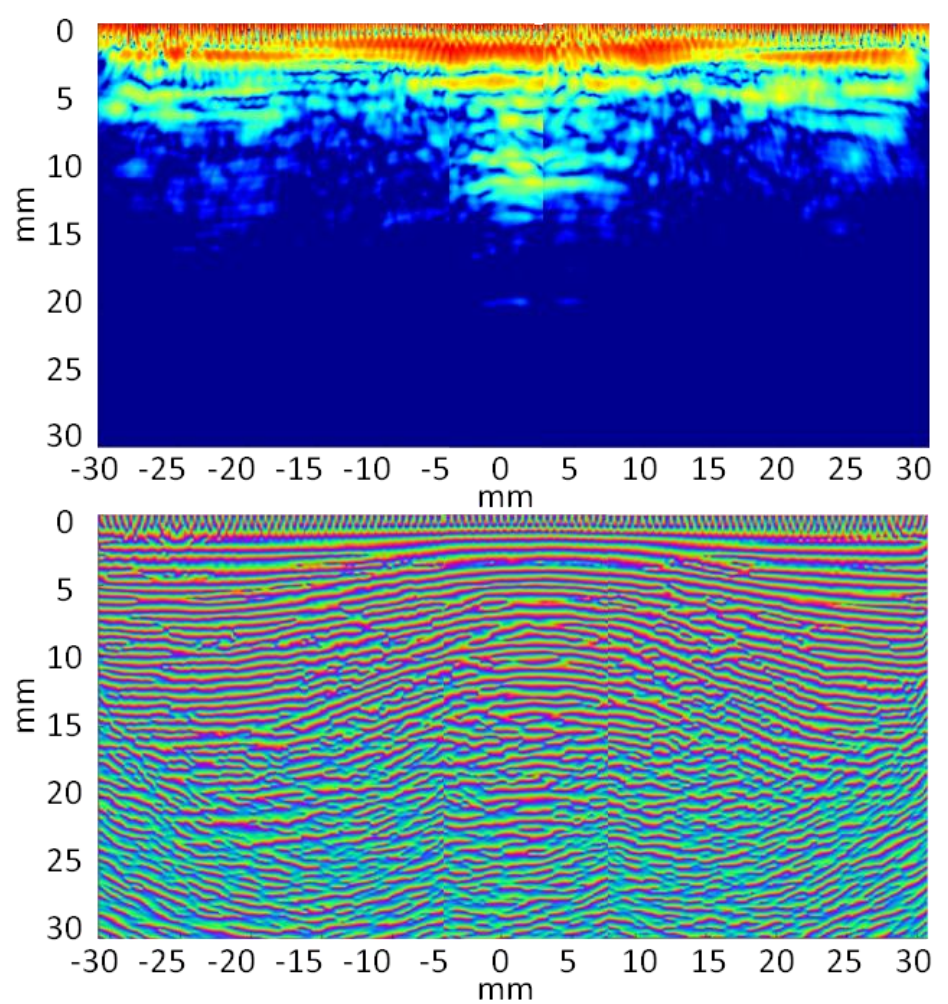

Figure 71: Reconstructed B-Scans of the Instantaneous Amplitude (above) and Instantaneous Phase (below) at $2.5 \mathrm{MHz}$ of the specimen $\mathrm{C}$ from the convex side of the wrinkle.

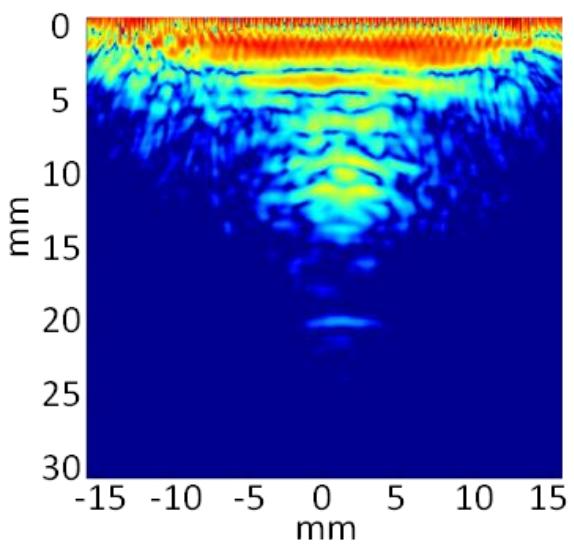

Figure 72: Detail of the Reconstructed B-Scans of the Instantaneous Amplitude at 2.5MHz of the specimen $\mathrm{C}$ from the convex side of the wrinkle. This is the inspection that was perform on the central part of the wrinkle without any composition with the left and the right inspection.

The instantaneous amplitude shows some waviness and some strong echoes at the centre of the wrinkle. In the instantaneous phase the wrinkle can be fully characterized. No echo appears that could be identified as the back echo (Figure 73). However, it should be noted that the manufacturing process of this wrinkle is more complicated than the process of the less severe wrinkles, leaving an area rich in resin that might interfere with the measurements. 


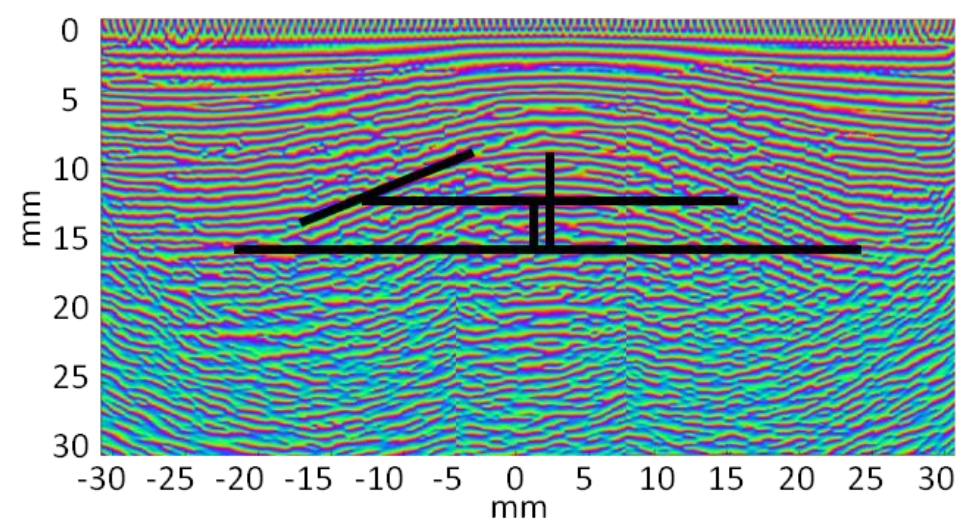

Figure 73: Measurement of the wrinkle in specimen $\mathrm{C}$ with a $2.5 \mathrm{MHz}$ probe.

The inspection from the concave side (Figure 74) doesn't really allow the detection of the wrinkle, because even if a wrinkle is perceive, there is no a clear line to follow. Only half of the specimen seems to be clearly represented and the maximum amplitude would be reached in diffuse area. The back echo is not visible.

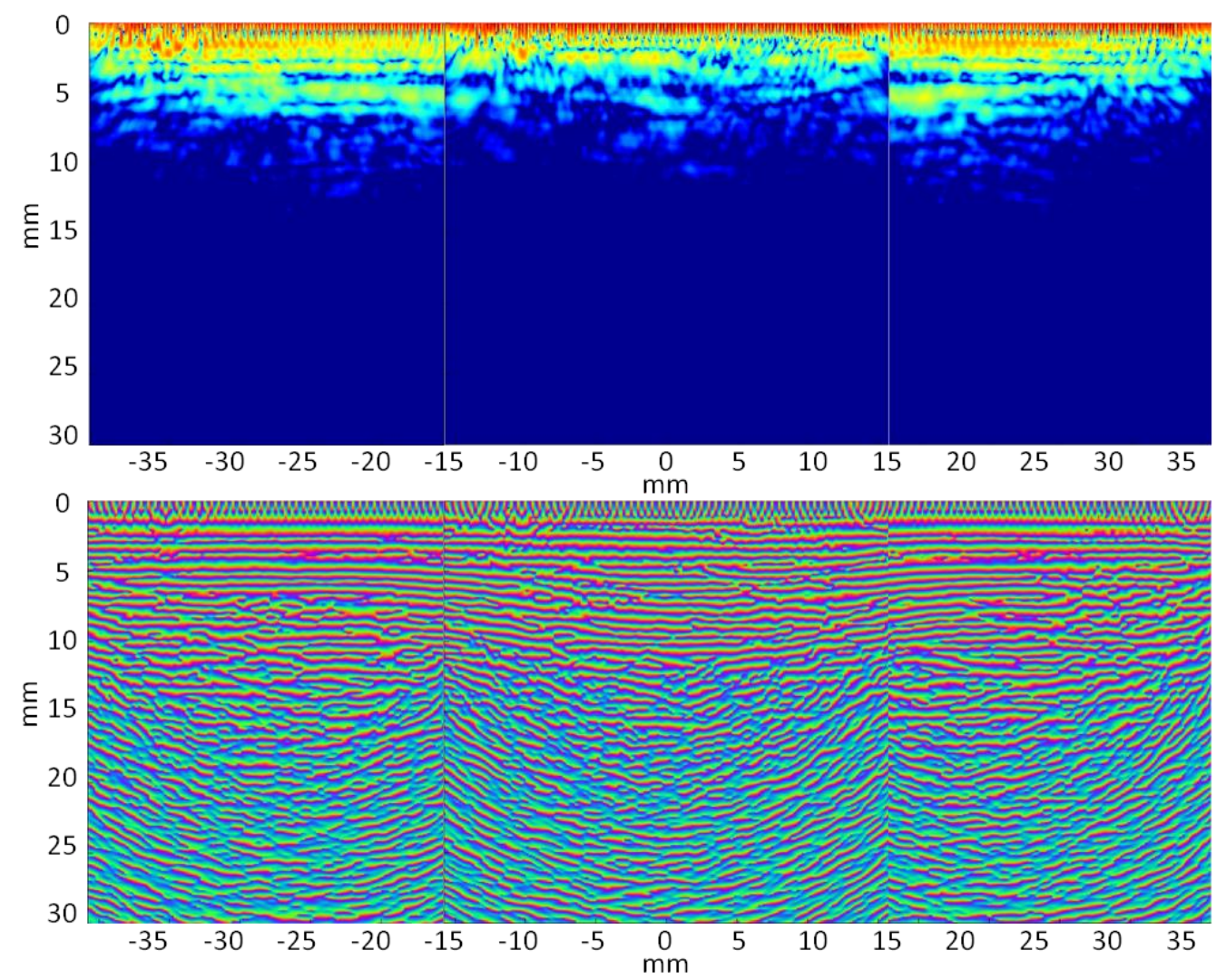

Figure 74: Reconstructed B-Scans of the Instantaneous Amplitude (above) and Instantaneous

Phase (below) at $2.5 \mathrm{MHz}$ of the specimen $\mathrm{C}$ from the concave side of the wrinkle.

The specimen $\mathrm{C}$ was then inspected with the $5 \mathrm{MHz}$ probe, from both faces (Figure 75 and Figure 76). In the inspection form the convex side (Figure 75), the amplitude still shows some waviness in the higher zone of the wrinkle and the instantaneous phase is doubling herself as expected. The back echo doesn't appears at any case and the wrinkle is not measurable because of the impossibility of following the lines. 

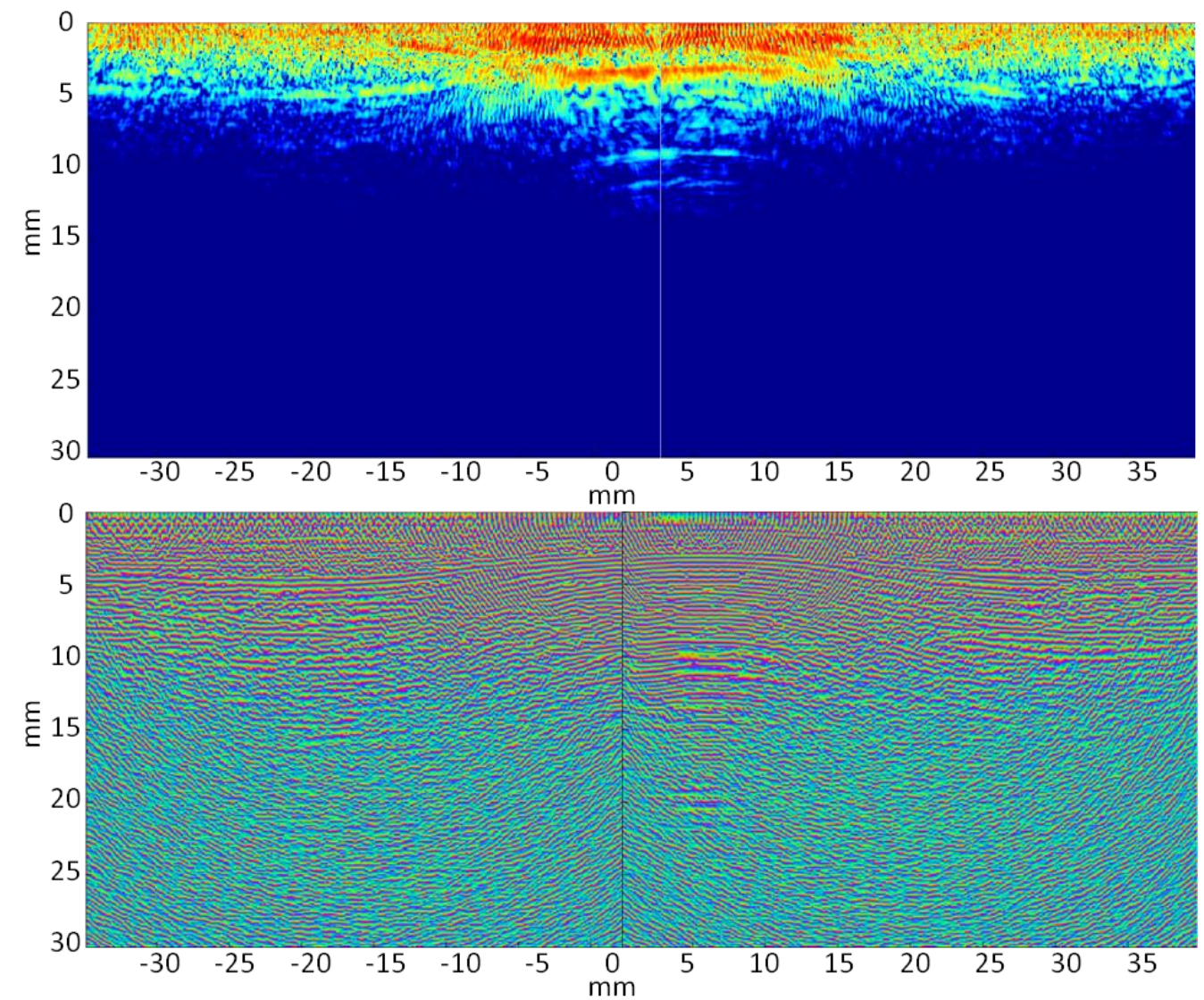

Figure 75: Reconstructed B-Scans of the Instantaneous Amplitude (above) and Instantaneous Phase (below) at $5 \mathrm{MHz}$ of the specimen $\mathrm{C}$ from the convex side of the wrinkle.
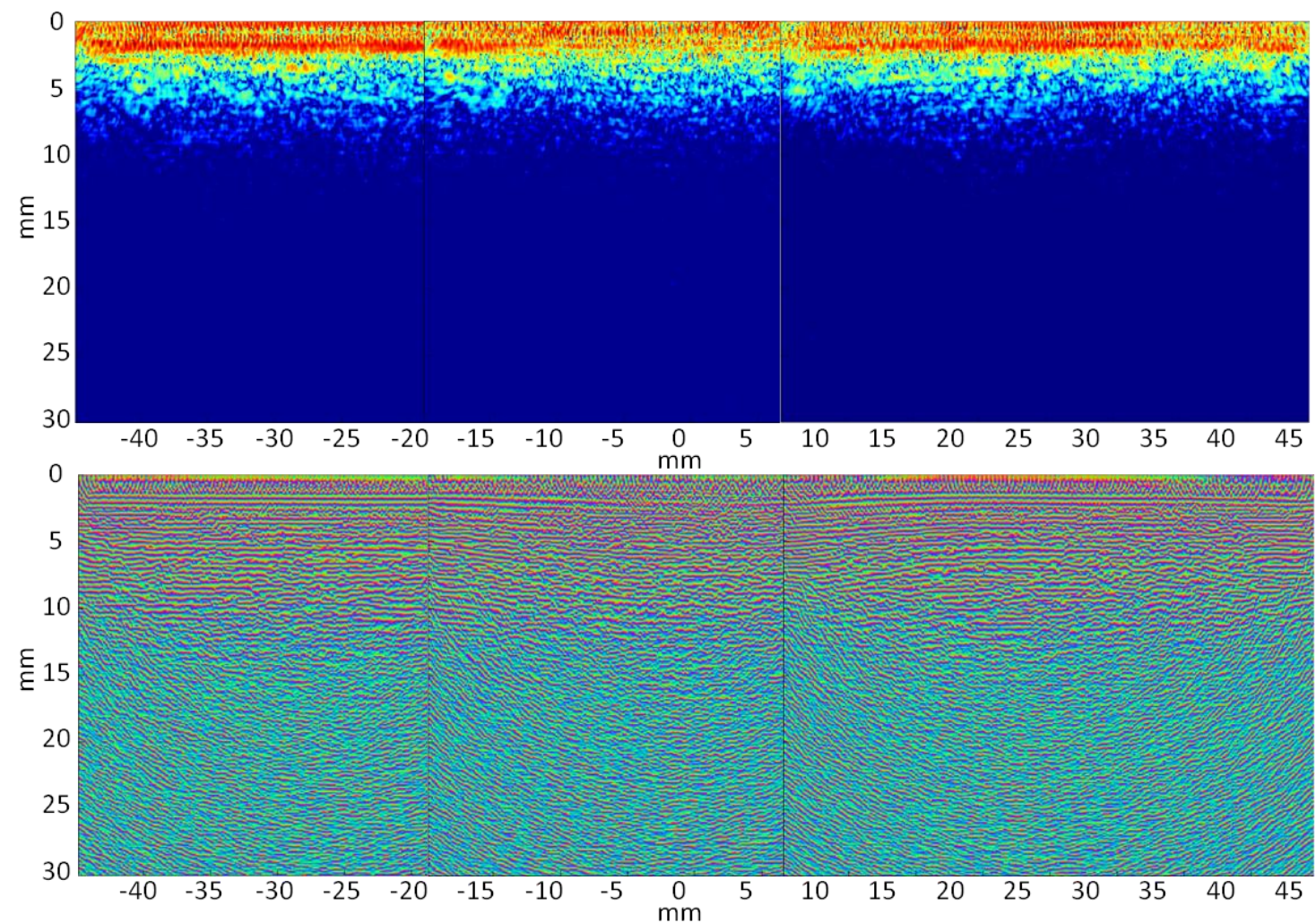

Figure 76: Reconstructed B-Scans of the Instantaneous Amplitude (above) and Instantaneous Phase (below) at $5 \mathrm{MHz}$ of the specimen $\mathrm{C}$ from the concave side of the wrinkle. 
In the inspection of this wrinkle from her concave size (Figure 76), the images doesn't show a wrinkle at all. A wrinkle may appear if the pixel size was reduced but it hasn't been possible to reduce it below $0.1 \mathrm{~mm}$.

The specimen $\mathrm{D}$ was first inspected with the $2.5 \mathrm{MHz}$ probe from its convex side (Figure 77). The back echo appears on both phase and amplitude but is clearer in the instantaneous amplitude images.

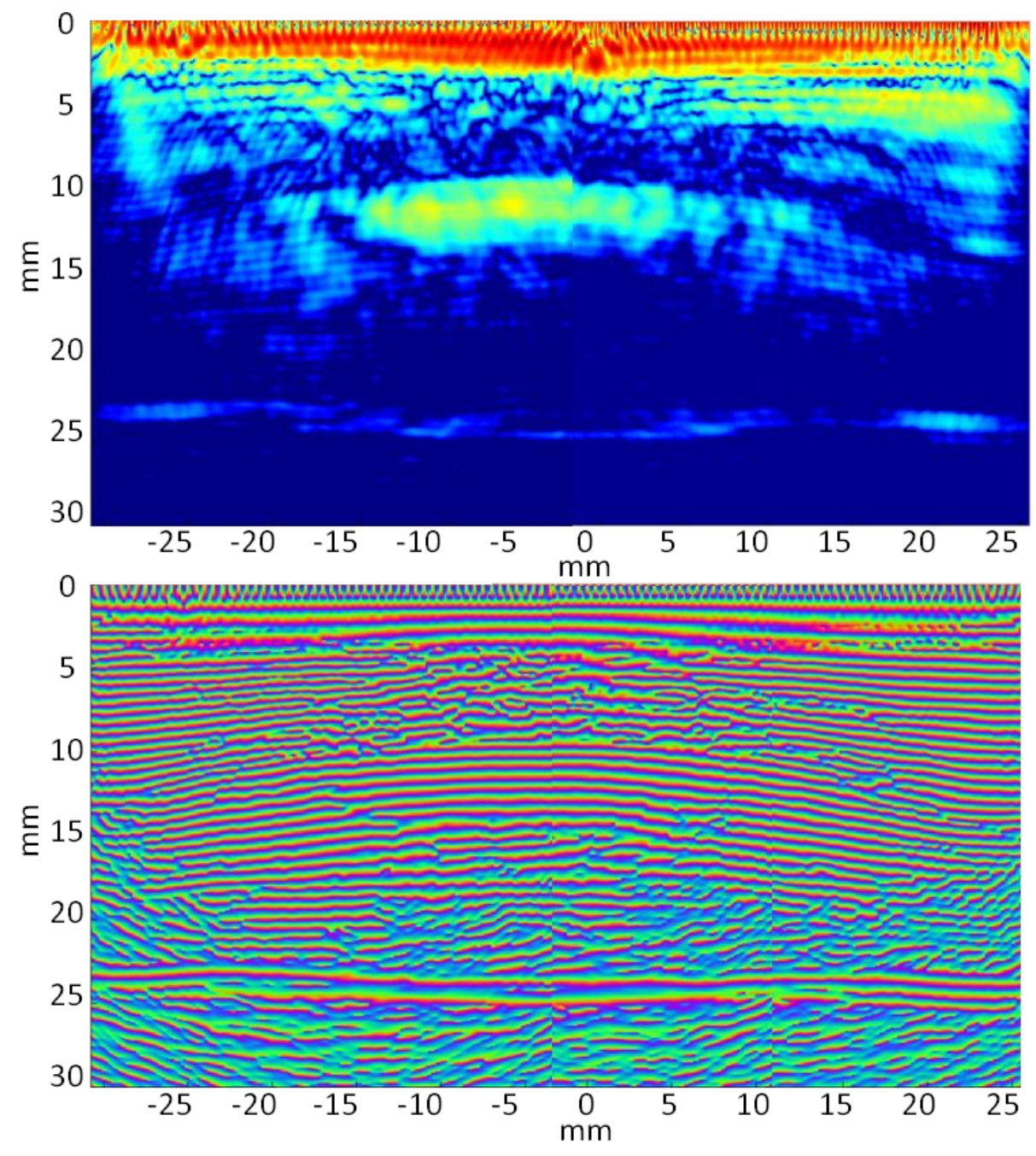

Figure 77: Reconstructed B-Scans of the Instantaneous Amplitude (above) and Instantaneous

Phase (below) at $2.5 \mathrm{MHz}$ of the specimen $\mathrm{D}$ from the convex side of the wrinkle.

The instantaneous amplitude shows the waviness, but it is in the instantaneous phase where the wrinkle can be detected and fully characterized. The wrinkle amplitude, angle and severity can be measure (Figure 78). 


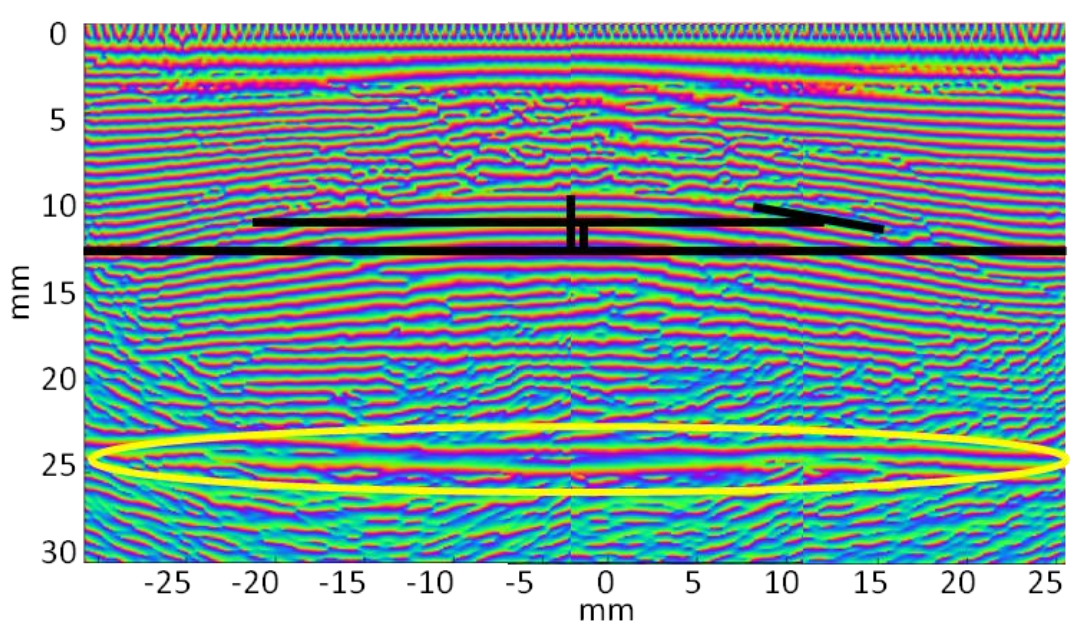

Figure 78: Measurement of the wrinkle parameters in specimen D with a $2.5 \mathrm{MHz}$ probe from the convex side of the wrinkle. The black wall echo is circled in yellow.

The specimen D was then inspected with the $2.5 \mathrm{MHz}$ probe from its concave side (Figure 79).
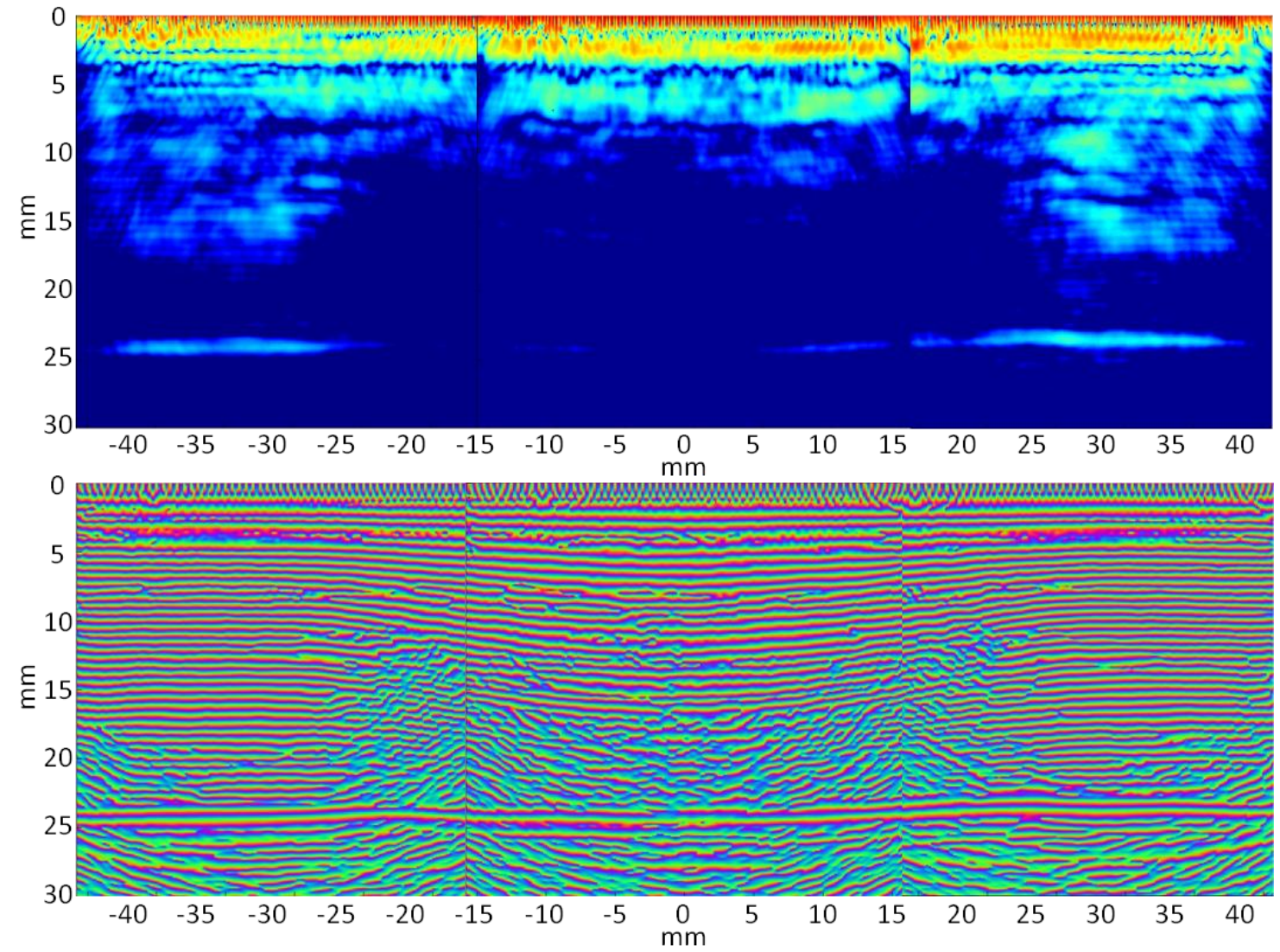

Figure 79: Reconstructed B-Scans of the Instantaneous Amplitude (above) and Instantaneous Phase (below) at $2.5 \mathrm{MHz}$ of the specimen $\mathrm{D}$ from the concave side of the wrinkle.

The wrinkle amplitude, angle and severity can be measure as shown in Figure 80. 


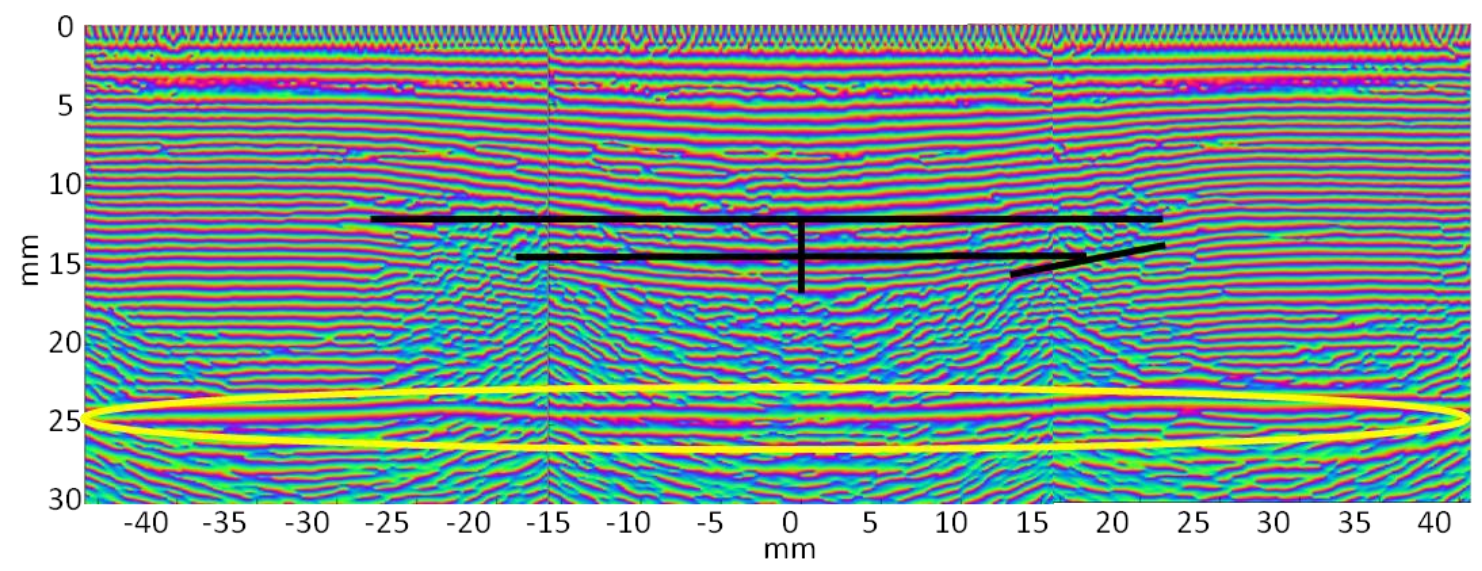

Figure 80: Measurement of the wrinkle parameters in specimen D with a $2.5 \mathrm{MHz}$ probe from the concave side of the wrinkle. The black wall echo is circled in yellow.

With $2.5 \mathrm{MHz}$, the image shows the whole part, with almost no interference. The flattened part of the wrinkle appears as a scattered signal. This can be due to the difference of resonant frequency. (The resonant frequency increases while the thickness of the layers decreases). The thinner layers have a higher resonant frequency, and therefore aren't well represented with the frequency that work better with the rest of the sample. A higher frequency, or a broader bandwidth, may be require in order to display a perfect image in that area of the wrinkle. This effect did not appear in the simulation using a $2.5 \mathrm{MHz}$ bandwidth, so the array probe used may have had a narrower bandwidth than this.
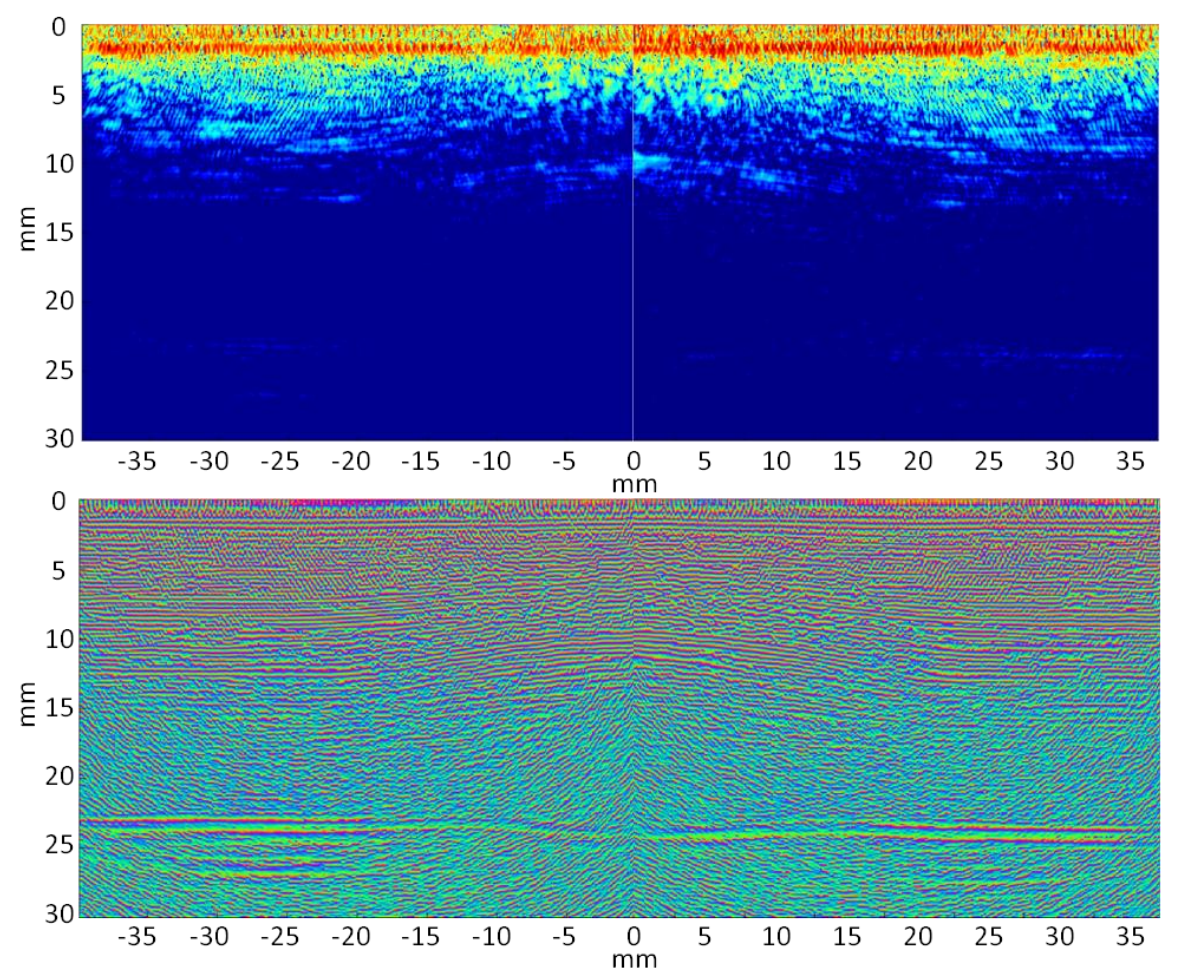

Figure 81: Reconstructed B-Scans of the Reconstructed B-Scans of the Instantaneous Amplitude (above) and Instantaneous Phase (below) at $5 \mathrm{MHz}$ of the specimen D from the convex side of the wrinkle. 
The specimen $\mathrm{D}$ was then inspected with the $5 \mathrm{MHz}$ probe. (Figure 81 and Figure 83). As expected from the simulation the instantaneous phase seems to be doubling herself (half the wavelength, twice the rate of phase increase with time). The back echo still appears on both phase and amplitude but only half of the specimen seems to be clearly represented. Beyond, they are too many interferences to visualize any pattern. A $3 \mathrm{MHz}$ frequency probe should probably be used to display an almost perfect image of this specimen. The wrinkle is measurable from the convex side (Figure 82).

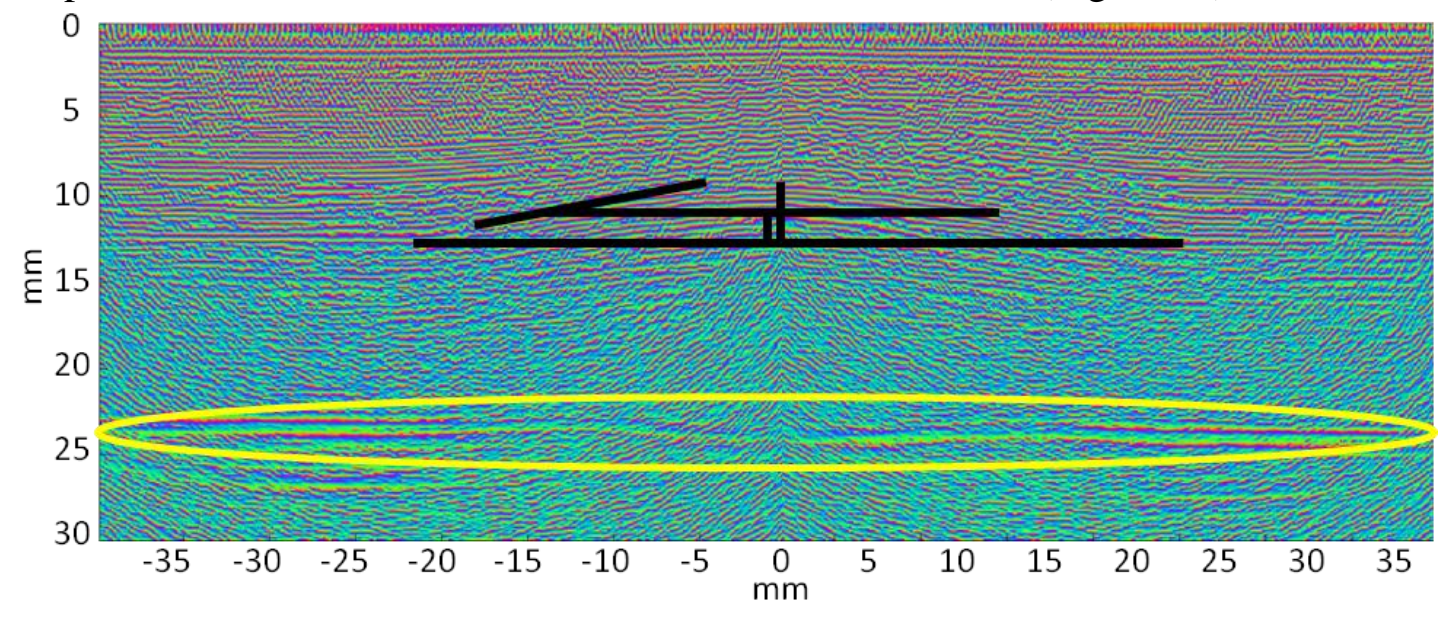

Figure 82: Measurement of the wrinkle in Specimen D with a $5 \mathrm{MHz}$ probe. The black wall echo is circled in yellow.
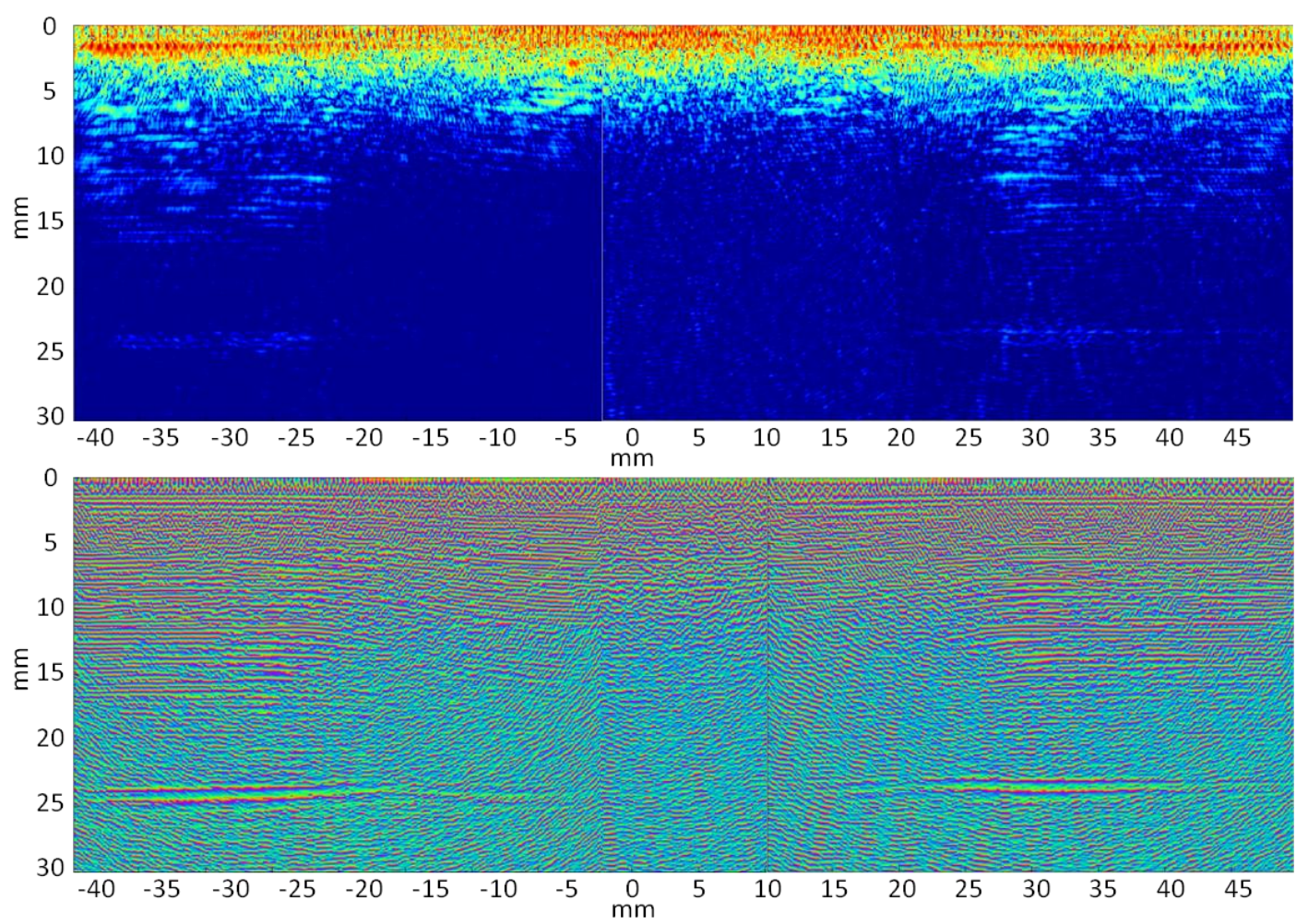

Figure 83: Reconstructed B-Scans of the Instantaneous Amplitude (above) and Instantaneous

Phase (below) at $5 \mathrm{MHz}$ of the specimen $\mathrm{D}$ from the concave side of the wrinkle. 
From her concave side (Figure 83), the wrinkle is not measurable with the method that is being used (Amplitude, severity or angle), because even if a wrinkle is perceive, there is no a clear line to follow. The signal does not come clearly to the bottom of the piece where the maximum amplitude is reached. In this particular case, the middle inspection point, seams very foggy.

\subsubsection{Inspections using the adapted-TFM algorithm to account for anisotropic velocities.}

Figure 84 shows the TFM instantaneous-phase image obtained for specimen B at $2.5 \mathrm{MHz}$ with a maximum propagation angle of 35 degrees. This image is obtained from the same inspection that Figure 66.

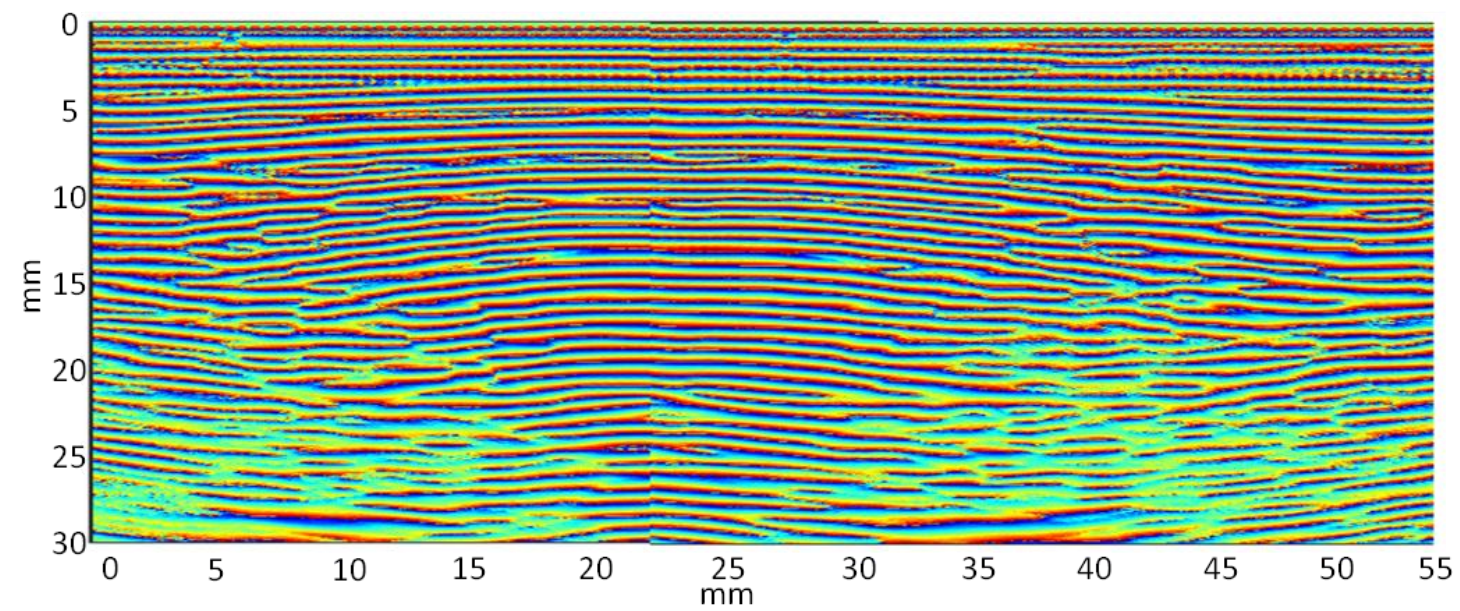

Figure 84: Reconstructed B-Scans of the Instantaneous Phase (below) at $2.5 \mathrm{MHz}$ of the specimen $\mathrm{B}$ from the convex side of the wrinkle.

Figure 85 shows the TFM instantaneous-phase image obtained for specimen B at $5 \mathrm{MHz}$ with a maximum propagation angle of 35 degrees. This image is obtained from the same inspection that Figure 69.

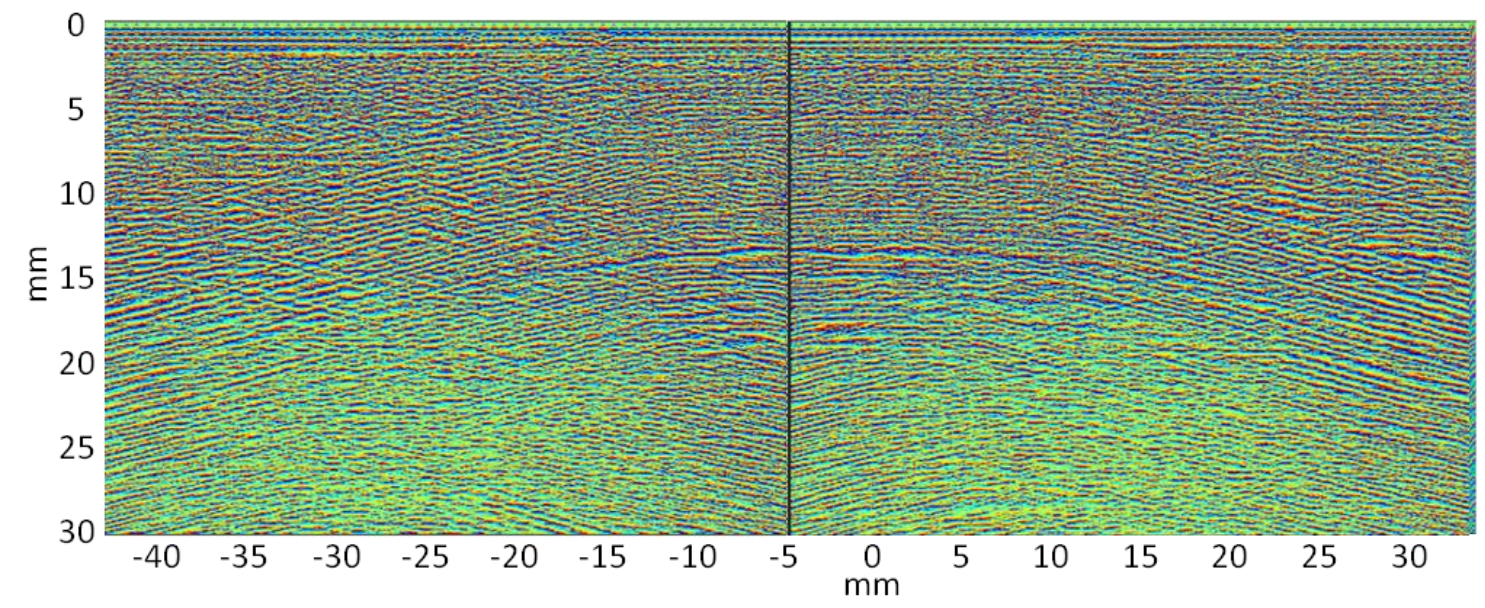

Figure 85: Reconstructed B-Scans of the Instantaneous Phase (below) at 5MHz of the specimen $\mathrm{B}$ from the convex side of the wrinkle. 
Figure 86 shows the TFM instantaneous-phase image obtained for specimen $\mathrm{C}$ at $2.5 \mathrm{MHz}$ with a maximum propagation angle of 35 degrees. This image is obtained from the same inspection that Figure 71.

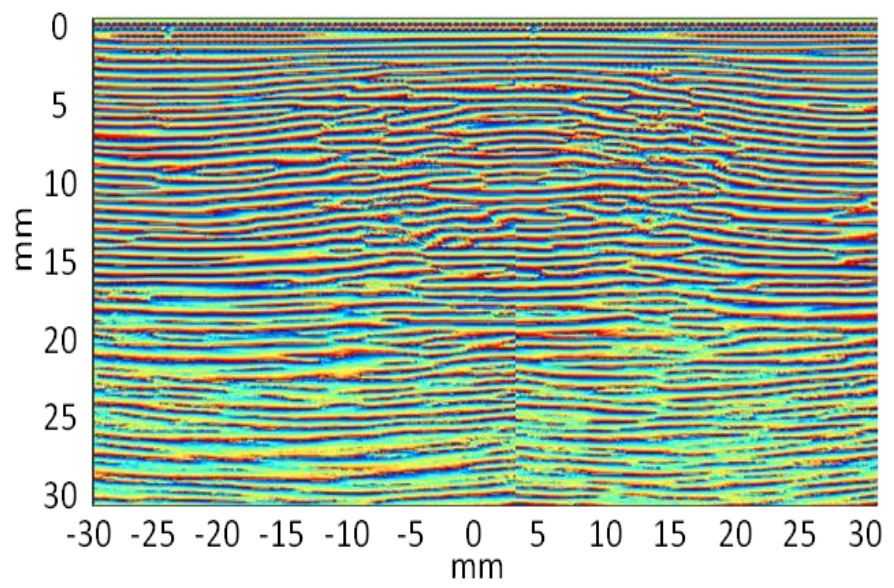

Figure 86: Reconstructed B-Scans of the Instantaneous Phase (below) at $2.25 \mathrm{MHz}$ of the specimen $\mathrm{C}$ from the convex side of the wrinkle.

Figure 87 shows the TFM instantaneous-phase image obtained for specimen $\mathrm{C}$ at $5 \mathrm{MHz}$ with a maximum propagation angle of 35 degrees. This image is obtained from the same inspection that Figure 75.

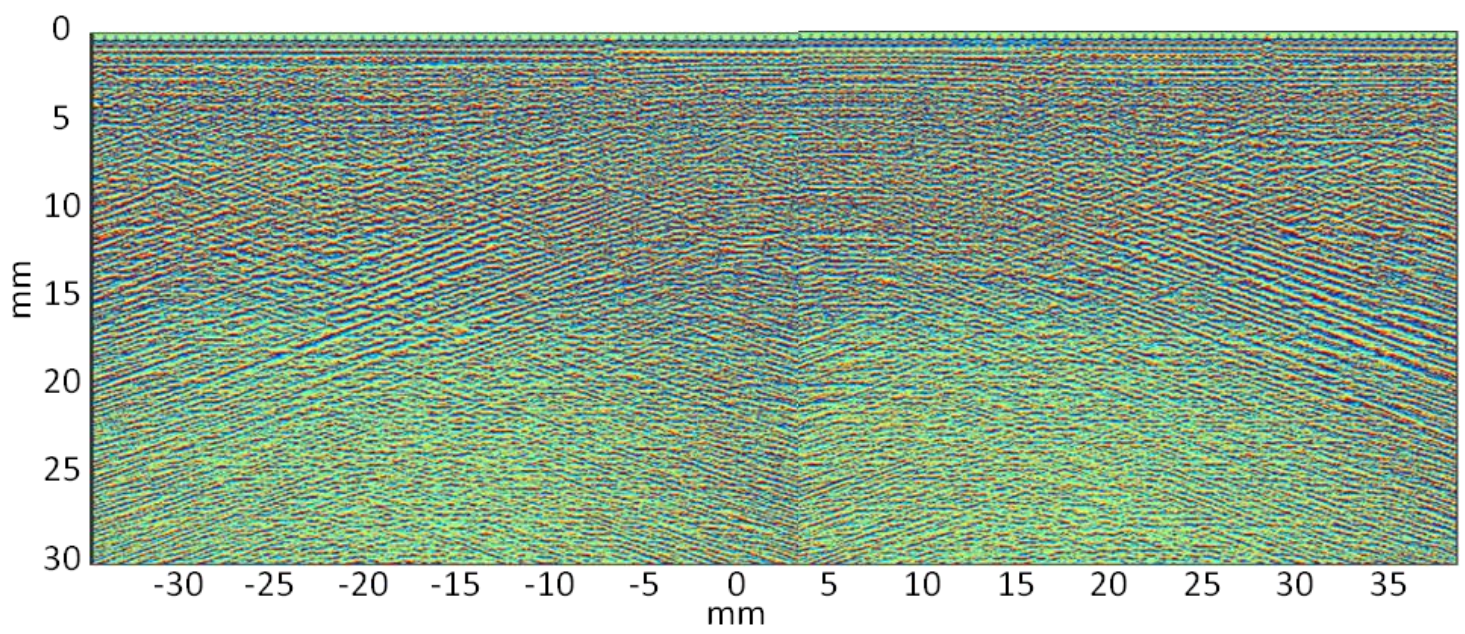

Figure 87: Reconstructed B-Scans of the Instantaneous Phase (below) at 5MHz of the specimen $\mathrm{C}$ from the convex side of the wrinkle.

Figure 88 shows the TFM instantaneous-phase image obtained for specimen D at 2.5 $\mathrm{MHz}$ with a maximum propagation angle of 35 degrees. This image is obtained from the same inspection that Figure 77. 


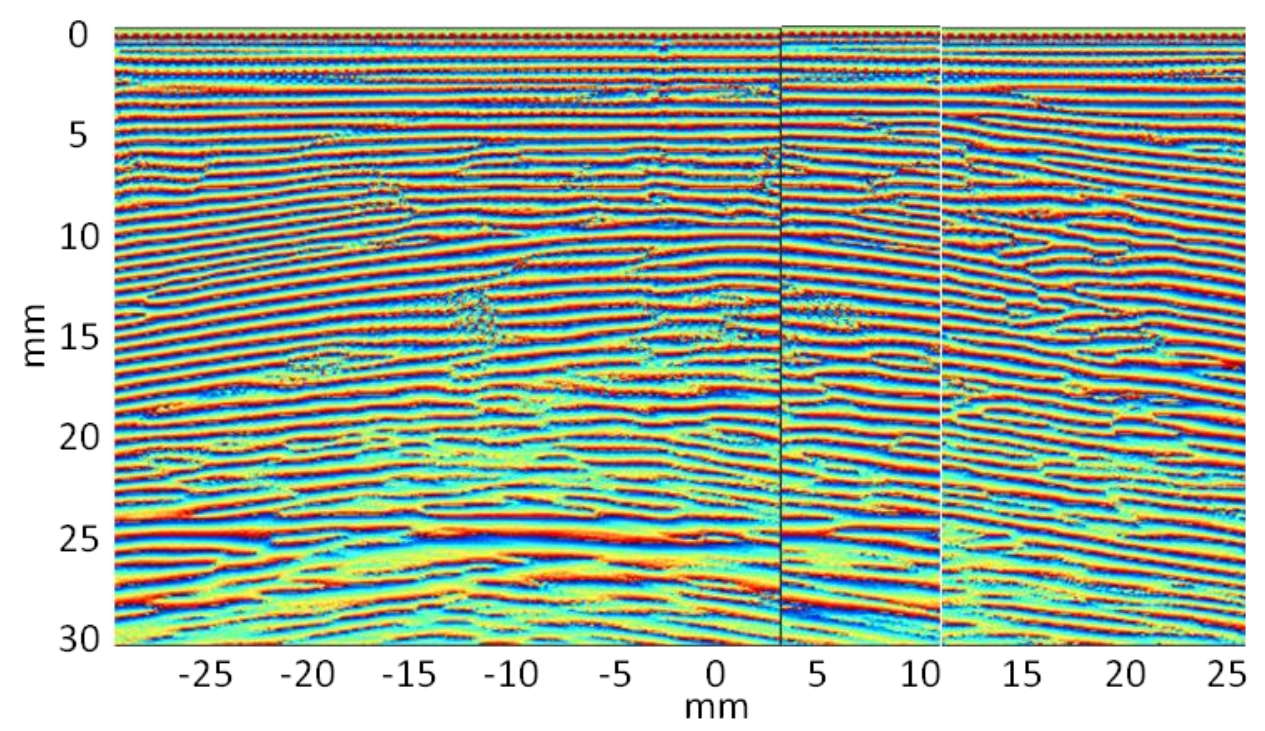

Figure 88: Reconstructed B-Scans of the Instantaneous Phase (below) at $2.25 \mathrm{MHz}$ of the specimen $\mathrm{D}$ from the convex side of the wrinkle.

Figure 89 shows the TFM instantaneous-phase image obtained for specimen D at $5 \mathrm{MHz}$ with a maximum propagation angle of 35 degrees. This image is obtained from the same inspection that Figure 81.

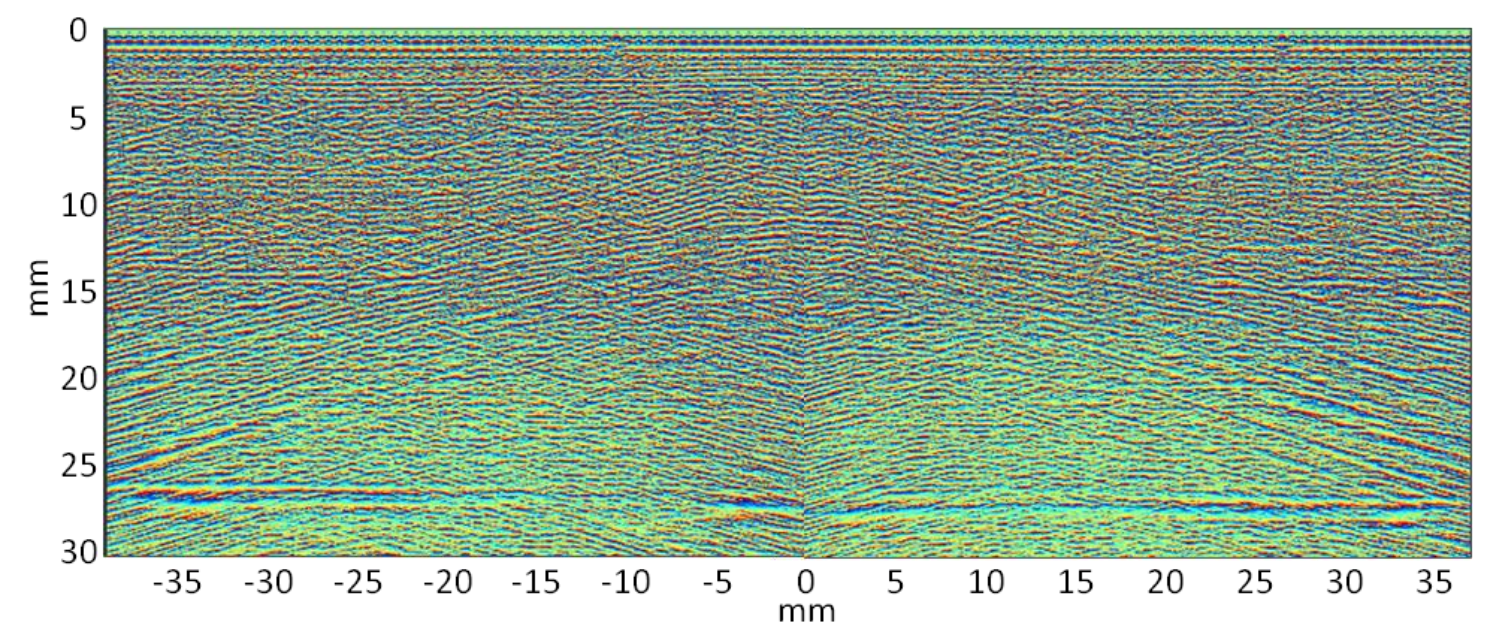

Figure 89: Reconstructed B-Scans of the Instantaneous Phase (below) at 5MHz of the specimen $\mathrm{D}$ from the convex side of the wrinkle.

\subsubsection{Results}

The measurements of the parameters were achieved with an electronic rule or protractor on the instantaneous phase B-Scan slices reconstructed with the isotropic TFM. The measured maximum wrinkle angle is unaffected by the TFM algorithm in this case. The improvement in imaging was not required for this particular measurement. However, the results do demonstrate the potential benefit of using an angle-dependent velocity in the TFM method to image the crucial maximum-angle section of a wrinkle. In this particular case, it was useful for proving that the correct location of maximum angle has been identified. 
The results obtained with the $2.5 \mathrm{MHz}$ probe and the $5 \mathrm{MHz}$ probe from the convex side of the sample are summarised in Table 12.

Table 12: Comparison between the actual parameters of the parts and those obtained from the convex side of the samples by the inspection with the TFM probes.

\begin{tabular}{|c|c|c|c|c|c|c|}
\hline \multirow{2}{*}{\multicolumn{2}{|c|}{$\begin{array}{c}\text { Specimen } \\
\text { and wrinkle } \\
\text { parameters. }\end{array}$}} & \multirow[b]{2}{*}{ Actual } & \multicolumn{2}{|c|}{$2.25 \mathrm{MHz}$} & \multicolumn{2}{|c|}{$5 \mathrm{MHz}$} \\
\hline & & & Measurec & Erel & Measured & Erel \\
\hline \multirow[t]{4}{*}{ B } & $\mathrm{H}(\mathrm{mm})$ & 3 & 3.6 & $20 \%$ & & \\
\hline & $\mathrm{L}(\mathrm{mm})$ & 53 & 47 & $11.32 \%$ & & \\
\hline & $\mathrm{A} / \mathrm{L}$ & 0.030 & 0.038 & $25 \%$ & & \\
\hline & $\theta$ & $8.5^{\circ}$ & $9^{\circ}$ & $5.88 \%$ & & \\
\hline \multirow[t]{4}{*}{ C } & $\mathrm{H}(\mathrm{mm})$ & 6 & 6.5 & $8.33 \%$ & & \\
\hline & $\mathrm{L}(\mathrm{mm})$ & 37 & 43 & $16.22 \%$ & & \\
\hline & $\mathrm{A} / \mathrm{L}$ & 0.090 & 0.075 & $16.67 \%$ & & \\
\hline & $\theta$ & $24^{\circ}$ & $22^{\circ}$ & $8.33 \%$ & & \\
\hline \multirow[t]{4}{*}{ D } & $\mathrm{H}(\mathrm{mm})$ & 3 & 3.2 & $6.67 \%$ & 3.5 & $16.67 \%$ \\
\hline & $\mathrm{L}(\mathrm{mm})$ & 53 & 49 & $7.55 \%$ & 44 & $16.99 \%$ \\
\hline & $\mathrm{A} / \mathrm{L}$ & 0.030 & 0.033 & $8.33 \%$ & 0.040 & $33.33 \%$ \\
\hline & $\theta$ & $8.5^{\circ}$ & $8.5^{\circ}$ & $0.00 \%$ & $10^{\circ}$ & $17.65 \%$ \\
\hline
\end{tabular}

The inspection from the concave side, only allow the detection and measurement of the wrinkle for sample $\mathrm{D}$ at $2.5 \mathrm{MHz}$. Both inspections from the concave side and from the convex side allow the detection of the wrinkle and a strong back echo appears. However the results from the concave size show measurement errors higher than the acceptable and up to $50 \%$. The results obtained from the concave side of the sample are summarised in Table 13.

Table 13: Comparison between the wrinkle parameters measured and expected at $2.5 \mathrm{MHz}$ for specimen D.

\begin{tabular}{|c|c|c|c|c|c|c|}
\hline \multirow{2}{*}{\multicolumn{2}{|c|}{$\begin{array}{c}\text { Specimen } \\
\text { and wrinkle } \\
\text { parameters. }\end{array}$}} & \multirow[b]{2}{*}{ Actual } & \multicolumn{2}{|c|}{ Convex } & \multicolumn{2}{|c|}{ Concave } \\
\hline & & & Measurec & crel & Measured & Erel \\
\hline \multirow[t]{4}{*}{ D } & $\mathrm{H}(\mathrm{mm})$ & 3 & 3.2 & $6.67 \%$ & 4.3 & $43.33 \%$ \\
\hline & $\mathrm{L}(\mathrm{mm})$ & 53 & 49 & $7.55 \%$ & 50 & $2.00 \%$ \\
\hline & $\mathrm{A} / \mathrm{L}$ & 0.030 & 0.033 & $8.33 \%$ & 0.045 & $50 \%$ \\
\hline & $\theta$ & $8.5^{\circ}$ & $8.5^{\circ}$ & $0.00 \%$ & $11.5^{\circ}$ & $35.29 \%$ \\
\hline
\end{tabular}

Since the wrinkle was recreated using only three inspections points, the border effect of any of the inspections may also be affecting the measurements. Figure 90 show the border effect on the instantaneous phase of sample $\mathrm{C}$ at $2.5 \mathrm{MHz}$. This effect could be avoided with an encoder that will allow to compose the B-Scan from the central AScan of each inspection. This effect is also present in the inspections using the adaptedTFM algorithm. Reducing the pixel size by increasing the digital waveform sampling frequency would also help to produce clearer images. 


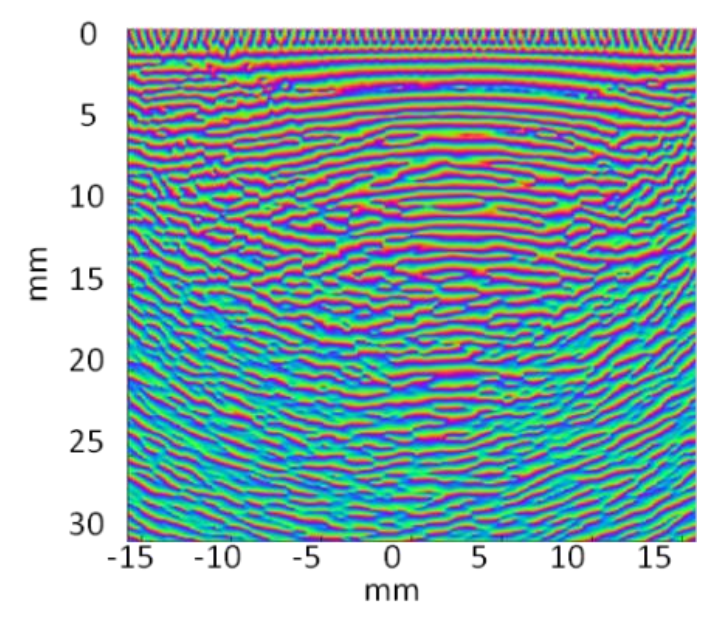

Figure 90: Reconstructed B-Scans of the Instantaneous Phase at 2.5 MHz of Sample C. The centre of the image present a deeper penetration than the sides due to the border effect.

\subsection{Comparison of results}

\subsubsection{Qualitative comparison}

As will be predicted by the simulations in chapter 5, interpretation was easier for the 2.25 and $2.5 \mathrm{MHz}$ probes. At $5 \mathrm{MHz}$, the instantaneous phase increases by $4 \pi$ radians per ply, as expected for a material that is excited by the second harmonic. Also, increasing the frequency has as a consequence a decreasing in the penetration of the signal in the material that causes that only the first half of the specimen seems to be clearly represented in the images - beyond this there are too many confusing interferences to visualise any clear pattern.

The glass-fibre layers of samples B and $\mathrm{C}$ have a dampening effect that prevents strong back-wall echoes to be obtained. No results were obtained when inspecting those samples with the $5 \mathrm{MHz}$ probes. When inspecting samples with internal glass-fibre layers the use of the resonant frequency seems even more important.

Outside the wrinkle area; all the specimen have relatively flat, even spaced plies. This flat region is visible at the right and left edges of each image. None of the inspections showed any further defects in the non-wrinkled area. For specimen D, all the techniques produced both amplitude and phase images that are relatively well locked to the plies, as will be predicted by the analytical model in Chapter 5. Whereas for specimens $\mathrm{B}$ and $\mathrm{C}$ some interference effects due to the glass plies are shown. In the amplitude and full waveform images stronger glass-fibre ply reflections are shown, as will be predicted by the model in Chapter 5. Figure 91 highly this effect in the inspection of sample B with the single element $2.25 \mathrm{MHz}$ immersion probe as an example. 


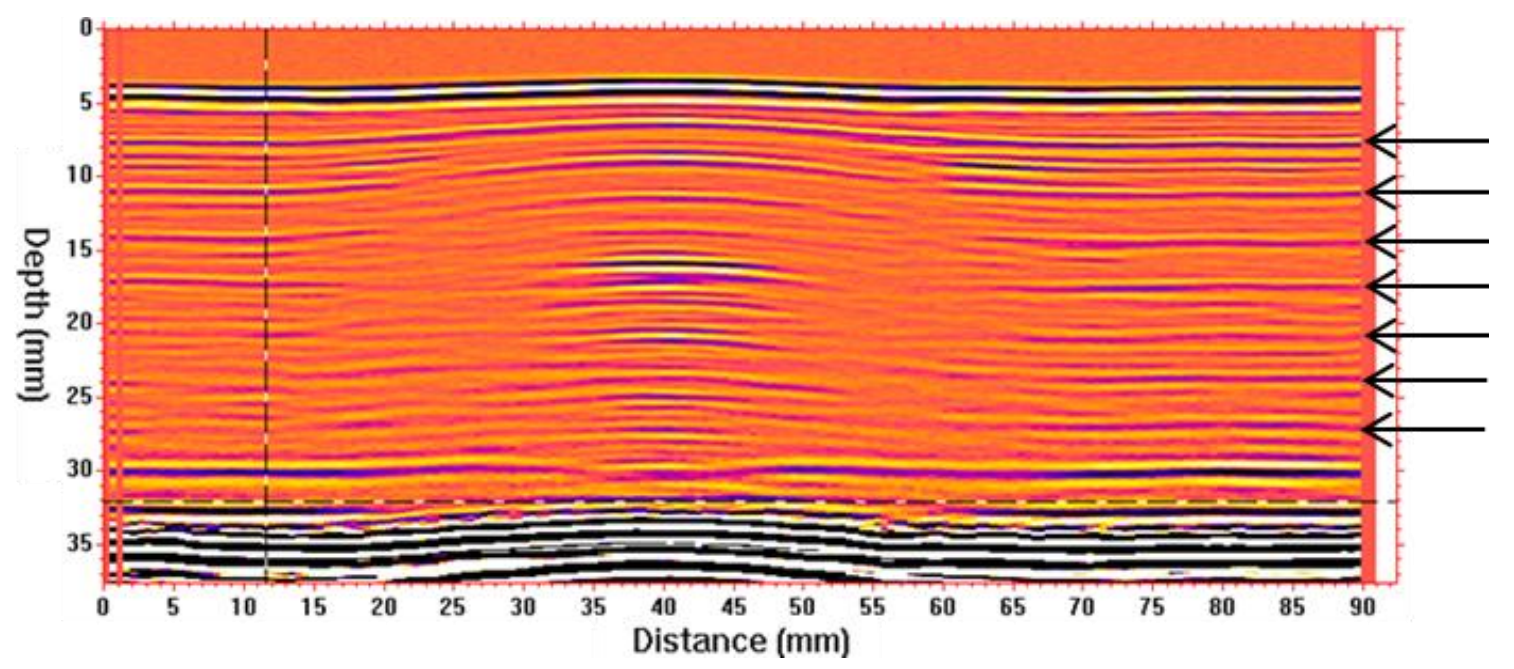

Figure 91: Reconstructed B-Scan of the full waveform at $2.25 \mathrm{MHz}$ of the specimen B. The stronger glass-fibre ply reflections in the flat region are pointed with arrows.

The wrinkling is much more obvious in the instantaneous phase images from the three techniques than in the full waveform or the instantaneous amplitude images. In the instantaneous-amplitude images from the FMC/TFM technique, some wrinkling becomes apparent but the wrinkling is clearer in the full waveform images from the other two techniques. This is probably because the full waveform contains both amplitude and phase information.

The imaging of the wrinkle area broadly agrees with the analytical-model simulations that will be presented in Chapter 5. The instantaneous amplitude of samples $\mathrm{B}$ and $\mathrm{C}$ is dominated by the GFRP-plies reflection. The instantaneous phase of samples $\mathrm{B}$ and $\mathrm{C}$ show a complex mix of CFRP ply reflection superimposed on both the strong GFRP ply reflections and the multiple reflections of the strong GFRP ply reflections. Compared with the true wrinkling, the grass-fibre multiple reflections have erroneously exaggerated wrinkle angles. The uniform reflections of the resin layers between CFRP plies dominates the response for sample D that has no internal GFRP plies. Therefore the individual plies are better imaged for sample D than for samples B and C.

An increased amplitude appears at middle of the three specimen at the peak of the wrinkle in the experimental amplitude and full waveform images using all three techniques. Because the reflection coefficient is approximately proportional to the resinlayer thickness, the increase amplitude may be caused by a thick resin layer at that depth. It can be assumed that the wrinkle manufacturing method left a thick resin-rich layer, caused by bridging where the second half of the specimen was laid-up into the wrinkle formed by the tool in the first half of the specimen. 
The thickness of the layers decreases significantly inside the wrinkle while the layers are compacting and this causes an increase in the resonance frequency. This effect is more apparent in sample $\mathrm{D}$, when being inspected with the $2.25 / 2.5 \mathrm{MHz}$ probes. The phase imaging in the thin-ply region above the wrinkle does not allow the tracking of every ply. The flattened part of the wrinkle appears almost as a scattered signal. The thinner layers have a higher resonant frequency, and therefore aren't well represented with the frequency that work better with the rest of the sample. The bandwidth of the lower frequency probes is insufficient for imaging the very thin plies of the wrinkle in sample D. The imaging of that area of sample D with the $5 \mathrm{MHz}$ probes are significantly better because the fundamental resonance of the thin wrinkled plies is close to the second harmonic of the flat plies. This problem is hidden by the interference patterns produced by the GFRP plies in samples B and C. The strong reflections of the GFRP dominate the response and allow the wrinkles to be imaged at both frequencies.

Inspections from the convex side of the wrinkle were perform only with the FMC/TFM technique. The dampening effect of the glass-fibre layers in samples B and $\mathrm{C}$ prevents proper inspection of the entire thickness. It was impossible to measure the wrinkle with the $2.25 / 2.5 \mathrm{MHz}$ probes because only half of the part presents a clear image and the reference layer was in the second half. With the $5 \mathrm{MHz}$ probe, almost all the image appears as a scattered signal. For sample D, the detection and measurement of the wrinkle was only possible with the $2.5 \mathrm{MHz}$ probe. However the results show measurement errors higher than the acceptable and up to 50\%. When inspecting thick samples with internal wrinkles the inspections may need to be carried out from both sides of the sample if the signal does not clearly penetrate to the full specimen.

\subsubsection{Quantitative comparison}

Table 14 summarise the results obtained by each of the three inspections techniques. No correction was applied in the measurements of the wrinkle parameters to account for the changes on sound velocity inside the sample that could distort the measurements.

Sample D was the only one where all the proposed parameters could be measured with the $5 \mathrm{MHz}$ probe using the commercial phased-array and FMC/TFM techniques. This is because sample D is mainly CFRP. For samples B and C, the ply-interface lines are not clear at $5 \mathrm{MHz}$, making it impossible to measure the wrinkle maximum height, angle and severity. One of the major difficulties encountered in defining the wrinkle accurately is to follow the line of maximum amplitude of the wrinkle (the reference layer). 
Table 14: Comparison between the actual parameters of the wrinkles and those obtained from the convex side of the specimens by each of the three inspections techniques.

\begin{tabular}{|c|c|c|c|c|c|c|c|c|}
\hline \multirow{2}{*}{\multicolumn{2}{|c|}{$\begin{array}{c}\text { Specimen } \\
\text { and } \\
\text { wrinkle } \\
\text { parameters }\end{array}$}} & \multirow{2}{*}{ Actual } & \multicolumn{2}{|c|}{ FMC/TFM } & \multicolumn{2}{|c|}{ Phased Array } & \multicolumn{2}{|c|}{$\begin{array}{c}\text { Single-element } \\
\text { focused }\end{array}$} \\
\hline & & & $\begin{array}{l}2.5 \\
\mathrm{MHz}\end{array}$ & $5 \mathrm{MHz}$ & $\begin{array}{l}2.25 \\
\mathrm{MHz}\end{array}$ & $5 \mathrm{MHz}$ & $\begin{array}{l}2.25 \\
\mathrm{MHz}\end{array}$ & $\begin{array}{l}5 \\
\mathrm{MHz}\end{array}$ \\
\hline \multirow[t]{4}{*}{ B } & $\mathrm{H}(\mathrm{mm})$ & 3 & 3.6 & & 3.15 & & 3.1 & \\
\hline & $\mathrm{L}(\mathrm{mm})$ & 53 & 47 & & 63 & & 55 & \\
\hline & $\mathrm{A} / \mathrm{L}$ & 0.030 & 0.038 & & 0.025 & & 0.028 & \\
\hline & $\theta$ & $8.5^{\circ}$ & $9^{\circ}$ & & $8.2^{\circ}$ & & $7.5^{\circ}$ & \\
\hline \multirow[t]{4}{*}{$\mathbf{C}$} & $\mathrm{H}(\mathrm{mm})$ & 6 & 6.5 & & 4.1 & & 4.0 & \\
\hline & $\mathrm{L}(\mathrm{mm})$ & 37 & 43 & & 41 & & 50 & \\
\hline & $\mathrm{A} / \mathrm{L}$ & 0.090 & 0.075 & & 0.050 & & 0.040 & \\
\hline & $\theta$ & $24^{\circ}$ & $22^{\circ}$ & & $13^{\circ}$ & & $14^{\circ}$ & \\
\hline \multirow[t]{4}{*}{ D } & $\mathrm{H}(\mathrm{mm})$ & 3 & 3.2 & 3.5 & 2.6 & 2.1 & 2.9 & 2.9 \\
\hline & $\mathrm{L}(\mathrm{mm})$ & 53 & 49 & 44 & 52 & 53 & 48 & 50 \\
\hline & $\mathrm{A} / \mathrm{L}$ & 0.030 & 0.033 & 0.040 & 0.025 & 0.020 & 0.030 & 0.029 \\
\hline & $\theta$ & $8.5^{\circ}$ & $8.5^{\circ}$ & $10^{\circ}$ & $7.6^{\circ}$ & $6.7^{\circ}$ & $7.6^{\circ}$ & $7.4^{\circ}$ \\
\hline
\end{tabular}

Recent studies (Xie et al. 2018) have shown that the key metric for determining the compression strength of a wrinkled composite is the maximum wrinkle angle, $\theta$. Therefore, this is the parameter that is going to be used to compare the three experimental methods. Figure 92 shows a comparison of the measured and actual maximum wrinkle angles for the three methods. Single-element immersion and commercial phased-array methods both underestimated the maximum wrinkle angle. For sample $\mathrm{C}$, the underestimate was about $50 \%$. The estimated error in maximum wrinkle angle for the FMC/TFM is approximately $\pm 10 \%$.

Sample $\mathrm{C}$ has a higher maximum wrinkle angle $\left(24^{\circ}\right)$ than the two other samples $\left(8.5^{\circ}\right)$. The only method that was able to image this steep angle with only a $10 \%$ underestimate was the FMC/TFM. The high relative errors in the measurements of the wrinkle angle with the single-element immersion and commercial phased-array methods may be explain if one of the GFRP interference echoes was measured erroneously. Complex response patterns make it difficult to discern the main echoes from interference echoes. 


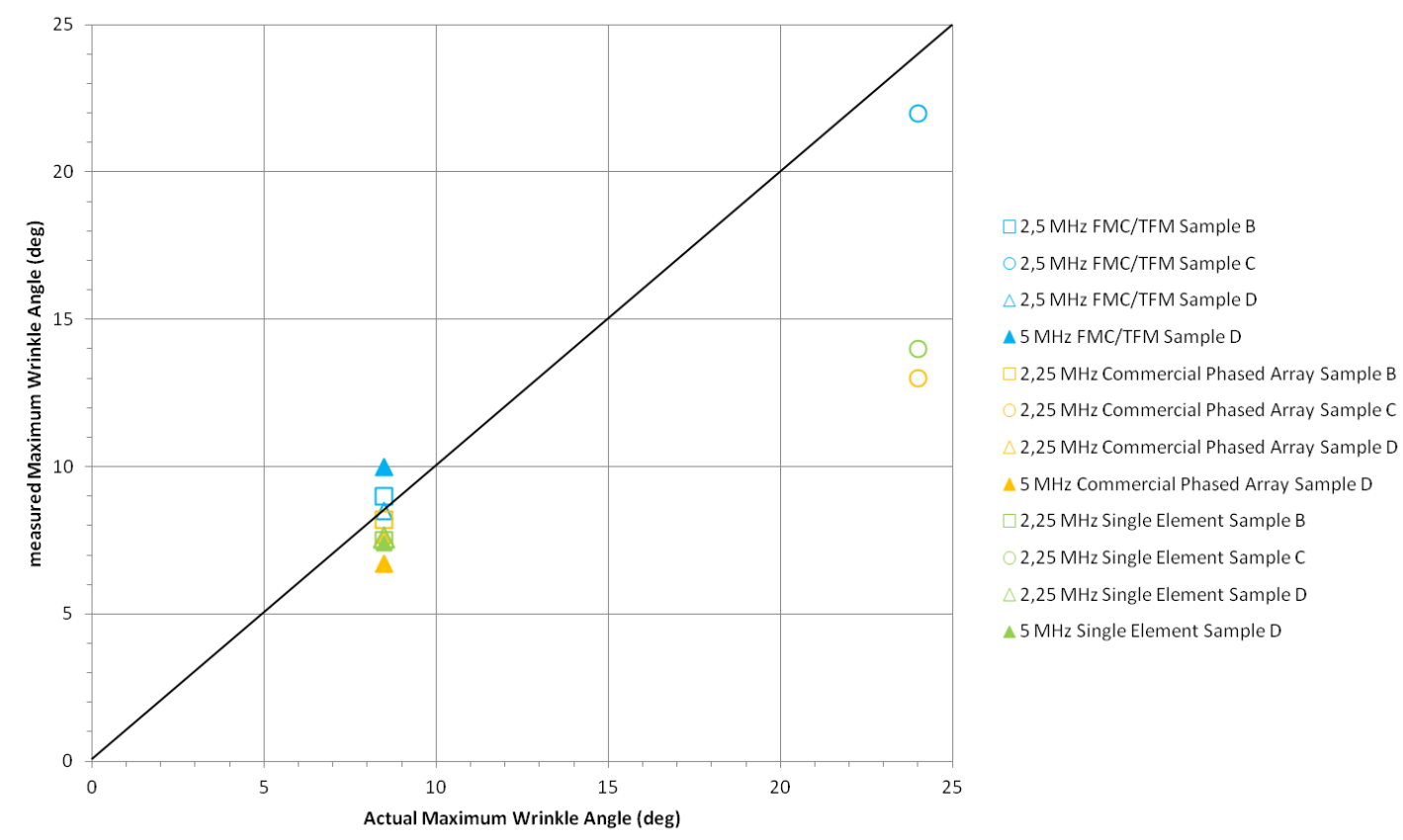

Figure 92: Graph showing a comparison of the measured and actual maximum wrinkle angles for the three methods and for $2.25 \mathrm{MHz}$ (solid symbols) and $5 \mathrm{MHz}$ (open symbols). The line represents where the measured angle equals the actual angle.

\subsubsection{Comparison of results}

With the FMC/TFM method, the characterization of the wrinkles with a reasonable precision was possible from the convex side of the samples using the instantaneous phase of the received signal and an appropriate inspection frequency (in this case $2.5 \mathrm{MHz}$ ). The resonant frequency seems to be the appropriate inspection frequency.

Commercial phased-array technology images have too many interferences from the stand-off and the characterization of the wrinkles with a reasonable precision was only possible from the $2.25 \mathrm{MHz}$ inspections.

With the single-element immersion scanning, the characterization of the wrinkle was possible using the instantaneous phase of the received signal was only possible from the $2.25 \mathrm{MHz}$ inspections.

The FMC/TFM present a clear benefit over the other two methods. The imaging appears to be improved by the fact that this method focus the reconstructed ultrasonic beam on every point in the B-Scan. The TFM algorithm that was used on the experiments assumed isotropic stiffness although the material of the samples was actually anisotropic. 


\section{CHAPTER 5 ULTRASONIC ANALYTICAL MODELLING}

In this chapter, the ultrasonic testing is modelled in order to predict the ultrasonic propagation through the layered material. First, the one-dimensional recursive analytical multi-later model that is used is explained and the resonance frequency of the plies is determined using the model. Then, the model is used to simulate the response from the mixed carbon/glass laminates. Finally, a preliminary $2 \mathrm{D}$ model is used to simulate the response of a simple carbon laminate.

\subsection{The one-dimensional recursive analytical multi-layer model}

A thin layer of resin remains between the plies of any laminate of composite material that has been manufactured using pre-impregnated composite fibres. Each resin-rich layer causes an small echo between the front and the back-wall echoes in the ultrasonic response of the laminate. Therefore, this resin-rich layer is key to make plies visible in a B-Scan (R A Smith et al. 2015).

An ultrasonic wave is partially reflected and partially refracted at any interface. For normal incidence plane waves, reflection $(\mathrm{R})$ and transmission $(\mathrm{T})$ coefficients can be calculated at each interface. An ultrasonic wave travelling from one composite ply to the next ply travels through two interfaces: first from the composite layer to the resinrich layer and then from the resin-rich layer to the next composite layer. In a resin-rich inter-ply resin layer the distance between the two interfaces is really small so multiple reflection occur. The overall reflection and transmission coefficients can be calculated thus resin-rich inter-ply layers are converted into single interfaces with complex reflection and transmission coefficients. This process is illustrated in Figure 93.

The absolute reflection coefficient of a single thin resin layer embedded in a composite can be calculated from equation (20).

$$
|r|=\frac{\left|\left(Z_{2}-Z_{1}\right)\left(Z_{2}+Z_{1}\right) \tan k_{2} l\right|}{\sqrt{4 Z_{2}^{2} Z_{1}^{2}+\left(Z_{2}^{2}+Z_{1}^{2}\right)^{2} \tan ^{2} k_{2} l}}
$$

The absolute transmission coefficient of a single thin resin layer embedded in a composite can be calculate from equation (21)

$$
|t|=\frac{2 Z_{1} Z_{2}}{\sqrt{4 Z_{2}^{2} Z_{1}^{2}+\left(Z_{2}-Z_{1}\right)^{2}\left(Z_{2}+Z_{1}\right)^{2} \sin ^{2} k_{2} l}}
$$


Where $\mathrm{Z}$ is the acoustic impedance of the material, $\mathrm{k}$ is the wave number $(2 \pi \mathrm{f} / \mathrm{c})$ and 1 is the thickness of the thin resin-rich inter-ply layer.
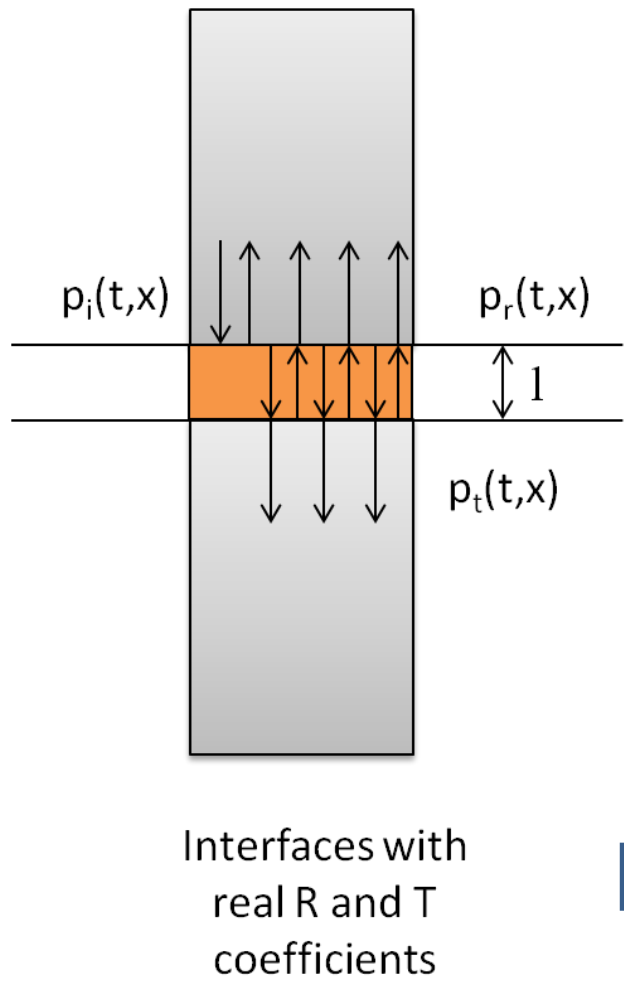

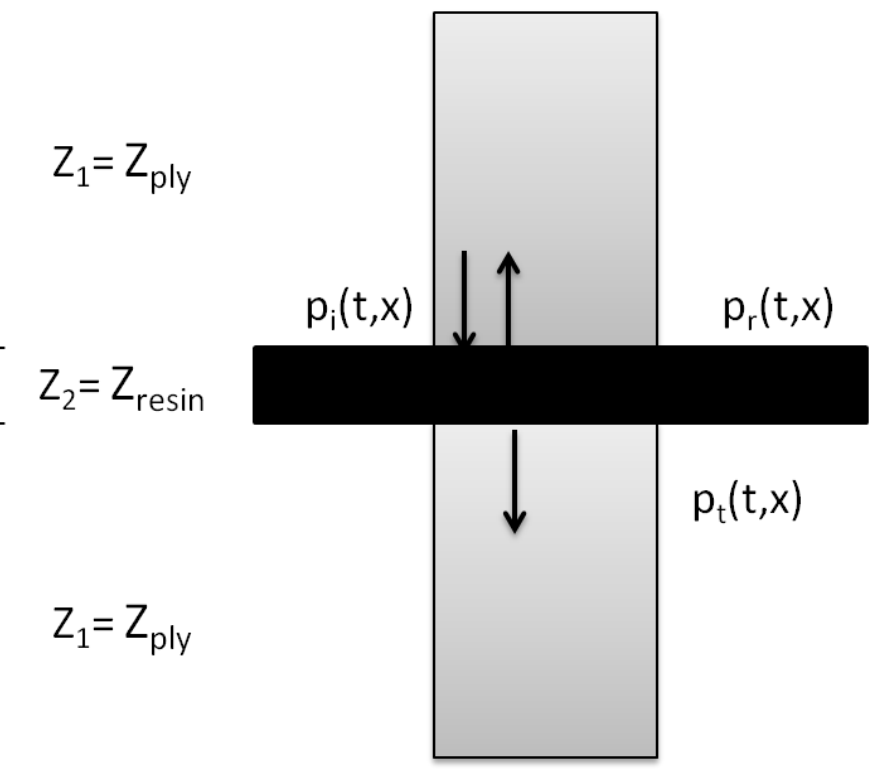

Resin layers with
complex R and $T$
coefficients

Figure 93:Diagram illustrating the process where the resin-rich inter-ply layers are converted into single interfaces with complex reflection and transmission coefficients. $\mathrm{Z}$ is the acoustic impedance of the material, $k$ is the wave number $(2 \pi \mathrm{f} / \mathrm{c}), 1$ is the thickness of the thin resin-rich inter-ply layer and $\mathrm{p}$ is the acoustic pressure.

Both the transmission and reflection coefficient are a function of frequency, among other things that depends on the material of the sample. The higher the reflection coefficient, the higher the receive echo of the resin-rich layer will be. The frequency that maximizes the reflection coefficient of the resin rich layer, is known as the resonance frequency.

(Robert A Smith 2010) developed a one-dimensional recursive normal-incidence analytical multi-layer model (The RAS Layer Model) and benchmarked it against other models and experiments. In the model, the single interfaces with complex reflection and transmission coefficients (obtained from the resin-rich inter-ply layers) plus its following inter-ply interface are then combined into joint reflection and transmission coefficients (Figure 94). Those coefficients are then successively combined with the following inter-ply interface into overall laminate reflection (R) and transmission (T) coefficients (Robert A. Smith et al. 2016). The model can be used to simulate the response of a composite laminate for a normal-incidence plane wave based on the thickness, density and compression modulus of each layer. In this model, the gradual change in the layer properties allow wrinkles to be modelled. The model calculates the 
pulse-echo frequency response of the laminate and then convolves it with the frequencydomain input signal.

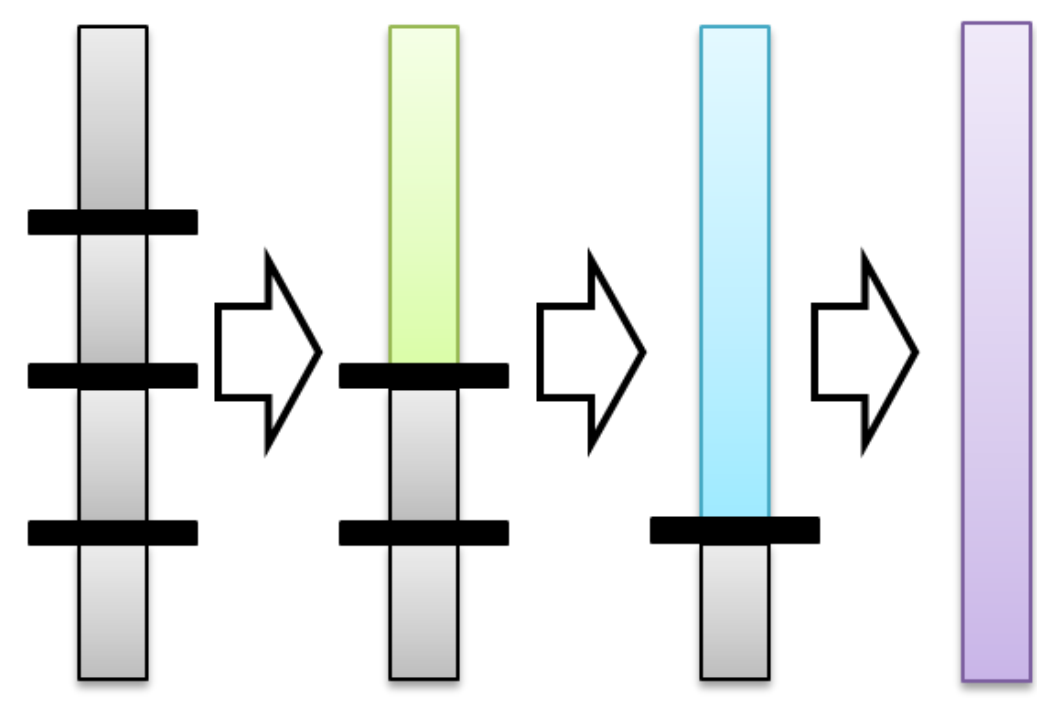

Figure 94: Diagram illustrating the process involved in the recursive analytical model

The longitudinal (compression) modulus $\mathbf{M}$ for isotropic materials is defined as the ratio of uniaxial stress to uniaxial strain when all strains in other directions are zero. $\mathrm{M}$ is of great interest for ultrasonic propagation studies where longitudinal-wave propagation is involved and can be calculated using equation (22) where c is the sound speed of a longitudinal wave and $\rho$ is the density of the material.

$$
M=\rho c^{2}
$$

The compression modulus is related to the Young's modulus and Poisson's ratio for isotropic materials via equation (23).

$$
M=E \frac{1-v}{(1+v)(1-2 v)}
$$

For transversely isotropic material, such as composites; transverse compression modulus (perpendicular to the axis of the fibre) and axial compression modulus (parallel to the axis of the fibre) can be calculated. The transversal compression modulus $\mathrm{M}_{11}$ of the fibre and the resin are of great interest when modelling an ultrasonic wave travelling through a composite laminate.

Composites materials can be described as an elastic, homogeneous, isotropic matrix with inclusions of another elastic, homogeneous, isotropic material. It is assumed that the composite material may be regarded as a quasi-homogenous and quasi-isotropic equivalent medium and described by effective elastic moduli and an effective density. The mixture rules that are used in the model in order to determine effective-medium properties for the composite plies are the Hashin (1965) mixture rules for long-fibre composites. The model calculate the transverse compression modulus using the Hashin 
isotropic-fibre expressions that still apply for ultrasonic propagation across the plies as shown by Hashin (1979).

The effective-medium properties figures for the water, resin, carbon and glass fibres that are built into the model are as follows in ¡Error! La autoreferencia al marcador no es válida.

Table 15: Material properties of component materials used in the one-dimensional recursive analytical multi-layer model.

\begin{tabular}{l|c|c|c|c} 
& $\begin{array}{c}\text { Compression } \\
\text { Modulus, } \\
\mathbf{M}_{\mathbf{1 1}}(\mathbf{G P a})\end{array}$ & $\begin{array}{c}\text { Density, } \boldsymbol{\rho} \\
\left(\mathbf{k g} / \mathbf{m}^{\mathbf{3}}\right)\end{array}$ & $\begin{array}{c}\text { Attenuation Coefficient } \\
\mathbf{( d B / m m / M H z})\end{array}$ & $\begin{array}{c}\text { Poisson } \\
\text { Ratio v }\end{array}$ \\
\hline Water & 2.05 & 998 & $\mathrm{n} / \mathrm{a}($ see text) & 0.5 \\
Epoxy resin & 10.7 & 1270 & 0.15 & 0.37 \\
Carbon Fibre & 16.0 & 1690 & 0 & 0.28 \\
Glass Fibre & 80.2 & 2570 & 0 & 0.20
\end{tabular}

In the model, both upper and lower surfaces of the laminate are connected to water. This means that the samples are modelled in immersion. The model includes attenuation due to visco-elastic damping in the resin but does not include frequencydependent attenuation in the water. This is because the input pulse is defined at the front surface of the specimen that is being modelled. No artificial noise was added for the simulations. The model is pulse-echo so the reflected response is used.

\subsection{Determination of the resonance frequency of the plies}

In order to determine the ideal probe frequency and bandwidth with which the inspections will be made, it is necessary to first determine the resonance frequency of the plies. The RAS Layer Model with Pulse Length Variation in Matlab is used to simulate some composites laminates.

The medium properties used for the simulations are summarised in Table 15. The model does not output the properties of the effective media (mixed carbon/epoxy layer and mixed glass/epoxy layer) nor does it require them as an input. In the model, the nominal inter-ply resin layer thickness is supposed to be $0.01 \mathrm{~mm}$. The fibre volume fraction is approximate $60 \%$ for the unidirectional carbon fibre and the woven glass.

To begin with, an 18 carbon fibre layers laminate with $0.6 \mathrm{~mm}$ carbon fibre plies is simulated. On this first approach, the number of layers is not critical for the determination of the resonance frequency of the plies and the simulation of thick laminates (with 42-49 layers) would increase needlessly the calculation time. Figure 95 show the simulated response from that laminate using a $1.5 \mathrm{MHz}$ centre frequency and a $3 \mathrm{MHz}$ bandwidth. The RAS Layer Model is a 1D model that generates A-Scans. The B-Scan in Figure 95 and next is, essentially, a series of stacked A-Scans where the horizontal axis is the position and the vertical axis is the ultrasound signal. 

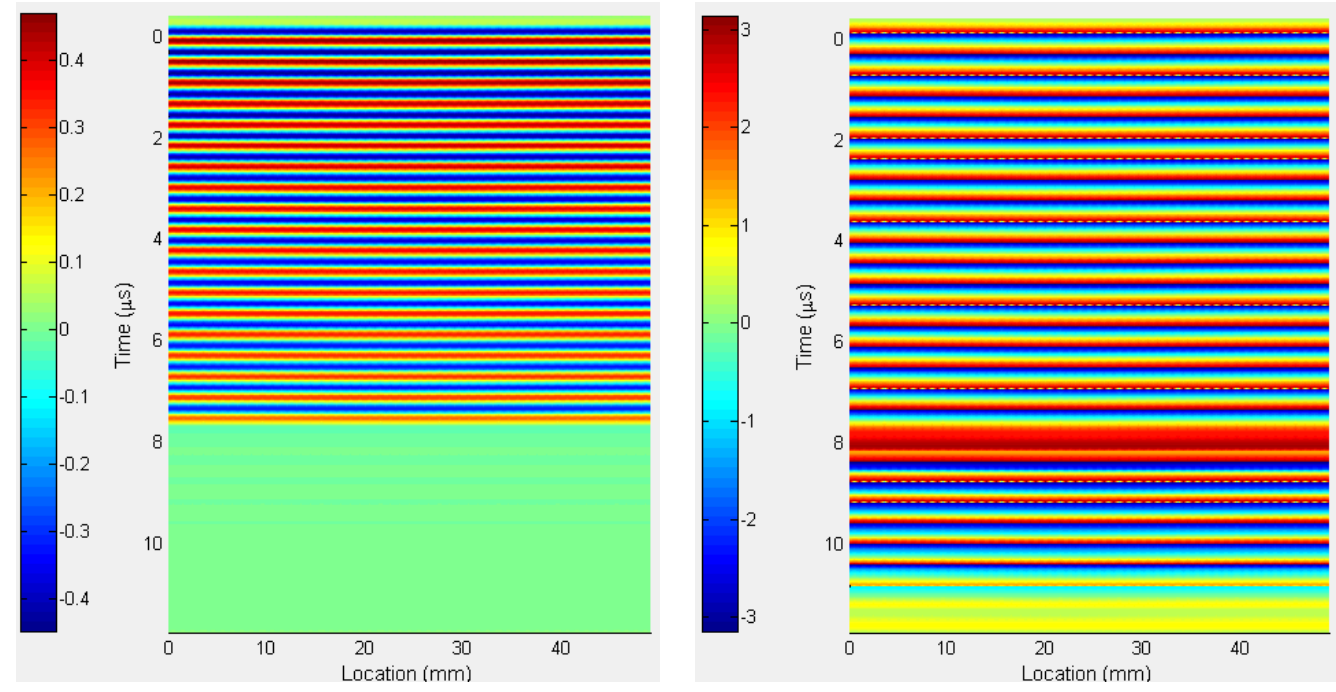

Figure 95: Simulated response from eighteen CFRP $0.6 \mathrm{~mm}$ thick plies using a $1.5 \mathrm{MHz}$ centre frequency and a $3 \mathrm{MHz}$ bandwidth. Full waveform (left) and instantaneous phase (right).

The reflection coefficient frequency spectrum of that laminate (Figure 96) allows the calculation of the resonant frequency that corresponds to a $0.6 \mathrm{~mm}$ carbon fibre ply. The model show that the fundamental resonance frequency that correspond to a $0.6 \mathrm{~mm}$ ply spacing in a carbon fibre composite is $2.3 \mathrm{MHz}\left(\mathrm{F}_{\mathrm{R} 1}\right)$. The second-harmonic resonance frequency is $4.7 \mathrm{MHz}\left(\mathrm{F}_{\mathrm{R} 2}\right)$.

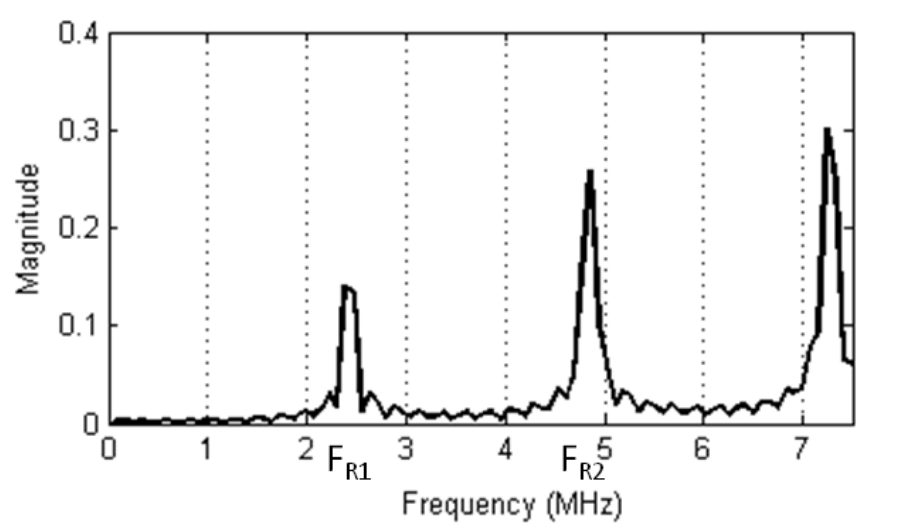

Figure 96: Reflection coefficient of an 18 layers carbon fibre laminate with a $0.6 \mathrm{~mm}$ ply thickness.

Nevertheless, the ply spacing decreases inside the wrinkle while the layers are compacting. This causes a change in the resonance frequency, which changes along the whole wrinkle. In order to evaluate this effect, several 18 carbon fibre layers laminates with a protruding wrinkle with increasing amplitude were simulated. As an example, Figure 97 show the simulated response from the laminate with a $2 \mathrm{~mm}$ high protruding wrinkle and Figure 98 show the reflection coefficient frequency spectrum of that laminate at the point of highest amplitude of the wrinkle. The ply thickness is at that point $0.488 \mathrm{~mm}$. 

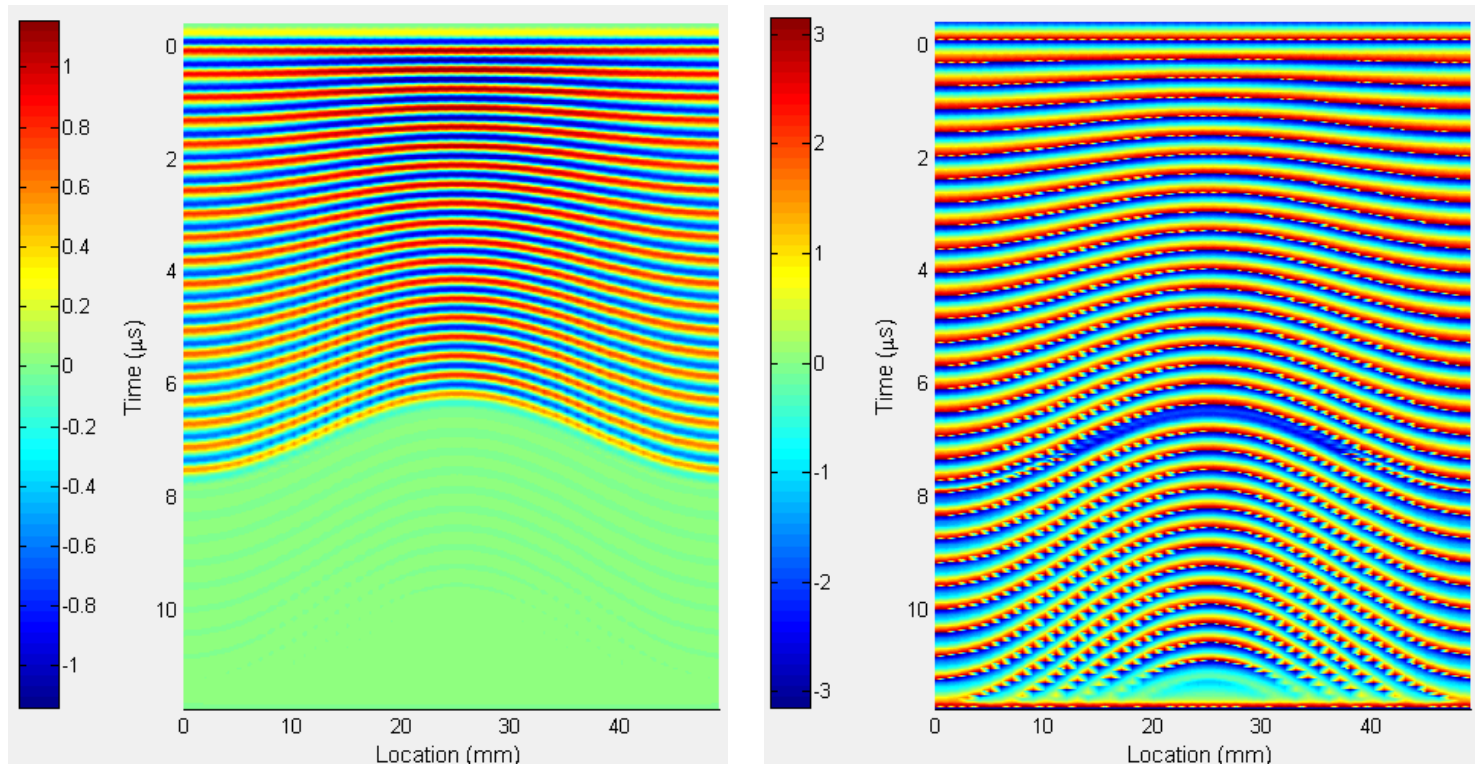

Figure 97: Simulated response from eighteen $0.6 \mathrm{~mm}$ thick plies with a $2 \mathrm{~mm}$ high protruding wrinkle using a $2.5 \mathrm{MHz}$ centre frequency and a $2.5 \mathrm{MHz}$ bandwidth. Full waveform (left) and instantaneous phase (right).

It should be noted that the centre frequency and bandwidth of the samples does affect the simulated response but does not affect the reflection coefficient of the laminate. In these simulations, the reflection coefficient is a function of the ply thickness. This is why different centre frequency and bandwidth were used on the different simulated response that are presented in this section.

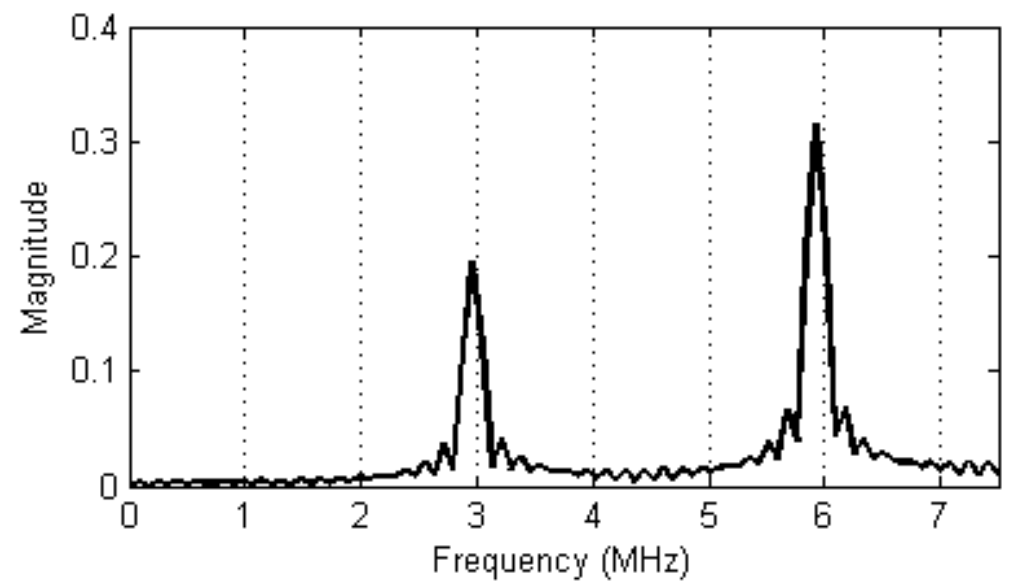

Figure 98: Reflection coefficient at the thinnest point of the wrinkle of an 18 layers carbon fibre laminate with a $2 \mathrm{~mm}$ protruding wrinkle. The ply thickness is at that point $0.488 \mathrm{~mm}$.

The bigger the wrinkle amplitude, the higher is the resonant frequency at the position of maximum deviation, as shown in Table 16. 
Table 16:Variation of the resonance frequency with the ply Thickness on a carbon wrinkled laminate

\begin{tabular}{ccc}
\hline Minimum Ply Thickness & Wrinkle Amplitude & Maximum Resonant Frequency \\
\hline $0.6 \mathrm{~mm}$ & $0 \mathrm{~mm}$ (Not wrinkled) & $2.3 \mathrm{MHz}$ \\
\hline $0.54 \mathrm{~mm}$ & $1 \mathrm{~mm}$ & $2.6 \mathrm{MHz}$ \\
\hline $0.488 \mathrm{~mm}$ & $2 \mathrm{~mm}$ & $2.9 \mathrm{MHz}$ \\
\hline $0.433 \mathrm{~mm}$ & $3 \mathrm{~mm}$ & $3.0 \mathrm{MHz}$ \\
\hline $0.266 \mathrm{~mm}$ & $6 \mathrm{~mm}$ & $3.9 \mathrm{MHz}$ \\
\hline
\end{tabular}

Because the resonance frequency increases inside the wrinkle, it seems wise to use a $2.5 \mathrm{MHz}$ probe (resonant frequency) to inspect carbon fibre specimens with a 0.6 $\mathrm{mm}$ thick plies but with a bandwidth that covers the increase of resonance frequency inside the wrinkle.

In the same way, several 18 glass fibre layers laminates are simulated. The reflection coefficient of the non-wrinkled area of the first laminate allows the calculation of the resonant frequency that corresponds to a $0.44 \mathrm{~mm}$ glass fibre ply. The resonant frequencies of a $0.44 \mathrm{~mm}$ ply thickness glass fibre can be calculated from Figure 99 . Therefore the resonance frequency that correspond to a $0.44 \mathrm{~mm}$ ply spacing in an e-glass fibre composite is $3.8 \mathrm{MHz}\left(\mathrm{F}_{\mathrm{R} 1}\right)$.

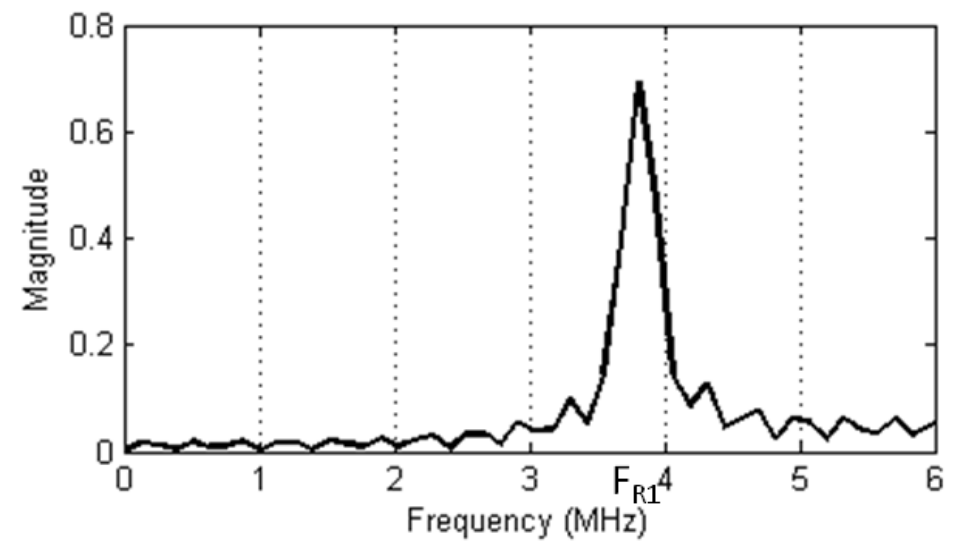

Figure 99: Reflection coefficient of an 18 layers e-glass fibre laminate with a $0.44 \mathrm{~mm}$ ply thickness.

In analogy, the ply spacing decreases inside the wrinkle while the layers are compacting, causing an increase in the resonance frequency. Multiple 18 glass fibre layers laminates with a protruding wrinkle with increasing amplitude were simulated. As an example, Figure 100 show the simulated response from the laminate with a $1 \mathrm{~mm}$ high protruding wrinkle and Figure 101 show the reflection coefficient frequency spectrum of that laminate at the point of highest amplitude of the wrinkle. The ply thickness is at that point $0.384 \mathrm{~mm}$. 

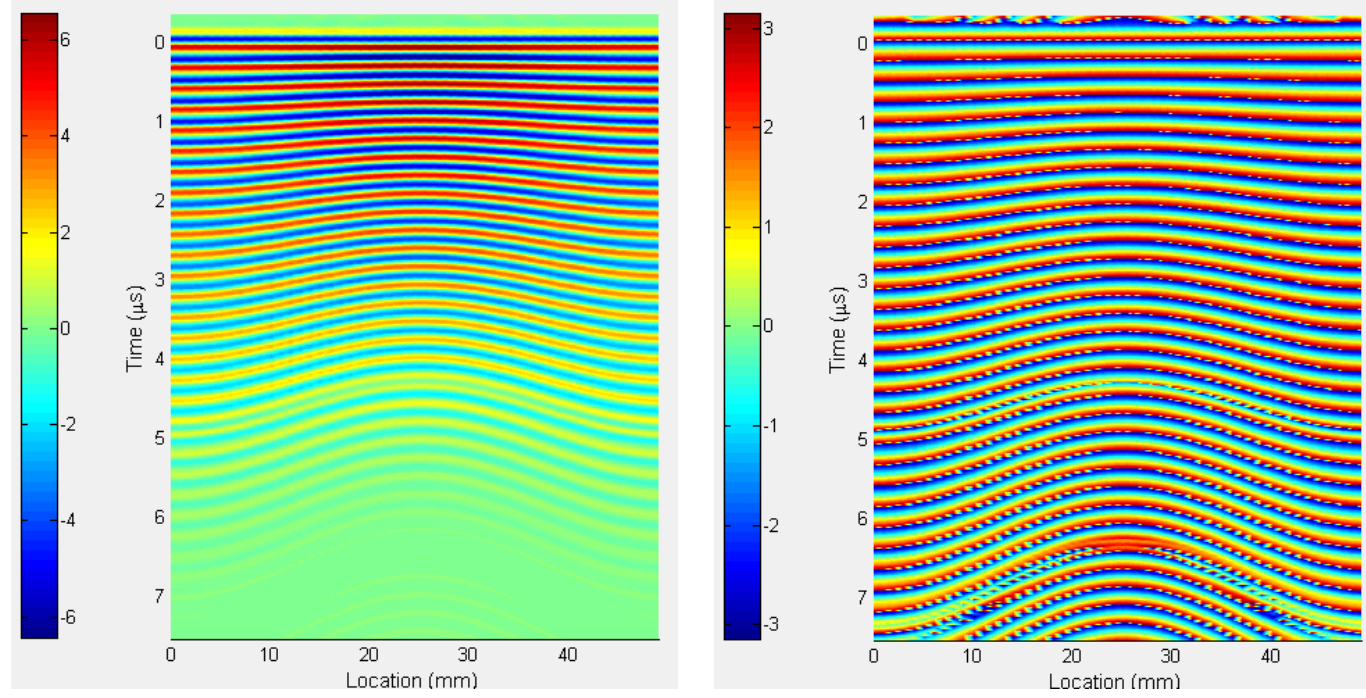

Figure 100: Simulated response from eighteen $0.44 \mathrm{~mm}$ thick plies with a $1 \mathrm{~mm}$ high protruding wrinkle using a $4 \mathrm{MHz}$ centre frequency and a $4 \mathrm{MHz}$ bandwidth. Full waveform (left) and instantaneous phase (right).

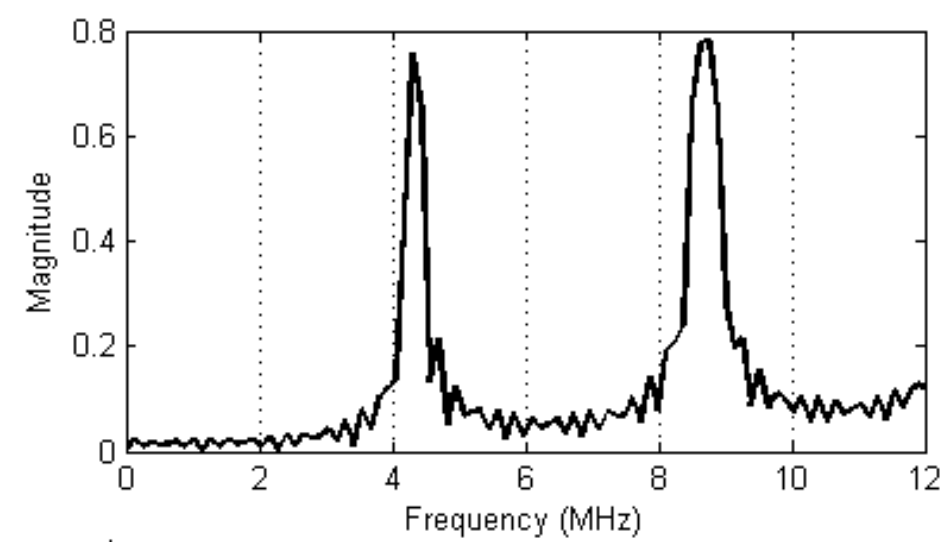

Figure 101: Reflection coefficient at the thinnest point of the wrinkle of an 18 layers glass fibre laminate with a $1 \mathrm{~mm}$ protruding wrinkle. The ply thickness is at that point $0.384 \mathrm{~mm}$.

The bigger the wrinkle amplitude, the higher is the resonant frequency at the position of maximum deviation, as shown in Table 17.

Table 17: Variation of the resonance frequency with the ply thickness on a wrinkled glass laminate

\begin{tabular}{ccc}
\hline Minimum Ply Thickness & Wrinkle Amplitude & Maximum Resonant Frequency \\
\hline $0.44 \mathrm{~mm}$ & $0 \mathrm{~mm}$ (Not wrinkled) & $3.8 \mathrm{MHz}$ \\
\hline $0.384 \mathrm{~mm}$ & $1 \mathrm{~mm}$ & $4.1 \mathrm{MHz}$ \\
\hline $0.328 \mathrm{~mm}$ & $2 \mathrm{~mm}$ & $4.3 \mathrm{MHz}$ \\
\hline $0.273 \mathrm{~mm}$ & $3 \mathrm{~mm}$ & $4.6 \mathrm{MHz}$ \\
\hline $0.106 \mathrm{~mm}$ & $6 \mathrm{~mm}$ & $6.1 \mathrm{MHz}$ \\
\hline
\end{tabular}


Because specimens $\mathrm{B}, \mathrm{C}$ and $\mathrm{D}$ are mainly carbon fibre, a $2.5 \mathrm{MHz}$ probe (resonant frequency of the carbon plies) was used to perform the inspections. The bandwidth of the probe should be enough to cover the resonant frequency of the woven glass. However, the glass fibre resonant frequency $(3.8 \mathrm{MHz})$ is closer to the second harmonic frequency of the carbon plies (4.7 MHz), so a $5 \mathrm{MHz}$ inspection frequency was also performed. In that second case, the phase is expected to be wrapping twice for each carbon ply, because it's at the second harmonic frequency. Also, the ideal probe, need to have a broad bandwidth that covers the range of resonance frequencies within the wrinkle.

\subsection{Model for a carbon laminate with a wrinkle}

Once the resonance frequency of the plies has been determined, laminates made of a single material should be simulated. The material chosen for the simulations is carbon fibre because the specimens are mainly carbon fibre. The purpose of this first simulation is to verify the suitability of the selected inspection frequencies without considering yet the effects introduced by the change of material. The selected probes should be able to cover the thickness changes within the wrinkle. A 36 carbon-ply laminate (carbon-fibre plies of thickness $0.59 \mathrm{~mm}$ with $0.01 \mathrm{~mm}$ resin layers) with a $3 \mathrm{~mm}$ amplitude wrinkle in the middle was simulated.

The simulated responses from that laminate are shown in Figure 102 for both probe options. As expected from the literature (Robert A. Smith et al. 2018b) the instantaneous phase increases by $2 \pi$ radians for each ply traversed in the bulk of the material that is excited by the fundamental ply resonance $(2.25 \mathrm{MHz})$ and by $4 \pi$ radians with an input-pulse that corresponds to the second harmonic $(5 \mathrm{MHz})$. The $2.25 \mathrm{MHz}$ probe excites the fundamental ply resonance of the non-wrinkle area and the whole range of ply thicknesses of the wrinkle are within the bandwidth of the probe which makes interpretation easier than for the $5 \mathrm{MHz}$ probes. The $5 \mathrm{MHz}$ probe excites the second harmonic of the plies except in the zone of the wrinkle where the plies become thinner. At $5 \mathrm{Mhz}, 2$ phase cycles in the non-wrinkle area corresponds to a single layer except in the zone above the wrinkle where a single layer corresponds to 1 phase cycle because the fundamental resonance frequency of the plies increases as the thickness decreases. This effect makes interpretation more difficult than for the $2.25 \mathrm{MHz}$ probes. It should be noted that the amplitude response in the region above the wrinkle is different for the two probes. In this region, the thickness of the plies is approximately half the thickness in the non-wrinkled area. The resonance frequency of the plies in the squashed area is about $5 \mathrm{Mhz}$.

Overall, both probe options are able to track the wrinkle both in amplitude and phase. Regardless of the probe frequency, the amplitude peaks are always at the resin layers between plies. Thus, the $5 \mathrm{MHz}$ probe response is a maximum amplitude (fundamental resonance) whilst the $2.25 \mathrm{MHz}$ probe response is a minimum amplitude (anti-resonance). The anti-resonance corresponds to the minimum spectral response that is always at half the fundamental resonance. 

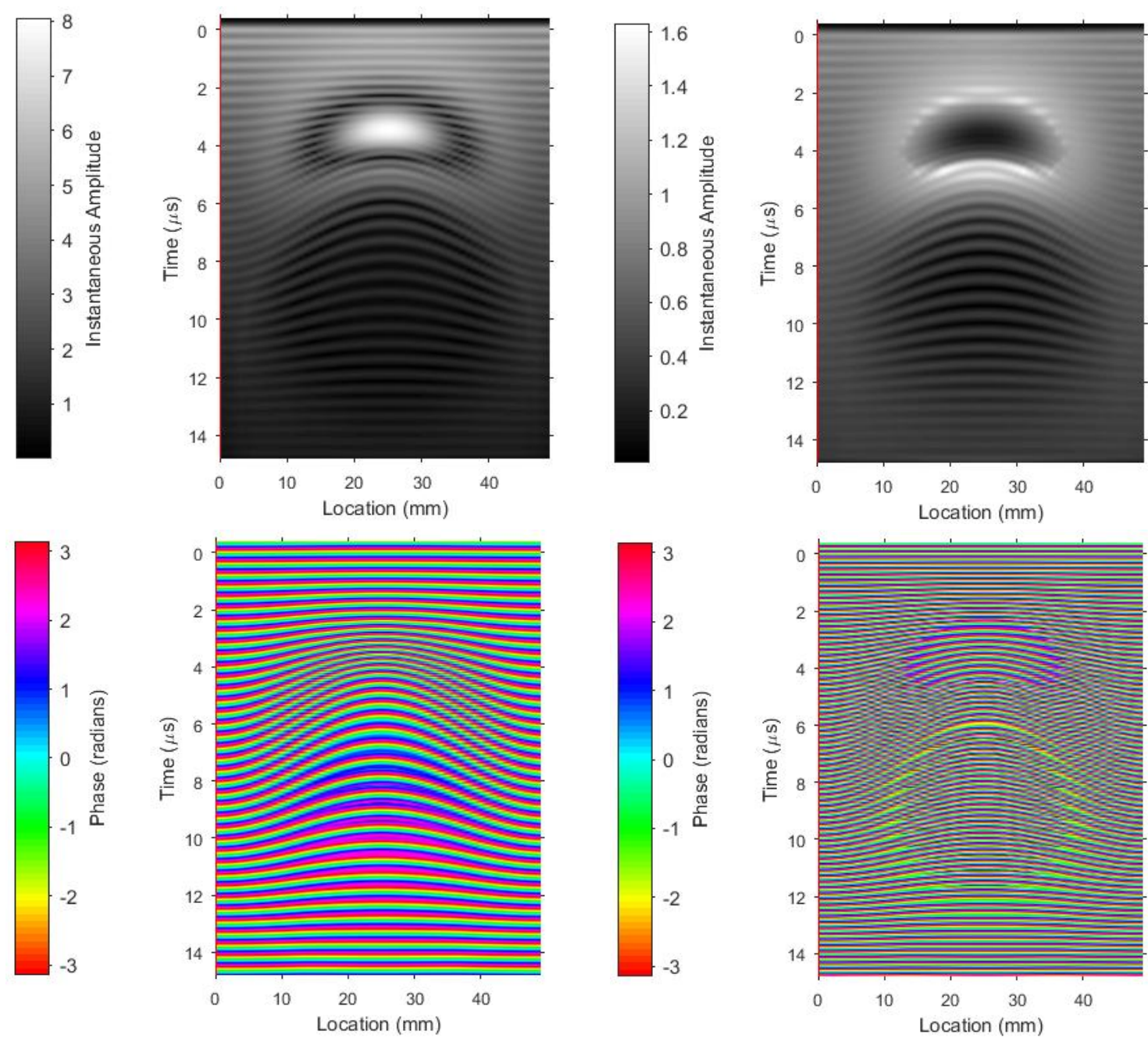

Figure 102: Simulated instantaneous amplitude (top) and phase (bottom) for 36 carbon-fibre plies of thickness $0.59 \mathrm{~mm}$ with $0.01 \mathrm{~mm}$ resin layers and a $3 \mathrm{~mm}$ amplitude wrinkle at the centre. $2.25 \mathrm{MHz}$ centre frequency and $2.25 \mathrm{MHz}$ bandwidth (left) and $5 \mathrm{MHz}$ centre frequency and $2.5 \mathrm{MHz}$ bandwidth (right).

\subsection{Models for the mixed carbon/glass laminates}

The RAS Layer Model with Pulse Length Variation in Matlab is then used to simulate several mixed carbon/glass hybrid composites.

The first mixed carbon/glass hybrid laminate that is simulated is a 36 plies laminate with a $3 \mathrm{~mm}$ wrinkle in the middle with carbon-fibre plies of thickness 0.59 $\mathrm{mm}$ and $0.01 \mathrm{~mm}$ resin layers but with a $0.44 \mathrm{~mm}$ thick glass-fibre ply every 6 th ply. Again, the number of layers is not critical to analyse the effect of the glass layers and the simulation of thick laminates would increase needlessly the calculation time. The simulations with $2.25 \mathrm{MHz}$ are shown in Figure 103. 

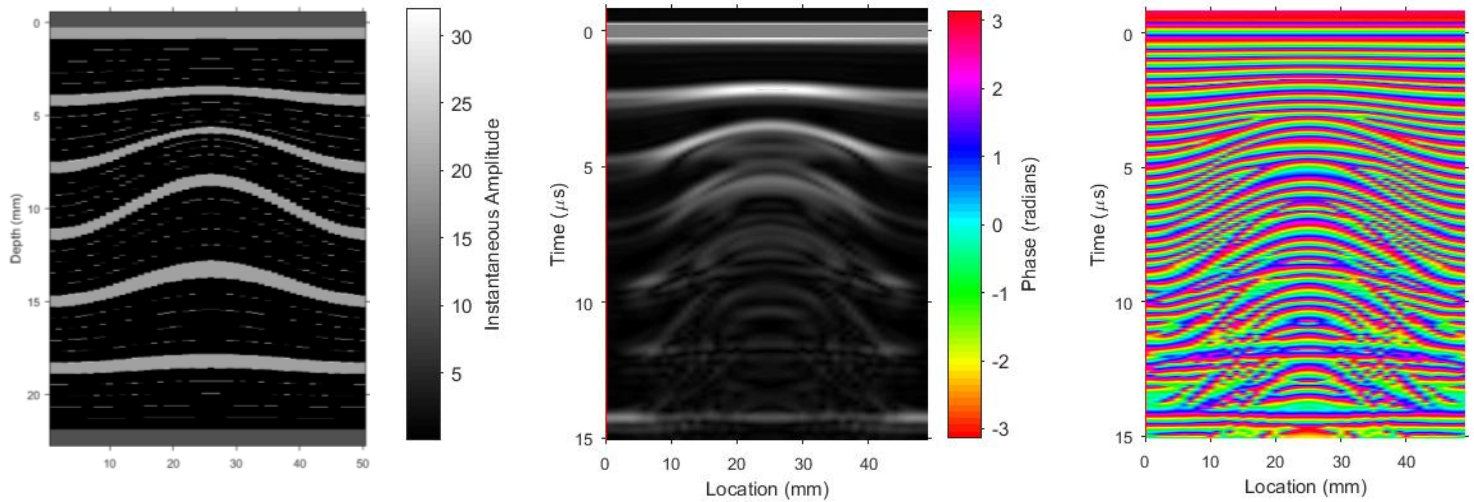

Figure 103. Simulated responses using a $2.25 \mathrm{MHz}$ centre frequency and $2.25 \mathrm{MHz}$ bandwidth for carbon-fibre plies of thickness $0.59 \mathrm{~mm}$ and $0.01 \mathrm{~mm}$ resin layers but with a $0.44 \mathrm{~mm}$ thick glass-fibre ply every 6th ply of a total 36 plies with a $3 \mathrm{~mm}$ wrinkle in the middle. Lay-up diagram (left), instantaneous amplitude (middle) and instantaneous phase (right).

The response is more complex than the response of the carbon laminate because the glass-fibre woven plies are highly reflective and dominate the responses. The glassply to resin-layer interface are actually the interface where reflection coefficient is higher. This is because the transverse stiffness of glass fibres is higher than the transverse stiffness of carbon fibres which causes the resin-layer itself to be more reflective than the carbon-fibre equivalent. Also, the reflection coefficient of the resin layer depends on its thickness (approximately $0.01 \mathrm{~mm}$ ).

In both amplitude and phase-response images, the primary reflections from deeper glass plies are interfering with the multiple reflections from the earlier glass plies and with the reflections from carbon-fibre plies. A very complicate interference pattern is create by the latter multiple reflections that have erroneously exaggerated wrinkle angles. The model assumes plane waves and infinite flat plies but of different spacing as the wrinkle is traversed which may exaggerate the amplitude of the multiple reflection whereas the real laminate has angled plies in the wrinkle area. This implies that in the actual experiment the multiple reflections may have significantly lower amplitudes what would simplify the pattern of interferences and the interpretation of the images.

In order to have a better understanding of the superimposition of phases from multiple reflections in a wrinkled glass/carbon hybrid, a wrinkled laminate with much lower reflection coefficients and plies of several wavelengths thickness has been simulated. The simulated responses of a $1.5 \mathrm{~mm}$ carbon-fibre composite plies separated by $0.2 \mathrm{~mm}$ resin layers using a $6 \mathrm{MHz}$ probe are shown in Figure 104.

In the phase-response images, the multiple reflections from deeper glass plies although lower they are still sufficient to interfere with the multiple reflections from the earlier glass plies and with the reflections from carbon-fibre plies.

Those complicate interference patterns should be expected when analysing the images from the real experiments. 

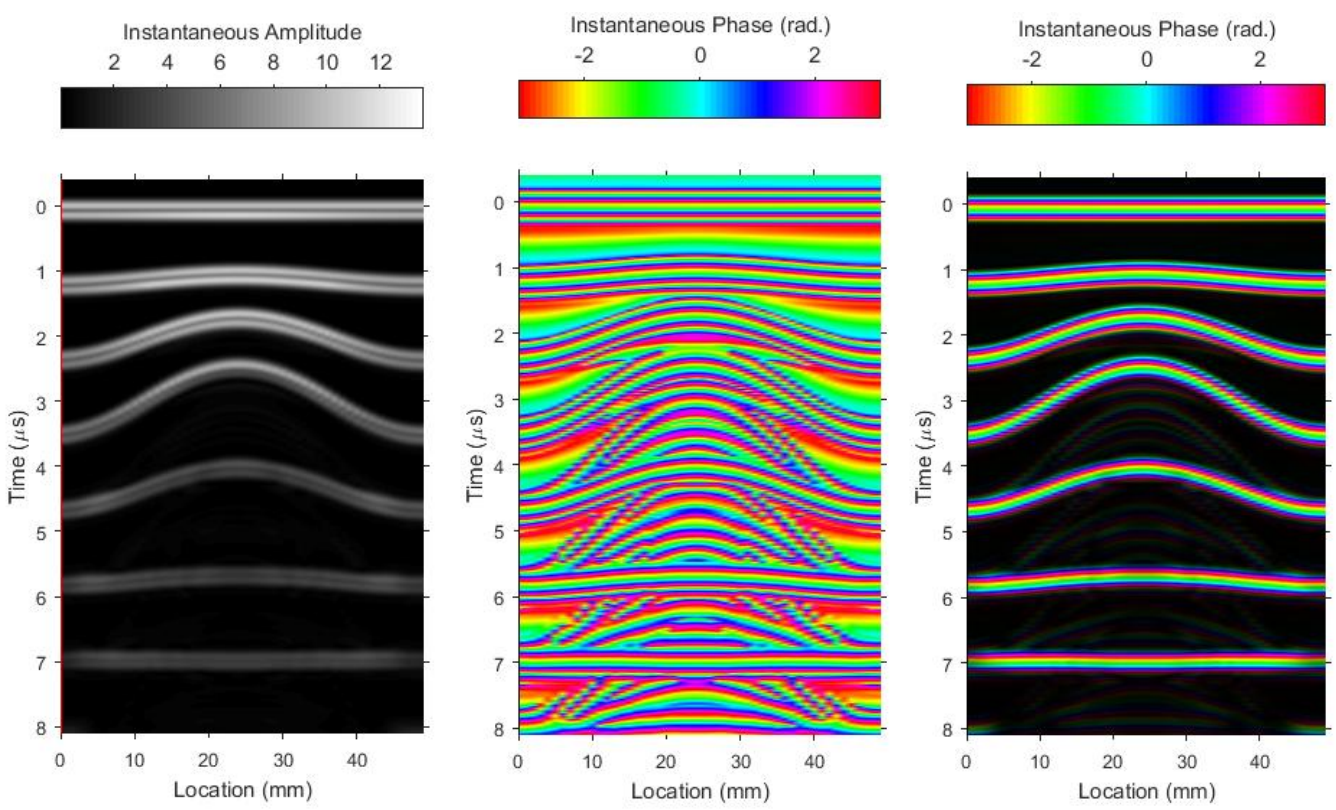

Figure 104. Simulated response from six $1.5 \mathrm{~mm}$ thick plies separated by $0.2 \mathrm{~mm}$ resin layers. (left) Instantaneous amplitude. (middle) Instantaneous phase. (right) Instantaneous phase in colour moderated by amplitude in brightness.

Finally, the the RAS layer Model with Pulse Length Variation was used to simulate the laminates of samples B, C and D.

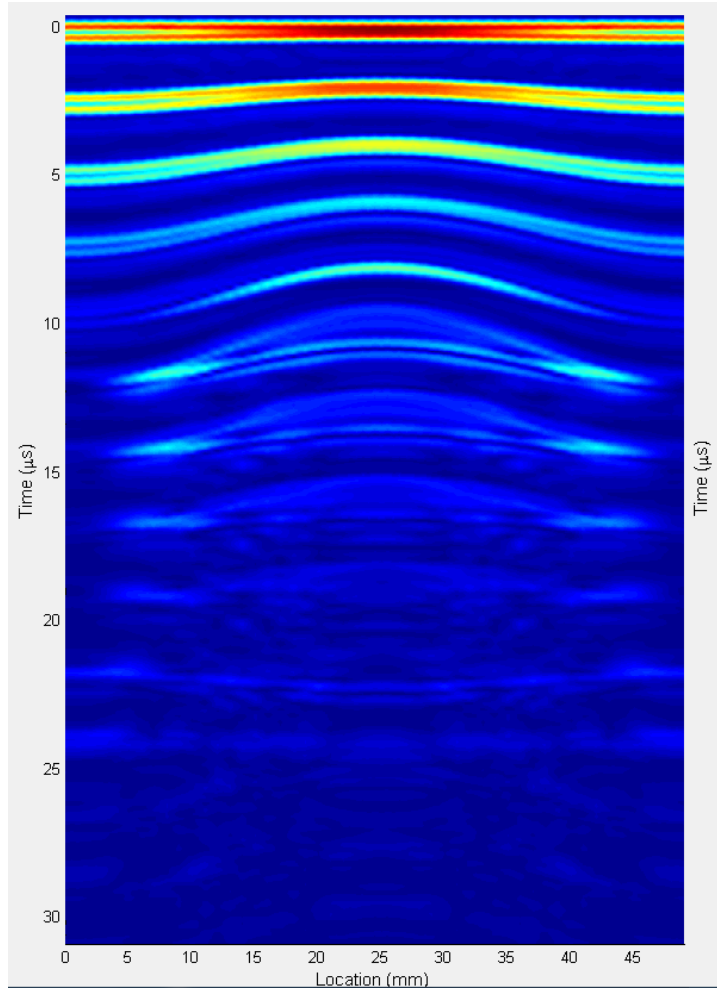

a

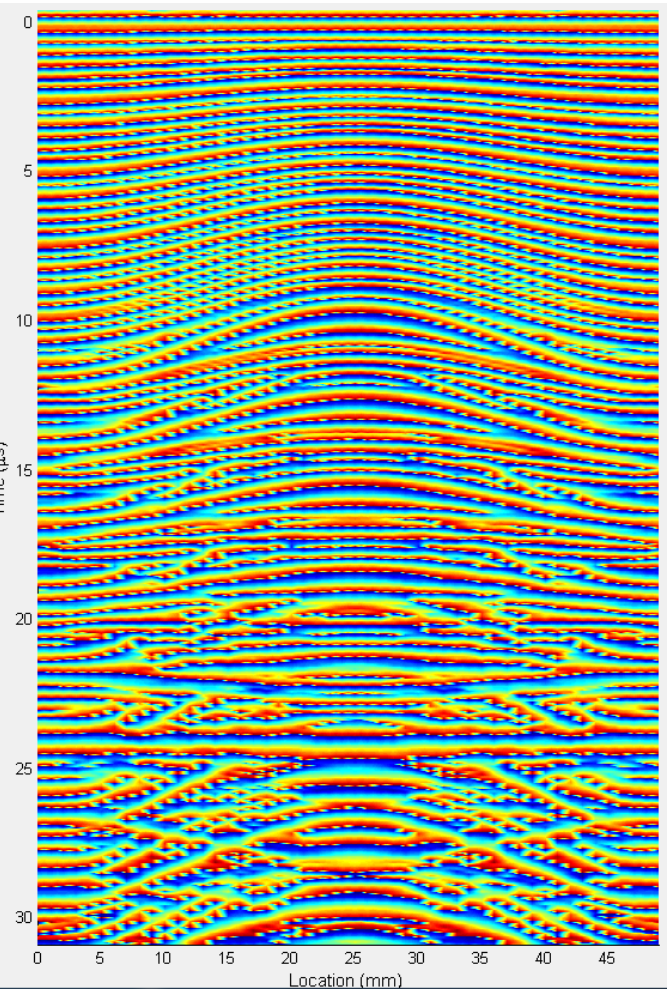

b

Figure 105: Simulation of instantaneous amplitude (a) and instantaneous phase (b) of the specimen B with the RAS Layer Model with Pulse Length Variation using a $2.5 \mathrm{MHz}$ Centre Frequency and a $2.5 \mathrm{MHz}$ Bandwidth. 
The lay-up of sample B was simulated using a $2.5 \mathrm{MHz}$ Centre Frequency and a 2.5 $\mathrm{MHz}$ Bandwidth (Figure 105) and a $5 \mathrm{MHz}$ Centre Frequency and a $5 \mathrm{MHz}$ Bandwidth (Figure 116). The Back echo would be found a little above $20 \mu$ s deep. In both the instantaneous amplitude images the echo of the wrinkle maximum amplitude point appears stronger than the echo of the layer immediately above despite being further away from the probe. A very complicate interference pattern appears. The echo of the glass layers in the area where the thickness of the carbon layers grows seems unfolded. Of the echoes appearing unfolded, only the below one would be real.

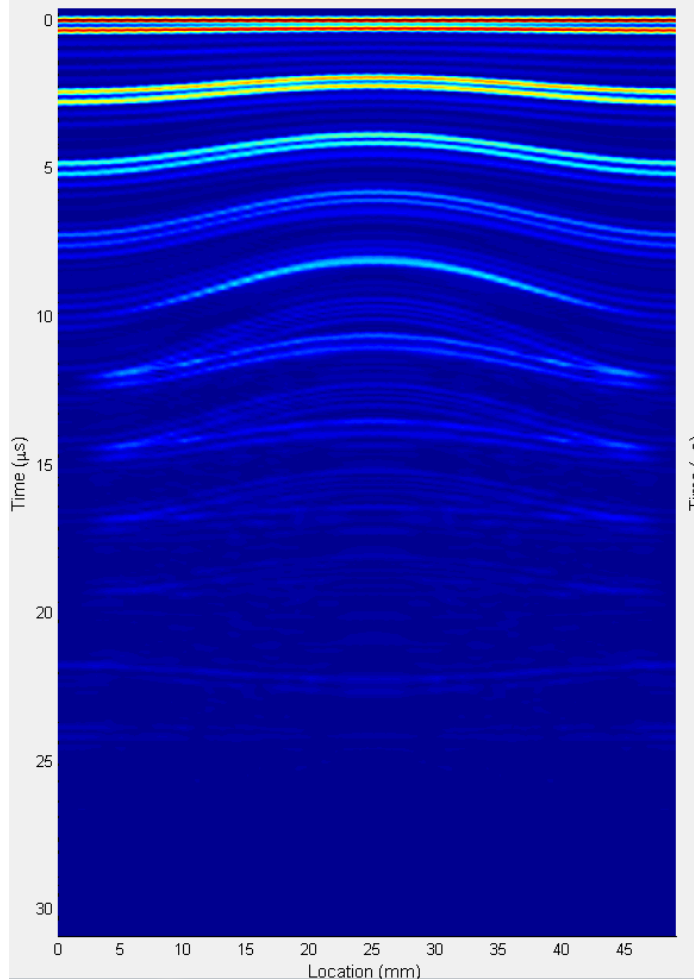

a

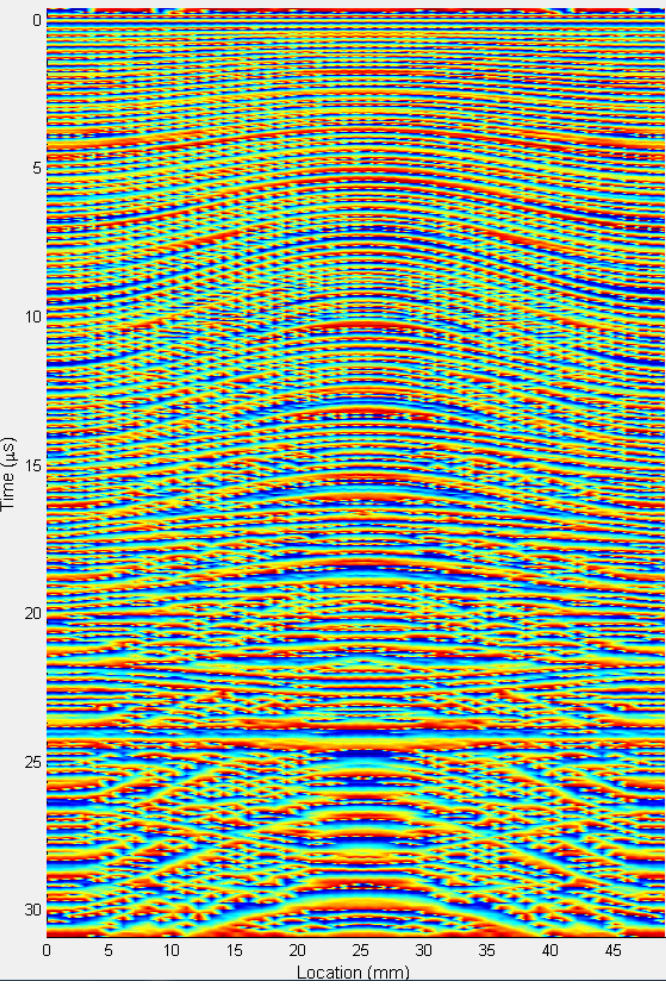

b

Figure 106: Simulation of instantaneous amplitude (a) and instantaneous phase (b) of the specimen B with the RAS Layer Model with Pulse Length Variation using a $5 \mathrm{MHz}$ Centre Frequency and a $5 \mathrm{MHz}$ Bandwidth.

The lay-up of sample $\mathrm{C}$ was then simulated using a $2.5 \mathrm{MHz}$ Centre Frequency and a $2.5 \mathrm{MHz}$ Bandwidth (Figure 107) and a $5 \mathrm{MHz}$ Centre Frequency and a $5 \mathrm{MHz}$ Bandwidth (Figure 108). The results of the simulation for this specimen are analogous to those obtained for the sample B. However, the interference pattern created by the latter multiple reflections is more complicated than in the images from sample B. This is because the amplitude of the wrinkle is higher in sample $\mathrm{C}$ than in sample $\mathrm{B}$. 


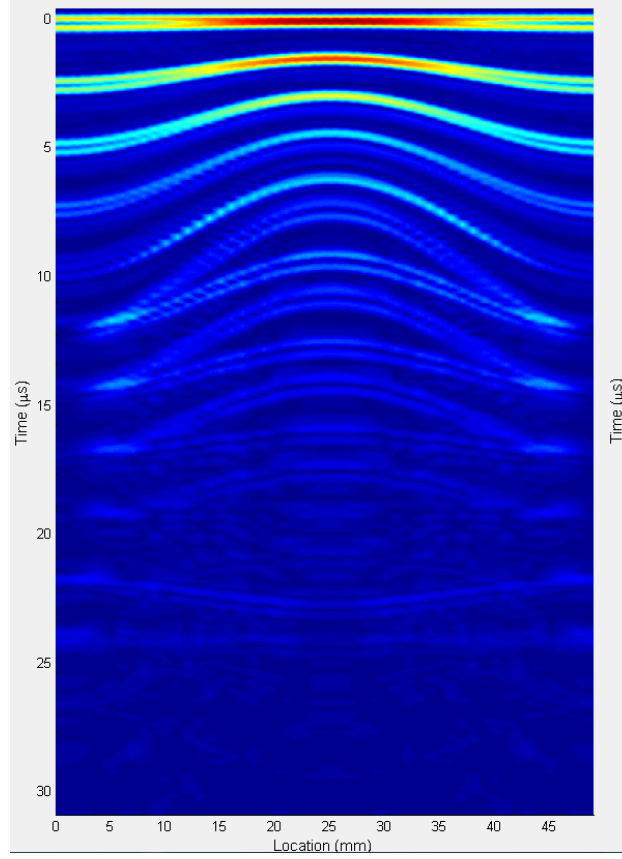

a

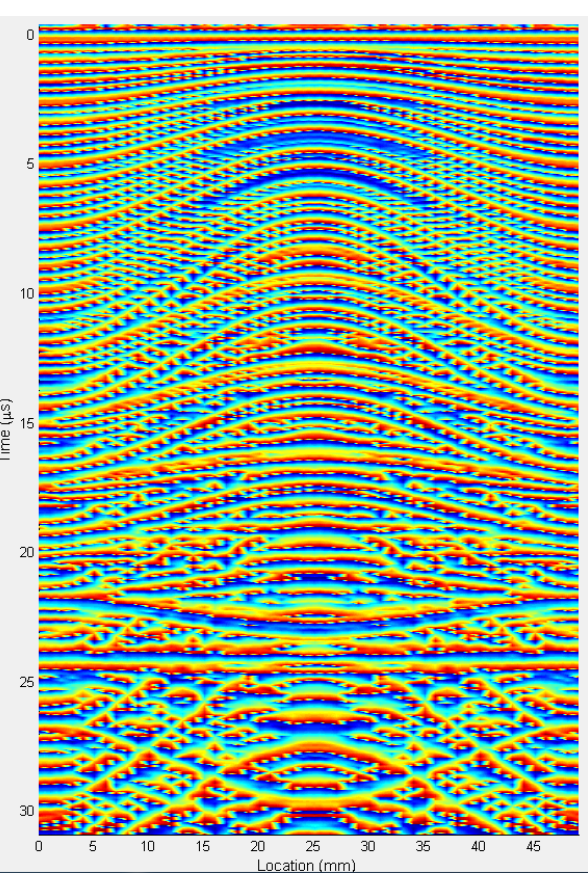

b

Figure 107: Simulation of instantaneous amplitude (a) and instantaneous phase (b) of the specimen $\mathrm{C}$ with the RAS Layer Model with Pulse Length Variation using a $2.5 \mathrm{MHz}$ Centre Frequency and a $2.5 \mathrm{MHz}$ Bandwidth.

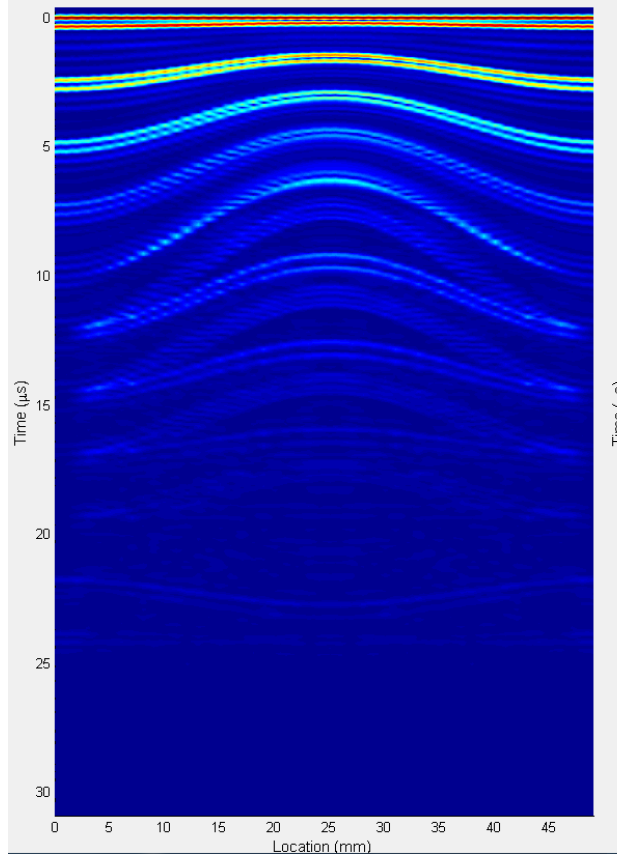

a

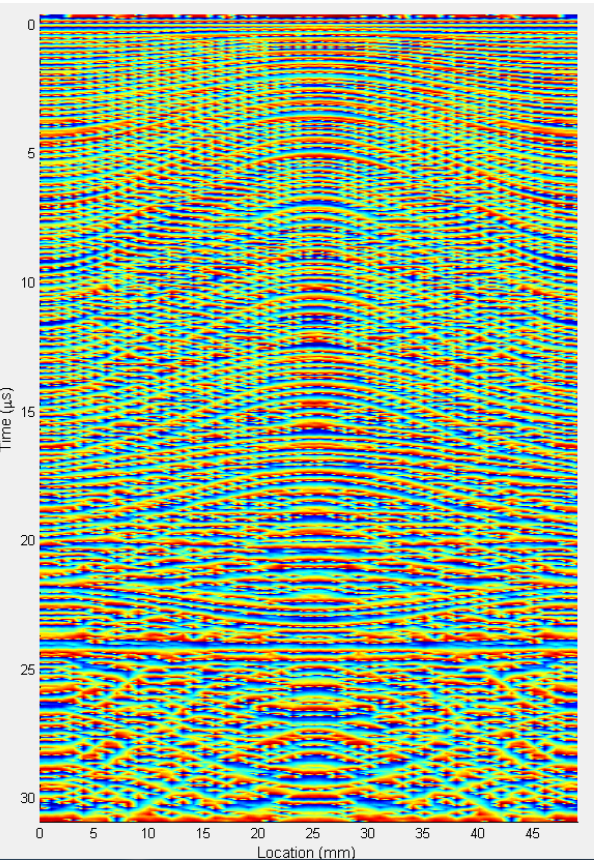

$\mathrm{b}$

Figure 108: Simulation of instantaneous amplitude (a) and instantaneous phase (b) of the specimen $\mathrm{C}$ with the RAS Layer Model with Pulse Length Variation using a $5 \mathrm{MHz}$ Centre Frequency and a $5 \mathrm{MHz}$ Bandwidth.

The lay-up of sample D was then simulated using a $2.5 \mathrm{MHz}$ Centre Frequency and a $2.5 \mathrm{MHz}$ Bandwidth (Figure 109) and a $5 \mathrm{MHz}$ Centre Frequency and a $5 \mathrm{MHz}$ Bandwidth (Figure 110). The patter of those images is simpler because sample D is mainly carbon fiber and there are no glass layers to create interferences. 


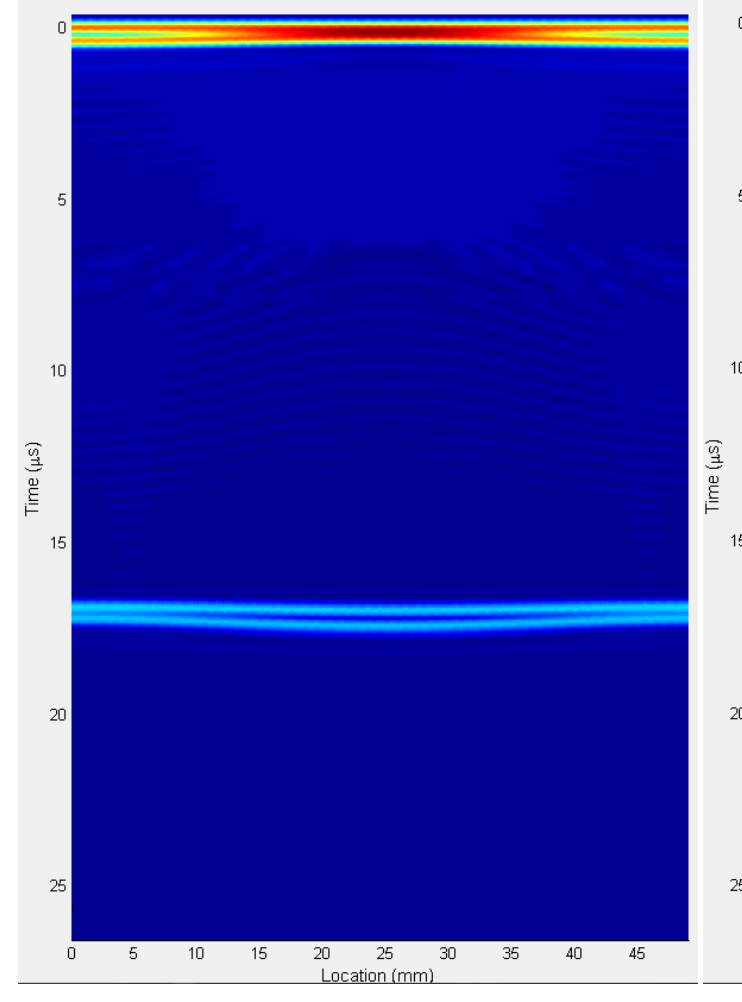

a

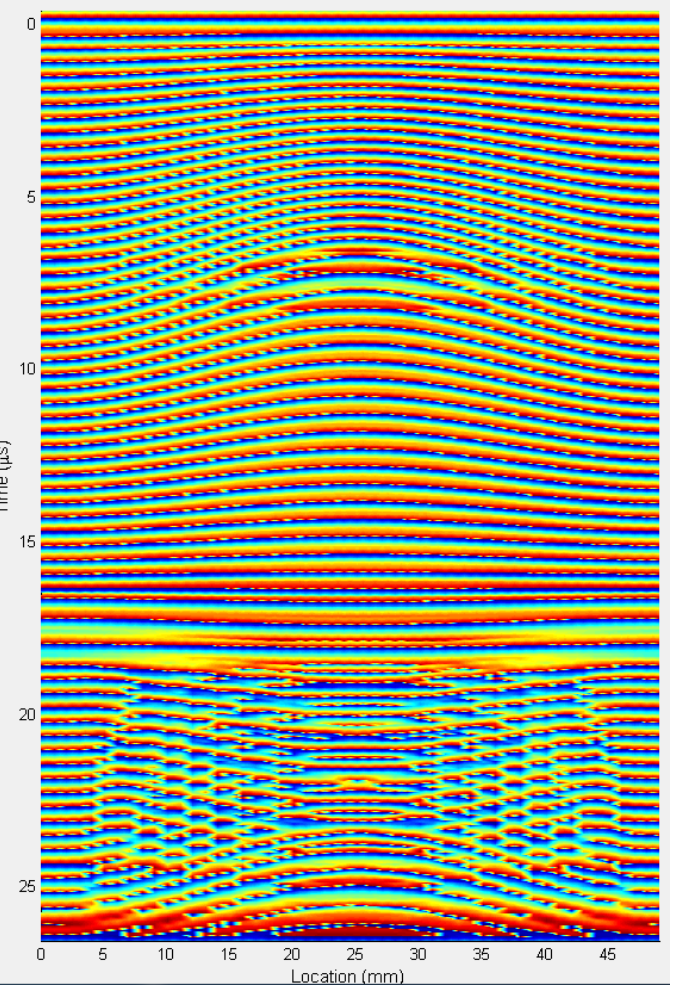

b

Figure 109: Simulation of instantaneous amplitude (a) and instantaneous phase (b) of the specimen D with the RAS Layer Model with Pulse Length Variation using a $2.5 \mathrm{MHz}$ Centre Frequency and a $2.5 \mathrm{MHz}$ Bandwidth.

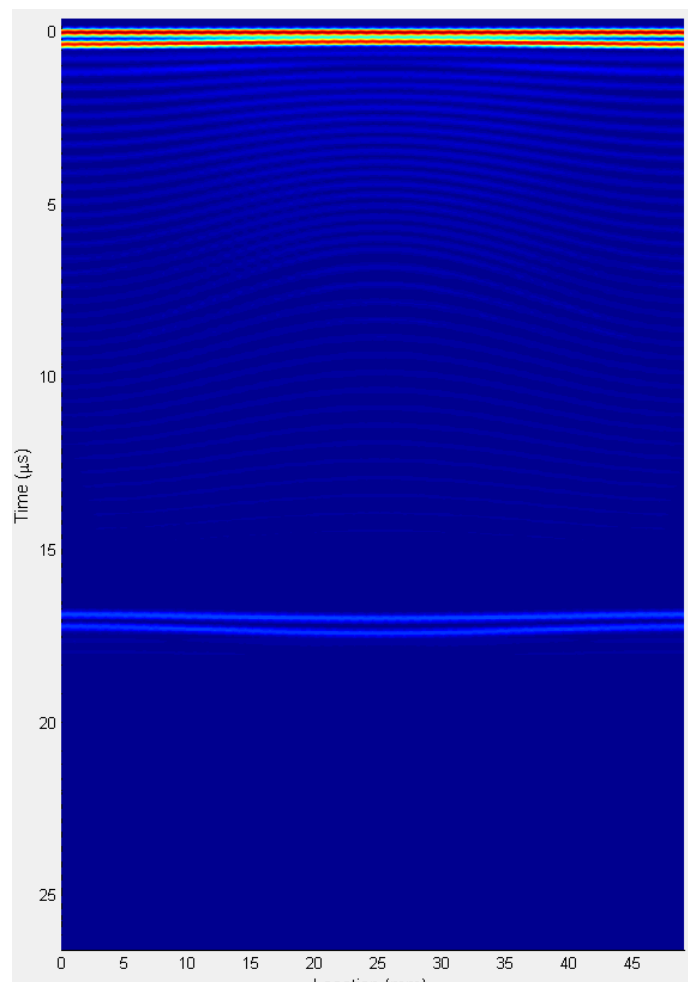

a

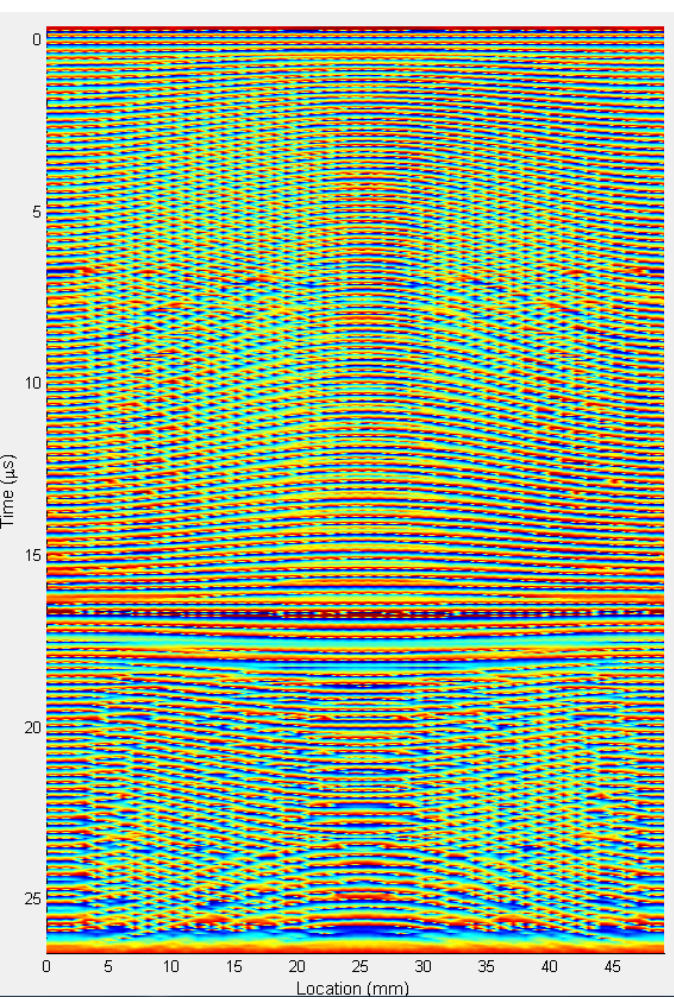

$\mathrm{b}$

Figure 110: Simulation of instantaneous amplitude (a) and instantaneous phase (b) of the specimen J with the RAS Layer Model with Pulse Length Variation using a $5 \mathrm{MHz}$ Centre Frequency and a $5 \mathrm{MHz}$ Bandwidth. 


\subsection{A preliminary 2D Model}

The effects of the highly anisotropic in-plane stiffness properties are not simulated in the one-dimensional recursive analytical multi-layer model. The one-dimensional model has shortcomings because several assumptions have to been made. The 1D model assumes normal incidence plane-wave ultrasound and only the transverse (to the fibres) compression modulus is required. It also assumes flat in-plane plies and resin layers. The actual wrinkled laminate has complicated shapes and at least two-dimensional modelling should be necessary to capture the ultrasonic wave propagation around a wrinkle and to model the effects of the anisotropy and the geometrical complexity and the true geometrical distortions of the plies. The conclusions from the one-dimensional recursive analytical multi-layer model about the responses from the wrinkled area should be tested against more accurate modelling.

Although a full 2D model has not been modelled, preliminary tests were conducted using TexGen to generate the geometry, Matlab and PZFlex software (Thornton Tomasetti, Cupertino, USA) to generate the material, PZFlex software to launch the model and Matlab to visualize the results.

The software used were those that were available in the laboratory. PZFlex is a commercial software package for finite element analysis that is widely used by leading ultrasonic research groups in academia due to its flexibility and speed for solving large, complex problems. The use of more powerful finite element analysis software will be slower and it may take several hours to solve simple scenarios. That is why this software was used for this first test.

TexGen is an open source software developed for modelling the geometry of textile structures. As a first approach, an 8 yarn laminate with a $3 \mathrm{~mm}$ high wrinkle was created in TexGen. Each yarn is $3.3 \mathrm{~mm}$ high in the non wrinkled area. It is the same height as the groups of 5 carbon plies that can be found between two glass plies in specimens $\mathrm{B}$ and $\mathrm{C}$.

TexGen does not allow the introduction of the yarns geometry as an equation. Therefore the geometry of the wrinkle has been simulated as follow. The layers of irregular geometry (thicker or thinner in the center) are created one by one. The coordinates $(\mathrm{x}, \mathrm{y})$ of three points per layer (the sides and the center of the middle line of the layer) are introduced. The thickness of all the layers at the sides is $3.3 \mathrm{~mm}$ (area without wrinkle) while the thickness of the layers in the central zone varies as a function of the wrinkle layer. The yarn is created in such a way that at the three points introduced, the section of the yarn in those points is perpendicular to the curve. The result of creating the layers in such a manner is that the thickness of the thin resin layers between the plies of composite material is irregular. It was proposed to use more than three points per yarn to create the geometry, but that hinders the process and does not present significant improvements in the results. The results are shown in Figure 111. 


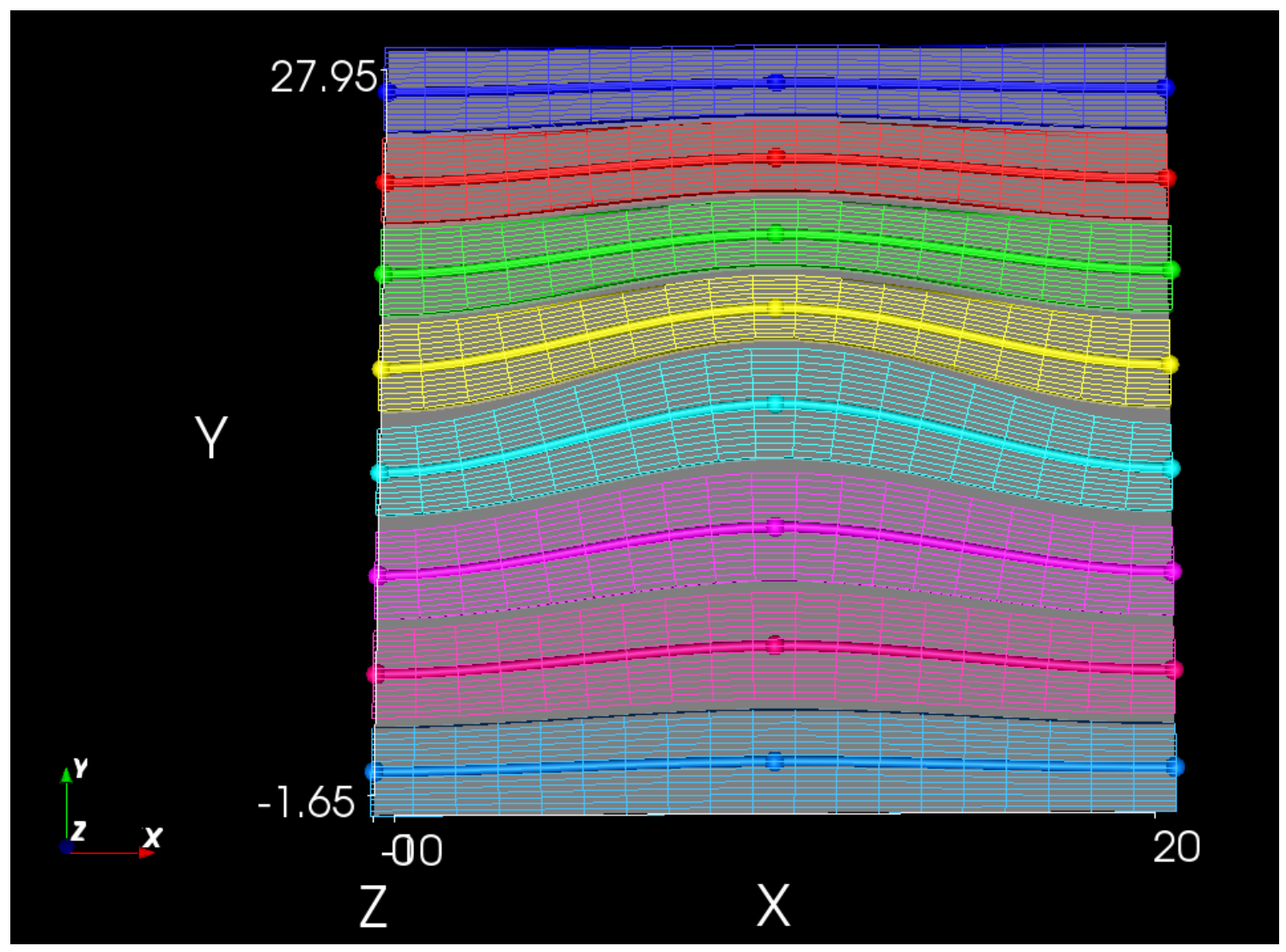

Figure 111: 8 yarn laminate with a $3 \mathrm{~mm}$ high wrinkle model generated with TexGen.

Once the geometry is generated using TexGen; the next step is to assign the material properties to the layers and to create the mesh.

Based on the material properties used for carbon and resin can be seen in Table 15; Young modulus (E), Bulk modulus (K), and shear modulus $(\mathrm{G})$ are calculated for carbon fiber $\left(E_{f}, K_{f}, G_{f}\right)$ and for the resin matrix $\left(E_{m}, K_{m}, G_{m}\right)$ using equations (24) (25) and (26) respectively.

$$
\begin{gathered}
E=\frac{\boldsymbol{M}_{\mathbf{1 1}} *(\mathbf{1}+\mathbf{v}) *(\mathbf{1}-\mathbf{2 v})}{(\mathbf{1}-\mathbf{v})} \\
K=\frac{E}{3 *(1-2 v)} \\
G=\frac{M_{11} *(1-2 v)}{2 *(1-v)}
\end{gathered}
$$

Once the Young modulus (E), Bulk modulus (K), and shear modulus (G) of both fibres and matrix are known, the elastics constants that characterise the laminate are calculated using Hashin (1965) mixture rules for unidirectional long-fibre composites which are given in equation (27) to (33). FVF is the Fiber-Volume-Fraction of the laminate which is supposed to be $60 \%$. Fibres are assumed to be placed at the '1' directions 


$$
\begin{gathered}
\boldsymbol{E}_{11}=\boldsymbol{E}_{\boldsymbol{f}} * \boldsymbol{F} \boldsymbol{V} \boldsymbol{F}+\boldsymbol{E}_{\boldsymbol{m}}(1-\mathrm{FVF}) \\
E_{22}=\frac{E_{f} E_{m}}{\left(E_{m} * F V F+E_{f}(1-\mathrm{FVF})\right)} \\
v_{12}=v_{f} * F V F+v_{m} *(1-F V F) \\
G_{12}=\frac{G_{f} G_{m}}{\left(G_{m} * F V F+G_{f}(1-\mathrm{FVF})\right)} \\
K_{22}=\frac{E_{f} E_{m}}{\left(E_{m} * F V F+E_{f}(1-\mathrm{FVF})\right)} \\
v_{23}=1-v_{12}-\frac{E_{22}}{3 K_{22}} \\
G_{23}=\frac{E_{22}}{2 *\left(1+v_{23}\right)}
\end{gathered}
$$

Due to the anisotropy of the material, the material properties are directionally dependent. Composite laminates can be considered transversally isotropic materials, because the material is symmetric about an axis of rotation (the axis of the fibre). In a 2D model, the properties of the material are introduced using the stiffness matrix. For transversally isotropic materials, the stiffness matrix contains just five independent stiffness properties (equation (34)). On that equation, fibres are still assumed to be placed at the ' 1 ' direction.

$$
\left[\begin{array}{c}
\sigma_{1} \\
\sigma_{2} \\
\sigma_{3} \\
\sigma_{4} \\
\sigma_{5} \\
\sigma_{6}
\end{array}\right]=\left[\begin{array}{ccccccc}
C_{11} & C_{12} & C_{12} & 0 & 0 & 0 & \\
C_{12} & C_{22} & C_{23} & 0 & 0 & 0 & \\
C_{12} & C_{23} & C_{22} & 0 & 0 & 0 & \\
0 & 0 & 0 & \frac{1}{2}\left(C_{22}-C_{23}\right) & 0 & 0 \\
0 & 0 & 0 & 0 & & C_{55} & 0 \\
0 & 0 & 0 & 0 & 0 & C_{55}
\end{array}\right]\left[\begin{array}{c}
\varepsilon_{1} \\
\varepsilon_{2} \\
\varepsilon_{3} \\
\varepsilon_{4} \\
\varepsilon_{5} \\
\varepsilon_{6}
\end{array}\right]
$$

The five independent stiffness elements are calculated for each composite layer using equation (35) to (39). The resultant stiffness matrix for CFRP lamina in GPa is shown in equation $(\mathbf{4 0})$.

$$
\begin{gathered}
\boldsymbol{C}_{\mathbf{1 1}}=\frac{\boldsymbol{E}_{\mathbf{1 1}} *\left(\mathbf{1}-\mathbf{v}_{\mathbf{2 3}}^{\mathbf{2}}\right)}{\left(\mathbf{1}-\mathbf{2} \boldsymbol{v}_{\mathbf{1 2}}^{\mathbf{2}}-\mathbf{v}_{\mathbf{2 3}}^{\mathbf{2}}-\mathbf{2} \mathbf{v}_{\mathbf{2 3}} \boldsymbol{v}_{\mathbf{1 2}}^{\mathbf{2}}\right)} \\
C_{22}=\frac{E_{22} *\left(1-v_{12}^{2}\right)}{\left(1-2 v_{12}^{2}-v_{23}^{2}-2 v_{23} v_{12}^{2}\right)} \\
C_{55}=G_{12}
\end{gathered}
$$




$$
\begin{gathered}
C_{12}=\frac{E_{11}\left(v_{12}+v_{12} v_{23}\right)}{\left(1-2 v_{12}^{2}-v_{23}^{2}-2 v_{23} v_{12}^{2}\right)} \\
C_{23}=\frac{E_{22} *\left(v_{23}+v_{12}^{2}\right)}{\left(1-2 v_{12}^{2}-v_{23}^{2}-2 v_{23} v_{12}^{2}\right)} \\
{\left[\begin{array}{l}
\sigma_{1} \\
\sigma_{2} \\
\sigma_{3} \\
\sigma_{4} \\
\sigma_{5}
\end{array}\right]=\left[\begin{array}{ccccccc}
14.3169 & 6.9425 & 6.9425 & 0 & 0 & 0 \\
6.9425 & 12.9508 & 6.4485 & 0 & 0 & 0 \\
6.9425 & 6.4485 & 12.9508 & 0 & 0 & 0 & \\
& 0 & 0 & 0 & 3.2512 & 0 & 0 \\
0 & 0 & 0 & 0 & 3.2906 & 0 \\
0 & 0 & 0 & 0 & 0 & 3.2906
\end{array}\right]\left[\begin{array}{l}
\varepsilon_{1} \\
\varepsilon_{2} \\
\varepsilon_{3} \\
\varepsilon_{4} \\
\varepsilon_{5} \\
\varepsilon_{6}
\end{array}\right]}
\end{gathered}
$$

PZFlex only allows the creation of a rectangular mesh. The thin resin layers determine the mesh element size because a minimum of three elements through the resin layer thickness is needed to capture the stress gradients. Three elements through the resin layer achieve an appropriate balance between computational efficiency and model accuracy. However, the principal direction of orthotropy in the wrinkled area do not coincide with the coordinate directions of the mesh (see Figure 112). Thus a relation is needed between the stresses and strains in both coordinates systems. That relation can be express as a transformation matrix and as a function of the angle between coordinates systems that is the angle of the wrinkle at that point.

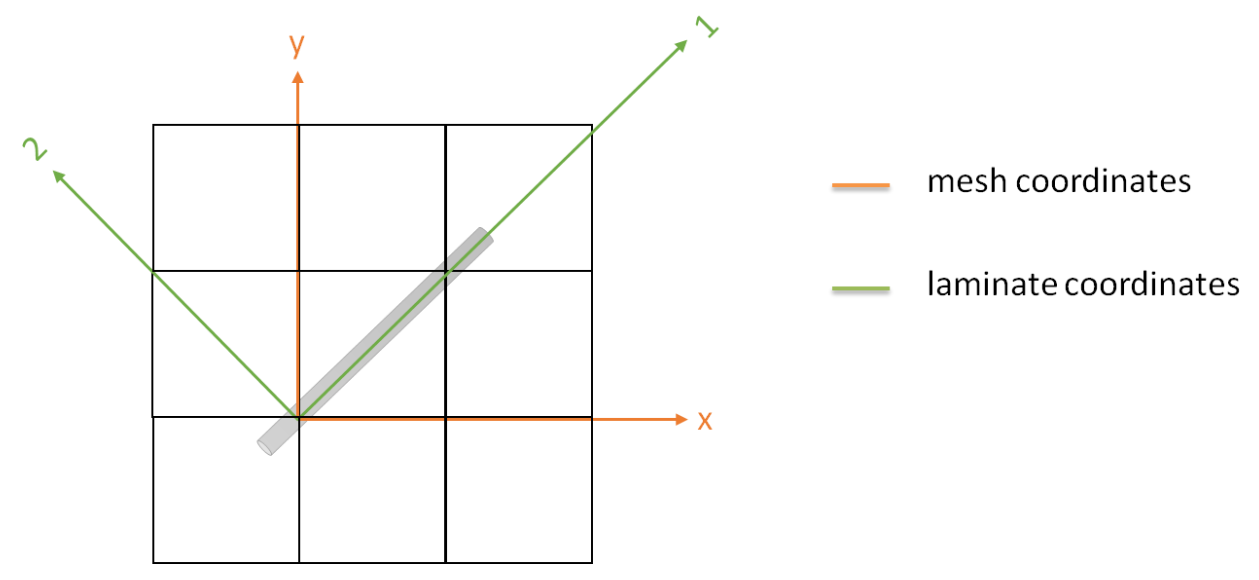

Figure 112: Detail of the mesh showing the difference between the principal direction of orthotropy in the laminate in the wrinkled area and the coordinate directions of the mesh.

However, the PZFlex code does not allow the introduction of a direction different from the mesh coordinates. Although the coordinate transformation from elementary mechanics of material has nothing to do with the material properties and is merely a rotation of stress directions; the solution that was used in this test was to create a different material for each angle of the fiber. A different stiffness matrix is needed for every different fiber angle in the wrinkle. For each material created, a matrix is introduced that is obtained by rotating the matrix of the equation (40) to match the principal material axes. The CFRP material properties were thus transformed to local coordinate systems relating to the orientation of the layers at each point of the wrinkle. 
The material rotate stiffness matrix are calculated using a matlab code, that is also used to assign the different materials to each element of the mesh. For the simple laminated proposes in this section, several tens of materials are needed. Figure 113 show the final material assignment for the proposed 8 layers laminate. Each color represent a different material with its own stiffness matrix.

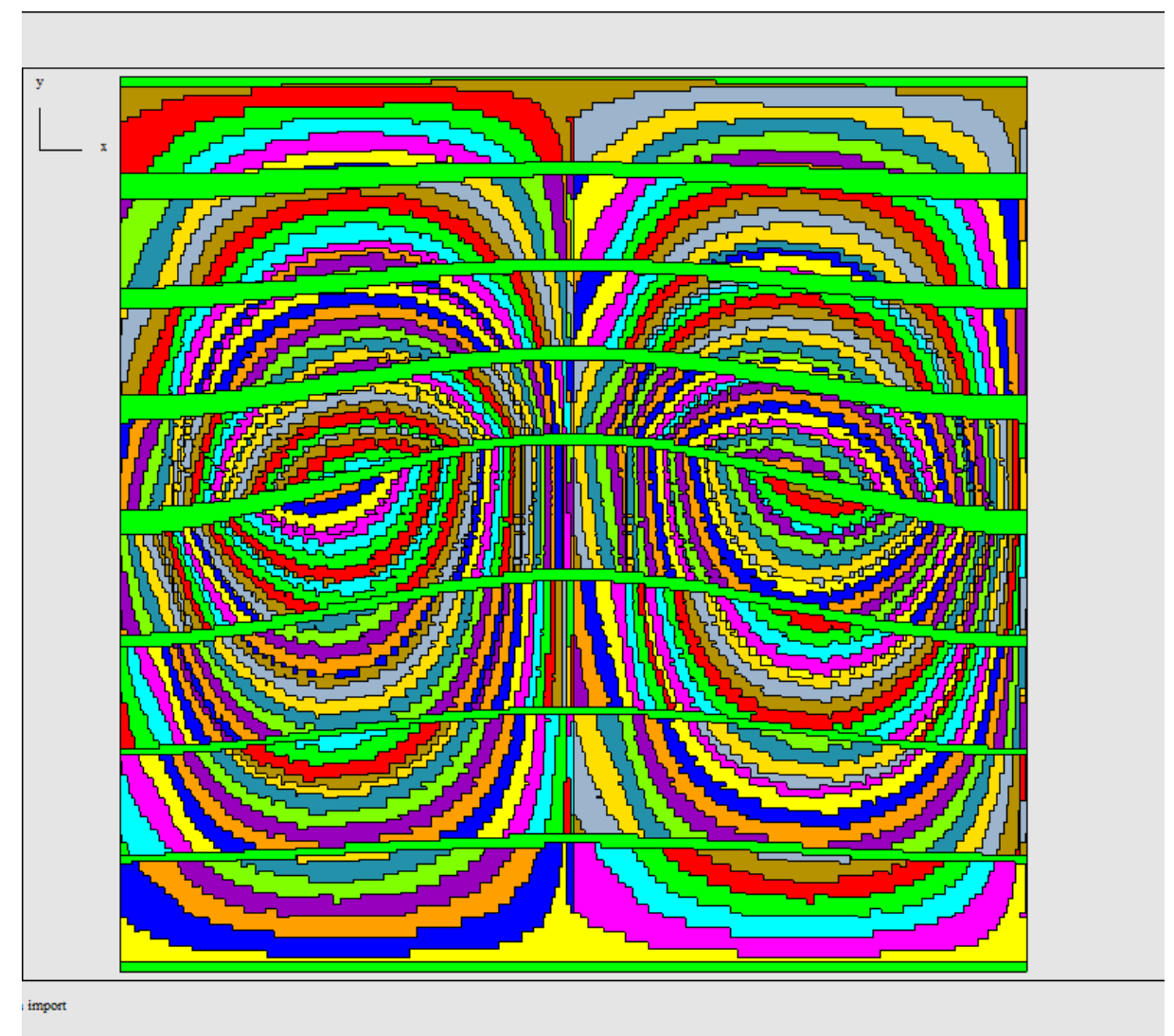

Figure 113: Final material assignment for an 8 layers laminate with wrinkle. Each color represent a different material.

Then a PZFlex model was constructed placing the laminate model between two water blocs (Figure 114). A pressure load that represent a $2.5 \mathrm{Mhz}$ transducer was applied at the top of the water bloc.

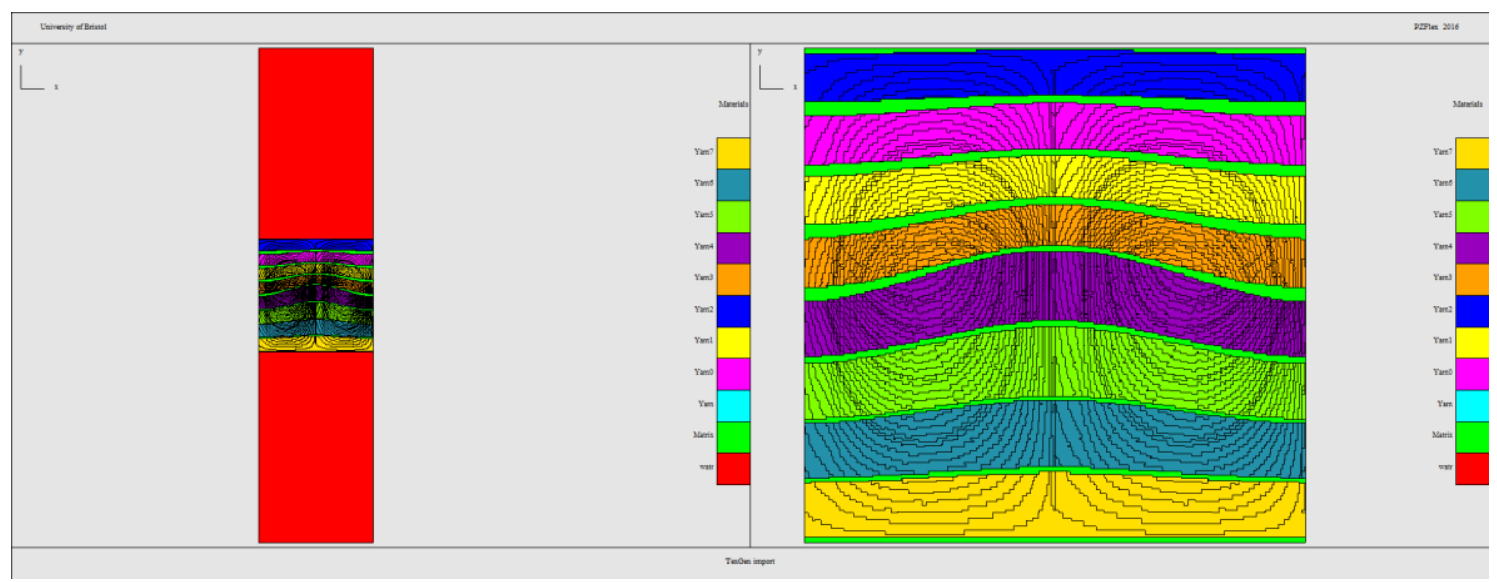

Figure 114: PZFlex Model for an 8 layers laminate with wrinkle. 
After running the model in PZFLEX, A-Scan and B-Scan from the simulation were plot in Matlab (Figure 115 and Figure 116 respectively). The B-Scan is formed from the different A-Scan obtained. The front and back echo appear clearly as strong echoes.
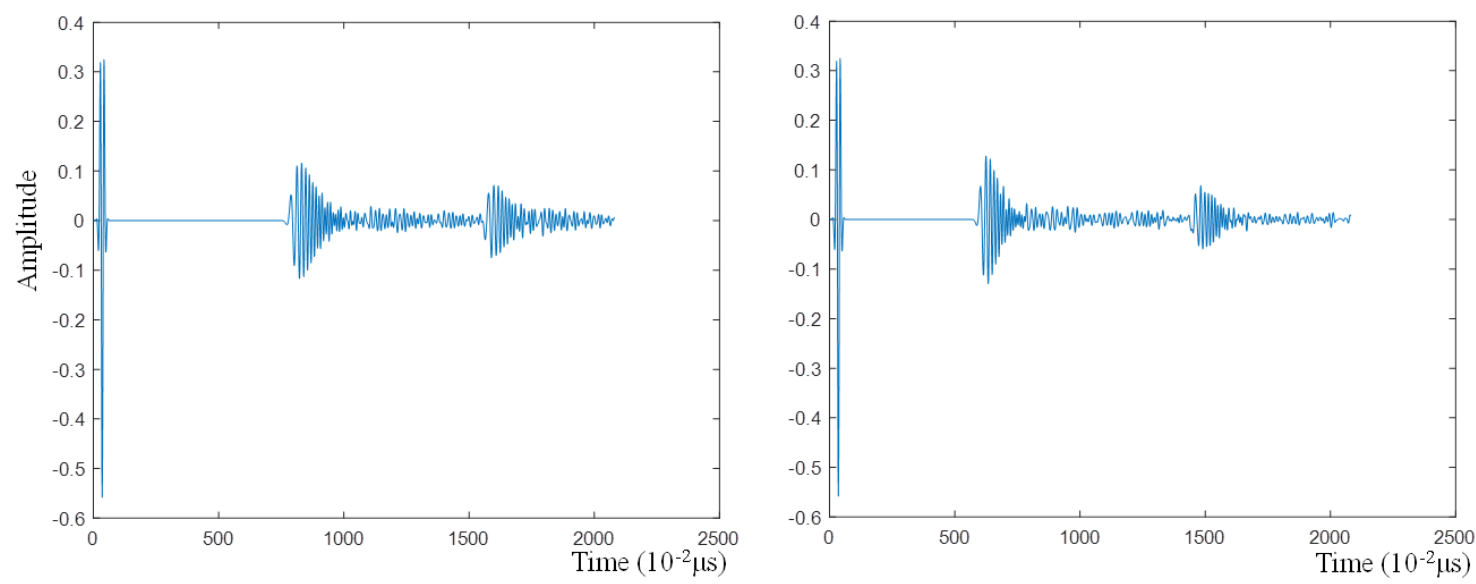

Figure 115: A-Scans at $2.5 \mathrm{MHz}$ for an 8 layers laminate. A-Scan at the area without the wrinkle (left) and A-Scan at the area of the wrinkle maximum amplitude (right).

Strong resin ply reflections are shown in the B-Scan, probably due to the fact that this model had thicker resin layer that the previous models. An interference pattern does appear in the lower layers of the B-Scan, as in the 1D recursive model results.

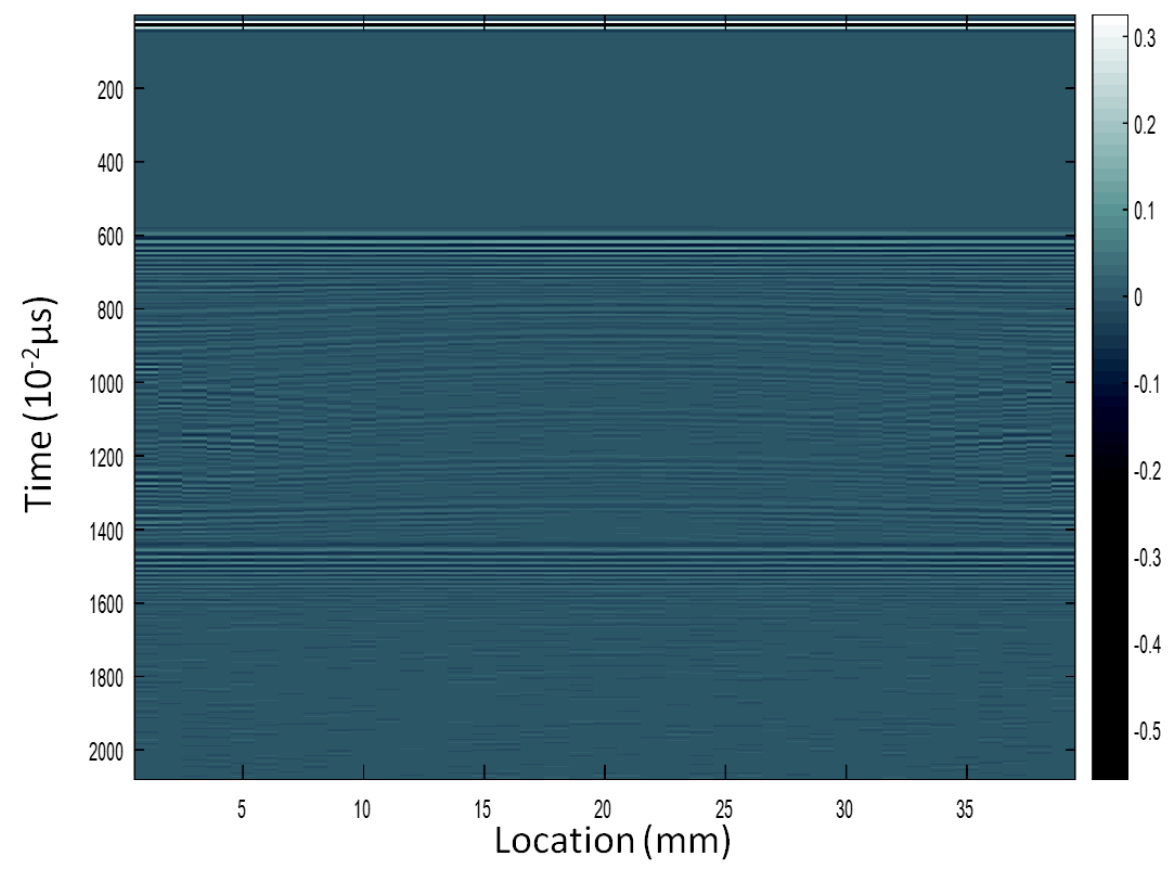

Figure 116: B-Scan at $2.5 \mathrm{MHz}$ for an 8 layers laminate with wrinkle. 
Although this 2D model present a more accurate response that the 1D model, this 2D model still need to be improved. These preliminary results highlight the difficulty to simulate the propagation of ultrasonic waves in laminates with wrinkles. In order to obtain an accurate model that would allow the prediction of the ultrasonic response of a laminate, it would be necessary to improve the 2D model.

PZFlex is widely used to model ultrasonic propagation, because in order to model the propagation of an ultrasonic wave in a material, a rectangular mesh is often sufficient. However, the propagation of an ultrasonic wave in a laminate with a wrinkle needs a different mesh.

Future work should look to improve the model generation. The actual geometry of the laminate should be simulated, with constant thick resin layers. Also the generation of the multiple materials is quite time consuming. A software that allow the introduction of a direction different from the mesh coordinates could be used so a single stiffness matrix can be used for each material. This would improve the model efficiency and would allow large 2D model to be implemented. 


\section{CHAPTER 6 CONCLUSIONS AND FUTURE WORK}

The work presented in this thesis addresses the detection and characterisation of out-of-plane wrinkles in thick-section glass-carbon hybrid laminates using nondestruction method from a very practical point of view.

In the first part of this thesis, the different NDT methods that are used for composite wind turbine blade inspection nowadays have been deeply described and analysed. The difficulties to inspect huge large structures are here presented and evidenced. In-situ wind turbine blade inspections present event more challenges. Eddy current techniques, Micro-focus X-Ray Computed Tomography and ultrasonic techniques were the only three techniques that were able to detect and characterise internal out-of-plane wrinkles in wind turbine blades. Among those techniques, ultrasound echo, commercial phased-array ultrasound technology and full-matrix capture with total-focusing method were identified as the most promising.

Prior to deal with the experimental part of this thesis, different parts were manufacture on which the mechanical and non-destructive tests will be carried out. A total of five thick composite samples were manufactured.

Comprehensive tensile and compression tests were carried out with the purpose to determine the degradation that internal out-of-plane wrinkles can cause in the mechanical properties of the material. Regarding the mechanical tests, main conclusions were extracted as described in the following:

- The presence of the wrinkle in the laminates degrades severely the tensile properties. The presence of internal woven glass-layers degraded the tensile strength by up to $30 \%$. The tensile strengths of the specimens with internal woven glass-layers and wrinkles were respectively $37 \%$ (for the 3 $\mathrm{mm}$ high wrinkle) and 58\% (for the $6 \mathrm{~mm}$ high wrinkle) of the tensile strength of the pristine sample. The tensile strength was approximately $63 \%$ lower in the specimen with a $3 \mathrm{~mm}$ high wrinkle but without internal woven glass-layers than in the respective pristine sample.

- The presence of internal woven-glass layers adversely affects the mechanical properties, causing a 38\% decrease in compression strength. The compression strengths of the specimens with internal woven glasslayers and wrinkles were respectively $37 \%$ (for the $3 \mathrm{~mm}$ high wrinkle) and $60 \%$ (for the $6 \mathrm{~mm}$ high wrinkle) of the compression strength of the Pristine sample. The compression strength was approximately 63\% lower in the specimen with a $3 \mathrm{~mm}$ high wrinkle but without internal woven glass-layers than in the respective pristine sample. 
- The wrinkle has approximately the same influence on the compression properties as the tensile properties.

Main conclusions for the non-destructive tests obtained through the laboratory tests are summarised as follows:

- The FMC/TFM method gave better results whilst phased-array technology and single-element immersion testing presented more challenges. This is explained by the superior focusing of TFM where every point in the Bscan image is made a focal point for reconstruction. To extend this further, an adapted-TFM algorithm was tested for the most complex sample - with a glass-fibre ply every sixth ply - and was compared with the standard TFM and the analytical model. There is a clear benefit in using the angledependent velocity correction within the adapted-TFM method, resulting in enhanced instantaneous-phase imaging of the whole wrinkle, particularly the steepest wrinkle angle and good agreement with the analytical-model results. The complex interferences in the experimental phase image diminish with depth whereas they increase with depth in the analytical-model phase image. This can be explained by the limitations of the one-dimensional, plane-wave, normal-incidence approximations of the analytical model and future work should include 2D and 3D finite-element modelling to prove this.

- Using the optimum inspection frequency (the ply-resonance frequency) is essential to obtain images that are easy to interpret and used to measure wrinkle parameters. The instantaneous-phase images proved best for visualizing plies in the wrinkle. A stand-off is required that is thick enough to put its multiple echo beyond the back-surface echo and a liquid standoff is preferred to avoid the mixed-mode reflection of the front surface, which comes in the middle of the sample image.

- Not all of the techniques allowed full characterisation of out-of-plane waviness on these specimens. All the techniques allowed the characterisation of a wrinkle in a UD carbon sample with a reasonable accuracy. For hybrid glass-carbon laminates, the glass layers make the inspections more difficult, because of the high reflectivity of the glass layers and the occurrence of a complex interference pattern. Phased-array technology presented similar results to the immersion tests, but the experimental results still show significant errors, probably due to artefacts caused by the solid stand-off wedge used. The method that has been used to measure the wrinkles requires the presence in the image of a clear line that tracks the maximum wrinkle amplitude. It is expected that less demanding specimens would allow a better characterization of the defect regardless of the inspection method. 
These points have summarized the main conclusions obtained through the presented experimental tests.

After presenting the mechanical and non-destructive test results, the results from the ultrasonic testing modelled that were perform in order to predict the ultrasonic propagation through the layered material was presented. A one-dimensional recursive analytical multi-later model and a preliminary 2D model were used to simulate the response from the mixed carbon/glass laminates.

The resonance frequency of the plies was determined using the one-dimensional recursive analytical multi-later model in order to determine the ideal probe frequency and bandwidth with which the inspections were made.

Finally, in the line of the work presented in this thesis, the following future works are enumerated as follows:

- The effects of the highly anisotropic in-plane stiffness properties are not simulated in the one-dimensional recursive analytical multi-layer model. at least two-dimensional modelling should be necessary to capture the ultrasonic wave propagation around a wrinkle and to model the effects of the anisotropy and the geometrical complexity and the true geometrical distortions of the plies. The conclusions from the one-dimensional recursive analytical multi-layer model about the responses from the wrinkled area should be tested against more accurate modelling. Although a prelimirar 2D model was presented in this thesis, future work should look to improve the $2 \mathrm{D}$ model generation. The actual geometry of the laminate should be simulated, with constant thick resin layers. A software that allow the introduction of a direction different from the mesh coordinates could be used so a single stiffness matrix can be used for each material. This would improve the model efficiency and would allow large 2D model to be implemented. A more accurate model will lead to a better understanding of the actual inspection images.

- In this thesis, the wrinkle angle was measured from the slope of the tangent to the curve at the point where it intersects with the imaginary inplane line at a distance. However, different methods exist for automatically detecting lines in two-dimensional images and measure their angle. Those methods are used for example for fingerprint enhancement or digital hair modelling. A comparison of the different available methods should be perform to identify the most promising methods. Using these methods would allow the characterization of wrinkles by knowing the angle of each fibre at each point of the wrinkle instead of discreetly characterising them with only 3 values (angle, height and severity). The ultimate goal being the full characterisation of the fibre direction at every point of as-manufactured composite components 
- In this thesis, two TFM algorithm were used to reconstruct the B-Scan slices after the FMC inspection: an isotropic TFM algorithm and an adapted-TFM algorithm to account for anisotropic velocities. Although a clear benefit in using the angle-dependent velocity correction within the adapted-TFM method was shown; the possibility of improving the imaging by developing a specific TFM algorithm should be further explored. 


\section{REFERENCES}

Adams, Daniel O.Hare, and Steven J. Bell. 1995. "Compression Strength Reductions in Composite Laminates Due to Multiple-Layer Waviness." Composites Science and Technology 53 (2): 207-12. https://doi.org/10.1016/0266-3538(95)00020-8.

Amenabar, I., A. Mendikute, A. López-Arraiza, M. Lizaranzu, and J. Aurrekoetxea. 2011. "Comparison and Analysis of Non-Destructive Testing Techniques Suitable for Delamination Inspection in Wind Turbine Blades." Composites Part B: Engineering 42 (5): 1298-1305. https://doi.org/10.1016/j.compositesb.2011.01.025.

B. Boashash. 1992. "Estimating and Interpreting the Instantaneous Frequency of a Signal-Part I: Fundamentals.” Proc. IEEE 80 (4): 519-38.

Balageas, D., C.-P. Fritzen, and A. Güemes. 2006. Structural Health Monitoring. Edited by \& A. Gemes D. Balageas, C.-P. Fritzen. London, UK: : ISTE. https://doi.org/http://doi.org/10.1002/9780470612071.

Barile, Claudia. 2019. "Innovative Mechanical Characterization of CFRP by Using Acoustic Emission Technique." Engineering Fracture Mechanics 210 (April): 414-21. https://doi.org/10.1016/j.engfracmech.2018.02.024.

Bender, J. J., S. R. Hallett, and E. Lindgaard. 2019. "Parametric Study of the Effect of Wrinkle Features on the Strength of a Tapered Wind Turbine Blade SubStructure." Composite Structures 218 (June): 120-29. https://doi.org/10.1016/j.compstruct.2019.02.065.

Blanch, M. J., and A. G. Dutton. 2003. "Acoustic Emission Monitoring of Field Tests of an Operating Wind Turbine.” In Key Engineering Materials, 245-246:475-80. Trans Tech Publications Ltd.

Bouloudenine, Abderraouf, Mouloud Feliachi, and Mohamed El Hadi Latreche. 2017. "Development of Circular Arrayed Eddy Current Sensor for Detecting Fibers Orientation and In-Plane Fiber Waviness in Unidirectional CFRP." NDT and E International 92 (December): 30-37. https://doi.org/10.1016/j.ndteint.2017.07.011.

Boychuk, A. S., A. S. Generalov, and A. V. Stepanov. 2014. "CFRP Structural Health Monitoring by Ultrasonic Phased Array Technique." In Proceedings of EWSHM 7th European Workshop on Structural Health Monitoring. Nantes, France. https://hal.inria.fr/hal-01022981.

Brizuela, J., J. Camacho, G. Cosarinsky, J.M. Iriarte, and J.F. Cruza. 2019. "Improving Elevation Resolution in Phased-Array Inspections for NDT." NDT and E International 101: 1-16.

Caminero, M. A., I. García-Moreno, G. P. Rodríguez, and J. M. Chacón. 2019. “Internal Damage Evaluation of Composite Structures Using Phased Array Ultrasonic Technique: Impact Damage Assessment in CFRP and 3D Printed Reinforced Composites." Composites Part B 165: 131-42. 
Chakrapani, Sunil Kishore, Vinay Dayal, and Daniel J. Barnard. 2013. "Investigation of Waviness in Wind Turbine Blades: Structural Health Monitoring." In AIP Conference Proceedings, 1511:310-16. American Institute of Physics Inc. https://doi.org/10.1063/1.4789063.

Chakrapani, Sunil Kishore, Vinay Dayal, Daniel J. Barnard, Aaron Eldal, and Ryan Krafka. 2012. "Ultrasonic Rayleigh Wave Inspection of Waviness in Wind Turbine Blades: Experimental and Finite Element Method." AIP Conference Proceedings 1430 (1): 1911-17. https://doi.org/https://doi.org/10.1063/1.4716444.

Davidson, Paul, and Anthony M. Waas. 2017. "The Effects of Defects on the Compressive Response of Thick Carbon Composites: An Experimental and Computational Study.” Composite Structures 176 (September): 582-96. https://doi.org/10.1016/j.compstruct.2017.05.046.

Denhof, Dimitri, Benjamin Staar, Michael Lütjen, and Michael Freitag. 2019. "Automatic Optical Surface Inspection of Wind Turbine Rotor Blades Using Convolutional Neural Networks." In Procedia CIRP, 81:1166-70. Elsevier B.V. https://doi.org/10.1016/j.procir.2019.03.286.

Dijkstra, E. W. 1959. "A Note on Two Problems in Connexion with Graphs." Numerische Mathematik 1 (1): 269-271. https://doi.org/https://doi.org/10.1007/BF01386390.

Drewry, Melody A., and George A. Georgiou. 2007. "A Review of NDT Techniques for Wind Turbines." Insight: Non-Destructive Testing and Condition Monitoring 49 (3): 137-41. https://doi.org/10.1784/insi.2007.49.3.137.

Drury, C. G., \& Fox, J. G. 1975. "The Imperfect Inspector.” In Human Reliability in Quality Control, edited by C. G. Drury \& J. G. Fox, 11-16. London, UK: Taylor \& Francis.

Ekanayake, Sarah, Sumit Gurram, and Robert H. Schmitt. 2018. "Depth Determination of Defects in CFRP-Structures Using Lock-in Thermography." Composites Part B: Engineering 147 (August): 128-34. https://doi.org/10.1016/j.compositesb.2018.04.032.

Enevoldsen, Peter, and George Xydis. 2019. "Examining the Trends of 35 years Growth of Key Wind Turbine Components.” Energy for Sustainable Development. Elsevier B.V. https://doi.org/10.1016/j.esd.2019.02.003.

Fahr, A, and A Y Kandeil. 1992. "ULTRASONIC C-SCAN INSPECTION OF COMPOSITE MATERIALS.” Engineering Journal of Qatar University 5: 20122.

Fernández-López, Antonio, Beatriz Larrañaga-Valsero, and Alfredo Guemes. 2014. "Wrinkle Detection with Ultrasonic Phased Array Technology." In Proccedings of the 6th International Symposium on NDT in Aerospace. Madrid, Spain. www.ndt.net/app.aeroNDT2014.

Galietti, U, D Palumbo, G Calia, and M Pellegrini. 2012. "Non Destructive Evaluation of Composite Materials with New Thermal Methods." In Proceedings of the 15th European Conference on Composite Materials. Venice, Italy. 
Gao, Bin, Libing Bai, Wai Lok Woo, Gui Yun Tian, and Yuhua Cheng. 2014. "Automatic Defect Identification of Eddy Current Pulsed Thermography Using Single Channel Blind Source Separation." IEEE Transactions on Instrumentation and Measurement 63 (4): 913-22. https://doi.org/10.1109/TIM.2013.2285789.

Ginzel, E A. 2009. "Near Field and Focusing Considerations with Wedges." Waterloo, ON, Canada.

Green Jr, Robert E. 2004. "Non-Contact Ultrasonic Techniques.” In Ultrasonics, 42:916. https://doi.org/10.1016/j.ultras.2004.01.101.

Gryzagoridis, J, and D Findeis. 2010. "Impact Damage Detection on Composites Using Optical NDT Techniques." Insight - Non-Destructive Testing and Condition Monitoring 52 (5): 248-51. https://doi.org/10.1784/insi.2010.52.5.248.

Hahn, F., C. W. Kensche, R. J.H. Paynter, A. G. Dutton, C. Kildegaard, and J. Kosgaard. 2002. "Design, Fatigue Test and NDE of a Sectional Wind Turbine Rotor Blade." Journal of Thermoplastic Composite Materials 15 (3): 267-77. https://doi.org/10.1177/0892705702015003455.

Hart, Peter E., Nils J. Nilsson, and Bertram Raphael. 1968. "A Formal Basis for the Heuristic Determination of Minimum Cost Paths." IEEE Transactions on Systems Science and Cybernetics 4 (2): 100-107. https://doi.org/10.1109/TSSC.1968.300136.

Hashin, Z. 1965. "On Elastic Behaviour of Fiber Reinforced Materials of Arbitrary Transverse Phase Geometry." Journal of the Mechanics and Physics of Solids 13 (3): 119-34. https://doi.org/https://doi.org/10.1016/0022-5096(65)90015-3.

1979. "Analysis of Properties of Fiber Composites with Anisotropic Constituents." Journal of Applied Mechanics 46 (3): 543-50. https://doi.org/doi:10.1115/1.3424603.

He, Yunze, Feilu Luo, and Mengchun Pan. 2010. "Defect Characterisation Based on Pulsed Eddy Current Imaging Technique." Sensors and Actuators, A: Physical 164 (1-2): 1-7. https://doi.org/10.1016/j.sna.2010.09.001.

He, Yunze, Guiyun Tian, Mengchun Pan, and Dixiang Chen. 2014a. "Impact Evaluation in Carbon Fiber Reinforced Plastic (CFRP) Laminates Using Eddy Current Pulsed Thermography." Composite Structures 109 (1): 1-7. https://doi.org/10.1016/j.compstruct.2013.10.049.

2014b. "Non-Destructive Testing of Low-Energy Impact in CFRP Laminates and Interior Defects in Honeycomb Sandwich Using Scanning Pulsed Eddy Current." Composites Part B: Engineering 59 (March): 196-203. https://doi.org/10.1016/j.compositesb.2013.12.005.

Heuer, H., M. Schulze, M. Pooch, S. Gäbler, A. Nocke, G. Bardl, Ch Cherif, et al. 2015. "Review on Quality Assurance along the CFRP Value Chain - Non-Destructive Testing of Fabrics, Preforms and CFRP by HF Radio Wave Techniques." Composites Part B: Engineering 77 (August): 494-501. https://doi.org/10.1016/j.compositesb.2015.03.022.

Holmes, Caroline, Bruce W. Drinkwater, and Paul D. Wilcox. 2005. "Post-Processing 
of the Full Matrix of Ultrasonic Transmit-Receive Array Data for Non-Destructive Evaluation." NDT and E International 38 (8): 701-11.

https://doi.org/10.1016/j.ndteint.2005.04.002.

Holub, Wolfgang, and Ulf Haßler. 2012. "Detection and Evaluation of Ondulations in Glass-Fiber Reinforced Materials." In 4th Conference on Industrial Computed Tomography, 49-54. Wels, Austria.

Hsu, David K., Kwang Hee Im, Chien Ping Chiou, and Daniel J. Barnard. 2011. "An Exploration of the Utilities of Terahertz Waves for the NDE of Composites." In AIP Conference Proceedings, 1335:533-40. https://doi.org/10.1063/1.3591897.

Hung, Y Y. 1999. "Applications of Digital Shearography for Testing of Composite Structures." Composites: Part B 30: 765-773.

www.elsevier.com/locate/compositesb.

Jasiüniené, E., R. Raišutis, R. Šliteris, A. Voleišis, A. Vladišauskas, D. Mitchard, and M. Amos. 2009. "NDT of Wind Turbine Blades Using Adapted Ultrasonic and Radiographic Techniques." Insight: Non-Destructive Testing and Condition Monitoring 51 (9): 477-83. https://doi.org/10.1784/insi.2009.51.9.477.

Jasiuniene, Elena, Renaldas Raišutis, Reimondas Sliteris, Algirdas Voleisis, E Jasiūnienè, R Raišutis, R Šliteris, A Voleišis, and M Jakas. 2008. "Ultrasonic NDT of Wind Turbine Blades Using Contact Pulse-Echo Immersion Testing with Moving Water Container." ULTRAGARSAS (ULTRASOUND) 63 (3). https://www.researchgate.net/publication/255607529.

Johnson, T. L., S. R. Fletcher, W. Baker, and R. L. Charles. 2019. "How and Why We Need to Capture Tacit Knowledge in Manufacturing: Case Studies of Visual Inspection.” Applied Ergonomics. https://doi.org/10.1016/j.apergo.2018.07.016.

Joosse, P. A., M. J. Blanch, A. G. Dutton, D. A. Kouroussis, T. P. Philippidis, and P. S. Vionis. 2002. "Acoustic Emission Monitoring of Small Wind Turbine Blades." In 2002 ASME Wind Energy Symposium, 401-11.

Jüngert, Anne. 2008. "Damage Detection in Wind Turbine Blades Using Two Different Acoustic Techniques." In Proceedings of the 7 Th Fib PhD Symposium. Stuttgart, Germany. https://www.researchgate.net/publication/228576960.

Jüngert, Anne, and Christian U Grosse. 2009. "Inspection Techniques for Wind Turbine Blades Using Ultrasound and Sound Waves." In NDTCE'09, Non-Destructive Testing in Civil Engineering.

Jurek, Michal, Maciej Radzienski, Pawel Kudela, and Wieslaw Ostachowicz. 2018. "Non-Contact Excitation and Focusing of Guided Waves in CFRP Composite Plate by Air-Coupled Transducers for Application in Damage Detection." In Procedia Structural Integrity, 13:2089-94. Elsevier B.V. https://doi.org/10.1016/j.prostr.2018.12.203.

Krautkrämer, Josef, and Herbert Krautkrämer. 1969. Ultrasonic Testing of Materials. Springer.

Krstulović-Opara, Lovre, Branko Klarin, Endri Garafulić, and Željko Domazet. 2011. "THE APPLICATION OF PULSE HEATING INFRARED THERMOGRAPHY 
TO THE WIND TURBINE BLADE ANALYSIS." In Proceedings of the 16th International Conference on Composite Structures. Porto (Portugal). http://www.fesb.hr/kk.

Larrañaga-Valsero, Beatriz, Robert A. Smith, Rostand B. Tayong, Antonio FernándezLópez, and Alfredo Güemes. 2018. "Wrinkle Measurement in Glass-Carbon Hybrid Laminates Comparing Ultrasonic Techniques: A Case Study." Composites Part A: Applied Science and Manufacturing 114 (November): 225-40. https://doi.org/10.1016/j.compositesa.2018.08.014.

Larrañaga-Valsero, Beatriz, Robert A Smith, Rostand B Tayong, Antonio FernándezLópez, and Alfredo Güemes. 2016. "Wrinkle Characterisation from Ultrasonic Scans of Composites." In Proceedings of the 55th Annual Conference of the British Institute of Non-Destructive Testing. Nottingham, United Kingdom.

Lee, Jung Ryul, He Jin Shin, Chen Ciang Chia, Dipesh Dhital, Dong Jin Yoon, and Yong Hak Huh. 2011. "Long Distance Laser Ultrasonic Propagation Imaging System for Damage Visualization." Optics and Lasers in Engineering 49 (12): 1361-71. https://doi.org/10.1016/j.optlaseng.2011.07.011.

Li, Chuan, Damien Pain, Paul D. Wilcox, and Bruce W. Drinkwater. 2013. "Imaging Composite Material Using Ultrasonic Arrays.” NDT and E International 53: 8-17. https://doi.org/10.1016/j.ndteint.2012.07.006.

Li, Jian, Viacheslav Slesarenko, Pavel I. Galich, and Stephan Rudykh. 2018. "Oblique Shear Wave Propagation in Finitely Deformed Layered Composites." Mechanics Research Communications 87 (January): 21-28. https://doi.org/10.1016/j.mechrescom.2017.12.002.

Li, Zhencheng, Licheng Zhou, Hongshuai Lei, and Yongmao Pei. 2019. "Microwave Near-Field and Far-Field Imaging of Composite Plate with Hat Stiffeners." Composites Part B: Engineering 161 (March): 87-95. https://doi.org/10.1016/j.compositesb.2018.10.058.

Liang, Tao, Wenwei Ren, Gui Yun Tian, Mutaz Elradi, and Yunlai Gao. 2016. "Low Energy Impact Damage Detection in CFRP Using Eddy Current Pulsed Thermography." Composite Structures 143 (May): 352-61. https://doi.org/10.1016/j.compstruct.2016.02.039.

Lin, Li, Huanqing Cao, and Zhongbing Luo. 2018. "Total Focusing Method Imaging of Multidirectional CFRP Laminate with Model-Based Time Delay Correction." NDT and E International 97 (July): 51-58. https://doi.org/10.1016/j.ndteint.2018.03.011.

_ 2019. "Dijkstra's Algorithm-Based Ray Tracing Method for Total Focusing Method Imaging of CFRP Laminates." Composite Structures 215 (May): 298-304. https://doi.org/10.1016/j.compstruct.2019.02.086.

Liu, Ping, Roger M. Groves, and Rinze Benedictus. 2014. "3D Monitoring of Delamination Growth in a Wind Turbine Blade Composite Using Optical Coherence Tomography." NDT and E International 64: 52-58. https://doi.org/10.1016/j.ndteint.2014.03.003. 
Maldague, X, and S Marinetti. 1996. "Pulse Phase Infrared Thermography." Journal of Applied Physics 79 (5): 2694-98. https://doi.org/10.1063/1.362662.

Marsh, George. 2002. "Finding Flaws in Composites.” Reinforced Plastics. https://doi.org/10.1016/S0034-3617(02)80227-2.

- 2011. "Meeting the Challenge of Wind Turbine Blade Repair." Reinforced Plastics 55 (4): 32-36. https://doi.org/10.1016/S0034-3617(11)70112-6.

Martin, Robert W., Alessandro Sabato, Andrew Schoenberg, Robert H. Giles, and Christopher Niezrecki. 2018. "Comparison of Nondestructive Testing Techniques for the Inspection of Wind Turbine Blades' Spar Caps." Wind Energy 21 (11): 980-96. https://doi.org/10.1002/we.2208.

Melnyk, S., I. Tuluzov, and A. Melnyk. 2014. "Method of Remote Dynamic Thermographic Testing of Wind Turbine Blades." In The 12th International Conference on Quantitative InfraRed Thermography. Bordeaux. www.ndt.net/?id=17667.

Meola, C., S. Boccardi, G. M. carlomagno, n. D. Boffa, E. Monaco, and F. Ricci. 2015. "Nondestructive Evaluation of Carbon Fibre Reinforced Composites with Infrared Thermography and Ultrasonics." Composite Structures 134: 845-53.

Mizukami, Koichi, Yoshihiro Mizutani, Kenshi Kimura, Akiyoshi Sato, Akira Todoroki, and Yoshiro Suzuki. 2016. "Detection of In-Plane Fiber Waviness in Cross-Ply CFRP Laminates Using Layer Selectable Eddy Current Method." Composites Part A: Applied Science and Manufacturing 82 (March): 108-18. https://doi.org/10.1016/j.compositesa.2015.11.040.

Mizukami, Koichi, Yoshihiro Mizutani, Akira Todoroki, and Yoshiro Suzuki. 2016. "Detection of In-Plane and out-of-Plane Fiber Waviness in Unidirectional Carbon Fiber Reinforced Composites Using Eddy Current Testing." Composites Part B: Engineering 86 (February): 84-94. https://doi.org/10.1016/j.compositesb.2015.09.041.

Montanini, Roberto, and Fabrizio Freni. 2012. "Non-Destructive Evaluation of Thick Glass Fiber-Reinforced Composites by Means of Optically Excited Lock-in Thermography." Composites Part A: Applied Science and Manufacturing 43 (11): 2075-82. https://doi.org/10.1016/j.compositesa.2012.06.004.

Mook, Gerhard, Rolf Lange, and Ole Koeser. 2001. "Non-Destructive Characterisation of Carbon-Fibre-Reinforced Plastics by Means of Eddy-Currents." Composites Science and Technology 61: 865-73. www.elsevier.com/locate/compscitech.

Moran, James, and Nik Rajic. 2019. "Remote Line Scan Thermography for the Rapid Inspection of Composite Impact Damage." Composite Structures 208 (January): 442-53. https://doi.org/10.1016/j.compstruct.2018.10.038.

Nagarajan, V. A., J. Selwin Rajadurai, and T. Annil Kumar. 2012. “A Digital Image Analysis to Evaluate Delamination Factor for Wind Turbine Composite Laminate Blade." Composites Part B: Engineering 43 (8): 3153-59. https://doi.org/10.1016/j.compositesb.2012.04.013.

Nelson, L. J., R. A. Smith, and M. Mienczakowski. 2018. "Ply-Orientation 
Measurements in Composites Using Structure-Tensor Analysis of Volumetric Ultrasonic Data." Composites Part A: Applied Science and Manufacturing. https://doi.org/10.1016/j.compositesa.2017.10.027.

Niezrecki, Christopher, Peter Avitabile, Julie Chen, James Sherwood, Troy Lundstrom, Bruce Leblanc, Scott Hughes, et al. 2014. "Inspection and Monitoring of Wind Turbine Blade Embedded Wave Defects during Fatigue Testing; Inspection and Monitoring of Wind Turbine Blade Embedded Wave Defects during Fatigue Testing." Structural Health Monitoring 13 (6): 629-43. https://doi.org/https://doi.org/10.1177/1475921714532995.

Nikishkov, Gennadiy, Yuri Nikishkov, and Andrew Makeev. 2013. "Finite Element Mesh Generation for Composites with Ply Waviness Based on X-Ray Computed Tomography." Advances in Engineering Software 58: 35-44. https://doi.org/10.1016/j.advengsoft.2013.01.002.

Nowers, Oliver, David J. Duxbury, Jie Zhang, and Bruce W. Drinkwater. 2014. "Novel Ray-Tracing Algorithms in NDE: Application of Dijkstra and A* Algorithms to the Inspection of an Anisotropic Weld." NDT and E International 61: 58-66. https://doi.org/10.1016/j.ndteint.2013.08.002.

Ozbek, Muammer, Daniel J. Rixen, Oliver Erne, and Gunter Sanow. 2010. "Feasibility of Monitoring Large Wind Turbines Using Photogrammetry." Energy 35 (12): 4802-11. https://doi.org/10.1016/j.energy.2010.09.008.

Pan, Mengchun, Yunze He, Guiyun Tian, Dixiang Chen, and Feilu Luo. 2012. "Defect Characterisation Using Pulsed Eddy Current Thermography under Transmission Mode and NDT Applications." NDT and E International 52 (November): 28-36. https://doi.org/10.1016/j.ndteint.2012.08.007.

Panda, Rabi Sankar, Prabhu Rajagopal, and Krishnan Balasubramaniam. 2018. "Rapid Guided Wave Inspection of Complex Stiffened Composite Structural Components Using Non-Contact Air-Coupled Ultrasound.” Composite Structures 206 (December): 247-60. https://doi.org/10.1016/j.compstruct.2018.08.024.

Park, Byeongjin, Yun Kyu An, and Hoon Sohn. 2014. "Visualization of Hidden Delamination and Debonding in Composites through Noncontact Laser Ultrasonic Scanning." Composites Science and Technology 100 (August): 10-18. https://doi.org/10.1016/j.compscitech.2014.05.029.

Peng, Tao, Yi-Zhong Zhao, Zhou Ke-Yin, Yao En-Tao, Yu Shi, and Ping Xu. 2014. "A Research of Wind Turbine Blade Delamination Detection Technology Based on the Acoustic Impact." In Proceedings of the 11th European Conference on NonDestructive Testing. Prague, Czech Republic.

Pieraccini, Massimiliano, Filippo Parrini, Matteo Fratini, Carlo Atzeni, and Paolo Spinelli. 2008. "In-Service Testing of Wind Turbine Towers Using a Microwave Sensor." Renewable Energy 33 (1): 13-21. https://doi.org/10.1016/j.renene.2007.02.001.

Pierce, S G, B Culshaw, W R Philp, F Lecuyer, and R Farlow'. 1997. "Broadband Lamb Wave Measurements in Aluminium and Carbon/Glass Fibre Reinforced Composite Materials Using Non-Contacting Laser Generation and Detection." 
Ultrasonics. Vol. 35.

Potter, J. N., P. D. Wilcox, and A. J. Croxford. 2018. "Diffuse Field Full Matrix Capture for near Surface Ultrasonic Imaging." Ultrasonics 82 (January): 44-48. https://doi.org/10.1016/j.ultras.2017.07.009.

Potter, K., B. Khan, M. Wisnom, T. Bell, and J. Stevens. 2008. "Variability, Fibre Waviness and Misalignment in the Determination of the Properties of Composite Materials and Structures." Composites Part A: Applied Science and Manufacturing 39 (9): 1343-54. https://doi.org/10.1016/j.compositesa.2008.04.016.

Pyrz, R. 1999. “Application of X-Ray Microtomography to the Study of Polymer Composites." In Proceedings of the ICCM-12. Paris (France).

Raišutis, R, E Jasiūnienè, R Šliteris, and A Vladišauskas. 2008. "The Review of NonDestructive Testing Techniques Suitable for Inspection of the Wind Turbine Blades." ULTRASOUND. Vol. 63. www.ndt.net/search/docs.php3?MainSource=27.

Raišutis, R, E Jasiūnienè, and E Žukauskas. 2008. "Ultrasonic NDT of Wind Turbine Blades Using Guided Waves." ULTRASOUND). Vol. 63.

Reddy, Abhishek, V. Indragandhi, Logesh Ravi, and V. Subramaniyaswamy. 2019. "Detection of Cracks and Damage in Wind Turbine Blades Using Artificial Intelligence-Based Image Analytics." Measurement 147 (December): 106823. https://doi.org/10.1016/j.measurement.2019.07.051.

Roach, Dennis, Stephen Neidigk, Tom Rice, Randy Duvall, and Josh Paquette. 2015. "Development and Assessment of Advanced Inspection Methods for Wind Turbine Blades Using a Focused WINDIE Experiment." In 33rd Wind Energy Symposium. Kissimmee, Florida, EEUU. https://doi.org/DOI: 10.2514/6.2015-0998.

See, Judi E., Colin G. Drury, Ann Speed, Allison Williams, and Negar Khalandi. 2017. "The Role of Visual Inspection in the 21 St Century." Proceedings of the Human Factors and Ergonomics Society Annual Meeting 61 (1): 262-66. https://doi.org/10.1177/1541931213601548.

Segers, Joost, Saeid Hedayatrasa, Erik Verboven, Gaétan Poelman, Wim Van Paepegem, and Mathias Kersemans. 2019. "In-Plane Local Defect Resonances for Efficient Vibrothermography of Impacted Carbon Fiber-Reinforced Polymers (CFRP)." NDT and E International 102 (March): 218-25. https://doi.org/10.1016/j.ndteint.2018.12.005.

Shepard, Steven M. 2007. "Flash Thermography of Aerospace Composites." In Proceedings of the IV Pan American Conference for Non Destructive Testing. Buenos Aires, Argentina.

Smith, R. A., L. J. Nelson, N. Xie, C. Fraij, and S. R. Hallett. 2015. "Progress in 3D Characterisation and Modelling of Monolithic Carbon-Fibre Composites." Insight: Non-Destructive Testing and Condition Monitoring 57 (3): 131-39. https://doi.org/10.1784/insi.2014.57.3.131.

Smith, R A, L J Nelson, R Tayong Boumda, N Xie, C Fraij, P D Wilcox, and S R Hallett. 2015. "Progress in Non-Destructive 3D Characterization and Modelling of 
Aerospace Composites.” In Proceedings of ASNT - NDT of Composites II. Seattle.

Smith, Robert A., Luke J. Nelson, Martin J. Mienczakowski, and Paul D. Wilcox. 2016. "Ultrasonic Tracking of Ply Drops in Composite Laminates." In AIP Conference Proceedings. Vol. 1706. American Institute of Physics Inc. https://doi.org/10.1063/1.4940505.

. 2018a. "Ultrasonic Analytic-Signal Responses from Polymer-Matrix Composite Laminates." IEEE Transactions on Ultrasonics, Ferroelectrics, and Frequency Control. https://doi.org/10.1109/TUFFC.2017.2774776.

2018b. "Ultrasonic Analytic-Signal Responses from Polymer-Matrix Composite Laminates." IEEE Transactions on Ultrasonics, Ferroelectrics, and Frequency Control 65 (2): 231-43. https://doi.org/10.1109/TUFFC.2017.2774776.

Smith, Robert A. 2010. "Use of 3D Ultrasound Data Sets to Map the Localised Properties of Fibre-Reinforced Composites." University of Nottingham.

Solodov, I., K. Pfleiderer, H. Gerhard, S. Predak, and G. Busse. 2006. "New Opportunities for NDE with Air-Coupled Ultrasound." In NDT and E International, 39:176-83. https://doi.org/10.1016/j.ndteint.2005.07.002.

Stoessel, R., N. Krohn, K. Pfleiderer, and G. Busse. 2002. “Air-Coupled Ultrasound Inspection of Various Materials.” In Ultrasonics, 40:159-63. https://doi.org/10.1016/S0041-624X(02)00130-0.

Su, Zhongqing, Chunhui Yang, Nan Pan, Lin Ye, and Li Min Zhou. 2007. "Assessment of Delamination in Composite Beams Using Shear Horizontal (SH) Wave Mode." Composites Science and Technology 67 (2): 244-51. https://doi.org/10.1016/j.compscitech.2006.08.019.

Su, Zhongqing, Lin Ye, and Ye Lu. 2006. "Guided Lamb Waves for Identification of Damage in Composite Structures: A Review." Journal of Sound and Vibration 295 (3-5): 753-80. https://doi.org/10.1016/j.jsv.2006.01.020.

Subhash, K. 1970. “The Discrete Hilbert Transform.” Proc. IEEE 58: 585-586.

Sutherland, Herbert, Alan Beattie, Bruce Hansche, Walt Musial, Jack Allread, Jim Johnson, and Mike Summers. 1994. "The Application of Non-Destructive Techniques to the Testing of a Wind Turbine Blade."

Szwedo, M, and P Hellstein. 2014. "Qualitative Diagnostics of Wind-Turbine Blades Inspection Using Active Thermography." In Proceedings of the 12th International Conference on Quantitative InfraRed Thermography. Bordeaux, France. www.ndt.net/?id=17750.

Takeda, Tomo. 2018. "Micromechanics Model for Three-Dimensional Effective Elastic Properties of Composite Laminates with Ply Wrinkles." Composite Structures 189 (April): 419-27. https://doi.org/10.1016/j.compstruct.2017.10.086.

Trudnowski, Anthony James. 2012. "Parametric Study of Heat Diffusion in Vibrothermography Using Analytical and Numerical Methods." Montana State University- Bozeman, College of Engineering. 
Wang, J., K. D. Potter, K. Hazra, and M. R. Wisnom. 2012. "Experimental Fabrication and Characterization of Out-of-Plane Fiber Waviness in Continuous FiberReinforced Composites." Journal of Composite Materials 46 (17): 2041-53. https://doi.org/10.1177/0021998311429877.

Wróbel, Gabriel, and Sebastian Pawlak. 2007. "Comparaison Study Pulse-Echo and through-Transmission in Glass Epoxi Composites." Journal of Achievements in Materials and Manufacturing Engineering 22 (2): 51-54.

Wu, Rong, Dongsheng Zhang, Qifeng Yu, Yuxi Jiang, and Dwayne Arola. 2019. "Health Monitoring of Wind Turbine Blades in Operation Using ThreeDimensional Digital Image Correlation." Mechanical Systems and Signal Processing 130 (September): 470-83. https://doi.org/10.1016/j.ymssp.2019.05.031.

Xie, Ningbo, Robert A. Smith, Supratik Mukhopadhyay, and Stephen R. Hallett. 2018. "A Numerical Study on the Influence of Composite Wrinkle Defect Geometry on Compressive Strength." Materials and Design 140 (February): 7-20. https://doi.org/10.1016/j.matdes.2017.11.034.

Yan, D., M. Sutcliffe, B. Wright, and I. Cooper. 2013. "Ultrasonic Imaging of Full Matrix Capture Acquired Data for Carbon Fbre-Reinforced Polymer." Insight: Non-Destructive Testing and Condition Monitoring 55 (9): 477-81. https://doi.org/10.1784/insi.2012.55.9.477.

Yang, Ruizhen, and Yunze He. 2015. "Eddy Current Pulsed Phase Thermography Considering Volumetric Induction Heating for Delamination Evaluation in Carbon Fiber Reinforced Polymers." Applied Physics Letters 106 (23). https://doi.org/10.1063/1.4922524.

. 2016. "Optically and Non-Optically Excited Thermography for Composites: A Review." Infrared Physics and Technology. Elsevier. https://doi.org/10.1016/j.infrared.2015.12.026.

Yang, Ruizhen, Yunze He, and Hong Zhang. 2016. "Progress and Trends in Nondestructive Testing and Evaluation for Wind Turbine Composite Blade." Renewable and Sustainable Energy Reviews. https://doi.org/10.1016/j.rser.2016.02.026.

Ye, Guoliang, Ben Neal, Alex Boot, Vasileios Kappatos, Cem Selcuk, and Tat Hean Gan. 2014. "Development of an Ultrasonic NDT System for Automated In-Situ Inspection of Wind Turbine Blades." In Proceedings of the 7th European Workshop on Structural Health Monitoring. Nantes (France). https://hal.inria.fr/hal-01020459.

Yu, Xudong, Madis Ratassepp, Prabhu Rajagopal, and Zheng Fan. 2016. “Anisotropic Effects on Ultrasonic Guided Waves Propagation in Composite Bends." Ultrasonics 72 (December): 95-105. https://doi.org/10.1016/j.ultras.2016.07.016.

Zeng, Zhi, Ning Tao, Lichun Feng, Yeshu Li, Yan Ma, and Cunlin Zhang. 2014. "Breakpoint Detection of Heating Wire in Wind Blade Moulds Using Infrared Thermography." Infrared Physics and Technology 64 (May): 73-78. https://doi.org/10.1016/j.infrared.2013.12.011. 
Zeng, Zhiwei, Jingjing Wang, Xiaohua Liu, Junming Lin, and Yonghong Dai. 2019. "Detection of Fiber Waviness in CFRP Using Eddy Current Method." Composite Structures, September, 111411. https://doi.org/10.1016/j.compstruct.2019.111411.

Zhang, Hong, Ruizhen Yang, Yunze He, Ali Foudazi, Liang Cheng, and Guiyun Tian. 2017. "A Review of Microwave Thermography Nondestructive Testing and Evaluation.” Sensors 17 (5). https://doi.org/10.3390/s17051123.

Zhang, Huiyi, and John Jackman. 2014. "Feasibility of Automatic Detection of Surface Cracks in Wind Turbine Blades." Wind Engineering 38 (6): 575-86. https://doi.org/10.1260/0309-524X.38.6.575.

Zhang, Jie, Bruce W. Drinkwater, and Paul D. Wilcox. 2011. "Effects of Array Transducer Inconsistencies on Total Focusing Method Imaging Performance." NDT and E International 44 (4): 361-68. https://doi.org/10.1016/j.ndteint.2011.03.001.

Zhang, Jie, Bruce W. Drinkwater, Paul D. Wilcox, and Alan J. Hunter. 2010. "Defect Detection Using Ultrasonic Arrays: The Multi-Mode Total Focusing Method." NDT and E International 43 (2): 123-33. https://doi.org/10.1016/j.ndteint.2009.10.001.

Zhou, H. F., H. Y. Dou, L. Z. Qin, Y. Chen, Y. Q. Ni, and J. M. Ko. 2014. "A Review of Full-Scale Structural Testing of Wind Turbine Blades." Renewable and Sustainable Energy Reviews. https://doi.org/10.1016/j.rser.2014.01.087. 


\section{APPENDIX A Tensile tests}

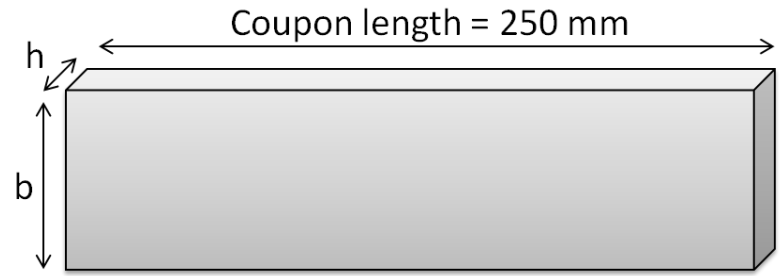

Figure 117: Tensile Coupon measures

Table 18: Tensile tests results of Sample Pristine 1

\begin{tabular}{|c|c|c|c|c|c|}
\hline & Coupon & $\mathrm{h}(\mathrm{mm})$ & $\mathrm{b}(\mathrm{mm})$ & Limite Load $(\mathrm{N})$ & Tensile Strenght (Mpa) \\
\hline & 1 & 2,21 & 25,6 & 64735 & 1144,21 \\
\hline & 2 & 2,2 & 24,8 & 51905 & 951,34 \\
\hline & 3 & 2,2 & 25,08 & 56766 & 1028,82 \\
\hline & 4 & 2,23 & 26 & 53227 & 918,02 \\
\hline & 5 & 2,21 & 25,59 & 69635 & 1231,3 \\
\hline & 6 & 2,24 & 24,27 & 58489 & 1075,86 \\
\hline Maximum & & & & 69635 & 1231,3 \\
\hline Minimum & & & & 51905 & 918,02 \\
\hline Average & & & & 59253,6 & 1054,738 \\
\hline Standard deviation & & & & 6845,862914 & 117,6724941 \\
\hline Coefficient of variation $(\%)$ & & & & 11,55349703 & 11,15656154 \\
\hline
\end{tabular}


Table 19: Tensile tests results of Sample B

\begin{tabular}{|c|c|c|c|c|c|}
\hline & Coupon & $\mathrm{h}(\mathrm{mm})$ & $\mathrm{b}(\mathrm{mm})$ & Limite Load $(\mathrm{N})$ & Tensile Strenght (Mpa) \\
\hline & 1 & 2,06 & 25,6 & 32937 & 624,56 \\
\hline & 2 & 2,1 & 25,61 & 32872 & 611,22 \\
\hline & 3 & 2,08 & 25,6 & 29865 & 560,87 \\
\hline & 4 & 2,06 & 25,6 & 38477 & 729,62 \\
\hline & 5 & 2,08 & 25,61 & 41830 & 785,2626678 \\
\hline & 6 & & & & \\
\hline Maximum & & & & 41830 & 785,2626678 \\
\hline Minimum & & & & 29865 & 560,87 \\
\hline Average & & & & 35196,2 & 662,3065336 \\
\hline Standard deviation & & & & 4328,938318 & 82,4297504 \\
\hline Coefficient of variation $(\%)$ & & & & 12,299448 & 12,44586098 \\
\hline
\end{tabular}


Table 20: Tensile tests results of Sample C

\begin{tabular}{|c|c|c|c|c|c|}
\cline { 2 - 5 } \multicolumn{1}{c|}{} & Coupon & $\mathrm{h}(\mathrm{mm})$ & $\mathrm{b}(\mathrm{mm})$ & Limite Load $(\mathrm{N})$ & Tensile Strenght $(\mathrm{Mpa})$ \\
\cline { 2 - 6 } & 1 & 2,01 & 26,2 & 18200 & 345,6 \\
\cline { 2 - 6 } & 2 & 2,02 & 26,3 & 29300 & 551,52 \\
\cline { 2 - 6 } & 3 & 1,99 & 26 & 22300 & 431 \\
\cline { 2 - 6 } & 4 & 1,98 & 25,9 & 24200 & 471,9 \\
\cline { 2 - 6 } & 5 & 2,02 & 26,3 & 22100 & 415,99 \\
\cline { 2 - 6 } & 6 & 2,01 & 26 & 22100 & 551,52 \\
\hline Maximum & & & & 29300 & 345,6 \\
\hline Minimum & & & & 23033,33333 & 439,8166667 \\
\hline Average & & & & 3323,485453 & 62,33740308 \\
\hline Standard deviation & & & & 14,42902512 & 14,17349723 \\
\hline
\end{tabular}


Table 21: Tensile tests results of Sample Pristine 2

\begin{tabular}{|c|c|c|c|c|c|}
\cline { 2 - 5 } \multicolumn{1}{c|}{} & Coupon & $\mathrm{h}(\mathrm{mm})$ & $\mathrm{b}(\mathrm{mm})$ & Limite Load (N) & Tensile Strenght $(\mathrm{Mpa})$ \\
\cline { 2 - 6 } & 1 & 2,05 & 20,28 & 59530 & 1431,9 \\
\cline { 2 - 6 } & 2 & 2 & 20,32 & 62219 & 1530,98 \\
\cline { 2 - 6 } & 3 & 2,06 & 20,27 & 68606 & 1643,01 \\
\cline { 2 - 6 } & 4 & 2,06 & 20,31 & 66571 & 1591,14 \\
\cline { 2 - 6 } & 5 & 2,01 & 20,3 & 61938 & 1517,98 \\
\cline { 2 - 6 } & 6 & 2 & 20,3 & 55731 & 1643,08 \\
\hline Maximum & & & & 68606 & 1372,68 \\
\hline Minimum & & & & 55731 & 1514,615 \\
\hline Average & & & & 62432,5 & 90,92836333 \\
\hline Standard deviation & & & & $6,8259,577551$ & 6,003397783 \\
\hline
\end{tabular}


Table 22: Tensile tests results of Sample D

\begin{tabular}{|c|c|c|c|c|c|}
\hline & Coupon & $\mathrm{h}(\mathrm{mm})$ & $\mathrm{b}(\mathrm{mm})$ & Limite Load $(\mathrm{N})$ & Tensile Strenght (Mpa) \\
\hline & 1 & 2,08 & 22,7 & 20721 & 438,86 \\
\hline & 2 & 2,08 & 22,82 & 26141 & 550,74 \\
\hline & 3 & 2,05 & 22,7 & 32387 & 695,97 \\
\hline & 4 & 2,05 & 22,8 & 24047 & 514,48 \\
\hline & 5 & 2,05 & 22,7 & 33981 & 730,22 \\
\hline & 6 & 2,08 & 22,8 & 21624 & 455,97 \\
\hline Maximum & & & & 33981 & 730,22 \\
\hline Minimum & & & & 20721 & 438,86 \\
\hline Average & & & & 26483,5 & 564,3733333 \\
\hline Standard deviation & & & & 5065,221343 & 111,8055541 \\
\hline Coefficient of variation (\%) & & & & 19,12595141 & 19,81056642 \\
\hline
\end{tabular}




\section{APPENDIX B Compression tests}

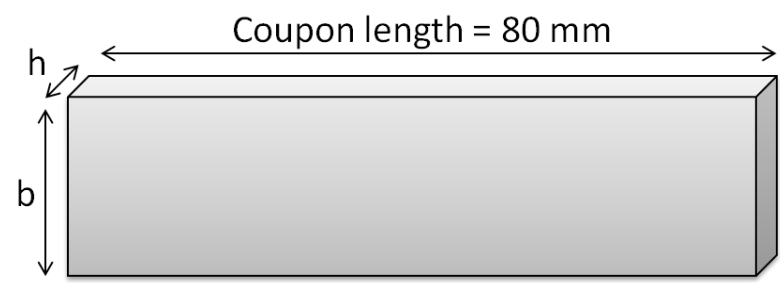

Figure 118: Compression coupon measures

Table 23: Compression tests results of Sample Pristine 1

\begin{tabular}{|c|c|c|c|c|c|}
\hline & Coupon & $\mathrm{h}(\mathrm{mm})$ & $\mathrm{b}(\mathrm{mm})$ & Limite Load (kN) & $\begin{array}{l}\text { Compression Strenght } \\
(\mathrm{Mpa})\end{array}$ \\
\hline & 1 & 2,01 & 25,61 & 34,8 & 645,25 \\
\hline & 2 & 2 & 25,61 & 39,1 & 583,56 \\
\hline & 3 & 2,01 & 25,61 & 23,9 & 616,15 \\
\hline & 4 & 2,01 & 25,61 & 32,8 & 607,34 \\
\hline & 5 & 2 & 25,62 & 30,9 & 645,36 \\
\hline & 6 & 2,01 & 25,61 & 26,9 & 612,24 \\
\hline Maximum & & & & 39,1 & 645,36 \\
\hline Minimum & & & & 23,9 & 583,56 \\
\hline Average & & & & 31,4 & 618,3166667 \\
\hline Standard deviation & & & & 4,992661281 & 21,70591215 \\
\hline Coefficient of variation (\%) & & & & 15,90019516 & 3,510484727 \\
\hline
\end{tabular}


Table 24: Compression tests results of Sample B

\begin{tabular}{|c|c|c|c|c|c|}
\hline & Coupon & $\mathrm{h}(\mathrm{mm})$ & $\mathrm{b}(\mathrm{mm})$ & Limite Load $(\mathrm{N})$ & $\begin{array}{c}\text { Compression Strenght } \\
(\mathrm{Mpa})\end{array}$ \\
\hline & 1 & 4,09 & 25,6 & 36496 & 348,56 \\
\hline & 2 & 4,05 & 25,69 & 40211 & 386,48 \\
\hline & 3 & 4,05 & 25,81 & 35658 & 341,13 \\
\hline & 4 & 4,05 & 25,5 & 44433 & 430,24 \\
\hline & 5 & 4,06 & 25,6 & 41504 & 399,32 \\
\hline & 6 & & & & \\
\hline & & & & & \\
\hline Maximum & & & & 44433 & 430,24 \\
\hline Minimum & & & & 35658 & 341,13 \\
\hline Average & & & & 39660,4 & 381,146 \\
\hline Standard deviation & & & & 3240,751925 & 32,96086868 \\
\hline Coefficient of variation (\%) & & & & 8,171253757 & 8,647832767 \\
\hline
\end{tabular}


Table 25: Compression tests results of Sample C

\begin{tabular}{|c|c|c|c|c|c|}
\hline & Coupon & $\mathrm{h}(\mathrm{mm})$ & $\mathrm{b}(\mathrm{mm})$ & Limite Load $(\mathrm{N})$ & $\begin{array}{c}\text { Compression Strenght } \\
(\mathrm{Mpa})\end{array}$ \\
\hline & 1 & 4 & 25,8 & 17100 & 165,7 \\
\hline & 2 & 4,1 & 25,9 & 25900 & 243,9 \\
\hline & 3 & 4,02 & 27 & 29100 & 268,1 \\
\hline & 4 & 4 & 26 & 24900 & 239,42 \\
\hline & 5 & 3,98 & 27 & 27800 & 258,7 \\
\hline & 6 & 3,98 & 26,9 & 28300 & 264,33 \\
\hline Maximum & & & & 29100 & 268,1 \\
\hline Minimum & & & & 17100 & 165,7 \\
\hline Average & & & & 25516,66667 & 240,025 \\
\hline Standard deviation & & & & 4024,266669 & 34,80249404 \\
\hline Coefficient of variation (\%) & & & & 15,77112999 & 14,49952882 \\
\hline
\end{tabular}


Table 26: Compression tests results of Sample Pristine 2

\begin{tabular}{|c|c|c|c|c|c|}
\hline & Coupon & $\mathrm{h}(\mathrm{mm})$ & $\mathrm{b}(\mathrm{mm})$ & Limite Load (N) & $\begin{array}{c}\text { Compression Strenght } \\
(\mathrm{Mpa})\end{array}$ \\
\hline & 1 & 3,61 & 21,86 & 48773 & 947,49 \\
\hline & 2 & 3,99 & 21,94 & 44666 & 872,04 \\
\hline & 3 & 4,3 & 21,9 & 47780 & 928,2 \\
\hline & 4 & 4,14 & 21,87 & 42593 & 827,43 \\
\hline & 5 & 3,77 & 21,97 & 44816 & 874,63 \\
\hline & 6 & 4,1 & 21,95 & 49234 & 956,44 \\
\hline Maximum & & & & 49234 & 956,44 \\
\hline Minimum & & & & 42593 & 827,43 \\
\hline Average & & & & 46310,33333 & 901,0383333 \\
\hline Standard deviation & & & & 2433,375753 & 46,40644403 \\
\hline Coefficient of variation $(\%)$ & & & & 5,254498463 & 5,150329604 \\
\hline
\end{tabular}


Table 27: Compression tests results of Sample D

\begin{tabular}{|c|c|c|c|c|c|}
\hline & Coupon & $\mathrm{h}(\mathrm{mm})$ & $\mathrm{b}(\mathrm{mm})$ & Limite Load $(\mathrm{kN})$ & $\begin{array}{c}\text { Compression Strenght } \\
(\mathrm{Mpa})\end{array}$ \\
\hline & 1 & 3,74 & 22,94 & 35,4 & 412,9 \\
\hline & 2 & 4,37 & 22,85 & 36 & 360,5 \\
\hline & 3 & 4,07 & 22,91 & 32,6 & 349,4 \\
\hline & 4 & 4,74 & 22,93 & 40,9 & 376,7 \\
\hline & 5 & 4,2 & 22,93 & 33,3 & 345,8 \\
\hline & 6 & 4,02 & 22,89 & 32,1 & 348,8 \\
\hline Maximum & & & & 40,9 & 412,876651 \\
\hline Minimum & & & & 32,1 & 345,7936162 \\
\hline Average & & & & 35,05 & 365,7 \\
\hline Standard deviation & & & & 2,972512966 & 23,527864 \\
\hline Coefficient of variation (\%) & & & & 8,48077879 & 6,434249947 \\
\hline
\end{tabular}

